\title{
CENAPROV y el crecimiento urbano de Pereira 1973-1987 Una mirada a la construcción barrial de Pereira desde sus márgenes
}

Otoniel Arias Quiceno Julián Andrés Restrepo Botero

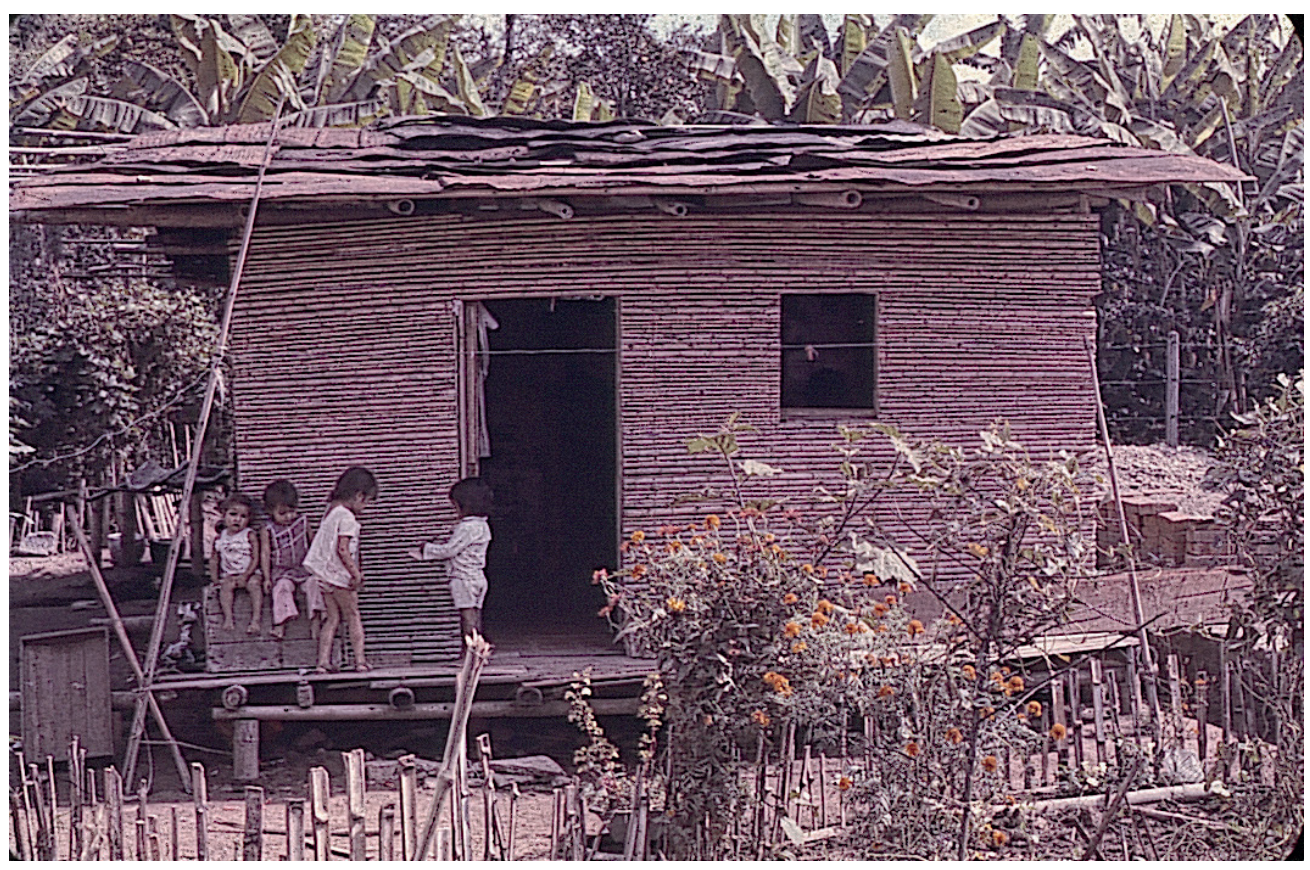

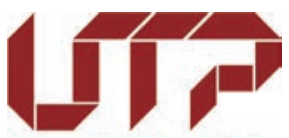

Universidad Tecnológica de Pereira
Facultad

de Ciencias de la Educación
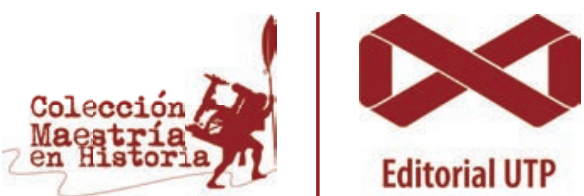

Editorial UTP 
Otoniel Arias Quiceno

(Pereira, Risaralda, Colombia, 1986)

Licenciado en Filosofía y Magíster en Historia de la Universidad Tecnológica de Pereira. Docente del sector oficial (Magisterio).

$\mathrm{Ha}$ publicado artículos en revistas nacionales de su especialidad.

ottoarias86@gmail.com

Julián Andrés Restrepo Botero (La Virginia, Risaralda, Colombia, 1985)

Licenciado en Pedagogía Infantil de la Universidad del Tolima y Magíster en Historia de la Universidad Tecnológica de Pereira. Docente del sector oficial (Magisterio).

Ha publicado artículos en revistas nacionales de su especialidad.

juli1385aa@gmail.com 


\section{CENAPROV Y EL CRECIMIENTO URBANO DE PEREIRA 1973-1987. UNA MIRADA A LA CONSTRUCCIÓN BARRIAL DE PEREIRA DESDE SUS MÁRGENES}

Otoniel Arias Quiceno

Julián Andrés Restrepo Botero

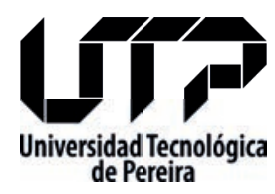

Colección Tesis Laureadas

Facultad de Ciencias de la Educación

Colección Maestría en Historia

2020 
Arias Quiceno, Otoniel

CENAPROV y el crecimiento urbano de Pereira 1973-1987. Una mirada a la construcción barrial de Pereira desde sus márgenes / Otoniel Arias Quiceno y Julián Andrés Restrepo

Botero. - Pereira: Editorial Universidad Tecnológica de Pereira, 2020

191 páginas (Colección Tesis Laureadas)

ISBN: 978-958-722-445-0 eISBN: 978-958-722-527-3

1. Pereira (Risaralda) - Colombia - Historia; 2. Pereira (Risaralda) - Colombia Urbanismo; 3. Pereira (Risaralda) - Colombia - Demografía; 4. Pereira (Risaralda) Colombia - Migración humana; 5. Pereira (Risaralda) - Colombia - Desarrollo Urbano; 6. Sociología Urbana

CDD. 986.132

(c) Otoniel Arias Quiceno

Julián Andrés Restrepo Botero

( ) Universidad Tecnológica de Pereira

Primera edición, 2020

ISBN: 978-958-722-445-0

eISBN: 978-958-722-527-3

Tesis Laureada

"CENAPROV y el crecimiento urbano de Pereira 1973-1987. Una mirada a la construcción barrial de

Pereira desde sus márgenes"

Trabajo de grado para optar al título de Magíster en Historia

Asesor: Dr. Jhon Jaime Correa Ramírez

Universidad Tecnológica de Pereira

Vicerrectoría de Investigaciones, Innovación y Extensión

Editorial Universidad Tecnológica de Pereira

Pereira, Colombia

Coordinador editorial:

Luis Miguel Vargas Valencia

luismvargas@utp.edu.co

Teléfono 3137381

Edificio 9, Biblioteca Central "Jorge Roa Martínez"

Cra. 27 No. 10-02 Los Álamos, Pereira, Colombia

www.utp.edu.co

Montaje y producción:

Christian Javier Niño Posada, cjnino@utp.edu.co

Maestría en Historia / Universidad Tecnológica de Pereira

Fotografía de portada:

Casa del barrio La Isla (Cuba, Pereira)

Archivo personal de Francisco Londoño Marulanda

Impresión y acabados:

Gráficas Olímpica

Pereira

Reservados todos los derechos 


\title{
Agradecimientos
}

\begin{abstract}
$A$ gradecemos de manera especial a todas las personas relacionadas con la Central Nacional Provivienda, quienes con sus testimonios permitieron reconstruir la historia de la entidad en la ciudad. A la docente María Elvira Naranjo, por facilitarnos el acceso a la documentación de archivo de CENAPROV en el barrio Policarpa Salavarrieta en la ciudad de Bogotá. A Emilsen Pérez y Brayan Quiroga quienes con su tiempo y disposición ayudaron a encontrar información importante sobre Pereira en el archivo de la entidad.

Agradecemos también la disposición del docente Jhon Jaime Correa por la orientación y acompañamiento en el proceso de investigación, así como al docente Germán Obando, quien dispuso de su tiempo para realizar las sugerencias de estilo. Finalmente debemos expresar especial agradecimiento a nuestras familias, quienes nos acompañaron y compensaron responsabilidades que debimos suspender mientras realizábamos la investigación.
\end{abstract}





\section{Contenido}

Agradecimientos .......................................................................... 3

Prólogo: Una invitación A Ver la historia URbana

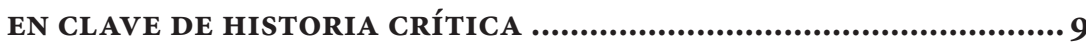

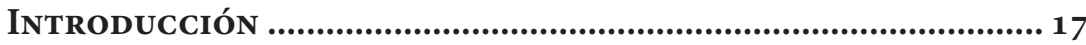

Capítulo uno: La ciudad de Pereira y sus migraciones

EN LA SEGUNDA MITAD DEL SIGLO XX .........................................27

Crecimiento urbano y barrial en América Latina ................................ 30

El crecimiento urbano de la ciudad de Pereira .................................. 39

El protagonismo de la izquierda en la lucha por la vivienda

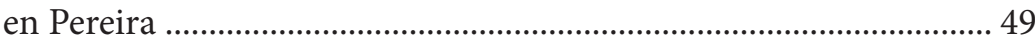

CAPÍTUlO DOS: DÉFICIT HABITACIONAL Y LAS OPORTUNIDADES DE VIVIENDA PARA LOS DESTECHADOS .......................................... 55

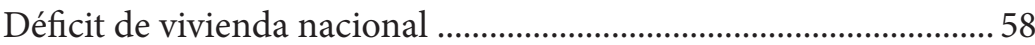

Déficit de vivienda en Pereira ...............................................................65

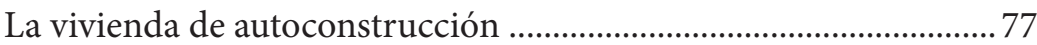

Capítulo tres: La Central Nacional Provivienda y la LUCHA POR EL DERECHO A LA VIVIENDA URBANA ........................ 85

La Central Nacional Provivienda en la década de 1960 ................... 89

La influencia de la Central Nacional Provivienda en Pereira .......... 96

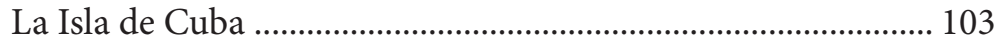

Leningrado I, II y III ………………………………..............113

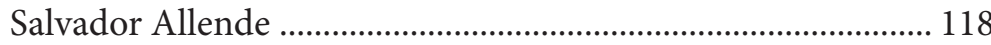

José Martí, José Antonio Galán y Carlos Alberto Benavides .. 119

Nueva Colombia y Jaime Pardo Leal ............................................ 123

Tres experiencias significativas en los municipios cercanos ....125

Declive de CENAPROV en Pereira .................................................. 133

Violencia política ……………………………………………........133

Juntas Directivas y Juntas de Acción Comunal ...........................138

Superintendencia Bancaria ........................................................ 141

Los urbanizadores privados ........................................................... 143

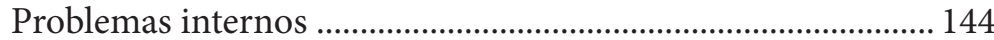

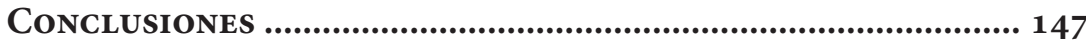

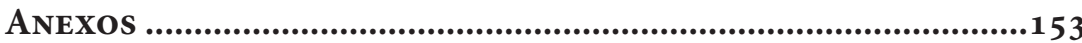

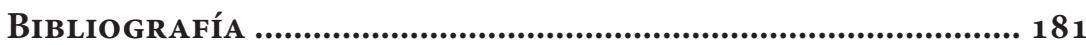




\section{Lista DE Fotografías}

Fotografía 1: Vista aérea del municipio de Pereira,

Septiembre 9/1946

Fotografía 2: Vista aérea del municipio de Pereira,

Enero 21/1955 46

Fotografía 3: Vista aérea del municipio de Pereira, Enero 21/1987 47

Fotografía 4: Invasión a las orillas del Río Otún en Pereira.

Segunda mitad del siglo XX

Fotografía 5: Vivienda de Autoconstrucción 1987.

Barrio 2.500 lotes

Fotografía 6: Carnés de Provivienda de Joaquín Botero, uno de los fundadores de CENAPROV en Pereira

Fotografía 7: Aerofotografía del sector suroccidental de

Pereira en 1969, donde se aprecia el inicio de conformación

urbana

Fotografía 8: Panorámica del Barrio La Isla de Cuba años 70 ..... 112

Fotografía 9: Terrenos cerca a la quebrada El Oso donde se construiría el barrio La Isla

Fotografía 10: Primeras viviendas del barrio Leningrado 115

FotOGRAFÍA 11: Aerofotografía del sector suroccidental de

Pereira, donde se aprecia el inicio de conformación urbana 118

Fotografía 12: Imagen de dirigentes de la Central Nacional

Provivienda instalando el primer aviso del Barrio

Santiago Londoño en Dosquebradas 128

Fotografía 13: Imagen de los pozos comunitarios del barrio Santiago Londoño en Dosquebradas

Fotografía 14: Amenaza contra los dirigentes de la Central

Nacional Provivienda en Pereira Eduardo García y

José Bautista 


\section{LISTA DE TABLAS}

TA BLA 1: Progresión demográfica de Pereira ........................................... 41

TABLA 2: Crecimiento de la población urbana de Pereira ..................... 41

TABLA 3: Déficit de vivienda nacional .....................................................59

TABLA 4: Necesidades y mercado de vivienda en Colombia .................. 64

TABLA 5: Déficit cuantitativo de vivienda en Pereira y

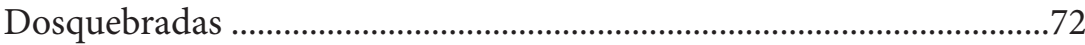

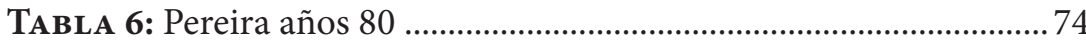

TABLA 7: Ordenanzas del Concejo Municipal, 1976 .............................. 75

\section{Lista de GrÁficos}

Gráfico 1: Viviendas ocupadas en Pereira, según el censo de 1951

Gráfico 2: Total de viviendas en Pereira, según el censo de 1964 66

Gráfico 3: Total de viviendas en Pereira, según el censo de 1973 ....6 69

Gráfico 4: Multiplicación de los centros de inquilinos de la Central Nacional Provivienda a nivel nacional .96

GrÁFICO 5: Estructura organizativa de CENAPROV 116

Gráfico 6: Plano de la ciudad de 1984, con ubicación Aproximada de lote en negociación para la construcción del Barrio Jaime Pardo Leal

Gráfico 7: Mapa de Pereira y ubicación de los barrios construidos por CENAPROV 


\section{Lista de Anexos}

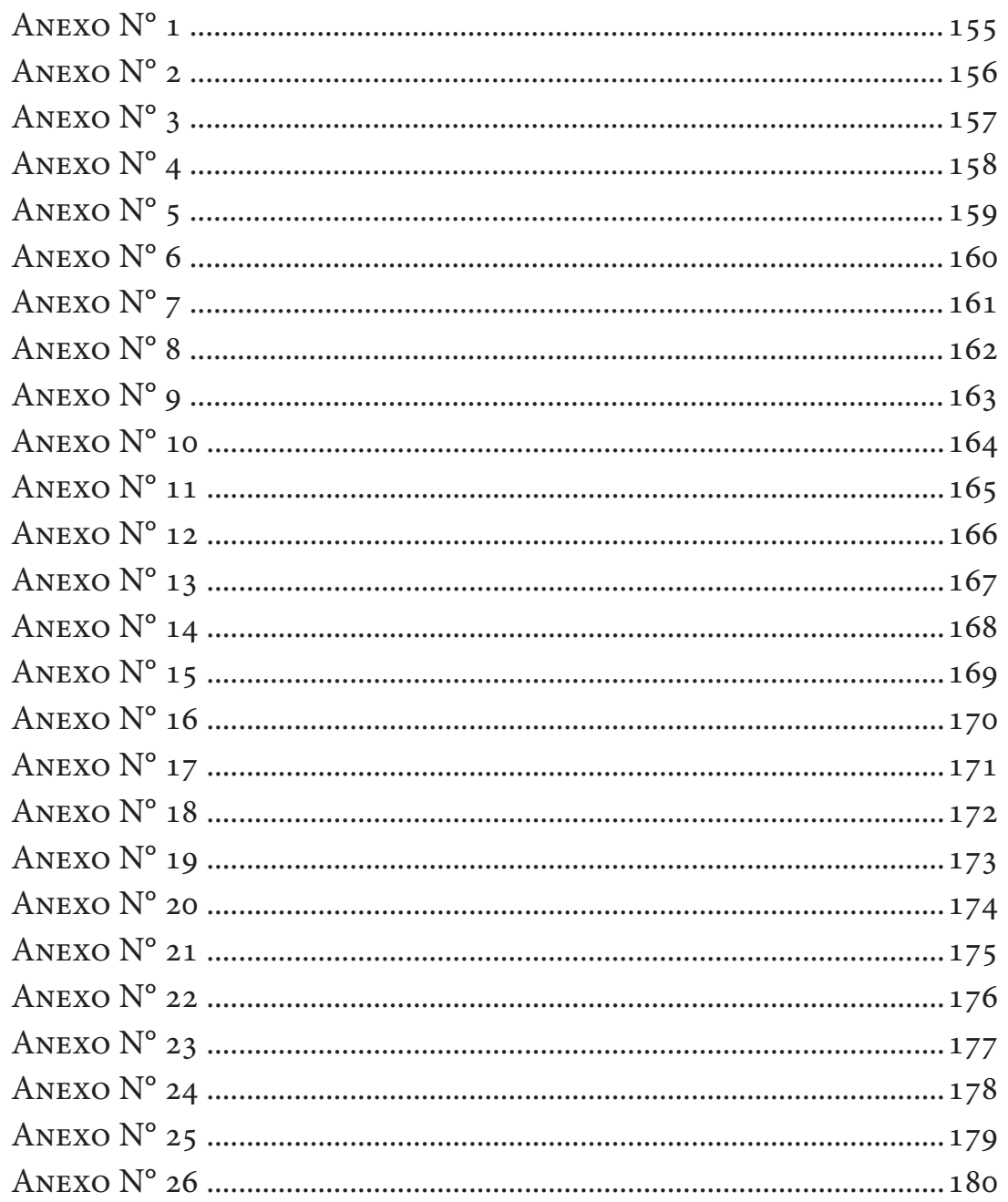




\section{Prólogo \\ UNA INVITACIÓN A VER LA HISTORIA URBANA EN CLAVE DE HISTORIA CRÍTICA}

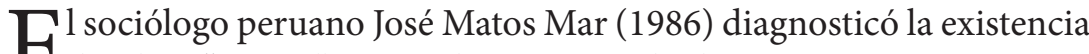
Cde dos "Perúes" para dar cuenta de la convivencia entre un "Perú Oficial" con instituciones estatales, partidos políticos, bancos, universidades, sindicatos, fuerzas de policía, etc., y un "Perú Marginado" de tradiciones, vendedores ambulantes, habitantes desprotegidos y sin techo, economías solidarias y de subsistencia (pp. 99-100). La obra de Matos Mar muy pronto se convirtió en un referente para investigar la construcción de las ciudades latinoamericanas, como espacios de hibridación entre lo moderno y lo tradicional, entre el "orden aséptico" de las élites y el "molesto desorden" del pueblo. Los postulados de Matos Mar coincidieron con un momento de ebullición sobre las cuestiones urbanas que se desarrollaba en la sociología hispanoamericana (Lefebvre, 1975). A su vez, se articularon con las ideas de José Luis Romero en su ya clásico texto Latinoamérica, las ciudades y las ideas (1976), en el que invitó a entender el desarrollo de las ciudades masificadas a comienzos del siglo XX como sociedades escindidas.

Las obras de Romero (1976), Lefebvre (1975) y Matos Mar (1986) establecieron un marco de análisis para un mismo problema: la crisis urbana, las formas de lo popular en las ciudades consideradas modernas, 
y las condiciones de los pobladores urbanos que se enfrentaron al proceso de migración acelerada del campo a la ciudad. Algunas de las preguntas señaladas en aquel tiempo por historiadores y sociólogos, son las que recogen Otoniel Arias y Julián Andrés Restrepo para el contexto de los años setenta y ochenta en Pereira, que primero fueron plasmadas en su tesis de maestría y ahora son convertidas en el libro que se presenta ${ }^{1}$.

La obra de Arias y Restrepo viene a complementar una historiografía regional que ha tomado como punto de partida no sólo las preguntas de Matos Mar, Romero y Lefebvre, sino también las de autores referentes en Colombia como Jacques Aprile-Gniset, Germán Mejía Pavony, Fabio Zambrano, Alfonso Torres y Fernando Botero Herrera, entre otros; a partir de los cuales se explican los procesos históricos y sociales del Viejo Caldas y, en especial, los del desarrollo urbano de Pereira. Además de lo anterior, Arias y Restrepo proponen un diálogo con los aportes locales, entre los que destacan Jaime Jaramillo (1963), Arturo Calle (1964), Hugo Ángel (1983), Morelia Pabón (1985), Óscar Arango (1989) y Jhon Jaime Correa (2014), entre otros.

Así pues, esta obra perfila dos aspectos que son fundamentales en la investigación histórica. El primero tiene que ver con demostrar que se aproxima a un vacío o problema historiográfico no resuelto, como lo es la historia urbana de Pereira y los problemas de vivienda en los años setenta y ochenta. Y el segundo, con establecer un marco teóricometodológico retomado de la historiografía y la teoría social, como lo es el enfoque de la historia desde abajo, los estudios subalternos y la construcción colectiva de la historia, que permiten otorgar voz a los actores sociales que han sido invisibles en las narrativas tradicionales.

De este modo, la obra tiene un engranaje entre historiografía y teoría que les permite a sus autores plantearse el objetivo de rastrear la incidencia que tuvo la organización de viviendistas Central Nacional Provivienda en el desarrollo urbano de Pereira desde 1973 hasta 1987. Dicho de otra forma, se trata de la historia de CENAPROV en Pereira tomada como pretexto para configurar un problema de investigación que entrecruza campos de la historia urbana, local y desde abajo, para contar varias historias que están conectadas: la historia de la urbanización popular en América Latina, la historia de la vivienda en Colombia, la urbanización en Pereira y las dinámicas de organización popular y política de la izquierda. Los autores son consistentes en este

1 La investigación obtuvo la calificación de Laureada y fue dirigida por el profesor Jhon Jaime Correa Ramírez. 
esfuerzo, al señalar que "reconocer la historicidad de los movimientos y luchas populares de vivienda en la ciudad de Pereira, supone al mismo tiempo, evidenciar la problemática en los usos del suelo y la solución de vivienda a nivel local, nacional" (p. 12).

Sin duda, son muchos los aspectos del libro que cautivarán al lector especializado, pero considero que dos resultan cruciales. El primero es la pertinencia como aporte a la historiografía urbana y regional, y el segundo, el uso de nuevas fuentes que sirven a futuras investigaciones. En la historiografía regional existe un vacío respecto de la comprensión de los procesos urbanos de los años cincuenta a ochenta del siglo $\mathrm{XX}$, periodo que corresponde a la transformación urbana (explosión demográfica, recepción de migrantes, generación de empleo calificado, desarrollo industrial y comercial y elementos de un desborde popular). La obra de Arias y Restrepo viene a aportar en parte en esta vía, porque permite entender la articulación entre políticos de izquierda y pobladores populares en procura de dar solución al problema de vivienda.

La inscripción de Arias y Restrepo en el campo de los estudios históricos urbanos es visible en el capítulo primero, en el que abordan el problema de la transformación y crecimiento urbano presentado en América Latina, Colombia y Pereira en la segunda mitad del siglo XX. Los autores proponen un panorama a partir de una bibliografía especializada sobre los conflictos por el desarrollo urbano en Colombia, los trabajos realizados sobre Pereira y los censos poblacionales. En el mismo capítulo se encuentra el apartado El protagonismo de la izquierda en la lucha por la vivienda en Pereira, donde los autores establecen la importancia de líderes como Santiago Londoño, Gildardo Castaño, Gloria Inés Ramírez, Stella Brand y Morelia Pabón, quienes al tiempo que eran partidarios de la izquierda política (Partido Comunista), estaban vinculados con los procesos por la vivienda popular en los años setenta y ochenta.

El segundo capítulo es una combinación de fuentes primarias y secundarias: estadísticas, fotografías y bibliografía, para poner en datos duros la cuestión de la vivienda en Pereira y enmarcar el objeto de estudio, así como el problema social que atendió la organización CENAPROV. Esto da paso al tercer capítulo, en el que Arias y Restrepo abordan la construcción histórica de CENAPROV desde sus inicios en Cali en los años cincuenta y en Bogotá en los años sesenta, ubicando la organización en el contexto histórico que vivió el país (crisis urbana, expansión demográfica y el Frente Nacional). 
Es pertinente señalar que los autores son críticos cuando analizan la influencia de CENAPROV en Pereira, primero, porque advierten que desde la entidad se gestionaron varios barrios en la ciudad y algunos más en los municipios vecinos de La Virginia, Dosquebradas y Santa Rosa de Cabal; y segundo, porque señalan que los actores que conformaban CENAPROV tenían intereses políticos que no se agotaban con la solución habitacional de los nuevos pobladores urbanos, sino que iban hasta la ideologización política que requería el Partido Comunista (PCC) y la Confederación Sindical de Trabajadores de Colombia (CSTC) (p. 123). Los autores además proponen una serie de explicaciones históricas para entender el declive de esta entidad a finales de los años ochenta, donde destacan la persecución política y militar hacia la Unión Patriótica, y algunas disposiciones administrativas.

Es igual de significativo que Arias y Restrepo hayan rescatado los archivos perdidos de CENAPROV en Bogotá, de los que recuperaron las secciones correspondientes a Pereira, y que son trabajados en el último capítulo en combinación con entrevistas a diferentes actores políticos y sociales de Pereira.

Es importante advertir las posibilidades para futuras investigaciones que dejan abiertas Otoniel Arias y Julián Restrepo

- La historia urbana de Pereira se enriquece con la perspectiva crítica: El desarrollo de la ciudad en clave de historia crítica permite entender más allá de los procesos institucionales que se dieron alrededor del Concejo y la Alcaldía Municipal. Se van explorando las contracaras del progreso y se hacen visibles los actores sociales que construyeron ciudad, más aún desde sus márgenes y en medio de difíciles condiciones para adaptarse a lo urbano. Aun se puede profundizar en las relaciones entre urbanización formal y la urbanización espontánea que tiene tantos perfiles (invasiones, autoconstrucción, planes de vivienda, etc.). A su vez, es necesario correlacionar las etapas económicas de la ciudad con las diferentes formas de urbanización, en qué medida el crecimiento o la recesión han determinado el número de pobladores que vienen de otros municipios; o de qué forma el desarrollo de un sector económico como la confección (entre los años cincuenta y noventa) demandó mayor mano de obra y pudo transformar las dinámicas urbanas.

- La relación entre urbanización y política bipartidista: Queda pendiente indagar los lazos entre las urbanizaciones populares y los partidos políticos tradicionales desde los años cuarenta. En 
los archivos del Concejo Municipal y en la prensa local es posible encontrar los discursos de líderes como Camilo Mejía Duque y Jaime Salazar Robledo defendiendo los intereses de barrios con los que tenían afinidad política (realización de acueductos, pavimentación de calles, construcción de escuelas y salones vecinales, etc.). Cabe preguntarse hasta qué punto la urbanización fragmentada de Pereira tiene raíces bipartidistas y en qué medida los barrios sirvieron como puntos nodales del proceso de intermediación entre políticos y ciudadanía.

- La historia barrial como protagonista: La historia urbana casi siempre se piensa en perspectiva funcional-estructural; se asume la ciudad como un sistema de relaciones y, en esa medida, se piensan los barrios como pequeños universos que sólo tienen sentido al ser parte de esa gran red llamada la ciudad. No obstante, sigue faltando la historia de los barrios para comprender sus dinámicas particulares. Algunos acercamientos que se han realizado todavía caen en la pesquisa de las anécdotas y no logran proponer etapas, trayectorias y procesos en la historia de los barrios. No quiere decir que los trabajos de historia oral que se han realizado sobre fundadores de barrios no sean importantes; claro que lo son, además de que constituyen un punto de partida para avanzar desde la disciplina histórica en el conocimiento de los mismos. Pero, por ejemplo, la historia del barrio Cuba sigue pendiente. Entender la formación de este barrio es la posibilidad de interactuar con diferentes momentos de la historia de la ciudad en los últimos sesenta años. Aún hay una pregunta sin respuesta: ¿cómo fue posible que un barrio creado por pobladores desplazados por la violencia se convirtió en la ciudadela más importante de Pereira? De igual forma, es necesario investigar esas figuras especiales que han sido las Juntas de Acción Comunal, muy criticadas por algunas personas porque se les ve como los nodos del clientelismo municipal, pero ¿qué significado han tenido y cómo contribuyeron al desarrollo de los barrios?

- Del barrio popular a la especialización de lo urbano (edificios residenciales, seguridad y distinción): La historia urbana crítica implica analizar la transición entre el barrio popular y las urbanizaciones residenciales, caracterizadas por tener otras lógicas de gestión y pobladores de clase media ascendente que por distintas razones se sienten interesados en la distinción que genera la privacidad y la uniformidad de los apartamentos. La historia reciente 
permite comprender esa nueva etapa de la ciudad para reconocer las implicaciones en las dinámicas de identidad y socialización de los barrios populares y sus pobladores. En este sentido, se pueden tomar prestadas algunas herramientas de la antropología urbana (Gravano, 2016) y la geografía crítica (Harvey, 2013, Garza, 2017), disciplinas que han avanzado mucho en la pregunta por las implicaciones del desarrollo urbano más contemporáneo y que se atreven hacer uso de categorías como ciudades neoliberales (Monreal, 2016), video seguridad y neoliberalismo autoritario (Bojórquez-Luque, Ángeles y Gámez, 2020), entre otras, las cuales pueden ser trabajadas desde la historia con sustento empírico.

Por lo anterior, la historia urbana en perspectiva crítica todavía tiene muchos frentes de batalla e incluso son muchos los mitos que debe seguir (de)construyendo, mucho más en una ciudad donde los desarrollos historiográficos siguen siendo lejanos a la ciudadanía en general, porque desde las clases dirigentes y los formadores de opinión pública se insiste en privilegiar los imaginarios fundamentados en mitos históricos que enaltecen las características de una "raza" especial o de una población proclive a la solidaridad, por no hablar de lo difícil que ha sido procurar que el "famoso civismo de los pereiranos" sea entendido como uno de los tantos imaginarios posibles de ciudad y no como una verdad absoluta (Correa, 2014). Es claro que es más sencillo congeniar con las visiones de ciudad que nos representan, pero es más democrático que el imaginario incluya a más personas, aunque no sea tan bonito o romántico.

Además de hablar de los múltiples aspectos positivos que tiene la obra de Otoniel Arias y Julián Restrepo, he querido realizar una invitación a continuar haciendo una historia urbana crítica, lo que implica seguir revisando, cada vez con más herramientas conceptuales y empíricas, el periodo de 1940 a 1990. Por último, quiero resaltar que este libro es uno de los aportes más recientes que surge desde la Colección de la Maestría en Historia de la UTP, una prueba más del compromiso cultural e investigativo de este posgrado con la región en la última década.

\section{Anderson Paul Gil Pérez ${ }^{2}$}

\footnotetext{
2 Maestro en Historia por la Facultad de Historia de la Universidad Autónoma de Sinaloa, México; Licenciado en Etnoeducación y Desarrollo Comunitario por la Universidad Tecnológica de Pereira, Colombia; actualmente estudiante del Doctorado en Ciencias Sociales de la Facultad de Ciencias Económicas y Sociales de la Universidad Autónoma de Sinaloa, México. andersonpaulgp@gmail.com
} 


\section{REFERENCIAS:}

Bojórquez-Luque, Jesús; Ángeles, Manuel; y Gámez, Alba (2020). "Videovigilancia y segregación espacial en tiempos del neoliberalismo autoritario. El caso de Los Cabos, Baja California Sur (México)". Revista CS, 31, 217-24

Correa, Jhon Jaime (2014). Civismo y educación en Pereira y Manizales (1925-1950): Un análisis comparativo entre sus sociabilidades, visiones de ciudad y cultura cívica. Pereira: Universidad Tecnológica de Pereira.

Garza, Gustavo (2017). Geografía e historia en Iberoamerica: integración del conocimiento social y el físicobiológico. Ciencias sociales, humanidades y derecho: Cómo pensar el mundo latinoamericano, 9-20.

Gravano, Ariel (2016). Antropología de lo urbano. Chile: Lom Editores.

Harvey, David (2013). Ciudades rebeldes. Del derecho a la ciudad a la revolución urbana. Madrid: Akal.

Lefebvre, Henri (1975). El derecho a la ciudad. Barcelona: Península.

Matos Mar, José (1986). Desborde popular y crisis del Estado. Perú: Instituto de Estudios Peruanos.

Monreal, Pilar (2016). "Ciudades neoliberales: ¿el fin del espacio público? Una visión desde la antropología urbana”. Quaderns-e, 21(1), 98-112.

Romero, José (1976). Latinoamérica, las ciudades y las ideas. Argentina: Siglo XXI Editores. 



\section{INTRODUCCIÓN}

Densar históricamente no sólo implica rastrear los acontecimientos de grandes hombres y grandes epopeyas sucedidas en el pasado. También implica, desentrañar el flujo de elementos y de procesos que posibilitan la conformación de territorios y espacios en una escala menor. Implica revisar lo que hay detrás de los lugares a los que ciudadanos anónimos concurren diariamente y en los que habitan, en los que nacen y mueren. El análisis crítico de los relatos históricos permite dilucidar que una buena dosis de sospecha frente a la idea totalizadora de las historias oficiales, es fundamental para comprender que cualquier conclusión en una investigación no puede ser tenida por regla general. Esto es, siguiendo a Carlo Ginzburg, comprender que la realidad es discontinua y heterogénea, sin que ello implique que el pasado se vuelva inalcanzable (Ginzburg, 2010).

Pensar en el desarrollo urbano de Pereira como constructo histórico remite también al desmonte de muchas figuras instauradas en la memoria oficial colectiva, de barrio y de desarrollo. Por tal razón, rastrear e indagar las formas de incorporación urbana en la ciudad, lleva a comprender que los procesos de organización social subalterna que han estado al margen de la historiografía oficial, poseían otrora su 
propia lógica y no son producto del azar. Esto significa, siguiendo la tesis de Michael Foucault, entender que detrás de las historias fluidas de los gobiernos, se dibujan otras historias de débil pendiente, casi inmóviles a la mirada como la historia del trigo, las minas de oro o las sequias (Foucault, 2002), y por qué no, las historias de la conformación del hábitat urbano, donde el protagonista no es el Estado sino grupos de individuos que, desde los márgenes y la precariedad, luchan por su incorporación vital dentro de la urbe.

El proceso de transformación urbana de la ciudad de Pereira durante el siglo XX llama particularmente la atención, debido a que las dinámicas de urbanización estatal generadas desde el Instituto de Crédito Territorial y el Fondo de Vivienda Popular, se vieron complementadas por la participación decidida de iniciativas de asociaciones de trabajadores, sindicalistas y grupos de ciudadanos, como fue el caso del Barrio Cuba, Alfonso López y El Río, estudiados por el padre franciscano Arturo Calle a mediados del siglo XX, y donde se retrata el esfuerzo y la iniciativa colectiva de migrantes de escasos recursos en su conformación (Calle, 1964).

De este modo, son muchas más las incitativas, las asociaciones y las organizaciones de viviendistas que para la época hicieron parte en la lucha por el derecho a una vivienda en la ciudad desde la legalidad y la ilegalidad, y que no han sido suficientemente retratadas o reconocidas dentro de la historiografía de la ciudad, como es el caso de la organización de viviendistas llamada: Central Nacional Provivienda CENAPROV. En ese sentido el presente texto busca llenar ese vacío historiográfico en la ciudad, de modo que, desde la subalternidad y la reconstrucción de estos relatos olvidados en los márgenes de la urbe, se pueda complementar la historia del crecimiento urbano de la ciudad. Lo que en otras palabras significa: hacer una historia más incluyente.

Precisamente, el objeto de estudio de esta investigación, está dirigido a aportar nuevos elementos que permitan entender el desarrollo urbano de Pereira en la segunda mitad del siglo XX, desde una perspectiva periférica, es decir, un tipo de relato marginal que pueda explicar la influencia que tuvo la organización de viviendistas llamada CENAPROV en el desarrollo urbano de la ciudad y del que no se da cuenta en la historiografía oficial. Para ello, se ha propuesto a partir de la metodología denominada Reconstrución Colectiva de la Historia (RCH) planteada por Alfonso Torres Carrillo en su texto Hacer Historia desde abajo y desde el Sur (Torres Carrillo, 2014), abordar el tema cotejando 
las diferentes fuentes de archivo, referencias bibliográficas y testimonios de los protagonistas que ubican la investigación en un marco nacional, incluso latinoamericano, permitiendo evidenciar el dinamismo sociopolítico y la manera en que se agruparon los ciudadanos alrededor de los movimientos populares como ocurrió en el caso CENAPROV, para dar solución al déficit habitacional y ocupacional del espacio dentro de la ciudad.

El $\mathrm{RCH}$, es una metodología que permite brindar un papel protagónico a los sectores populares y reconocer su protagonismo, para ello Alfonso Torres Carrillo, plantea siete criterios metodológicos, entre los que se destacan el consolidar una construcción de conocimiento articulada a las luchas sociales alternativas, servir de eje constructor del conocimiento sobre el pasado, localizar con precisión el objeto de estudio sin perder la mirada de conjunto promoviendo el dialogo de saberes, incorporando un amplio abanico de fuentes, entre las que se destacan la oralidad, revistas producidas por organizaciones sociales e instituciones, periódicos, archivos personales, normas, estadísticas, investigaciones, libros entre otros (Torres Carrillo, 2014).

No obstante, no todo el planteamiento colectivo y transformador de la Reconstrucción Colectiva de la Historia $(\mathrm{RCH})$ se tomará para esta investigación. Es preciso hacer claridad que, pese a que se trabajó directamente con la comunidad, esta no hizo parte de la construcción de los objetivos del proyecto investigativo, y este tampoco nació de intereses colectivos por llevar a cabo dicha investigación. Por lo demás, su estructura sus fuentes y su relación analítica se presentan como pertinentes y útiles para la ejecución del presente proyecto.

Se calcula que para los años 80 , en Colombia, un total de un millón 600 mil personas tenían problemas para acceder a la vivienda, esto quiere decir que, para una población aproximada de 27 millones de habitantes en el país, cerca de 10 millones se encontraban enfrentando en condición de deficitarios de vivienda (Arango Zuluaga, 1986).

Se trata de un déficit habitacional producto de la demanda industrial por mano de obra, así como por los procesos migratorios derivados de la violencia bipartidista - que afectó a la población campesina de departamentos vecinos como Valle del Cauca, Tolima, Caldas y Quindío a mediados del siglo XX - y de los que la ciudad de Pereira fue receptora (Pabón, 1985). Al problema de la vivienda se asociaban además la dotación de servicios públicos, la educación, la salud y el desempleo como las principales problemáticas de la ciudad para la época. 
Reconocer la historicidad de los movimientos y luchas populares de vivienda en la ciudad de Pereira, supone al mismo tiempo, evidenciar la problemática en los usos del suelo y la solución de vivienda a nivel local, nacional, y como ya se ha escrito, latinoamericano. Esta nueva mirada, permite también rastrear las formas en que diversas colectividades, grupos de desplazados y migrantes del campo, lucharon por acceder a una vivienda en la ciudad, o más precisamente en su periferia, a fin de mejorar sus condiciones de vida o al buen decir de David Harvey, posibilita observar la lucha por el derecho a reinventar la ciudad (Harvey, 2013).

Éste, que podría denominarse nuevo paradigma en el desarrollo urbano de la ciudad, invita a discutir nuevamente la idea de civismo que caracteriza el discurso oficial en la consolidación de la ciudad de Pereira, que en manos de la Sociedad de Mejoras Públicas ha sido el estandarte de la identidad pereirana en el marco del proyecto modernizador adelantado en la ciudad por parte de lo que se ha denominado la élite cívica quien de la mano de la ideología del civismo, impulsó el comercio, la industria y un variado tipo de obras de ornato en la ciudad (Correa, 2014). La brevedad en los análisis e investigaciones que analizan de manera incipiente la aparición del barrio "pirata" como surgido por generación espontánea, motiva que en esta investigación se intente problematizar la idea según la cual, los procesos de urbanización conocidos como "piratas e ilegales" son espontáneos, poco planificados, surgiendo de la noche a la mañana como retrata comúnmente la prensa local (La Tarde, 6 Septiembre 1977).

Por supuesto, comprender el caso CENAPROV y su influencia en el crecimiento barrial de Pereira permite un diálogo constante con diferentes disciplinas, y de una u otra manera con diferentes campos de la historia, en la medida que se nutre de la política, de las mentalidades y de la economía. De esta manera, el trabajo del historiador, como bien sugiere Alfonso Torres Carrillo, se nutre de las diferentes experiencias existentes, así como de disciplinas que puedan aportar teorías para el entendimiento de las hipótesis planteadas, como lo es el caso de la sociología, antropología y la demografía (Torres Carrillo, 1993).

Pese a que las investigaciones sobre la ciudad y la historia urbana son ejercicios relativamente recientes en Colombia, dado que no superan la tres décadas, es importante reconocer que en la actualidad se ha venido buscando llevar el análisis urbano, más allá del lugar común de la biografía de la ciudad, los pormenores de sus fundadores y la 
descripción de espacios concurridos tradicionalmente y que son motivo de orgullo por parte de sus pobladores, por una idea de ciudad como ese lugar de encuentros ideológicos, cotidianidades, reivindicaciones, luchas comunes, quimeras y azares. De lo que se trata es de: "historiar la ciudad, encontrarle una explicación desde la perspectiva de su temporalidad" (Mejía Pavony \& Zambrano Pantoja, 2000, pág. 51).

Desde la década de los 70, existen trabajos a nivel latinoamericano, en países como Argentina, Brasil, México y Colombia, que han permitido el surgimiento de importantes investigadores alrededor de la historia urbana, como lo son: Germán Mejía Pavony, Fabio Zambrano, Mauricio Archila Neira, José Luis Romero, Jacques Aprile, Carlos Alberto Torres, Alfonso Torres Carrillo, entre otros. Quienes se han interesado en abordar este importante tema historiográfico, que amplía un panorama teórico y metodológico, para comprender lo urbano en Colombia desde la investigación histórica, además de ofrecer una mirada sobre diferentes procesos que se han llevado a cabo en algunas ciudades latinoamericanas sirviendo a su vez de referente comparativo para el caso de Pereira.

Cabe aclarar que, para el análisis urbano de Pereira, es muy poca la producción en estudios sobre historia urbana, salvo los adelantados por la Universidad Católica de Pereira desde su pregrado de arquitectura y los adelantados por el grupo de investigación: Políticas, Sociabilidades y Representaciones Histórico-Educativas de la Universidad Tecnológica de Pereira. También resulta importante resaltar el aporte de las diferentes monografías y memorias adelantadas en los diferentes barrios, bien sea por iniciativas particulares de algunos ciudadanos o por el respaldo a manera de concurso de la administración municipal, claro ejemplo de éste último, es la Monografía del Barrio Cuba, importante ejercicio que retrata el proceso histórico de transformación urbana de la zona suroccidental de la ciudad a partir de su conformación inicial a finales de los años 50 y comienzos de la década de los 60. Transformación en la que también tuvo incidencia la Central Nacional Provivienda CENAPROV.

Otro de los trabajos que han servido de referente para el análisis del objeto de estudio de esta investigación, es el adelantado por el padre franciscano Arturo Calle, cuya lectura permite comprender los procesos de expansión urbana en la ciudad y la manera como se gestaron los procesos de urbanización subnormal o pirata en algunos sectores de la ciudad por la década de los 60. Dicha investigación, se 
apoya en importantes datos estadísticos que describen el panorama de los habitantes de tres barrios que sumaban el 25\% de la población total de la cuidad para la época (180.000 habitantes) y sus difíciles modos de inserción en la vida económica, política y social de Pereira (Calle, 1964). Lo que en otras palabras significa un análisis de los fenómenos sociales que se iban consolidando en la ciudad en la segunda mitad del siglo XX, en materia de expansión urbana a causa de los procesos migratorios.

Para dar continuidad a esta idea de ciudad planteada por Arturo Calle, es importante considerar el concepto de ciudad formal y ciudad informal, utilizado por Carlos Alberto Torres en su texto La ciudad informal colombiana. Barrios construidos por la gente (Torres Tovar, 2009) bajo esta distinción se enmarca la ciudad que ha sido pensada y desarrollada bajo los marcos de la legalidad y teniendo en cuenta las exigencias de ley en materia urbanística, mientras que la ciudad informal se desarrolla con los mínimos requisitos, como sucede con los urbanizadores piratas o a través de las invasiones de terrenos.

Ligada a las concepciones de formalidad e informalidad y al proceso de transformación del suelo en el tiempo, no se puede pasar por alto la visión de territorio y de barrio que implica esta investigación, para ello el concepto territorios identitarios, al que pertenece el barrio, se aborda desde Gilberto Giménez, en su texto Territorio, cultura e identidades (Giménez, 1999), donde hace particular referencia al territorio como un determinante en las relaciones socio espaciales, el barrio se convierte en un espacio de apropiación física y simbólica, donde se construyen lazos culturales e imaginarios que definen al individuo, colectiva o individualmente.

El lugar social en que se desarrolla esta investigación, aterriza en el barrio como unidad de análisis material y simbólico, en la medida en que los procesos de conformación de vivienda implicaban relaciones sociales ligadas igualmente con componentes políticos e ideológicos, como elementos clave en la consolidación del tejido social y en el desarrollo del compromiso de las comunidades.

Otro de los conceptos centrales que hacen parte del entramado conceptual de esta investigación es el de vivienda autoconstruida. La modalidad de autoconstrucción es un concepto de orden urbanístico y arquitectónico que fue empleado por el Estado y por los grupos viviendistas para solucionar el problema habitacional en los sectores populares en Colombia desde la segunda mitad del siglo XX (Robledo, 1985). Esta solución consiste principalmente en una forma 
de construcción paulatina y artesanal realizada por el deficitario de vivienda después de haber adquirido un lote con o sin servicios básicos. Motivado por el anhelo y la posibilidad de tener una casa, emplea tiempo, recursos y esfuerzo para edificar paso a paso su vivienda (Turner, 1976). Entre sus ventajas el proceso de autoconstrucción, según John Turner, se encuentra la satisfacción de las necesidades de los usuarios, de modo que de la mano de la participación popular, sean los individuos en su autonomía y libertad personal, quienes decidan cómo desean construir sus viviendas y no tengan que depender de la maquinaria del Estado (Turner, 1976).

En la ciudad de Pereira la modalidad de autoconstrucción fue el principal mecanismo mediante el cual el estado a través de entidades como el ICT y el fondo de vivienda popular enfrentaron el déficit habitacional, al igual que lo hicieron las diferentes organizaciones de viviendistas, entre ellas CENAPROV.

Tan significativo es acudir a otras disciplinas en la comprensión de las dinámicas que rodearon ciertos procesos urbanos que, resultó un referente inevitable el trabajo adelantado por Jacques Aprile-Gniset en su texto La ciudad colombiana. En dicho trabajo, se logra construir un aparataje conceptual que permite comprender muchas de las relaciones socio - espaciales alrededor del desarrollo urbano en las nacientes ciudades. Aspectos como el incremento acelerado de algunas urbes, su desarrollo económico y estructural, la presión sobre la tierra urbanizable, el déficit habitacional, el problema del crecimiento ilegal a manera de urbanizaciones piratas e invasiones y las concepciones de colonización popular agraria u urbana (Aprile-Gniset, 1992) permitieron hacer una ajustada radiografía de la manera en que se consolidaron las urbes en el territorio colombiano.

Por todo lo anterior, el presente ejercicio investigativo es pertinente para la consolidación del acervo documental de la historiografía de la ciudad. Su comprensión, desde un punto de vista heurístico, permite abordar el tema de investigación desde una pluralidad de fuentes de naturaleza documental, oral, visual, etc. A partir de la cuales es posible seguir el rastro a las formas de organización social de los viviendistas en la construcción de algunos barrios de la ciudad de Pereira desde un punto de vista multicausal, sin desconocer las disputas a nivel ideológico dentro de la organización en el contexto político de la temporalidad acotada.

Por otra parte, en el presente análisis se indagará por el papel que 
jugaron las entidades estatales como el ICT y el Fondo de Vivienda Popular en la solución al déficit de la vivienda en el país y en el municipio de Pereira. Y también la forma en que las organizaciones de carácter político como CENAPROV encuentran su asidero en la ciudad, articulando planes de vivienda, en comunidades que se hallaban en barrios piratas o que estaban fuera de las soluciones de vivienda de interés social, como lo eran los planes de vivienda del Instituto de Crédito Territorial ICT.

En consecuencia, la objetivo del presente trabajo investigativo, es rastrear la incidencia que tuvo la organización de viviendistas Central Nacional Provivienda en el desarrollo urbano de la ciudad de Pereira, desde el momento en que dicha organización empieza a hacer presencia en la ciudad en el año de 1973, y hasta el momento de su declive en 1987 por múltiples causas, entre ellas, la persecución política de la que fue objeto, y que coincide con el asesinato del dirigente de la Unión Patriótica Jaime Pardo Leal ese mismo año y en 1989 con el asesinato del también reconocido dirigente de la Unión Patriótica a nivel regional Gildardo Castaño Orozco.

En ese orden de ideas, la presente investigación se compone esencialmente de tres capítulos construidos desde una perspectiva que pasa por analizar el objeto de estudio en su generalidad hasta ubicar y rastrear su incidencia en el caso puntual de Pereira. En el primer capítulo se analizarán los fenómenos migratorios y el crecimiento de las ciudades en Latinoamérica a través del estudio de José Luis Romero, a fin de poderlos contrastar con la exclusividad de los fenómenos migratorios en Colombia en la segunda mitad del siglo XX, particularmente el centro occidente del país, producto del fenómeno de la violencia bipartidista, analizados suficientemente por Jacques Aprile, Marco Palacios, Frank Safford, Orlando Fals Borda, Germán Guzmán, Eduardo Umaña y Carlos Miguel Ortiz. A partir de allí, se determinará el impacto que tuvieron esos movimientos de población en la explosión urbana de la ciudad de Pereira y el protagonismo que tuvieron los movimientos de izquierda en la ciudad en la reivindicación de los derechos de quienes carecían de vivienda.

En el segundo capítulo, se rastreará el fenómeno del déficit habitacional en Colombia y particularmente en la ciudad de Pereira con ayuda de las investigaciones que realizaron Jorge Robledo y Oscar Arango a mediados de los años 80 . Se intentará además analizar el alcance y el contexto de las políticas estatales de vivienda para afrontar el 
déficit desde el nivel nacional al local, con programas como el Instituto de Crédito Territorial y el Fondo de Vivienda Popular. A partir de allí, se intentará comprender la dimensión de la problemática de la vivienda en la ciudad y el drama de los asentamientos urbanos ilegales, por medio de la interpretación de fuentes primarias como lo son, los censos y la prensa.

Con una comprensión más amplia del panorama deficitario de la vivienda a mediados del siglo XX, se intentará rastrear desde un contexto global y local la concepción de vivienda autoconstruida - según las concepciones del arquitecto inglés John Turner - usada tanto por organizaciones de viviendistas formales e informales como es el caso el ICT y CENAPROV en la ciudad de Pereira.

El tercer capítulo es un análisis sobre la incidencia de CENAPROV en el crecimiento urbano de la ciudad de Pereira a partir de la década de 1970, por medio del archivo existente y proporcionado por la misma organización en Bogotá, así como de investigaciones realizadas por la socióloga Gloria Elvira Naranjo y las entrevistas realizadas a muchos de los miembros de la organización en la ciudad. Se iniciará con un análisis sobre la presencia de CENAPROV a nivel nacional, derivada de las luchas populares agrarias por la tierra, sus formas organizativas en las ciudades en la lucha por una vivienda para los destechados, el proceso de conformación de sus barrios en la ciudad de Pereira de la mano de constantes tensiones, luchas y acuerdos con los representantes del poder público en el municipio.

Finalmente, de la mano de testimonios, comunicados internos de la misma organización y algunos archivos de prensa, se intentarán esclarecer algunas de las causas del declive de la organización en la ciudad a finales de la década de 1.980. Entre las que se destacan, la violencia política de la que fue objeto, pues muchos de sus representantes a nivel local eran miembros de la Unión Patriótica; los cambios legales en los requisitos para adelantar planes de vivienda; la tensión entre las Juntas Directivas de CENAPROV y las Juntas de Acción comunal al interior de los barrios; la presión que Superintendencia Bancaria ejerció sobre la entidad, el aumento de la empresa privada en la construcción de vivienda en la ciudad, las conflictos internos entre los directivos regionales de la organización, minarían en los barrios construidos por CENAPROV buena parte del tejido social construido de los antiguos moradores.

Como es de suponer, esta investigación, no desconoce, ni pretende 
pasar por alto, que dicha organización de viviendistas, emerge del Partido Comunista Colombiano PCC, con propósitos organizativos y asociativos, que buscaban, además de brindar una solución de vivienda a los destechados, fortalecer una base social y electoral en los lugares de influencia, permitiendo a sus dirigentes contar con opciones reales de ser elegidos en cargos públicos.

No en vano, la toponimia urbana de los barrios que dicha organización logró legalizar en la ciudad, sirve de indicio, que permitiría dar cuenta de la filiación ideológica de sus representantes y dirigentes. Así, barrios como La Isla de Cuba, Leningrado, Jaime Pardo Leal, Santiago Londoño, José Antonio Galán, entre otros, permiten poner en discusión la relevancia y protagonismo de la izquierda en la lucha popular por la vivienda en la ciudad de Pereira.

Hoy día, la Central Nacional Provivienda -recientemente declarada organización víctima del conflicto armado en Colombia (Ver anexo 1)- tiene una presencia espectral en la ciudad. Después de múltiples amenazas, asesinatos a muchos de sus dirigentes y disputas internas entre sus miembros, la organización fue permeada por un paulatino declive. Razón por la cual, en el presente no cuenta con la capacidad organizativa de otros tiempos. Los testimonios de sus protagonistas, en su lucha por el derecho a ocupar una vivienda en la ciudad, permiten reconocer la dimensión que tuvo la organización en la transformación urbana de la ciudad de Pereira y los rastros de acontecimientos pasados que perduran para servir de complemento disonante a las historias oficiales que llenan de orgullo a los pereiranos.

Cabe destacar que, para la realización de la presente investigación, ha sido clave la ayuda de diferentes personas que de una u otra manera fueron protagonistas del accionar de CENAPROV en la ciudad y que estuvieron prestos a proporcionar información valiosa como lo fueron: Jairo Mejía Vélez, Miguel Castañeda, Fernando Botero, Duván Restrepo, Francisco Londoño, Carlos Alfredo Crosthwaite, Manuel Ayala, entre otros. Agradecemos también la valiosa asesoría tanto del Director del Programa de Maestría en Historia de la UTP John Jaime Correa, así como el acompañamiento de la Doctora María Elvira Naranjo Botero, docente del Departamento de Sociología de la Universidad Nacional de Colombia, quien adelantó la investigación sobre la historia de CENAPROV a nivel nacional y construyó el archivo de la organización, permitiendo con ello, el acceso a documentos de diferente naturaleza que reposan en la sede de la organización PROVIVIENDA en el Barrio Policarpa Salavarrieta de la ciudad de Bogotá. 


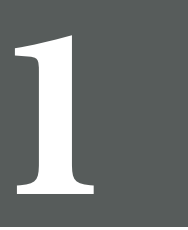

\section{CAPÍTULO UNO:}

La ciudad de Pereira y sus MIGRACIONES EN LA SEGUNDA MITAD DEL SIGLO XX 

T a efectiva comprensión de la transformación urbana al interior de Luna ciudad, conlleva la necesidad de lograr poner de manifiesto la contextualización de cuestiones relacionadas con los modos de vida, las prácticas económicas, los procesos migratorios, el tejido urbano, la industrialización, el conflicto social, las tensiones y decisiones a nivel político que, en todo caso, intervienen para que dichas transformaciones urbanas sean posibles en determinado lugar.

Indagar por la influencia que tuvo la Central Nacional Provivienda CENAPROV en el desarrollo urbano de la ciudad de Pereira en la segunda mitad del siglo XX implica emprender la comprensión de las realidades sociales que subyacen alrededor de la problemática de la vivienda, como lo son: el crecimiento demográfico en las ciudades, las migraciones, la pobreza. Todas ellas, realidades compartidas por la mayor parte de los países latinoamericanos a mediados del siglo XX.

Por tal motivo, el propósito del presente capítulo, será realizar un acercamiento al contexto migratorio y demográfico de la segunda mitad del siglo XX, desde la perspectiva general del acontecer latinoamericano, hasta la situación relativa a las dinámicas propias del ámbito colombiano o local de la ciudad de Pereira, lo que permitirá dilucidar algunas de las causas más relevantes, que alentaron la emergencia de la lucha por la vivienda en la ciudad de Pereira, y con ello, la aparición de entidades de carácter oficial y no oficial como CENAPROV, cuyo objetivo era facilitar la solución de vivienda para los destechados en la ciudad.

Este acercamiento, permitirá colocar de manifiesto el primer objetivo sobre la que descansa la investigación: Las dinámicas urbanas y migratorias de la segunda mitad del siglo XX, son tan propias del contexto colombiano, como de buena parte del resto de países latinoamericanos. 


\section{Crecimiento urbano y barrial en América Latina}

Según el historiador Eric Hobsbawm, en lo que denominó la edad dorada del siglo XX, esto es, a partir de 1.950, la población del tercer mundo creció a un ritmo espectacular. No obstante, en América Latina el aumento de la población se dio aún más de prisa (Hobsbawm, 2015). En esta dirección, la presente investigación se circunscribe en un momento histórico de mediados de siglo XX, caracterizado por las crisis migratorias al interior de los países latinoamericanos, de las que Colombia no fue ajena, y en las cuales, gran parte del campesinado migró hacia las ciudades grandes e intermedias, seducido por la posibilidad de mejorar las condiciones de vida familiares o compelido por la necesidad de salvaguardar la vida, ante la amenaza inminente de la violencia política generalizada en el país.

Este fenómeno migratorio, agudizó el déficit de vivienda y servicios en las urbes, lo que en consecuencia derivó en un aumento de tugurios y asentamientos populares dentro de la ciudad o para el caso concreto en sus márgenes (Torres Carrillo, 1993). La consecuencia de la migración interna en el caso colombiano aumentó la presión demográfica en las ciudades, situación que, aunada a una incapacidad estatal para resolver la demanda de vivienda, conllevó a la aparición de un sin número de asentamientos ilegales que modificaron la fisonomía y el paisaje de las ciudades.

Lo anterior, parece coincidir con el planteamiento de Henri Lefebvre, según el cual, la transformación de la ciudad en el siglo XX, se dio como consecuencia de procesos globales, como el incremento de la producción material, las modificaciones en el modo de producción, las relaciones campo-ciudad, las relaciones de clase, propiedad y las intervenciones de instituciones más generales que proceden del Estado (Lefebvre, 1975, pág. 71).

Teniendo presente, como se ha sugerido ya, que el crecimiento urbano no es exclusivo de un lugar determinado, sino un fenómeno que impactó Latinoamérica a mediados del siglo XX, conviene considerar que para comprender cualquier dinámica de transformación urbana al interior de una ciudad, se precisa del análisis crítico de muchas variables, como lo son: Los procesos de producción que en la ciudad intervienen, las formas del trabajo, las ideologías, los procesos migratorios de los que la ciudad es receptora, las relaciones y modos de vida de quienes la habitan, su relación con el campo que la circunda y las decisiones institucionales, empresariales, económicas -y hoy en día ambientales- 
que inciden en su transformación ${ }^{1}$. Huelga aclarar que, en ésta investigación no serán analizadas todas las variables mencionadas, sino algunas que han sido consideradas de mayor relevancia, como lo son: Los procesos migratorios ligados a la relación campo-ciudad, algunas políticas institucionales en el marco de la agenda internacional de los gobiernos, las ideologías y algunas formas de producción que alentaron el arribo de pobladores a las ciudades.

De este modo, la comprensión de lo que puede significar la ciudad se torna aún más compleja y plural, resistiéndose a cualquier intento de simplificación o reducción al ámbito urbanístico y arquitectónico, sobre todo, si de lo que se trata es de procurar una explicación amplia de sus cambios. En este sentido, la ciudad como ese espacio o territorio donde se desarrolla la vida urbana, edificada como producto del trabajo y esfuerzo de quienes la habitan, es también un lugar de encuentros, un lugar de cambios (Lefebvre, 1975) o más específicamente un escenario de tensiones y como se verá más adelante, de confrontaciones entre distintos grupos sociales que buscan un espacio de inclusión dentro del engranaje industrial y económico, así como mejores condiciones de vida para quienes, como en el caso colombiano, huían de la violencia bipartidista que les azotaba a partir de mediados del siglo XX.

La lucha por el espacio social dentro de la urbe para contrarrestar las prácticas segregacionistas dentro de la misma, el derecho a una vivienda digna, al uso pleno de los lugares públicos de esparcimiento y a poder incidir sobre la transformación urbana, es lo que algunos teóricos urbanos contemporáneos enmarcan dentro de la lucha por el derecho a la ciudad y la producción social del hábitat ${ }^{2}$. De modo que, al rastrear la forma en que una organización social como CENAPROV luchó por el derecho a la vivienda en los márgenes de la ciudad de Pereira, también se dilucidan modos de vida distintos a los de la ciudad tradicional, dinámicas migratorias, procesos de modernización y confrontaciones ideológicas que permitirán entender de un modo más amplio sus procesos de crecimiento.

Durante el siglo XX, Latinoamérica vivió un proceso de explosión demográfica derivado de la crisis económica de los años treinta y de los continuos éxodos de población rural a las ciudades a causa de la baja de precios en el campo y la consecuente disminución en calidad

1 Para entender mucho mejor la relación entre la ciudad y el medio ambiente, puede consultarse el texto de Mike Davis Las Ciudades Muertas. 2007.

2 Cfr. https://www.youtube.com/watch?v=yfH7j-37lbM 
de vida de los campesinos. Esto aun a pesar de que, según Safford y Palacios (Safford \& Palacios, 2012) los efectos de la gran depresión en Colombia fueron más breves que en el resto de Latinoamérica. No obstante, aquella crisis impactó en la salida de flujos de capital externo, en la caída del precio del café, en el desempleo y en la inflación (Safford \& Palacios, 2012, pág. 396).

En este orden de ideas, los procesos de crecimiento demográfico en Colombia y el éxodo de población rural hacia la urbe, terminaron ajustándose a las pautas latinoamericanas (Safford \& Palacios, 2012, pág. 433). Así, a partir de los años treinta, gran parte de la población campesina en Latinoamérica, inicia su proceso migratorio hacia las ciudades, bajo el supuesto de una esperanza de mejorar las condiciones de vida familiar ligadas al empleo, es decir en cuanto el campesino lograra vincularse al sector comercial, industrial o de servicios de la ciudad.

En el caso colombiano, el rápido ascenso demográfico que tuvo el país entre los años que van de 1950 a 1973, explica el hecho de que en menos de medio siglo el país, que en el censo de 1938 tenía al 71\% de su población establecida en el campo, a fin de siglo tuviese el 70\% de su población en las ciudades (Safford \& Palacios, 2012, pág. 433) En consecuencia, el desborde demográfico y la redistribución geográfica, es uno de los grandes cambios acaecidos en Colombia al igual que en el resto de Latinoamérica durante el siglo XX. Movimiento que aunado al inicio de una industrialización incipiente y al paulatino despegue de la agricultura, permite pasar de un país rural a un país de ciudades (Safford \& Palacios, 2012, pág. 429). De allí que, Carlos Arango, en su texto La lucha por la vivienda en Colombia, afirme que:

Colombia adquiere su fisonomía urbana a partir de los años 50 del presente siglo. Si en 1950 la población urbana llegaba solo al 30\% y la rural al 70\%, para 1980 los términos de ésta relación se habían invertido, pasando la población urbana a ser del orden del $70 \%$ y la rural del 30\%. El proceso de concentración urbana ha operado principalmente en cuatro grandes ciudades: Bogotá, Cali, Medellín y Barranquilla que albergan al $45 \%$ de la población urbana. Al mismo tiempo Colombia mantiene una red de centros urbanos intermedios. Siete ciudades se acercan al medio millón de habitantes: Cartagena, Bucaramanga, Cúcuta, Manizales, Pereira, Armenia e Ibagué (Arango Zuluaga, 1986, pág. 83).

Los migrantes colombianos inician su proceso de desplazamiento a las ciudades motivados por una apuesta económica y la esperanza de tener algo que ofrecer en los mercados urbanos. De este modo, los nuevos 
moradores, esperaban ganar mejores condiciones de salud, educación, ingresos, vivienda y hasta libertades personales (Safford \& Palacios, 2012, págs. 435-436). De otro lado, hubo otra forma de migración relacionada con la inseguridad y el fenómeno de la violencia bipartidista que, a mediados del siglo XX en vastas zonas del país, forzó la migración de aproximadamente dos millones de personas y que, en consecuencia, repercutió en el paso de una población mayoritariamente rural a una mayoritariamente urbana (Rueda, 2000). De acuerdo con Alfonso Torres Carrillo en su Estudio sobre los pobladores urbanos en Colombia: "en la década del 50 se sumó el aluvión migratorio de campesinos, expulsados de las zonas rurales por la violencia, agudizándose el déficit de vivienda y de servicios, el incremento de la tugurización y los asentamientos populares" (Torres Carrillo, 1993, pág. 132).

La Violencia política bipartidista (1946-1965) analizada por (Guzmán, Fals Borda, \& Umaña, 2005) como un proceso estructural con motivaciones políticas, a las que se sumaron factores de índole económico, y de clase social, constituye un aspecto singular en relación al resto de Latinoamérica, pues a diferencia de los países vecinos, la violencia en Colombia fue el detonante principal de los éxodos de campesinos hacia las ciudades.

La cartografía que realizan (Guzmán, Fals Borda, \& Umaña, 2005) en el texto: La violencia en Colombia, fija la atención en la comprensión de las circunstancias de actores individuales y colectivos inmersos en el conflicto (Universidad Nacional de Colombia, 1994). Permitiendo poner de manifiesto la representación de La Violencia más allá del lugar común de una entidad anónima que arrasa todo a su paso, y en cambio evidencia con contundencia las responsabilidades políticas de las oligarquías liberales y conservadoras, como auspiciadoras directas de la violencia que ejercieron multitud de campesinos en los campos de Colombia, y que como consecuencia contribuyó a la generación de un puñado de problemas asociados, entre ellos, los fenómenos del desplazamiento y las migraciones (Guzmán, Fals Borda, \& Umaña, 2005).

Por su parte, para el urbanista Jacques Aprile, mucho antes de que el fenómeno de La Violencia tomara un tinte político partidista, había germinado a finales del siglo XIX como un conflicto de intereses por la tierra entre colonos y latifundistas que el mismo autor denomina: La colonización popular agraria. Situación que sería el origen subyacente del fenómeno de la violencia política acaecido en el país entre 1945 
y 1965 y que impactó a las zonas más ricas y potencialmente más prosperas en lo relativo a la producción de cafetera de exportación, esto es, la región central andina (Aprile-Gniset, 1992).

La agudización de la violencia durante el siglo XX en el campo, fue el mecanismo a través del cual los sectores económicos apropiaban y recuperaban zonas de colonización agraria; situación que dejó, según el mismo Aprile, más de 300 mil muertos y alrededor de 3 millones de campesinos desterrados, provocando migraciones forzadas del campo no solo hacia las grandes ciudades, sino también a pequeños poblados que no pasaban de 20.000 habitantes (Aprile-Gniset, 1992).Para Jacques Aprile, la violencia rural es la partera de la ciudad colombiana. Esto debido a que, la concentración y posterior aglomeración de los recién llegados a causa de la violencia, propicia la adecuación de las ciudades y las condiciones para sustituir la colonización popular agraria por la colonización popular urbana. En otras palabras, la lucha por el derecho al suelo dentro y/o en los alrededores de la urbe para adelantar proyectos de construcción de vivienda ilegal para los colonos urbanos destechados (Aprile-Gniset, 1992).

Pese a que, como ya se afirmó, la violencia constituye un lugar preponderante en los estudios sobre los procesos migratorios en Colombia, conviene mencionar, que la violencia no fue el único factor determinante del éxodo masivo de población del campo a la ciudad en el país. Factores como el aumento las altas tasas de fecundidad, el deceso de las tasas de mortalidad en la ciudad, la modernización de la agricultura, del transporte y la infraestructura de servicios (Sanchéz L. M., 2008) aunados a la precarización de la vida de los pobladores del campo con respecto a los urbanos, la búsqueda de seguridad y la esperanza de llegar a beneficiarse de la modernización en las ciudades, también influyeron, aunque en menor medida en los continuos éxodos de población rural hacia las urbes. De acuerdo con Lina María Sánchez:

Es coherente la tesis de que los procesos económicos mundiales, ligados a la acumulación capitalista, incidieron directamente en las migraciones del campo a la ciudad, en cuanto a la penetración de la agricultura comercial (café, ganado, caña etc.) generó cambios sobre la propiedad de la tierra, y dejó fuera de juego a los pequeños campesinos sin tierra. Por supuesto, la falta de tierras se reflejó en una situación socio-económica precaria para los campesinos, motivando su éxodo a las ciudades. La única esperanza del campesino era, entonces, poder construir su proyecto de vida en las ciudades beneficiándose del "prometedor" proceso de modernización, al cual le apostaba el Estado y del cual hizo generosa propaganda (Sanchéz L. M., 2008). 
Como puede apreciarse, los movimientos poblacionales y los procesos de redistribución geográfica no son causados por el azar, sino por circunstancias muy específicas y de ellas se derivan múltiples consecuencias tanto sociales como económicas, que incidirán, como se verá más adelante, en los procesos de autoconstrucción, de invasión o urbanización pirata, como una manera de solucionar el problema de la vivienda de los recién llegados a la ciudad.

Frente la creciente tendencia de desequilibrio poblacional entre el campo y la ciudad, el Estado colombiano reconoció el fenómeno de sub normalización como una de las problemáticas que enfrentaban las principales ciudades del país. Por ello, como resultado del informe del economista Lauchlin Bernard Currie, quien fue enviado a Colombia en 1949 por el Banco Mundial, se derivaron estrategias económicas y políticas que buscaban contrarrestar la desigualdad y elevar el nivel de vida de la población en Colombia. En materia urbana, por ejemplo, una de las estrategias consistía en: "orientar los flujos migratorios hacia las ciudades intermedias y los centros locales a través de incentivos que alivien la presión demográfica sobre las cuatro grandes ciudades" (Departamento Nacional de Planeación , 1975, pág. 145). Dicho de otra manera, el Informe Currie planteaba desviar el flujo migratorio de las grandes ciudades (Bogotá, Barranquilla, Cali y Medellín) hacia varias ciudades intermedias como Ibagué, Manizales y Pereira, con el propósito de aliviar la presión demográfica en las grandes ciudades.

Otra de las estrategias consistía en la creación de un plan integral de atención de la población marginal que crecía en las ciudades, denominado Programa de integración de servicios en zonas marginales, cuyo propósito era satisfacer las demandas de la población vulnerable en los aspectos relacionados con la salud, educación, vivienda y trabajo (Departamento Nacional de Planeación , 1975). Lo que permitiría, según dicho informe, incluir a una mayor cantidad de personas en los beneficios del desarrollo económico.

Este proceso que se vivió en ciudades capitales y ciudades intermedias en Colombia, ocurría simultáneamente en el resto de Latinoamérica, generado como consecuencia del desborde demográfico de las ciudades. Los nuevos habitantes y sus familias ocuparon las zonas periféricas de la ciudad y los barrios piratas fueron estableciéndose poco a poco, lo que produjo el desborde urbano en la ciudades grandes y medianas como consecuencia de la crisis rural y su migración hacia la urbe (Romero, 1999). 
Como es de suponer, según José Luis Romero, el crecimiento urbano modificó la fisonomía de las ciudad latinoamericana, lo que se reflejaba no únicamente en la proliferación de barrios, sino además, en la imposibilidad de contar con una infraestructura efectiva que satisfaga las demandas de consumo, vivienda y sosiego para todos (Romero, 1999). En palabras del autor:

\begin{abstract}
Decenas y decenas de ciudades que tenían entre veinte y cuarenta mil habitantes hacia 1930 multiplicaron su población por tres o por cuatro en cuarenta años, y a veces por más, produciéndose en pequeña escala los mismos fenómenos sociales que en las grandes ciudades. Ciudades con 200.000 habitantes se sintieron masificadas y vieron su infraestructura superada por el crecimiento de la población. Y casi podría agregarse que aún en ciudades más pequeñas todavía pero de crecimiento acelerado se advirtieron los mismos efectos (Romero, 1999, pág. 398).
\end{abstract}

De esta manera, la concentración de inmigrantes repercute en la aparición de una escisión cualitativa en la población de la ciudad que Romero denomina, sociedad escindida, según la cual, en la ciudad coexisten dos tipos de sociedades: una tradicional y normalizada existiendo dentro de un sistema convenido de normas, en oposición a la anómica o grupo inmigrante, marginal, carente de vínculos y sin un sistema de normas sociales compartido (Romero, 1999). En este sentido, conviene tener en cuenta algunas características de la población anómica propuestas por el autor, que serán relevantes en la comprensión de los propósitos de este análisis:

Era un conjunto de seres humanos que luchaban por la subsistencia, por el techo, esto es, por sobrevivir; pero que luchaban también por tratar de vivir, aunque el precio de ese goce fuera alto. Y ambas luchas entrañaban la necesidad de aferrarse en algún lugar de la estructura de la sociedad normalizada, seguramente sin autorización, acaso contra determinada norma, quizá violando los derechos de alguien perteneciente a aquella sociedad y que miraba asombrado al intruso (Romero, 1999, pág. 402).

Aunque las condiciones de vida de los nuevos moradores mejoraron, su existencia seguía siendo dura. Y en este sentido se puede afirmar que la sociedad anómica de la que habla José Luis Romero, también emergió en las ciudades colombianas. Aquellos pobladores estaban ubicados a las afueras de las ciudades, en condiciones de hacinamiento e insalubridad y alejados de zonas residenciales de clase media y alta. En otras palabras, los nuevos residentes de la urbe, luchaban para ocupar un espacio difícil de obtener dentro de la sociedad normalizada: 
Cada vez deben emplear jornadas más largas en el transporte y trabajar en empleos por lo general mal remunerados. Pocos se afilian a sindicatos, asociaciones de vecinos o de cualquier otro tipo. Las ciudades no están equipadas para ofrecer a los habitantes, en particular a los pobres, opciones para el tiempo libre (...) Una de las principales metas de los habitantes de las ciudades es tener vivienda propia (Safford \& Palacios, 2012, págs. 436-438).

Asimismo, no sobra señalar que para la época la carencia de la vivienda era un tema de palpitante actualidad, puesto que, por un lado, estaba el descontento de los nuevos moradores de la ciudad ante la desidia de los partidos políticos tradicionales y la poca efectividad de los planes de vivienda de los sucesivos gobiernos de turno, y por otro lado, a nivel internacional se establecieron acuerdos en el contexto de la declaración universal de los derechos humanos de 1948 y la Convención Internacional sobre los Derechos Económicos, Sociales y Culturales (DESC), en 1966, donde la vivienda entró a ser considerada un bien vital para el desarrollo de las personas (Programa de divulgación científica , 2007).

Aunque el mencionado aluvión migratorio propició la implementación de políticas públicas de solución de vivienda para las clases populares, como la promovida por el Instituto de Crédito Territorial ICT en 1939 -considerada una de las realizaciones con mayor contenido económico-social (El Tiempo, 1991) en el gobierno de Eduardo Santos (1938-1942)-, dichos esquemas de construcción y financiación de vivienda que empezaron con buen ritmo fueron disolviéndose en los años 70 y 80, en ocasiones por problemas de insolvencia financiera o también por la corrupción de los políticos que manejaban dichas entidades (Safford \& Palacios, 2012, pág. 438). En consecuencia, empezaron a surgir diferentes tipos de asociaciones que trataban de suplir las funciones públicas que no asumió eficientemente el Estado. Asociaciones que emergieron de forma ilegal y fueron denominadas invasiones, en algunos casos permeadas por elementos organizativos y con carácter político como CENAPROV.

Muchos de estos urbanizadores empiezan a ocupar terrenos periféricos y de poco valor, no aptos para la construcción de vivienda, ya sea por estar en terrenos anegadizos, erosionados, o zonas de alto riesgo de catástrofes (Safford \& Palacios, 2012, pág. 439). Lo que profundizó la estigmatización social de las comunidades que habitaban dichos tugurios, la estratificación, la segregación y la imposibilidad de construir un tejido social sólido entre los nuevos moradores y los 
antiguos habitantes de la ciudad:

Desbordados por la masividad de las nuevas poblaciones urbanas, los políticos y sus asesores internacionales concluyeron que el tesón de los pobres y las leyes del mercado resolverían el problema de la vivienda antes que los esquemas estatales de oferta de vivienda popular. Al ocurrir así, se vio rápidamente el surgimiento de ciudades divididas o segregadas en diferentes submundos urbanos, cuyo nexo principal no son relaciones de ciudadanía (Safford \& Palacios, 2012, pág. 439).

De otro lado, conviene resaltar que el periodo al que se hace alusión, estaba caracterizado en el contexto internacional y también nacional, por la guerra fría, su demarcación anticomunista y la tesis del "enemigo interno" (de Zubiría, 2015). Existía en el país el temor profundo, aupado por algunos sectores políticos, a la influencia que pudieran tener los acontecimientos de la revolución China (1949) y la revolución cubana (1959) en el acontecer nacional, situación que efectivamente contribuyó a dar legitimidad a las insurgencias (FARC, ELN, EPL), y a su método de guerra de guerrillas, a partir del decenio de los años 60 en el que surgieron (Palacios, 2012, pág. 17).

En el aspecto político y social, pese a estar en los últimos años del Frente Nacional, que duró oficialmente hasta 1974, el país padeció un incremento de la lucha de clases, la consolidación del pensamiento de izquierda en muchas organizaciones sociales, el aumento de huelgas y paros cívicos como el de 1977, la estabilización y repunte de los movimientos sindicales, las movilizaciones indígenas, campesinas, estudiantiles y de mujeres, así como el crecimiento de las invasiones en las ciudades y las luchas urbano-regionales ${ }^{3}$. Luchas sociales que tuvieron un auge protagónico, de acuerdo con Sergio De Zubiría Samper, hasta el año de 1981 (de Zubiría, 2015, pág. 27).

Para los propósitos demostrativos de esta investigación, es clave señalar que organizaciones de viviendistas como CENAPROV, aparecieron en medio del contexto anteriormente referido, signadas por un carácter ideológico y político particular, que contribuyó -como se verá más adelante- a que su influjo en la comunidades marginales de las ciudades, fuera más allá de posibilitar la obtención de vivienda propia, impulsando la consolidación de una base electoral de origen popular que posibilitó a muchos de sus representantes, afines al Partido

3 Pese a que en la época referida se vivía un ambiente de recuperación de la autonomía política de muchas organizaciones, no hay que desconocer que al mismo tiempo hubo un incremento de la represión oficial, así como la persistencia de la cooptación, el clientelismo y la utilización permanente del Estado de Sitio (de Zubiría, 2015, pág. 29). 
Comunista, una opción real de participación política.

\section{El crecimiento urbano de la ciudad de Pereira}

Pereira, una ciudad intermedia de Colombia, fundada en el año 1863, no permaneció ajena a las circunstancias que vivía el país, ni a las que ocurrían en Latinoamérica. El dinamismo que sufría la época en relación al desborde urbano y demográfico en la década de 1970 a 1980, alentó una marcada aceleración urbana heredada de procesos de largo aliento, dentro de los cuales se pueden identificar fenómenos como: La violencia en centro occidente del país, la bonanza cafetera, la ubicación estratégica de la ciudad como polo de desarrollo comercial, las vías de acceso y los procesos de industrialización; un sinnúmero de aspectos sobre los cuales se elaborará una breve descripción, con el ánimo de contextualizar el momento histórico que vivía la ciudad y que afectaba directamente sus dinámicas urbanas.

En torno al fenómeno de la violencia, existen numerosas producciones realizadas por cronistas e historiadores en textos tales como: Colombia Amarga de Germán Castro Caicedo, Estaba la paja pinta sentada en el verde limón escrita por Alba Lucía Ángel, Estado y subversión en Colombia: La violencia en el Quindío años 50 de Carlos Miguel Ortiz, Bandoleros, gamonales y campesinos escrito por Gonzalo Sánchez y Donny Meertens. En éste último, se describen aspectos críticos de la violencia bipartidista en los municipios del Viejo Caldas y Norte del Valle, que motivaron desplazamientos forzados hacia las ciudades principales: Pereira, Manizales y Armenia convirtiéndolas en refugios a la hora de huir de la adversidad que se ensañaba en el sector rural (Sanchéz \& Meertens, 1983).

Como es de esperarse, la llegada de los nuevos pobladores a las urbes, generó desequilibrios sociales y económicos, y profundas tensiones entre la tradicional población citadina, que se vio sorprendida por la avalancha migratoria, y los nuevos residentes venidos del campo con costumbres ajenas y menos sofisticadas. La anterior afirmación, es resaltada por Hugo Ángel Jaramillo, cuando señala que:

Las condiciones políticas que agitaron la república después del asesinato del doctor Gaitán, fueron muy tensas y difíciles para la vida económica. El azote de la violencia trajo con sigo y consecuencialmente un éxodo hacia las ciudades el que aumentó sus tasas demográficas y por ende, grandes problemas sociales provenientes del desajuste conductual de los nuevos moradores (Jaramillo, 1983, pág. 551). 
Para el periodo comprendido entre 1945 y 1960 a la ciudad de Pereira llegó una gran oleada de migrantes campesinos, como consecuencia de la violencia en los departamentos circundantes a Caldas, la zona rural de Quindío, norte del Valle y Tolima (Calle, 1964). Generando múltiples problemas para la ciudad, que no se encontraba preparada para suplir la demanda de vivienda, servicios básicos, educación y salud de los recién llegados. Según datos del Dane, la población pasó de 115.342 habitantes en 1951 a 188.365 en el año 1964. En el censo de 1973 Pereira contaba con 208.430 habitantes (Dane, 2018). Así, entre el censo de 1951 y el de 1973, la ciudad experimentó un aumento poblacional estimado en 111.535 habitantes, elevando notablemente su densidad demográfica.

Dicho aumento, también se puede constatar en las cifras de la población urbana de Pereira, debido a que entre los censos de 1.951 y 1.973 la población urbana de Pereira se incrementó en 110.614 habitantes en la cabecera municipal. Estableciendo con ello una tasa de crecimiento de acuerdo a los censos del Dane de 50.03 entre los censos de 1.951 y de 1.964 época que coincide con los primeros años de la violencia bipartidista en el país. Del 25.46 entre los censos de 1.964 y de 1.973. Y de 22.19 entre los censos de 1.973 y 1.985 , evidenciando con ello una paulatina disminución en las tasas de crecimiento poblacional urbano a mediados de los años 80 (Dane, 2018).

Las cifras anteriores evidenciaban el aumento dramático de la población en la segundad mitad del siglo XX (véase Tabla 1 y 2), incrementando la demanda de necesidades por suplir para los recién llegados, necesidades urgentes que la ciudad no estaba en condiciones de satisfacer integralmente. Adicionalmente, el hecho de que la ciudad sirviera de albergue o asilo, para aquella población que, como ya se anotó, en buena medida huía de la violencia, explicaría en parte, la creación del leitmotiv: "la ciudad refugio" en el imaginario colectivo de muchos de sus habitantes (Grupo de acción comunitaria y social (ACCOMS), 1990, pág. 18).

De acuerdo al análisis de Carlos Alberto Torres, en su texto La ciudad informal colombiana, las dinámicas de crecimiento de Pereira fueron diferentes a las del resto de la región, pues su ubicación geográfica, al estar entre las ciudades de Bogotá, Medellín y Cali, propició el desarrollo económico que posteriormente le permitió un crecimiento acelerado y capacidad de acoger nuevos habitantes, como consecuencia de las problemáticas socio-políticas padecidas en la región (Torres Tovar, 2009). 
Tabla 1: Progresión demográfica de Pereira.

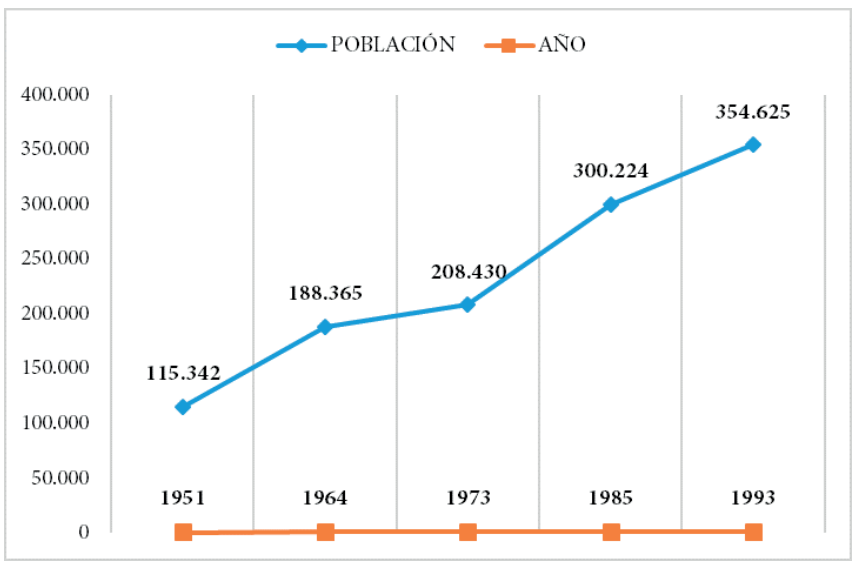

Fuente: Elaboración propia a partir de los censos de 1951, 1964, 1973, 1985, 1993 consultados en: Biblioteca Virtual DANE http://biblioteca.dane.gov.co/biblioteca/categories/45/

Tabla 2: Crecimiento de la población urbana de Pereira.

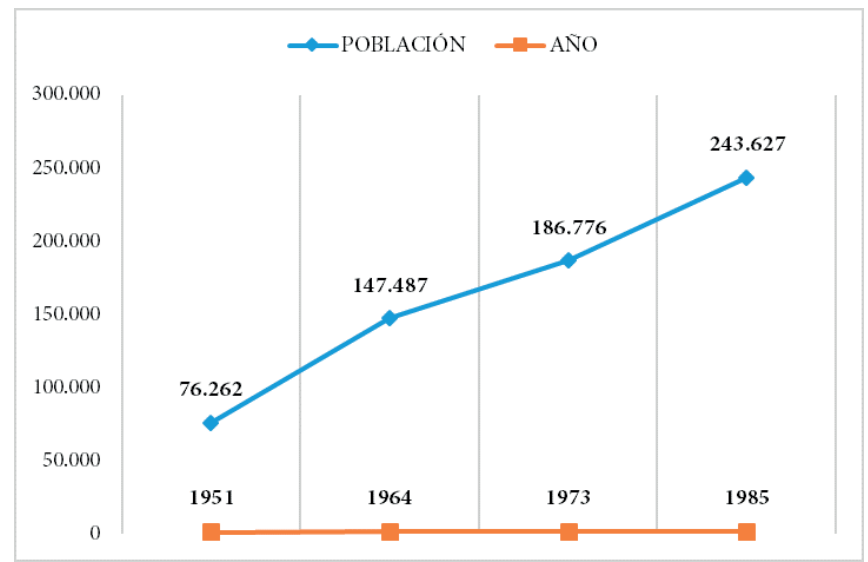

Fuente: Elaboración propia a partir de los censos de 1951, 1964, 1973, 1985, 1993 consultados en: Biblioteca Virtual DANE http://biblioteca.dane.gov.co/biblioteca/categories/45/

Según el trabajo investigativo de Viviana Mejía Gómez, Migraciones y poblamiento urbano: Pereira 1950-1975, entre 1951 y 1973 la ciudad de Pereira enfrentó muchas problemáticas asociadas al masivo crecimiento poblacional derivado de los éxodos masivos de población llegados de los departamentos de Caldas, Antioquia, Tolima y Valle. Según el mentado estudio "los migrantes se instalaron en las calles, plazas, parques, 
andenes, barrios piratas y zonas de invasión” (Mejía Gómez, 2017). Generando con ello una problemática social al interior de la ciudad reflejada suficientemente en los diarios de la época, donde el drama y la miseria padecidos por los migrantes contrastaban con el imaginario de ciudad cívica creado por la sociedad tradicional (Mejía Gómez, 2017).

De un momento a otro los habitantes de Pereira empezaron a notar que había mucha más gente, que se oían más gritos, que los nuevos habitantes quería participar de la vida urbana a cualquier precio. De hecho, sí hubo más gente y en poco tiempo se notó que constituían una fuerza urbana que se acrecentaba como un arroyo. En general se experimentó una explosión urbana. De acuerdo con la información del DANE para 1973 el municipio de Pereira era el que mayor población tenía con relación a los municipios de todo el departamento de Risaralda (Mejía Gómez, 2017, págs. 54-55).

De acuerdo al censo poblacional de 1951 el Departamento de Caldas, que para entonces tenía adscrito al municipio de Pereira, contaba con gran parte de su población cuyo lugar de nacimiento correspondía a otros departamentos. Así, con un total de 1.067.057 habitantes en 1951, el departamento de Caldas contaba 113.351 de ellos nacidos en Antioquia, 23.613 nacidos en Cundinamarca, 39.837 nacidos en Tolima y 37.259 nacidos en Valle (Dane, 2018). Esta característica que podría denominarse migratoria, siguió siendo una constante, al punto que para el censo de 1964 el municipio de Pereira contaba con 147.487 habitantes en su cabecera municipal, de los cuales el $54.6 \%$ o 80.585 tenían un lugar de origen distinto al municipio (Dane, 2018). Las cifras absolutas para el mismo año 1964 determinaban que el departamento de Caldas contaba con 1.455.872 habitantes, de los cuales nuevamente buena parte de su población nacida en otros departamentos procedía principalmente de Antioquia 101.162, Cundinamarca 17.695, Tolima 49.874 y Valle del Cauca 65.044 (Dane, 2018).

Para el año de 1973 conformado ya el departamento de Risaralda y con una población urbana de 321.302 habitantes, su población inmigrante en la cabecera, según lugar de nacimiento correspondía principalmente a 23.242 nacidos en Antioquia, 45.501 nacidos en Caldas, 13.471 procedentes del Quindío, 7.444 nacidos en Tolima, 23.919 procedentes del Valle y 1.749 nacidos en Cundinamarca (Dane, 2018). En este orden de ideas, se puede deducir que desde mediados del siglo XX el municipio de Perera ha sido receptor de un número importante de migrantes procedentes de departamentos vecinos. Así lo constata además un estudio del Departamento Nacional de Estadística del año 2003, sobre 
los movimientos migratorios en la ciudad de Pereira. En dicho estudio, se pone en evidencia que los migrantes acumulados de toda la vida hacia esta ciudad, provienen principalmente de cinco departamentos: Caldas, Risaralda, Valle del Cauca, Antioquia y Quindío. (DANE, 2019).

Conviene entonces ahora indagar respecto a ¿dónde se establecieron y a qué se dedicaban las personas que iban llegando a Pereira? ¿Cuáles eran las condiciones de la ciudad en la época? En general, según el estudio de Pabón (1985), la mayoría de migrantes hacia el departamento de Risaralda en el periodo intercensal 1964-1973 se establecieron en la zona urbana (Pabón, 1985). Según el análisis comparativo entre el censo de 1951 y 1964 realizado por Mejía Gómez (2017) , la población económicamente no activa se incrementa de manera significativa tanto en hombres como en mujeres, lo que permite suponer que existía en la ciudad un alto número de personas sin empleo, motivo por el cual existió preocupación por parte de la administración municipal de que la desocupación aumentara los indicies de delincuencia y marginalidad en el municipio (Mejía Gómez, 2017).

Según el mismo estudio, hacia mediados de los setenta la agricultura y en especial la caficultura no comportan un nivel de importancia significativo en el empleo, de este modo, buena parte de la población inmigrante en Pereira se empieza a emplear en oficios como: artesanos, vendedores, agricultores, ganaderos, trabajadores de oficios personales, empleados de oficina y técnicos (Mejía Gómez, 2017).

Grosso modo, los procesos migratorios derivados principalmente de la violencia, aunados al paulatino desarrollo económico, industrial y comercial de la ciudad, se ubicó en el imaginario colectivo y se proyectó como el lugar que tenía algo que ofrecer, en términos de bienestar, de refugio y de oportunidades para los recién llegados. El incremento poblacional de la ciudad de Pereira, constatado en el resultado de los diferentes censos relacionados en el cuadro 1, derivaron además en una paulatina urbanización extendida y en un crecimiento espacial fuera del centro de la ciudad en la segunda mitad del siglo XX (véase Fotografías $1,2,3)$. De hecho, llama la atención que antes del periodo de la violencia política, entre el censo de 1870 y 1912, Pereira figure como la ciudad de mayor crecimiento demográfico del país, por encima de grandes capitales como Bogotá, Medellín, Cali y Barranquilla (Zambrano, 1994).

Pereira como ciudad intermedia, venía siendo reconocida dentro del

4 Incremento del $92.4 \%$ de población masculina y $63.3 \%$ de población femenina económicamente no activa (Mejía Gómez, 2017). 
país, como un centro de desarrollo y modernización desde comienzos del siglo XX. Hacia 1914 la ciudad ya contaba con el servicio de alumbrado público, en 1918 contaba con servicio de acueducto y para 1921 con el servicio de ferrocarril. Estos hechos demuestran que la ciudad, de forma temprana, se colocaba en sintonía con las grandes urbes del país, desplegando un proceso paulatino de modernización que la ubicaría en una posición de privilegio con relación a otras ciudades intermedias de similares características, como bien afirma Jhon Jaime Correa:

\begin{abstract}
Ambas ciudades (Pereira y Manizales) fueron epicentro de cambios significativos en su estructura económica y demográfica, lo mismo que en su infraestructura urbana y en los modos de vida de sus habitantes. Se podría hablar de esta etapa como el inicio de los procesos de modernización, a partir de los cuales estos poblados fueron dejando atrás su imagen de aldeas comerciales de zona de frontera de colonización, para proyectarse y articularse al mercado interno nacional, lo mismo que hacia las rutas para el intercambio mundial capitalista del momento (Correa, 2014).
\end{abstract}

En este sentido, uno de los factores que fortalecieron el desarrollo comercial e industrial de la ciudad y, por ende, su paulatino crecimiento demográfico, fue la posición estratégica en la que se encuentra Pereira, como corredor vial necesario para la conexión del centro occidente del país con el sur y con la zona de la costa atlántica, posición que la convirtió en una zona indispensable para el intercambio comercial a mediados de siglo XX. De acuerdo con Fabio Zambrano:

La construcción de ferrocarriles siguió privilegiando determinadas zonas, y se puede afirmar que el transporte férreo siguió estructurando de manera importante el territorio hasta 1938, y tuvo que ver en la localización industrial, ordenamiento al que se sumaron las carreteras: allí donde se dio mayor competencia entre estos medios de transporte se generó una nueva tendencia a una primacía demográfica mayor (Zambrano, 1994, pág. 61).

Puede vislumbrarse que, posiblemente, la suma de todas estas circunstancias abonó el terreno para el asentamiento de nuevas industrias, la llegada de desplazados por la violencia en busca de mejores oportunidades y para el crecimiento habitacional desordenado en su periferia. Además de esto, puede significar que la llegada de población rural hacia ciudades como Pereira, no está asociada exclusivamente al fenómeno de la violencia, sino también a elementos de tipo económico como la industrialización incipiente de las urbes jalonada por la implementación de una agricultura comercial, que para la región del centro occidente del país se basaba en el cultivo de café. 


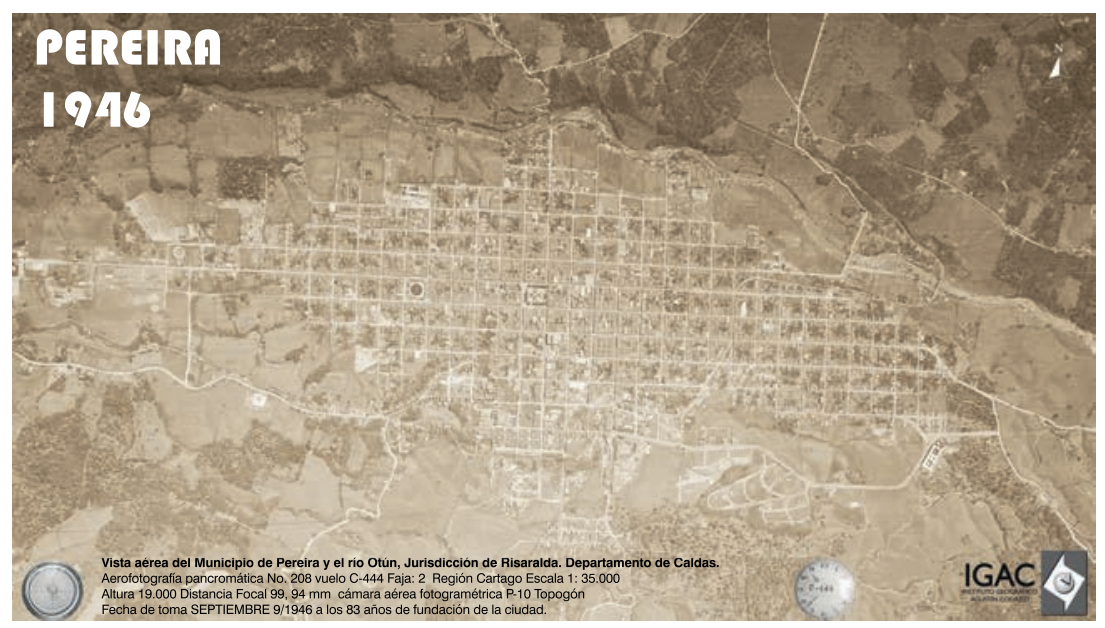

Fotografía 1: Vista aérea del municipio de Pereira, Septiembre 9/1946.

Fuente: IGAC.

La bonanza cafetera de mediados de siglo (1948-1956) promovió el aumento de las tasas de crecimiento económico nacional (Safford \& Palacios, 2012, pág. 442) y con ello, convirtió a la región centro occidental del país en un importante eje comercial de gran proyección, que posibilitó el fortalecimiento del mercado interno y el desarrollo de importantes vías de comunicación. En este sentido, el cultivo del café y su comercialización, posibilitaron la circulación de grandes capitales de dinero provenientes de los altos costos que alcanzó este producto en el mercado internacional, capitales que fueron invertidos, especialmente en el sector inmobiliario y en la industria de la construcción (Rivera, 2013).

La apuesta por consolidar la producción del café en el país desde mediados del siglo XIX, generó importantes movimientos poblacionales desde la cordillera occidental hacia la cordillera central, vinculadas al crecimiento masivo del cultivo, beneficiadas además por condiciones ambientales óptimas para su producción (Zambrano, 1994). En consecuencia, la ciudad de Pereira ubicada en la cordillera central del país, empezó a tener un protagonismo destacado a mediados de siglo $\mathrm{XX}$ en el concierto nacional, por su proyección productiva creciente, figurando dentro de las 10 principales ciudades del país, a partir de 1930, a tal punto, que para el censo cafetero de 1980, la ciudad de Pereira ocupaba el primer lugar en producción de café en el país (Rivera, 2013).

El orden económico y el desarrollo agroindustrial del cultivo del café 
concentróla atención del Estado en el producto que se convertiría durante las décadas de los 60, 70 y 80 en el número uno de las exportaciones nacionales. Su producción y demanda internacional lograron que se movilizaran recursos del Estado con el objetivo de mejorar las vías de acceso a la ciudad y los servicios públicos, la ciudad de Pereira se proyectaba como un polo de desarrollo para el centro occidente del país (Rivera, 2013).

En materia urbana, la ciudad seguía recibiendo un importante flujo de personas en busca de mejores oportunidades, atraídas por la demanda de mano de obra en las fincas que circundan las ciudades del eje cafetero y sus municipios aledaños. Este fenómeno promovió dos aspectos importantes a mediados de las década de los 70, primero: La aparición pequeños poblados en las veredas cercanas a la ciudad de

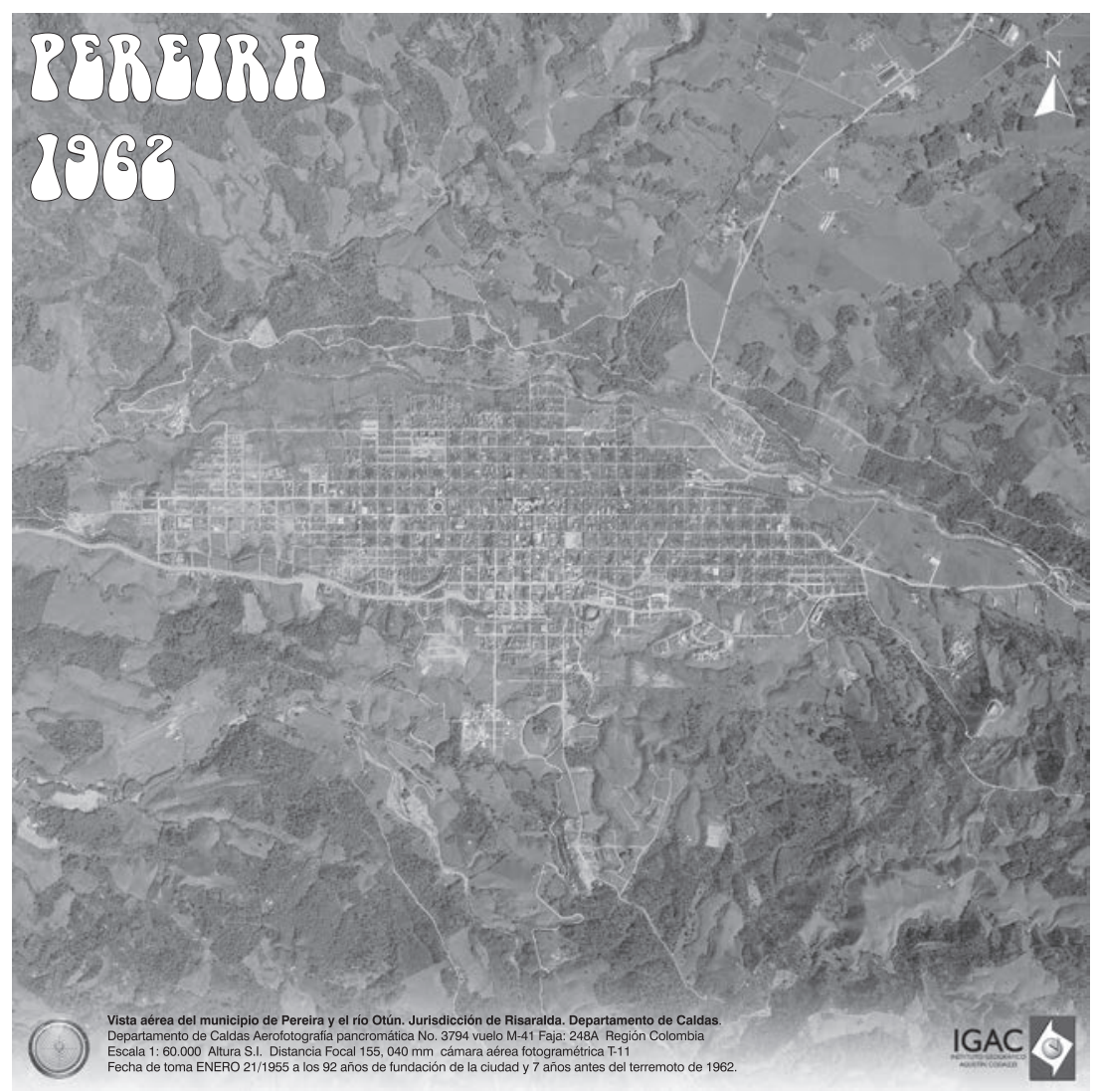

Fotografía 2: Vista aérea del municipio de Pereira, Enero 21/1955.

Fuente: IGAC. 
carácter no oficial o pirata, concentraciones conformadas en su mayoría por caficultores, como sucedió en los caseríos de la vereda Tribunas, Huertas y Condina en la zona sur occidental de la ciudad (Rivera, 2013); y segundo, la llegada de gran número de población flotante de acuerdo

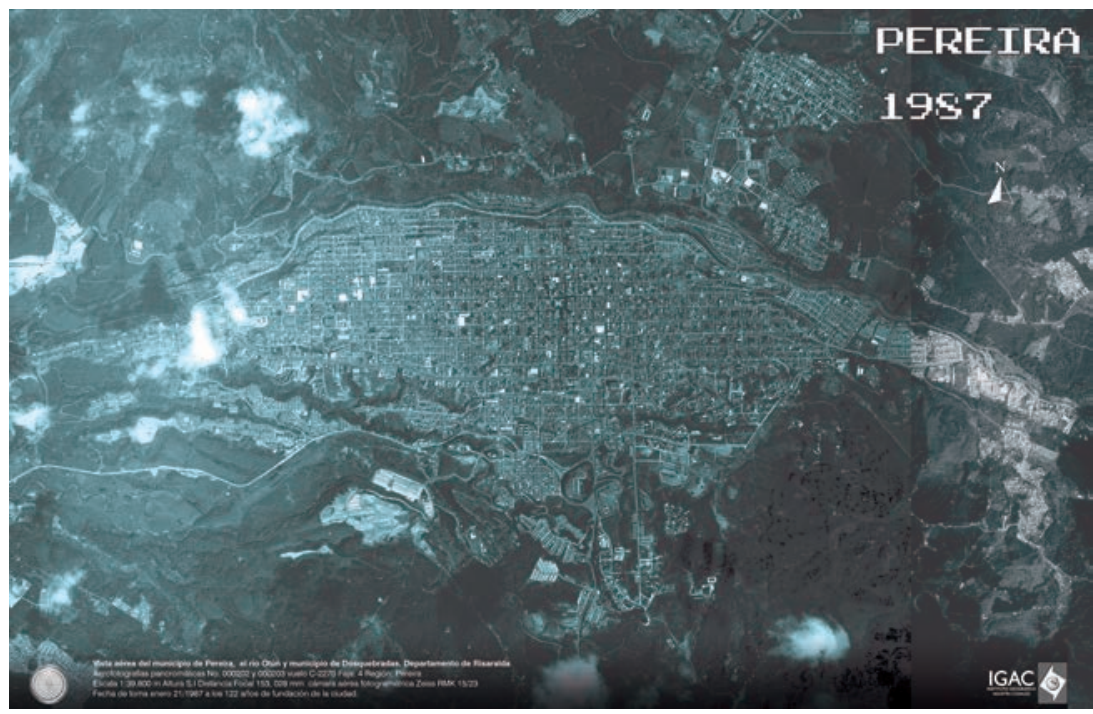

Fotografía 3: Vista aérea del municipio de Pereira, Enero 21/1987.

Fuente: IGAC.

a la estacionalidad de la producción cafetera que demandaba abundante mano de obra para la recolección de la cosecha en los tres últimos meses del año (Pabón, 1985).

El cultivo del café no solo impulsó los procesos migratorios, también impulsó un desarrollo paulatino en la ciudad en materia de infraestructura y comercio. Esto es así, pues siguiendo la tesis de Montoya Ferrer, la actividad comercial ha jugado un papel fundamental desde la fundación de la ciudad, con el crecimiento de sectores clave en la actividad cafetera y manufacturera. Además de dedicarse a la producción agrícola, la ciudad abanderaba la tecnificación y la industrialización de los procesos asociados al cultivo como las trilladoras desde 1930, las cuales al contratar mano de obra asalariada contribuyen en el surgimiento de un proletariado urbano (Montoya, 2013).

La incipiente industrialización cafetera fue la puerta de entrada para el emplazamiento en la ciudad, de diferentes empresas con capital extranjero, como se logra evidenciar a partir del censo industrial de los años 30, con la llegada de compañías de carácter internacional, como 
lo fueron: Compañía de tejidos de lana Omnes Ltda en 1950, Hilos cadena en 1958, Nicole en 1975, TPL en 1971, Comestibles la Rosa S.A en 1960 (Upegui, Alberto; Casas Jairo, 1960). Como era de esperarse, el establecimiento de estas empresas en la ciudad, aunado a la llegada de la asociación de industriales ANDI durante los años 50, generaron una importante oferta de empleo que, fortaleció la ya conocida vocación comercial por la cual fue reconocida la ciudad desde el siglo XIX, y que constituyó un acicate adicional para que muchas personas llegarán en busca de empleo 5 .

De este modo, la ciudad caracterizada por actividades netamente agrícolas y comerciales en la década de los años 1930, inició un proceso de industrialización con capital extranjero a partir de 1940. Este cambio, aunado a la llegada de gran cantidad de campesinos a causa de la violencia, permitió el florecimiento de una clase obrera incipiente y de pequeños artesanos atraídos por la oferta laboral, los cuales ocuparían los barrios piratas o barrios de emergencia ubicados en las zonas periféricas y los espacios no poblados dentro del casco urbano (Calle, 1964). De este grupo de personas emergió el capital humano que sirvió de base social a la organización de viviendistas CENAPROV.

Para resumir, se encuentra que el fenómeno migratorio fue determinante para comprender las dinámicas de las ciudades, no solo en Colombia, sino también - como ya lo manifestaba José Luis Romero - en el resto de Latinoamérica. Los procesos de desplazamiento de grandes flujos migratorios de los sectores rurales a las zonas urbanas se hacen evidentes en la fisonomía de las ciudades. Esto es así, pues comienzan a tomar cada vez mayor protagonismo los lugares periféricos y las zonas ejidales. Protagonismo que se expresó en la lucha denodada de los nuevos moradores por la vivienda y por un espacio dentro de la ciudad.

\section{El protagonismo de la izquierda en la lucha por la vivienda en Pereira}

El análisis de la situación política que vivía la ciudad de Pereira en la segunda mitad del siglo XX, es relevante, en la medida en que la organización de viviendistas CENAPROV, objeto de esta investigación, se expande y es acogida en la ciudad, gracias a la gran cantidad de personas sin techo afrontando el drama de la vivienda, la incapacidad estatal para atender la situación y ambiente socio-político de la época

5 Huelga aclarar, que algunas de estas empresas se instalaron en el sector de Dosquebradas, que para entonces pertenecía al municipio de Santa Rosa de Cabal, pero de igual manera afectaron directamente a la ciudad de Pereira dada su cercanía. 
caracterizado por la lucha y la reivindicación de los derechos sociales, así como el protagonismo de dirigentes políticos de izquierda, como Gildardo Castaño (1948-1989) ${ }^{6}$ o el mismo Santiago Londoño (19271982) $)^{7}$, abanderando aquellas luchas mediante "brigadas de salud" o las recordadas "peñas culturales".

En lo que respecta al contexto ideológico y político que vivía la ciudad, no menos importante es señalar el gran impulso de los movimientos sociales surgido a partir de la década de 1960.:

Esta fue una década de gran auge de los movimientos sociales y culturales en la ciudad de Pereira. Fue la época que en torno a la Universidad Tecnológica y al Partido Comunista de Pereira, bajo la dirección del médico Santiago Londoño hijo, se consolidaron espacios de articulación y de contacto entre intelectuales de diversos horizontes políticos y artísticos de carácter emancipatorio (Martínez, Serna, \& Correa, 2013).

La irrupción de los movimientos sociales se extendería a las décadas de 1970 y 1980, dado que la ciudad no era ajena al contexto de polarización y agitación social que se vivía en el resto del país, movilizaciones y protestas estudiantiles en 1971, huelgas de maestros y campesinos, evidenciaban la influencia de los movimientos de izquierda y de la guerra fría en Latinoamérica.

Las agitadas condiciones sociales de los años 70, fueron en parte la consecuencia esperada de una fuerte lucha del movimiento sindical que, se afianzó con la irrupción del pensamiento socialista en el Antiguo Caldas desde la década de 1930 y con la conformación de 29 organizaciones sindicales, entre ellos el de ferrocarriles, escogedoras de café, braceros, mineros, obreros de construcción, sastres, zapateros, carpinteros (Escobar, 1966) y el Sindicato de Educadores de Risaralda desde 1.967 con sus mil afiliados (Diario de Risaralda, 1966). De este modo, iniciativas abanderadas por el partido comunista como la

6 Gildardo Castaño fue concejal de Pereira en representación de la Unión Nacional de Oposición en el período de 1976 a 1982, por el Frente Democrático de 1982 a 1986 y por la Unión Patriótica desde 1986 hasta el 6 de enero de 1989, fecha en que fue acribillado al salir de su casa (El Diario, 2009).

7 Santiago Londoño fue un intelectual orgánico de partido, quienes lo conocieron lo describen como un miembro importante del partido comunista, un humanista respetado por su militancia. También hizo parte del Movimiento Obrero Revolucionario (Martínez, Serna, \& Correa, 2013). Otros referentes lo definen como un Médico de gran influencia política e intelectual en la ciudad de Pereira, reconocido socialmente por pensar siempre en los más humildes, brindó ayuda económica para asistencia médica a muchas personas necesitadas en la ciudad y fue reconocido por compartir los ideales de ideología marxista que propendían por sociedades más justas e igualitarias (El Diario, 2014). 
Huelga Nacional del Café en 1934, fue acogida por amplios sectores de trabajadores vinculados a la industria y el comercio en la región. Luchas que en Pereira recibieron los principios ideológicos del comunismo, defendidos por personalidades de la talla de María Cano, Lisímaco Salazar, Ignacio Torres Giraldo, Neftalí González o Julio Restrepo Toro (Salazar, 2015).

En este orden de ideas, Pereira, ciudad reconocida por su carácter liberal frente a las posturas políticas tradicionales de la política regional caldense, empezó a dar un giro electoral en el que los partidos políticos de izquierda v.g. el Partido Comunista Colombiano PCC, la Unión Patriótica, la ANAPO, la Unión Nacional de Oposición UNO y el Frente Democrático, empiezan a ser reconocidos en la contienda electoral. Así lo demuestran los comicios electorales celebrados entre 1972 y 1988 , donde los partidos de izquierda pasarían de tener un participación incipiente de 333 votos en 1972 a multiplicarse hasta 3.216 en 1988 lo que podría significar la consolidación de una nueva opción política (Gil, Tascón, \& Bedoya, 2013).

Según datosrecogidos delaprensalocalenlas elecciones presidenciales de 1.986 el candidato presidencial de izquierda promovido por la UP Jaime Pardo Leal, obtuvo en Risaralda 5.974 votos (El Diario, 1986), una cifra record para la izquierda en la región. Esto es significativo en la medida en que la dirigencia regional de ese movimiento político era asumida por el dirigente de izquierda Gildardo Castaño, quien como se verá más adelante, fue protagonista de la lucha de los destechados en la ciudad y muy cercano a la organización de viviendistas CENAPROV.

Durante este período, se evidencia también el auge en la ciudad de las ideas comunistas, que bien podían ser conocidas por medio de la literatura y la música, derivadas de la atmósfera política e ideológica que se vivía en Latinoamérica, en parte debido a que muchos exiliados de la violencia y divulgadores de las ideas comunistas empezaron a poblar esta zona del país (El Diario, 2016). De hecho, llama particularmente la atención el que la clase política tradicional, a través de la prensa, manifestara su desencanto respecto a la difusión de las ideas de corte comunista en los entornos escolares, como lo hizo en su momento el gobernador de Risaralda Carlos Arturo Ángel Arango, en el periódico La Tarde el 22 de julio de 1977:

Experiencia dolorosa es ver como en los colegios y escuelas se escucha más "La Internacional" que el Himno Nacional Colombiano", dijo el gobernador Carlos Arturo Ángel Arango al instalar el seminario para tesoreros de los fondos educativos 
para el país en acto cumplido ayer jueves en el recinto del "Instituto Veracruz" de Santa Rosa de Cabal (La Tarde, 22 julio 1977).

Del mismo modo, en la década de los 70 líderes de izquierda, adheridos a diferentes movimientos reivindicativos -como el partido comunista colombiano PCC, a la Unión de Mujeres Demócratas UMD, Grupo Firmes, el MOIR, la Unión Nacional de Oposición UNO, la Unión Revolucionaria Socialista, los movimientos sindicales como la Asociación de porfesores de la educación media APROR, el Sindicato de Educadores de Risaralda SER, el sindicato de trabajadores de La Rosa, las escogedoras de café-, empezaron a destacarse en la ciudad en el orden político y académico promoviendo diferentes luchas sociales, por ejemplo, las de la reivindicación de los derechos de las mujeres o la de la búsqueda de una solución al problema de vivienda para quienes engrosaban la estadística de personas afectadas por el déficit habitacional (El Diario, 2016).

Es importante resaltar el trabajo de Stella Brand, liderando la Unión de Mujeres Demócratas UMD, movimiento feminista que denunció las lamentables condiciones cotidianas que vivían las familias y las mujeres en la ciudad. Según la investigación de Gil, Bedoya, \& Tascón, (2013) Stella Brand, participó en la construcción de la Casa de La Mujer y la Familia en 1984, y también en la consolidación y mejoramiento de barrios populares ubicados en zonas deprimidas de la ciudad de Pereira como: José Martí, Leningrado, La Isla y Santiago Londoño en el Municipio de Dosquebradas.

Lo anterior pone de manifiesto que por fuera de las estrategias estatales para solucionar el déficit de vivienda como el ICT, coexistiría también y principalmente en los asentamientos una alta incidencia de grupos y organizaciones con intereses políticos particulares en la creación de nuevos barrios y sectores en la ciudad.

Es en estos tugurios y asentamientos populares donde emerge el accionar político de organizaciones de izquierda como CENAPROV, que abanderaron la lucha por el derecho a la vivienda en gran parte del territorio nacional, especialmente entre la población que se encontraba por fuera de los programas de solución de vivienda que ofrecía el Estado a través del Instituto de Crédito Territorial ${ }^{8}$, o en programas de urbanizadores de carácter privado, muchos de ellos oportunistas de la

8 Según Marco Palacios, muchos políticos también abanderaron la lucha por la solución de vivienda, como estrategia electoral (Safford \& Palacios, 2012). 
precariedad general, que ayer como hoy, estafaban a personas incautas ofreciendo falsas soluciones de vivienda (Arango Zuluaga, 1986).

Era tal la magnitud de personas recién llegadas a la ciudad de Pereira entre la década de los 60 y los 70, que fue casi que imposible incluirlos dentro de los programas de planeación de la administración municipal, como se puede colegir del análisis realizado por el sociólogo Fray Arturo Calle Restrepo, en lo relativo a la ciudad teórica y la ciudad real (Calle, 1964, pág. 131). En dicho análisis, se explican las dificultades en el proceso de asimilación y adaptación de la población migrante a la ciudad, pues el proceso de adaptación no dependía únicamente del individuo, sino de que la ciudad misma también facilitara y ofreciera las garantías necesarias al individuo para su adaptación y su posterior asimilación a esta nueva vida.

En otras palabras, los migrantes que recibió la ciudad se cobijaron bajo el ideal de una ciudad garantista y con oportunidades para solucionar sus dificultades, una ciudad teórica. Pero se encontraron por el contrario con una ciudad expulsora que los empujó hacia la periferia, pues la ciudad misma bajo sus programas administrativos no solucionó, por lo menos no eficientemente, a mediano plazo sus necesidades básicas de transporte, educación, servicios públicos y trabajo, la ciudad real les impuso una ardua tarea de adaptación.

La similitud existente entre los modelos explicativos de José Luis Romero sobre la ciudad escindida, referenciada en la introducción de esta reflexión, y el modelo de la ciudad real/la ciudad teórica propuesto por Arturo Calle, salta a la luz. Calle evidencia que Pereira no se encontraba tan alejada de la realidad social que afrontaba el resto del continente, en tanto que Romero desarrolla su reflexión en letras mayúsculas, con el telón de fondo de una Latinoamérica en transición hacia las ciudades masificadas. Ejemplo de este punto de encuentro, fue el acrecentamiento de los barrios piratas y de emergencia a las orillas del río Otún y en la periferia de la ciudad como lo describe a lo largo de su texto el autor colombiano (Calle, 1964).

La definición del concepto urbanización pirata, que se usará en adelante en el presente análisis, será la que propone Carlos Arango en su texto La lucha por la vivienda en Colombia (1986). En esta obra, el urbanizador pirata en muy pocas oportunidades aparece como dueño de la tierra, funge la mayor parte de las veces de intermediario entre el propietario y los necesitados de vivienda. Generalmente la urbanización pirata inicia con una promesa de venta por parte del dueño del terreno 
(Arango Zuluaga, 1986).

Es importante tener en cuenta este matiz, debido a que las urbanizaciones auspiciadas por CENAPROV en Pereira, adquirían la propiedad del terreno a través de su compra, pero no contaban con los permisos y requisitos legales para urbanizar, estos permisos los adquieren de modo paulatino y doloroso. De modo que, esta ambivalencia, propietario-legítimo/urbanizador-ilegal, ocasionaba que CENAPROV pudiese ser definida ocasionalmente como una forma de urbanización pirata por la autoridad municipal y los entes de control. De hecho, para el año de 1968, fue aprobada la ley 66 en el Congreso de la República mediante la cual, se autorizaba a la Superintendencia Bancaria, la intervención y posterior manejo de las urbanizaciones piratas que no cumpliesen los requisitos legales para su construcción y funcionamiento (Arango Zuluaga, 1986).

El surgimiento de los barrios piratas, supone como es lógico, la aparición de múltiples necesidades y de demandas de servicios por parte de los invasores. A los problemas relacionados con la informalidad laboral e inseguridad de dichas comunidades, se sumaban los problemas relativos a la carencia de redes de alcantarillado, agua potable y electricidad. Lo que determinó que la apuesta de sus moradores, después de consolidar su espacio, se concentrara en la obtención de servicios públicos para sus barrios, a través de la protesta social o la intermediación de algún político de talante clientelista.

De forma simultánea a la eclosión del barrio pirata en la periferia de la ciudad, emergen también los barrios legales, asentamientos barriales bajo la modalidad de autoconstrucción y con ayuda del Instituto de Crédito Territorial ICT. Algunos de éstos fueron: Cuba (1961, ICT) San Fernando (1967), Galán (1967, ICT), Villa del rio (1979), El Plumón (1977), Nacederos (1977) (Valderrama, Gil, \& Correa, 2013; Giraldo Botero, 2013).

El desborde demográfico de la ciudad, al tiempo que vuelve evidentes los problemas de planeación urbana, también propicia la aparición de urbanizadores legales e ilegales (piratas), los cuales, a su vez impulsan la construcción de barrios populares entre la década de 1970 y 1980, especialmente en la zona suroccidental de la ciudad. Durante la década de 1970 y hasta 1990 se construyeron 124 barrios, 60 planes de vivienda y 51 sectores de invasión (Gil, Tascón, \& Bedoya, 2013).

El surgimiento de nuevas lecturas sobre la realidad urbana, y la necesidad de comprender mejor los procesos migratorios y su 
adaptación a la urbe, se constituyen en el estímulo para intentar abordar y comprender el tema del déficit de vivienda y el crecimiento de algunos barrios en condición de marginalidad, de los que saldrá posteriormente el capital humano que dará sustento a los procesos de lucha por la vivienda al interior de la ciudad.

En resumen, para aventurar una comprensión mayor del crecimiento urbano que vivió la ciudad de Pereira en la segunda mitad del siglo XX y para comprender más allá de la superficie, la incidencia de las organizaciones de viviendistas en dicho proceso, ha sido menester en éste capítulo, considerar las causas que detonaron los procesos migratorios desde una perspectiva latinoamericana y local, articulando elementos como la violencia, la industrialización de la ciudad, las dinámicas migratorias y los imaginarios colectivos alentados por el Estado, como elementos que enmarcaron la llegada de nuevos pobladores a la ciudad.

Para enriquecer y nutrir aún más el análisis propuesto, fue importante también, describir y establecer brevemente el contexto ideológicopolítico que se vivía en la época, Desde lo que estaba pasando en el mundo hasta aterrizar en la región, dentro de la estricta temporalidad acotada en la presente investigación.

La organización de viviendistas denominada Central Nacional Provivienda constituía una de las banderas del Partido Comunista Colombiano y la Unión Patriótica en su trabajo de organización social de masas y en su lucha por el derecho a la vivienda para los destechados. 


\section{CAPÍTULO DOS:}

DÉFICIT HABITACIONAL Y LAS OPORTUNIDADES DE VIVIENDA PARA LOS DESTECHADOS 

$\mathrm{C}^{\mathrm{l}}$ problema de la vivienda en Colombia como en el resto de CLatinoamérica es un asunto de orden estructural en el que subyacen elementos tan relevantes como la desigualdad social, debido a que son en su gran mayoría los sectores populares y más vulnerables de la población quienes afrontan el déficit habitacional (Robledo, 1985). La explosión demográfica derivada de migraciones y procesos de desplazamiento del campo a la ciudad, en los que se trasladó el problema de la precariedad de la vivienda en el campo, a las carencias en los centros urbanos, conllevaron, además, a la aparición de nuevos modos de segregación social a partir de conductas económicas como: La especulación en los precios del suelo y el valor del arrendamiento.

El arribo de los nuevos pobladores a la ciudad de Pereira en la segunda mitad del siglo XX, por algunas de las causas establecidas en el capítulo anterior, impuso una serie de nuevas necesidades a los pobladores de la urbe y nuevos desafíos para la administración municipal de la época. Una de estas necesidades fue la de brindar solución al déficit habitacional de los recién llegados a los márgenes de la ciudad.

Este déficit habitacional, como bien afirma Jorge Enrique Robledo, es un déficit padecido por la población campesina en Colombia mucho antes de migrar a la ciudad, ya fuese por la imposibilidad de tener vivienda propia y/o por la precariedad de la habitada. De lo que puede inferirse que no es solo la migración a la ciudad la causa mecánica o primordial del déficit habitacional, sino que éste es un problema estructural padecido por los moradores del campo que se trasladan en sus migraciones a la urbe (Robledo, 1985).

En este sentido, en el presente capítulo se realizará un bosquejo a propósito del déficit cuantitativo y cualitativo de la vivienda en Colombia derivado de la incapacidad estatal para garantizar el derecho 
a una vivienda digna para la ingente y enorme avalancha de migrantes y desplazados llegados a las ciudades a lo largo del siglo XX. A partir de allí, se rastreará el papel que jugó CENAPROV como organización de viviendistas con ideología de izquierda en Colombia - desde el nivel nacional al local - al tiempo que se estudiaran también las formas de autoconstrucción de vivienda con participación comunitaria, como elementos paliativos de la responsabilidad estatal en la lucha por el derecho a la vivienda digna.

\section{Déficit de vivienda nacional}

Por lo que se logra inferir del análisis de José Luis Romero, tanto en Colombia como en el resto de Latinoamérica el encuentro entre los nuevos habitantes de las ciudades, es decir, los venidos del campo y los antiguos moradores de la urbe, fue bastante brusco en un primer momento. Así, durante las primeras fases de la masificación de las ciudades, la sociedad normalizada o tradicional mediante un proceso lento de confrontación, logró que los recién llegados, o lo que se denomina la sociedad anómica, aceptara respetar algunas reglas básicas -como aprender a tomar el bus, conocer las calles, gestionar un documento de identidad o acudir a un puesto de policía - para después irla incluyendo de manera paulatina y forzosa en la mecánica social de la ciudad (Romero, 1999). En Pereira, como bien lo hace notar Jhon Jaime Correa en su investigación, la propaganda cívica se constituyó como un medio informal de educación ciudadana a través de la radio y la prensa que buscaba la trasformación de ciertos hábitos sociales o defender el peso de ciertas tradiciones morales (Correa, 2014).

La integración recíproca se dio además en la coincidencia de necesidades de empleo, vivienda y servicios tanto de los grupos de migrantes como de gran número de miembros de la clase media y popular de la ciudad tradicional. Sus necesidades mutuas favorecieron la aproximación, el emparentamiento y la creación de tejido social. La incorporación de buena parte de la sociedad anómica comienza, en palabras de Romero "a partir del momento en que los grupos migrantes consiguieron un techo y, sobre todo, un trabajo" (Romero, 1999, pág. 404).

Tal era la precariedad de la población migrante, que podría afirmarse que el denominador común de sus condiciones de existencia era la imposibilidad de identificarse como una clase obrera propiamente dicha. Pese a que entre ellos había algunos obreros, sus ingresos fijos eran 
insuficientes, sus familias estaban fragmentadas y habitaban viviendas precarias, sin servicios básicos y en los bordes urbanos (Romero, 1999). En síntesis, los empobrecidos sectores populares citadinos, más el contingente de migrantes y desplazados venidos del campo, eran quienes para la segunda mitad el siglo XX, hacían parte de las cifras que determinaban la existencia de un enorme déficit habitacional en Colombia.

Los migrantes campesinos que padecieron el déficit habitacional cuantitativo en las ciudades de Colombia, según Jorge Enrique Robledo, abandonaron los ranchos en el campo con pisos de tierra, llenos de bichos, mal aireados y sin servicios, para habitar los márgenes de las ciudades, guareciéndose de las inclemencias del clima en habitaciones insignificantes donde, hacinados hombres, mujeres, niños y adultos mayores, compartían en áreas mínimas dormitorios, comedor y cocina (Robledo, 1985). "Para el año de 1970, el 61\% de la población económicamente activa vivía con una densidad promedio entre 3.5 y 7.9 personas por habitación" (Robledo, 1985, pág. 10).

Tabla 3: Déficit de vivienda nacional.

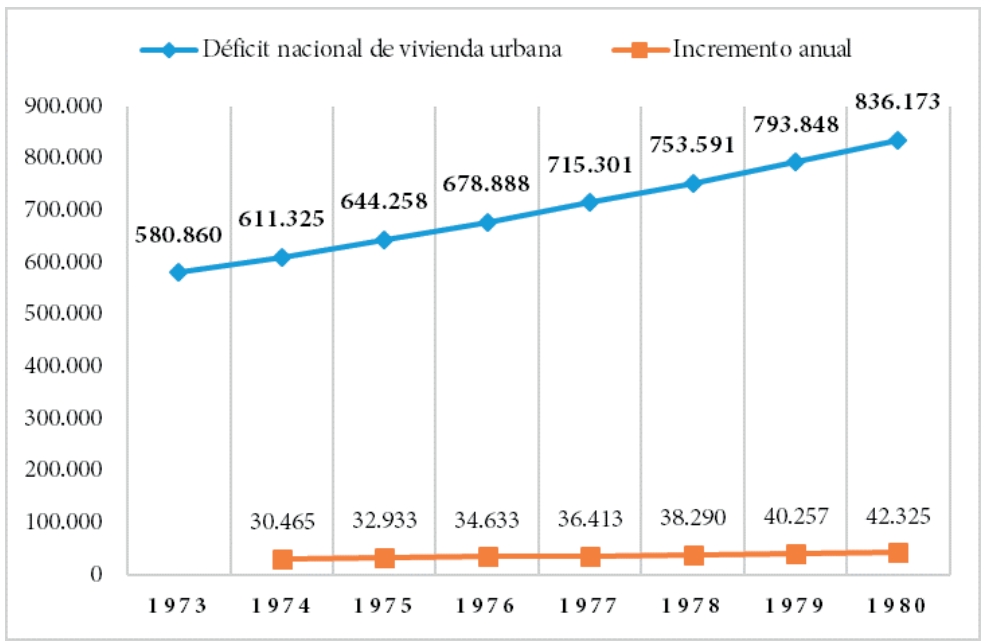

Fuente: CENAC, CEN 12-76. Tomado y modificado de Robledo Jorge E. El drama de la vivienda en Colombia y la política del "sí se puede". Áncora, 1985 Pág. 181.

Tan dramática era la situación de estas familias que, en el año 1980 según datos del Centro Nacional de Estudios de la Construcción, el déficit de vivienda a nivel nacional era de 836.173 unidades (Ver Tabla 3). Lo que traducido significa que aproximadamente una de cada cuatro 
familias carecía de una vivienda para su uso exclusivo. Al punto que para el año de 1983 en un país que contaba con 5.210.000 hogares, se disponía únicamente de 3.977 .000 viviendas, lo que implicó un déficit habitacional de 1.233.000 (Robledo, 1985). Lo anterior, sin considerar el déficit rural, que, aunque poco conocido, también ha sido evidente, sobre todo por la precariedad y nivel de desatención estatal hasta el presente siglo?.

De la mano del déficit cuantitativo viene el cualitativo, que implica un nivel de análisis mucho más sutil y complejo pues no se determina la ausencia de vivienda sino su calidad. En este sentido, a la proporción de familias sin un techo habrá que sumar las que lo tienen, pero en condiciones desfavorables, poco higiénicas, inseguras, estrechas o parafraseando a Jorge Robledo, donde es prácticamente imposible el desenvolvimiento de actividades humanas acordes a la evolución general de la sociedad (Robledo, 1985).

El déficit en la calidad de la vivienda implica considerar elementos relacionados con el bienestar de las personas que habitaban inmuebles precarios. Por ejemplo, el de la carencia de servicios públicos óptimos, que repercute en la calidad de vida de las personas. De acuerdo con un estudio publicado por el Ministerio de Salud de la época, para el año de 1982 el 40\% de las enfermedades que aquejaban a la población colombiana derivaban de la calidad del agua que consumían (Robledo, 1985).

Según el mismo estudio, en lo relativo al estado sanitario de las viviendas, al finalizar el año de 1981 de un total de 26.352.200 habitantes urbanos en Colombia, solo 15.744 .800 contaban con servicio de acueducto; 12.560 .000 habitantes urbanos contaban con servicio de alcantarillado; y aproximadamente 14 millones de habitantes disponían de sus excretas por mecanismos inadecuados (Robledo, 1985). Sumado a lo anterior, el hecho de que, en 1981 según un informe del Ministerio de Minas y Energía, solo 15.5 millones de habitantes contaba con servicio de energía (Robledo, 1985). De lo que se deduce que, prácticamente la mitad de la población no podía servirse de los beneficios derivados de la electricidad, como la iluminación, refrigeración, comunicación, seguridad y demás actividades de orden doméstico. En general, según Jorge Robledo:

(...) quienes sufren el déficit "cualitativo" adquieren en los extramuros de las

9 https://www.elespectador.com/economia/articulo-223631-deficit-habitacional-el-campo-de-16-millones-de-viviendas-gobierno 
ciudades, a donde casi nunca llegan las rutas de transporte urbano, lotes sin ningún servicio público ni obra de urbanización. La vivienda termina siendo el fruto de muchísimos años de trabajo familiar, y los materiales deben comprarlos a pequeños especuladores que hacen su agosto revendiéndolos a sobreprecio (Robledo, 1985, pág. 16).

El déficit habitacional, entendido como la ausencia de viviendas propias y en condiciones dignas para las familias dentro de la ciudad, presenta un panorama precario en el orden nacional, situación que es suficientemente referenciada en el estudio de Jorge Robledo y que coincide con la información presentada por Carlos Arango Zuluaga en su texto La lucha por la vivienda en Colombia, al señalar ambos que en 1980 tanto el déficit cuantitativo como cualitativo en Colombia rondaba las 800 mil viviendas. Esto es, aproximadamente un millón $600 \mathrm{mil}$ colombianos afrontaban el problema en uno $u$ otro sentido (Arango Zuluaga, 1986).

Las cifras anteriores permiten una mayor comprensión del panorama que se presentaba en las ciudades colombianas alrededor de la problemática de la vivienda. Situación que venía creciendo desde de la década de 1950 y que alcanzó quizá, su mayor dimensión, en el momento en que el país adquirió su fisonomía urbana.

Cabe destacar que para 1980 el país contaba con una población aproximada de 27.737 .905 habitantes ${ }^{10}$, más del $40 \%$ de los colombianos se encontraban sin vivienda propia o se encontraban en viviendas sin las más mínimas condiciones de salubridad, servicios básicos, seguridad y vías de acceso, tal era el caso de las invasiones generalmente localizadas en sectores periféricos y zonas de riesgo.

Tan dramático era el déficit habitacional que, según Arango Zuluaga, para la década de 1980 el $43 \%$ de las familias urbanas en Colombia vivían en casas alquiladas (Arango Zuluaga, 1986). Cifra a la que se le podría anexar la de la enorme cantidad de caseríos de invasión ubicados en los cinturones de miseria de las ciudades y a las orillas de los ríos, como medida paliativa a la que acudían los afectados para resolver su situación ${ }^{11}$.

En lo relacionado a las políticas de Estado para enfrentar el déficit habitacional, hasta el año 1936 con la constitución del Banco Central Hipotecario $\mathrm{BCH}$, la única actividad constructora de vivienda existente

10 Información tomada de: https://www.populationpyramid.net/es/colombia/1980/

11 No hay que olvidad que uno de los programas que más lanzó a la fama al narcotraficante Pablo Escobar en sus primeros años de vida pública fue el programa de "Medellín sin tugurios", lo que le valió también llegar al Congreso de la República en representación del Partido Liberal. 
en el país era la que se hacía por encargo (Robledo, 1985) ${ }^{12}$. No obstante, sólo hasta 1953, el BCH convirtió los créditos hipotecarios a largo plazo para vivienda en el centro de su actividad financiera; créditos que según el mismo Robledo iban dirigidos principalmente a la clase media y alta de la sociedad y que de algún modo hicieron posible el nacimiento de planes de vivienda a nivel urbano (Robledo, 1985).

Otra de las entidades estatales creadas para disminuir el déficit fue el Instituto de Crédito Territorial ICT. Fundado a partir del decreto de ley 200 de 1939 como entidad encargada de fomentar el establecimiento de bancos de crédito en Colombia, la realización de préstamos para vivienda campesina hasta $1956^{13}$, y de allí en adelante préstamos a los sectores de medianos ingresos de la clase obrera y popular en el país (Robledo, 1985).

Muy de la mano del ICT, se encontraba además el fomento de las corporaciones de ahorro y vivienda CAV, fortaleciendo de esta forma el gobierno al sector vinculado a la industria de la construcción. Esta situación supuso un viraje de la economía, presentado como la estrategia principal -ideada por Lauchlin Currie en $1961^{14}$ - incluida en el plan de desarrollo del gobierno del presidente Misael Pastrana Borrero durante su mandato (1970-1974).

Esta estrategia suponía que la intensificación masiva de la migración del campo hacia la ciudad, activaría la industria de la construcción y con ella el desarrollo urbano. El énfasis en la industria de la construcción absorbería la migración procedente del campo, posibilitando el mejoramiento de la producción industrial y agrícola, lo que al mismo tiempo estimularía la generación de empleo (Acevedo Vélez, 2009). En ese orden de ideas la construcción de vivienda se convirtió en prioridad de la acción estatal, -a través de mecanismos como la creación del UPAC ${ }^{15}$ y el FAVI ${ }^{16}$ - para darle un nuevo impulso a la economía

12 La vivienda por encargo, se realiza a pedido de quien la contrata, ya sea para habitar en ella o para alquilarla. Esta forma de construcción de vivienda supone la disposición de capital importante por parte de quién la contrata, pues al ser única y no estar dentro de un plan de vivienda popular, supone que sus costos de producción son mucho más elevados.

13 Es importante aclarar que, solo hasta 1942 el ICT tuvo una sección de vivienda popular urbana, pero es sólo hasta 1956 se especializa en asuntos de habitación para la ciudad (Robledo, 1985). 14 Antiguo funcionario del Banco Mundial. Enviado por la Misión Económica del Banco Internacional de Reconstrucción y Fomento, en solicitud del Presidente Mariano Ospina Pérez en 1.949, y cuyo propósito fue establecer un programa global de desarrollo para mejorar el nivel de vida de la población colombiana (Acevedo Vélez, 2009).

15 Sistema que permitía reajustar las tasas de interés de los créditos, modificar el método de pago para extenderlos a 15 años (Junguito, 2018).

16 Fondo de Ahorro y Vivienda. 
nacional (Junguito, 2018).

Sin embargo, la estrategia de Pastrana Borrero no fue la única. El presidente Belisario Betancur, hacia el año de 1982, incluyó dentro de sus propuestas de gobierno el programa de la casita sin cuota inicial para los pobres, que fue conocida bajo el slogan de la política del "Sí se puede", y en la cual, se pretendió que las viviendas fueran financiadas por las Corporaciones de Ahorro y Vivienda CAV nuevamente a través de los créditos hipotecarios del UPAC (Robledo, 1985).

Estas entidades y las diversas estrategias gubernamentales, fueron desbordadas por la demanda de vivienda popular, debido a que la explosión demográfica continuaba de la mano del flujo migratorio del campo hacia la ciudad, lo que incrementaba el déficit, impidiendo que las soluciones de vivienda lograran compensar la magnitud de la demanda.

Los créditos para vivienda ofrecidos por entidades como las CAV, el $\mathrm{BCH}$ e incluso el ICT tuvieron la peculiaridad de estar dirigidos a sectores de la población que contaban con estabilidad laboral e ingresos crecientes. Esto es, a los sectores de mayores ingresos de la clase obrera y popular para que los adjudicatarios pudiesen cumplir con las cuotas establecidas (Robledo, 1985).

En la segunda mitad del siglo XX, para la mayor parte de migrantes y desplazados llegados a las ciudades grandes o intermedias como Pereira, dichos créditos para vivienda resultaron esquivos, en la medida en que, las dificultades para obtener empleo, imposibilitaban pagar una cuota inicial o persistir en el pago de la deuda bancaria, situación que hacía imposible la adquisición de vivienda. Por esa razón, buena parte de dicha población se vio compelida a invadir con sus ranchos terrenos ejidales, lotes a las afueras de la ciudad y las orillas de los ríos, como medida desesperada para enfrentar una sociedad expulsora que les negaba el derecho a la vivienda.

La banca colombiana, única capaz de financiar el 100\% del crédito para la vivienda de las familias más empobrecidas del país, no estaba dispuesta a acometer una empresa de financiamiento que le pudiera generar inseguridad en los pagos y poca rentabilidad ${ }^{17}$. La anterior afirmación se demostró en el estudio realizado por el CENAC, con el cual se evidenció que la oferta de financiación de vivienda estructuraba

17 Las corporaciones de ahorro y vivienda CAV, ni durante los años 70, $80 \mathrm{o} 90$, han tenido intención de eliminar el pago de la cuota inicial de sus créditos para vivienda, pese a que son autorizadas por parte del gobierno a financiar hasta en un $100 \%$ su valor (Tiempo, 1997). 
sus variables dependiendo del estrato social de los demandantes (Ver Tabla 4), siendo mucho mayor la oferta de financiación para los estratos altos, y menor para los estratos bajos que, como se sabe, eran quienes más acuciantemente la requerían.

Tabla 4: Necesidades y mercado de vivienda en Colombia.

\begin{tabular}{|cccc|}
\hline Estrato & $\begin{array}{c}\text { Valor de las viviendas (miles de } \\
\text { \$ de 1981) }\end{array}$ & Demanda efectiva & Oferta estimada \\
\hline Bajo & & 105.0 & 3.5 \\
\hline Medio Bajo & $400-1.200$ & 32.4 & 3.3 \\
\hline Medio Medio & $1.200-2000$ & 26.6 & 6.7 \\
\hline Medio Alto I & $2.000-3.500$ & 13.7 & 7.0 \\
\hline Medio Alto II & $3.500-5.000$ & 2.2 & 3.5 \\
\hline Alto & Más de 5.000 & 1.5 & 3.1 \\
\hline Total & & $\mathbf{1 8 1 . 4 0 0}$ & 27.1 \\
\hline
\end{tabular}

Fuente: CENAC, CEN 93-81. Tomado y modificado de Robledo, Jorge E. El drama de la vivienda en Colombia y la política del "sí se puede". Áncora, 1985, pág. 181.

Por último, la desfinanciación de los programas de vivienda por parte del Estado también minó la posibilidad de disminuir el déficit habitacional, según comenta Jorge E. Robledo en su texto El drama de la vivienda en Colombia, los aportes del presupuesto nacional a dicha entidad entre 1974 y 1981 nunca superaron el 22.6\% de las entradas, lo que implicó que buena parte de los ingresos corrientes del ICT provinieran de su propia actividad comercial y de operaciones de crédito interno (Robledo, 1985). Según estudios de Roel Janssen ${ }^{18}$ la iniciativa del gobierno en los programas de vivienda como el ICT o la Caja de Vivienda popular -que otrora promovieron las soluciones de vivienda más económicas del mercado- centró el $66.0 \%$ de sus esfuerzos en beneficio de las clases medias; y el 13.2\% en las clases altas; el $21.8 \%$ en beneficio de las familias de escasos recursos; y el 4\% para los estratos más bajos (Robledo, 1985, pág. 116). Todo lo cual, confirmó la tendencia a limitar drásticamente el crédito de vivienda a las personas más pobres de las ciudades, aquellas que sin saberlo, terminaron pagando las consecuencias de la política fiscal restrictiva de las entidades públicas y privadas, acudiendo forzados como carne de cañón de prácticas malsanas como la especulación con el precio del suelo urbano y la adquisición

18 Reconocido sociólogo que se dedicó al estudio de los asentamientos pobres en los márgenes del oriente de Bogotá, plasmado en su libro: Vivienda y luchas populares en Bogotá. 1984 
de lotes de engorde, ofertados por algunas empresas constructoras, por terratenientes y un sinnúmero de urbanizadores piratas.

\section{Déficit de vivienda en Pereira}

En la ciudad de Pereira, la situación no fue distinta a la de las principales ciudades del país. De hecho, para comprender el déficit habitacional en Pereira, es indispensable ligarlo con el déficit en el municipio de Dosquebradas, puesto que ambos municipios hacen parte del área metropolitana y gran parte de las soluciones al problema de la vivienda y servicios públicos de los nuevos moradores de Pereira fueron atendidas o trasladadas a Dosquebradas. De hecho, es en el año de 1.950 cuando el ICT se hizo presente en Pereira para empezar la ejecución de las primeras urbanizaciones populares "a raíz de la violencia social que trajo a la ciudad miles de familias campesinas que huían de la desolación y el exterminio de sus parcelas" (Sociedad de Mejoras Pereira, 1989).

Gráfico 1: Viviendas ocupadas en Pereira, según el censo de 1951.

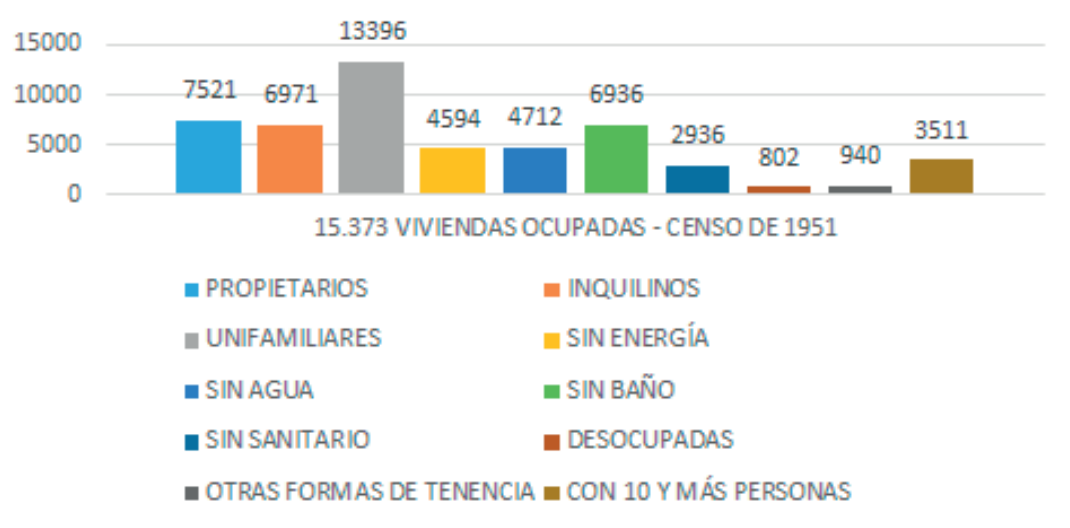

Fuente: Elaboración propia a partir del censo de 1951consultado en: Biblioteca Virtual DANE http://biblioteca.dane.gov.co/biblioteca/categories/36/

Tomando como punto de partida y referente el censo de 1951, la ciudad de Pereira que aún hacía parte del departamento de Caldas, evidenciaba desde entonces falencias significativas en cuanto a la tenencia de la vivienda y la calidad de la misma. De un total de 15.373 viviendas ocupadas el $44.9 \%$ eran habitadas por inquilinos, el $29.8 \%$ carecía de servicio de energía, el 30.6\% no tenía agua, por ende, el $45.1 \%$ no tenía baño y el 19.2\% no contaban con sanitario (Ver Gráfico 1).

Es hacia el año de 1959 aproximadamente cuando inicia el 
asentamiento poblacional de invasión en el sector de Cuba (Torres Tovar, 2009). Según el texto: La monografía del barrio Cuba, hacia el año de 1.960 la ciudad de Pereira padecía el problema demográfico producto del éxodo de campesinos llegados de regiones vecinas a causa de la violencia política. Este desborde poblacional incidió para que la ciudad recibiera aproximadamente 50.000 personas en un término menor de 13 años, desborde que incrementó el déficit habitacional en cerca de 6.800 viviendas (Grupo de acción comunitaria y social (ACCOMS), 1990). No obstante, según otras versiones como la de Carlos Alberto Torres, en la época de los sesenta se presentó un índice de hacinamiento de 6,11 hab/ viv, con lo que se estimó un déficit de 10.000 viviendas (Torres Tovar, 2009).

\section{Gráfico 2: Total de viviendas en Pereira, según el censo de 1964.}

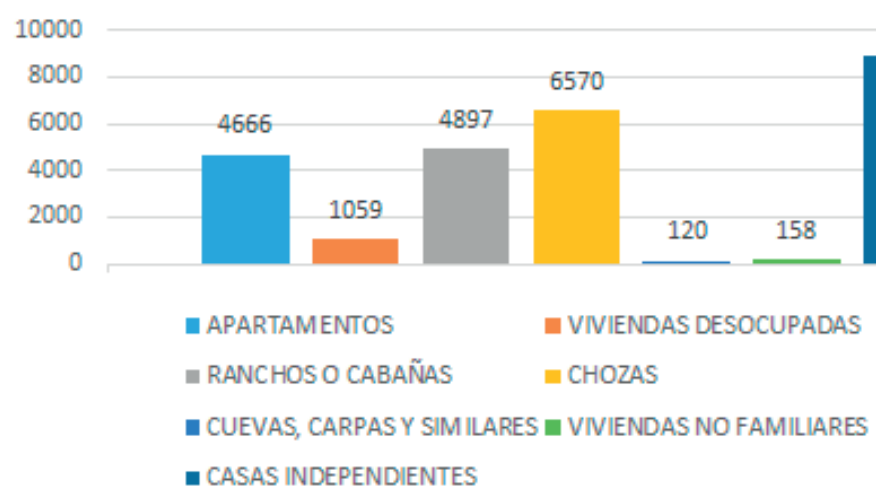

Fuente: Elaboración propia a partir del censo de 1964 consultado en: Biblioteca Virtual DANE http://biblioteca.dane.gov.co/biblioteca/categories/44/

Según Datos del DANE en el censo de 1964, sobre un total de 25.122 viviendas ocupadas el $42.1 \%$ estaban arrendadas, el $60 \%$ no tenía agua y el $17.4 \%$ vivía en condiciones de hacinamiento puesto que habitaban en ellas de 9 a 11 personas. Resulta importante considerar algunas otras variables tenidas en cuenta por el censo de 1964 y que permiten dimensionar un poco más el panorama en torno a las carencias relacionadas con la vivienda y sus condiciones de habitabilidad, como lo son: el número de ranchos, chozas y viviendas desocupadas (Ver Gráfico 2).

Del censo de 1964 se puede destacar el número de chozas y ranchos o cabañas, factor que podría ser asociado a los asentamientos de invasión o 
los barrios piratas muy comunes en la ciudad en dicha época. Invasiones, que no contaban con condiciones dignas, seguras e higiénicas para ser habitadas, y en donde el denominador común era que los propietarios fuesen los dueños de los ranchos más no del terreno, como sucedió con el asentamiento de invasión en el sector de cuba 1959 o con el Barrio el Río en Pereira (Ver Fotografía 4) estudiado por el sociólogo Fray Arturo Calle, y cuya descripción evidencia las limitaciones y riesgos en la composición de los materiales de construcción, en las vías de acceso, en la carencia de servicios públicos esenciales y de espacios de esparcimiento (Calle, 1964).

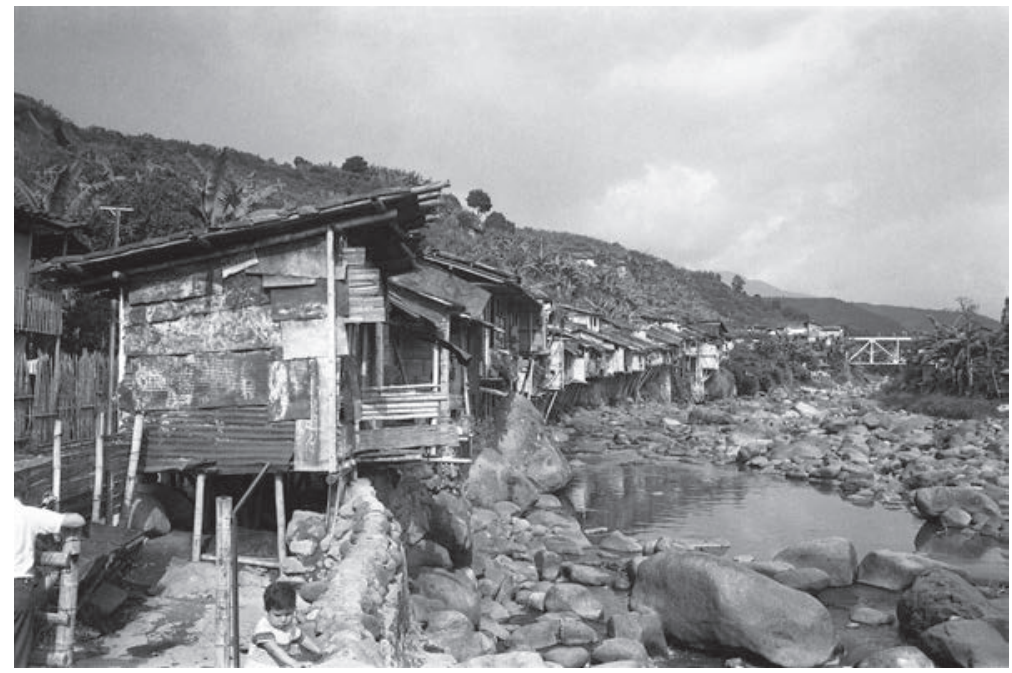

Fotografía 4: Invasión a las orillas del Río Otún en Pereira. Segunda mitad del siglo XX. Fuente: Archivo fotográfico de José García Jaramillo.

De hecho, en la prensa local de la ciudad por estos años son continuas las publicaciones dedicadas a retratar el problema de las invasiones tanto en Pereira como en municipios aledaños a la ciudad como La Virginia. En una publicación del periódico el Diario de Risaralda del 30 de noviembre de 1966, se hace alusión a la demolición por parte de la secretaría de Obras Públicas distrital, de 60 ranchos piratas ocupados por aproximadamente 200 familias en el sector del 30 de agosto, los cuales, según dicho reportaje, no cumplían ni requisitos técnicos ni estéticos, lo que causaba daño a la ciudad.

En las primeras horas de la mañana de hoy se dará comienzo a la demolición de 
gran cantidad de ranchos construidos en la Urbanización Pirata propiedad del señor Nicolás Benítez, situada sobre el costado sur de la Avenida 30 de Agosto, terrenos que fueron ocupados por unas 200 familias construyéndose allí unos 60 ranchos de guadua y esterilla, sin llenar ningún requisito técnico ni estético, ocasionando con ello un gran daño a la ciudad. La anterior medida fue ordenada por la alcaldía municipal y será cumplida por la Secretaría de Obras Públicas distrital, en colaboración con funcionarios de los permanentes de oriente y occidente y unidades de la policía local (Diario de Risaralda, 30 noviembre 1966).

Pese a que según el censo del DANE para el año 1964 el 96.88\% de los edificios de la ciudad 23.379 estaban destinados para la habitación, la demanda de la vivienda en la ciudad y la necesidad de espacio habitable se incrementó, desbordando la capacidad de una adecuada respuesta estatal y obligando a que muchas de las personas que llegaban a la ciudad se agruparan y encontraran, en algunos casos, refugio en organizaciones viviendistas espontáneas o de carácter nacional dedicadas a atender la problemática de los destechados, este fue el caso de CENAPROV.

Por supuesto que con el paso de los años y para el censo de 1973, se incluirán nuevas características de la vivienda que permiten dilucidar aspectos y detalles que no fueron tenidos en cuenta en censos anteriores, como el número de inquilinatos, viviendas en construcción y viviendas en edificios no aptos (Ver Gráfico 3). Todos ellos, componentes de una ciudad que a medida que crecía en tamaño también hacía cada vez más difícil su comprensión, haciendo evidentes como plantea Torres, la falta de una planificación oportuna que se hace latente en el Plan Piloto de 1967. El cual, desde entonces anotaba la dispersión de núcleos urbanos aislados en la ciudad, con las consiguientes dificultades de transporte y el alto costo de servicios públicos en esos sectores (Torres Tovar, 2009).

Resulta interesante resaltar, como lo evidencia el gráfico siguiente, que a medida que pasan los años y crece el número de pobladores, el número de viviendas en Pereira aumenta significativamente pasando de 15.373 en 1951 a 85.510 en 1985. (Dane, 2018). De acuerdo con el estudio de Carlos Torres, pese a que en la década de los setenta fueron construidos más de 60 barrios en la ciudad por entidades como el ICT ${ }^{19}$ y el FVP, también tuvieron mucho protagonismo las iniciativas particulares en el surgimiento de numerosos barrios de invasión y urbanización ilegal, en

19 Según palabras de Carlos Torres: "El ICT actuó en este periodo como el principal promotor de la construcción de vivienda y de la expansión de la ciudad con la creación de barrios que, como en el caso de Cuba, estaban fuera de los sectores consolidados y densificados. Esta entidad llegó a tener un papel decisivo en la urbanización de la ciudad en las siguientes tres décadas" (Torres Tovar, 2009). 
Gráfico 3: Total de viviendas en Pereira, según el censo de 1973.

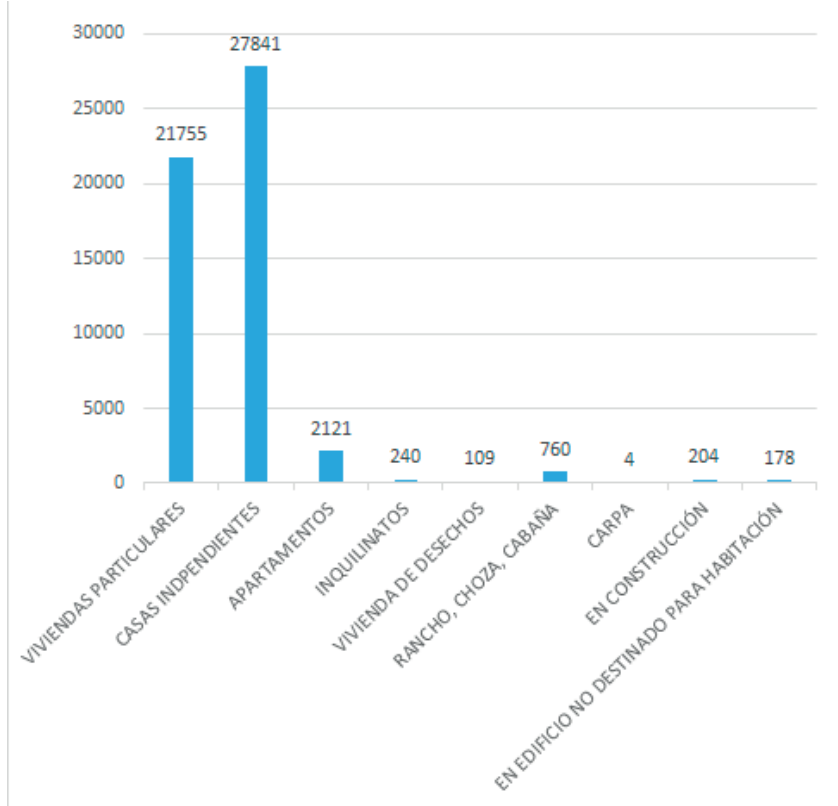

Fuente: Elaboración propia a partir del censo de 1973 consultado en: Biblioteca Virtual DANE http://biblioteca.dane.gov.co/biblioteca/categories/45/

sectores como: Cuba, Villa Santana y el Ferrocarril (Torres Tovar, 2009). Lo cual denota una constante en lo relativo al déficit habitacional en la ciudad que, aunque no es muy evidente en el censo de 1973, sí lo es en la prensa local, donde se publicaron noticias relacionadas con invasiones de terrenos en diversas zonas de la ciudad por parte de centenares de familias acosadas por problemas de vivienda:

Once sectores de esta capital fueron invadidos este fin de semana por cerca de 50 familias que reclamaban vivienda (...) las zonas ocupadas por las gentes sin recursos y sin techo son las siguientes: Paz del Rio, en inmediaciones del barrio Kennedy al oriente de la ciudad, San Luis Gonzaga, en la carretera que de Pereira conduce a la capital del vecino departamento del Quindío; Barrio Risaralda, sector de Nacederos, zona aledaña a la calle 23 entre carreras 13 y 14, Barrio San Nicolás, riberas de la Quebrada El Oso, El Naranjito, sectores nor-oriental de la avenida del Ferrocarril y Vereda el Lembo en inmediaciones del municipio de Dosquebradas (...) Los integrantes de las familias habían optado por no retirarse de esas tierras, hasta que las autoridades no les garanticen techo para sus hijos. El número de personas que se encuentran en los mencionados sectores ascienden a 250, figurando entre ellas niños de escasos años, a quienes se les observa en sus rostros desnutrición y retraso 
físico (...) los padres que participan en el movimiento se encuentran sin trabajo, causa que los obligó a adoptar esa posición, con el fin de defender sus familias. Gran parte de los invasores residían en humildes viviendas fabricadas con cartón y otros elementos, en riberas del Río Otún y Consota de esta capital, mientras que otro número de familias vivían en partes aledañas a la acequia del municipio de Dosquebradas, donde debieron salir por falta de recursos para pagar la mensualidad del arrendamiento (La Tarde, 6 Septiembre 1977).

De lo anterior, se puede inferir la dramática situación que padecían centenares de personas en asentamientos ilegales, catalogados por la prensa de la época como modelos tuguriales en las laderas de las montañas próximas al río Otún, como el Barrio Granada, cuyas viviendas estaban fabricadas con esterilla y cartón. Cada rancho constituía un solo cuarto donde se hacinaban entre cinco y ocho personas. El barrio no contaba con vías de acceso adecuadas, no contaban con acueducto, ni alcantarillado y en muchas ocasiones sin servicio de energía. El agua la adquirían abriendo pozos, que no daban abasto para tantas familias y que a su vez contribuían a la erosión del terreno, colocando en riesgo a las familias que habitaban allí (La Tarde, 13 Septiembre 1977).

Conforme a la realidad descrita, el fenómeno de las organizaciones de viviendistas se remonta en la ciudad de Pereira a la década de 1960 momento en que se intensifica el drama migratorio y se produce un aumento exponencial tanto en la población en la ciudad ${ }^{20}$, como en el número de asentamientos informales. Para comprender la dinámica de los mentados asentamientos informales, se precisa distinguir su clasificación de acuerdo a su origen en dos tipos como recomienda Torres Tovar (2009): las invasiones y los planes de vivienda.

Las primeras se caracterizan por estar ubicadas en terrenos de propiedad pública, de morfología lineal debido a su ubicación alrededor de ríos y quebradas, constituyen el $46 \%$ de los asentamientos de origen informal en la ciudad. Las segundas, se caracterizan por ser procesos de urbanización al margen de la planificación oficial, como el caso de CENAPROV, con planificación morfológica previa, aunque ubicados en la periferia de la ciudad, lo que dificultaba el acceso a servicios públicos, representaron el 54\% de los barrios informales en la ciudad (Torres Tovar, 2009).

La continua problemática de las invasiones, con el continuo apoyo que tuvieron por parte de organizaciones, grupos y personas con

20 Según Oscar Arango la ciudad de Pereira cuenta con un poblamiento urbano reciente, puesto que el 86\% de sus barrios se crearon con posterioridad a 1950 (Arango Gaviria, 1989). 
intereses políticos particulares, aunado a la incapacidad estatal para atender suficientemente el déficit habitacional en la ciudad en la época, posibilitó que para el año de 1979 el gobierno municipal en cabeza de César Gaviria Trujillo alcalde de la Ciudad de Pereira, iniciara la gestión del marco legal local que posteriormente sirvió como soporte para reglamentar la legalización de algunos planes de vivienda. En una noticia de prensa publicada en el periódico La Tarde el $1^{\circ}$ de junio de 1979 se establecen los requisitos que deben cumplir todas estas organizaciones de viviendistas para la legalización de sus planes de vivienda:

La Superintendencia Bancaria entrará a ejercer vigilancia sobre los planes de vivienda populares residenciales progresivos, al notificarse del Decreto expedido por la Alcaldía en el pasado fin de semana. La disposición, que ordena la ejecución de programas de vivienda contiene disposiciones sobre funcionamiento de comités de organización de éstos planes. Señala el Decreto:

El Alcalde de Pereira en uso de sus atribuciones legales Decreta:

Artículo $1^{\circ}$ Para la prestación de asistencia técnica a los planes de vivienda popular deberán cumplirse los siguientes requisitos previos:

a. Obtención de la Personería Jurídica

b. Concepto técnico favorable del Comité Municipal de Vivienda sobre el terreno en el cual se desarrollará el plan y de la capacidad financiera de la comunidad que lo va adquirir.

c. Certificación de Planeación Municipal sobre el número de soluciones de vivienda que pueden construirse en el lote.

d. Inscripción en la Secretaría de Gobierno de los socios del plan específico con base al número de viviendas certificadas por Planeación Municipal.

e. Someter a consideración del Comité Municipal de Vivienda los Estatutos y la organización fiscal-administrativa del plan, la cual deberá ser ratificada por la Superintendencia Bancaria.

f. Carta compromisoria de la junta directiva del Plan sobre el manejo de los recursos destinados al plan aprobado por la Superintendencia Bancaria.

g. Sujeción a la acción estipulada por la Superintendencia bancaria para este tipo de planes.

Artículo $2^{\circ}$. No podrá ser anunciado ningún plan sin el cumplimiento de los requisitos previos estipulados en el Artículo $1^{\circ}$.

Artículo3 $3^{\circ}$. El recibo de dinero y promoción del plan sin el cumplimiento de los requisitos exigidos por la Superintendencia Bancaria acarreará las sanciones previstas en la ley 66 de 1.968.

Artículo $4^{\circ}$. No podrán ser iniciadas las obras de adecuación de lotes sin la autorización previa del departamento de Planeación Municipal (La Tarde, 1 Junio 1979).

Pese a las medias tomadas por la administración municipal, el problema de la vivienda parecía más crítico, pues para el año de 1982 
el déficit había aumentado a cerca de 14.000 soluciones faltantes y posteriormente, en 1.986 rondando la cifra de las 18.600 soluciones inexistentes, sobre un total de 60.000 hogares (Arango Gaviria, 1989). Sin embargo, las cifras que Oscar Arango toma del Fondo de Vivienda Popular FVPP solo tenían en cuenta las personas o familias que mostraban interés por adquirir vivienda, excluyendo a las familias que no evidenciaban este interés, pero que sí padecían el déficit habitacional, y no lo expresaban principalmente por motivos económicos derivados de su imposibilidad de adquirir algún tipo de crédito financiero para acceder a una vivienda. Estas familias se convirtieron en invasoras y en el mejor de los casos en inquilinos, lo que incrementó las cifras de un déficit que se aproximaba a las 25 mil soluciones de vivienda faltantes hacia el año de 1986.

En lo que respecta al censo de 1985, a pesar de que cifras globales del censo arrojan un total de 83.510 viviendas, el diagnóstico de sus características se realiza a partir de las 76.663 viviendas que se encontraban ocupadas con personas presentes. De las cuales 1.052 se encontraban sin ningún tipo de servicio público, 4.086 con energía únicamente, 5.018 con letrina y 1.379 sin cocina (Dane, 2018).

Tabla 5: Déficit cuantitativo de vivienda en Pereira y Dosquebradas.

\begin{tabular}{|ccc|}
\hline Items & Número & Porcentaje \\
\hline Total & 59.595 & 100.0 \\
\hline Mejorar o cambiar & 4.557 & 7.6 \\
\hline Ampliar & 1.852 & 3.1 \\
Construir & 1.304 & 2.2 \\
\hline Adquirir & 18.647 & 31.3 \\
\hline No tiene interés & 33.262 & 55.8 \\
\hline
\end{tabular}

Fuente: Datos tomados y modificados del texto de Oscar Arango, Pereira, años 80, 1989, pág. 66.

Aunque los gráficos permiten evidenciar un aumento y mejoramiento progresivo en la calidad de la vivienda existente, las cifras censales de 1.985 solo permiten apreciar un diagnóstico cuantitativo y cualitativo de la vivienda existente en Pereira para la época, más no un balance real del déficit habitacional en la ciudad y el drama para los que no tenían donde habitar. Será Oscar Arango, quién en su texto Pereira años 80 (1989), con datos tomados de las distintas entidades como el ICT Y el FVP calcula el porcentaje aproximado del déficit de vivienda en la ciudad para el 
año de 1.986 incluyendo, a las personas que no mostraban interés en adquirir vivienda, pero continuaban padeciendo el déficit (Ver Tabla 5).

Estas cifras coinciden parcialmente con los datos brindados por Jairo Arango, ex director del ICT y exalcalde de Pereira entre 1988 y 1990, quien en una entrevista redondeó el déficit habitacional en la ciudad en alrededor del $40 \%$ entre los estratos 0 al 2, es decir, una déficit cercano a las 5.000 soluciones de vivienda para la ciudad (Arango, 2018). Situación que era similar en las ciudades contiguas, pues para la misma época Manizales poseía un déficit de 4.086 y Armenia de 11.694 (Arango Zuluaga, 1986).

Estos datos, además de aspirar a definir cuantitativamente la problemática habitacional en la ciudad, sacaron a la luz pública las dificultades socioeconómicas y de habitabilidad de las familias en inquilinatos, las viviendas cedidas o prestadas, los cuartos subarrendados, el hacinamiento y las invasiones. Todas estas formas de solucionar parcialmente la dramática situación relativa a la vivienda de muchos habitantes que en buena medida desbordaron las estrategias que brindaba la administración municipal de la época con ayuda del Instituto de Crédito Territorial y el Fondo de Vivienda Popular.

Al contrastar el panorama del déficit habitacional con la situación socioeconómica de los nuevos habitantes de las ciudades, se retrata una problemática que desborda las capacidades estatales o administrativas, pues aunque el Instituto de Crédito Territorial ICT y el Fondo de Vivienda Popular fueron los principales protagonistas de la construcción formal hasta los años noventa (Torres Carrillo, 1993) era evidente que éstos no lograban contener la dramática avalancha que vivía la ciudad en la segunda mitad del siglo XX, por cuenta del crecimiento demográfico derivado de las migraciones.

Las respuestas ante esta notable problemática por parte de la administración municipal de Pereira se encontraban dentro del marco de las políticas nacionales que enfrentaban el déficit habitacional con estrategias que tenían como principal fortaleza el Instituto de Crédito Territorial ICT y el fondo de vivienda popular FVPP como consta en el acuerdo 121 de 1976, por el cual el Concejo Municipal de Pereira creó este último (Concejo Municipal Pereira, 1976) y en menor escala la Empresa de Desarrollo Urbano de Pereira EDUP y la Corporación Autónoma Regional del Risaralda CARDER, como se puede evidenciar en la siguiente tabla ante las soluciones que habían otorgado para el año de 1986. 
Tabla 6: Pereira años 80.

\begin{tabular}{|cc|}
\hline Constructor & Unidades \\
\hline Total & 27.08 \\
\hline F.V.P & 230 \\
\hline E.D.U.P & 70 \\
\hline I.C.T. & 638 \\
\hline Carder & 138 \\
\hline U. Privado & 1.632 \\
\hline
\end{tabular}

Datos tomados y modificados del texto de Oscar Arango, Pereira, años 80, 1989.

Este cuadro permite observar cómo en Pereira la concentración de la propiedad urbana y las soluciones de vivienda se desarrollaron especialmente por urbanizadores privados, lo que implicó un grave problema de encarecimiento de la tierra urbana, situación que afectó directamente las comunidades de estratos 0 al 2, quienes no contaban con los recursos necesarios para acceder a créditos otorgados por la banca o por urbanizadores privados.

Pese a lo anterior, es importante resaltar que el ICT fue determinante en el crecimiento barrial de la ciudad, desde su creación en la década de 1950 hasta su liquidación en la década de 1990. De acuerdo con Rivera "el ICT proporcionó durante sus años de atención local siete mil soluciones adjudicadas de vivienda. Esto quiere decir que sobre un total de 57.500 unidades de vivienda ocupadas que encontró el censo de 1985, un 12\% fueron construidas por esta entidad" (Rivera, 2013, pág. 307).

Algunos de los barrios más destacados construidos por esta entidad y que se localizan en su periferia fueron: Providencia, Boston, San Luis Gonzaga, San Camilo, diferentes etapas del Barrio Cuba, Gamma, Olímpico, Jardín, Libaré, Alfonso López, Popular Modelo, Ciudadela Perla del Otún (2500 lotes), siendo este último uno de los baluartes del ICT, dada su magnitud y su carácter cooperativo bajo la modalidad de autoconstrucción. A este proyecto se vincularon dirigentes de diferentes comunidades del orden local.

A menor escala funcionó el Fondo de Vivienda Popular que también buscó solucionar el déficit habitacional en la ciudad, fue creado en 1976 bajo acuerdo del Concejo Municipal de Pereira número 121, por el cual se fundó dicha entidad pública con carácter autónomo administrativa y financieramente, su objetivo quedó consagrado en el artículo $2^{\circ}$ : 
Atender a la solución del problema de vivienda popular, mediante la construcción de viviendas y de cualquier otra clase de obras referentes a la infraestructura necesaria para aquel fin, en armonía con los demás organismos del estado que cumplan similar función y obedeciendo a las directrices urbanísticas señaladas en forma general para el municipio (Concejo Municipal Pereira, 1976).

En la siguiente tabla se pueden observar las soluciones de vivienda que se gestionaron en Pereira en el período 1976-1986 por parte del Fondo de Vivienda Popular:

Las soluciones ofrecidas por el FVPP se orientaron especialmente a otorgar lotes con servicios, como consta en diferentes ordenanzas del Concejo Municipal de Pereira, por las cuales se otorgaban lotes a diferentes agremiaciones de trabajadores con el objetivo de construir soluciones de vivienda conjuntamente con el ICT. Ejemplo de estas es el acuerdo número 7 de enero 21-1971, por medio del cual se destinó lote de terreno de propiedad del municipio, para la construcción de viviendas para el sindicato de lustrabotas de Pereira (Concejo Municipal Pereira, 1971).

Tabla 7: Ordenanzas del Concejo Municipal, 1976.

\begin{tabular}{|ccc|}
\hline Tipo de programa & Número de soluciones & Inversión en millones $\$$ \\
\hline Total & 1.645 & 104.0 \\
\hline Lotes con servicios & 1.342 & 33.5 \\
\hline Viviendas & 252 & 65.6 \\
\hline Créditos & 52 & 4.9 \\
\hline
\end{tabular}

Fuente: Datos tomados y modificados del texto de Oscar Arango, Pereira, años 80, 1989.

Estos acuerdos y ordenanzas constituyeron la respuesta oficial que operó en el municipio de Pereira para enfrentar la problemática de vivienda en las comunidades de estratos 0 al 2. Sin embargo, de forma simultánea y ante la ingente demanda de los sectores populares, diferentes grupos de viviendistas - entre los que se destacan CENAPROV, urbanizadores piratas e invasores - se agruparon para construir barrios en las zonas periféricas, principalmente en el suroccidente de la ciudad. Agrupaciones en su mayoría con intereses políticos, lideradas por dirigentes del partido liberal y conservador, o por cooperativas de trabajadores y organizaciones gremiales como los zapateros, los trabajadores del Ferrocarril de Occidente, los coteros, entre otras 
(Arango Gaviria, 1989).

De hecho, para 1987 frente a un total de 200 barrios en la ciudad, se identificaron 86 en condición de subnormalidad conformados mucho antes de 1976 y ubicados en 9 de las 11 comunas de la ciudad (Arango Gaviria, 1989). Estos barrios carecían de servicios básicos de salud, recreación, educación formal y en su gran mayoría eran deficitarios en servicios de alcantarillado, saneamiento básico, energía, acueducto, no contaban con vías de acceso apropiadas y no eran atendidos por el transporte público.

De este modo, se puede apreciar la existencia múltiples formas de hacer frente a la problemática aparte de las invasiones por parte del sector formal e informal, como lo fueron el autoconstrucción y el desarrollo progresivo. Dentro de las diferentes formas de organización legalmente constituidas con personería jurídica en el municipio de Pereira se encontraban: comités, corporaciones, asociaciones y planes de vivienda, para un total de 78 organizaciones, que se discriminan de la siguiente manera: $4 \%$ comités, $8 \%$ corporaciones, $17 \%$ asociaciones y 71\% planes de vivienda normalmente en manos del ICT o el FVPP (Arango Gaviria, 1989). Estos datos no incluyen a CENAPROV puesto que su personería jurídica pertenecía al orden nacional y no estaba radicada en la ciudad de Pereira.

Respecto a las organizaciones de viviendistas en Pereira y Dosquebradas resalta su relación directa con algún tipo de directorio político o ideológico, lo que resulta fácilmente rastreable en la toponimia de los barrios, con los cuales se brindó homenaje a algún tipo de dirigente político o social, bien podía ser un desaparecido, un asesinado a causa de la violencia política, una persona influyente en la región o un líder comunitario que se encontraba activo en la época, tal fue el caso del Barrio Sinaí, levantado en homenaje a Sinaí Giraldo, profesional de las asociaciones de vivienda en la ciudad (Arango Gaviria, 1989) o el Barrio Santiago Londoño en Dosquebradas construido en 1981 por la Central Nacional Provivienda, en homenaje a un médico e intelectual de la ciudad importante líder comunista, gestor de muchos espacios políticos y culturales en la ciudad como la Sociedad Amigos del Arte (Martínez, Serna, \& Correa, 2013).

En este orden de ideas, la segunda mitad del siglo XX sirve como referente para comprender la situación urbana de la ciudad de Pereira, en ella convergen diferentes formas de lucha por la vivienda, que pasaban desde la oficialidad hasta la subnormalidad, y que a partir de los años 
50 se reflejan en la expansión acelerada del área urbana, implicando con ello la construcción de asentamientos informales, la mayor parte ubicados en los cauces de los ríos y quebradas o laderas (Torres Tovar, 2009). Por lo cual en este aspecto podría concluirse que:

El desarrollo de barrios informales en Pereira y su área metropolitana ha estado ligado históricamente a una constante inmigración que ha superado la capacidad de la infraestructura de la ciudad para responder las demandas de suelo, vivienda, espacio público y equipamientos urbanos (Torres Tovar, 2009, pág. 249).

Una vez expuesto el déficit habitacional a nivel local y la variedad de planes de vivienda, alternativas y las propuestas de solución por parte de organizaciones independientes y de la administración municipal de la época, coordinadas con las estrategias de orden nacional, conviene rastrear la forma de ejecución de dichos planes de vivienda y describir la participación que en ellos tuvieron las comunidades.

\section{La vivienda de autoconstrucción}

Como se ha sugerido con anterioridad el desborde en la demanda de vivienda y la incapacidad estatal para afrontarlo motivó a los demandantes de vivienda y a las entidades promotoras de las mismas a buscar soluciones alternativas para afrontar dicha situación, una de las cuales fue la auto-construcción. Esta solución consistía principalmente en una forma de construcción paulatina realizada de manera artesanal por parte de quienes aspiraban a una vivienda después de haber adquirido un lote con o sin servicios. Motivados por la posibilidad de tener una casa, empleaban tiempo adicional a sus jornadas de trabajo, recursos y gran esfuerzo para edificar paso a paso su vivienda.

Aunque no era la solución de vivienda más económica en el mercado -debido a que el propietario, con su escaso sueldo debía afrontar la compra de materiales y el pago de jornales- sí tenía la ventaja de permitirle al propietario el poder diseñar su casa a su antojo, se procuraban respetar lo mejor posible los lineamientos básicos de la arquitectura en lo relativo a la seguridad. La auto-construcción en el país se presentó como la principal alternativa para quienes era imposible pagar una casa de contado o veían frustrados sus intentos de acceder a un crédito bancario. La implementación de esta estrategia y su origen se puede rastrear en toda Latinoamérica y más allá del Continente.

Siguiendo la tesis de Jorge Robledo, la modalidad de autoconstrucción empezó a ser institucionalizada y reglamentada en el país, a partir de 
los años 1958 y 1959 con la implementación por parte del ICT de los programas de Ayuda Mutua y Casas Inconclusas (Robledo, 1985), se establecieron como política pública en el contexto de la Alianza Para el Progreso APP, conocida como el programa de ayuda externa establecido en los años 60 por el gobierno de Estados Unidos como una manera de implementar reformas de orden político, económico y cultural en Latinoamérica, reformas que propiciarían condiciones de desarrollo económico ${ }^{21}$ y estabilidad política creciente para orientar el cambio social, impedir el avance del comunismo y la influencia de la revolución cubana en el contexto de la guerra fría (Rojas D. M., 2010).

Uno de los objetivos planteado por la APP fue el incremento de los planes de vivienda de bajo costo. Así durante el gobierno de Alberto Lleras Camargo (1958-1962) y hasta el año de 1963 se construyeron en Colombia 131.313 viviendas, la mitad de ellas para las familias denominadas de bajos ingresos. De hecho, uno de los más grandes proyectos de autoconstrucción implementado como modelo ejemplar en el gobierno de Lleras Camargo fue: Ciudad Kennedy en Bogotá (Rojas D. M., 2010).

Bajo la consigna de John F Kennedy "no preguntes qué puede hacer el país por ti, sino qué puedes hacer tú por el país", la modalidad de autoconstrucción se impulsó exitosamente; tras ella existía todo un andamiaje de orden ideológico que ayudó a promoverla en países desarrollados como Inglaterra y en buena parte de Centro y Suramérica, que, como ya se afirmó, continuaban padeciendo un gran déficit habitacional durante el siglo XX (Turner, 1976).

Uno de los pioneros más conocidos de la auto-construcción fue John Turner, arquitecto inglés, reconocido por su trabajo social a mediados del siglo XX como asesor y estudioso de asentamientos en las barriadas de Lima Perú (Fernandez Maldonado, 2015) quien a partir de 1957 promovió el concepto de la vivienda auto-gestionada. En uno de sus textos más conocidos, Housing by people, proyectó la conciencia que tuvo sobre la necesidad de aportar por medio de la arquitectura informal un apoyo ante las necesidades de miles de personas que habitaban en barrios autoconstruidos (Turner, 1976).

Entre sus ventajas el proceso de autoconstrucción, según Turner, satisface las múltiples necesidades de los usuarios, lo que conlleva, por

21 La Agencia Internacional para el Desarrollo AID y el Banco Internacional de Reconstrucción y Fomento BIRF, eran las entidades encargadas de administrar los préstamos para Colombia entre (1962-1969). 
supuesto, una crítica mordaz a la simplificación de grandes proyectos de estructuras homogenizadas y repetidas a gran escala por el Estado para resolver el déficit. La vivienda estandarizada mass housing, según Turner, donde el Estado confina a los más pobres, propiciando la cultura de las carencias, el vandalismo y muchas más necesidades. Se priva al individuo de autonomía, libertad personal y dignidad, no quedando en el sujeto otro camino que el de ser absorbido por la maquinaria del Estado de bienestar, que alentaba de este forma, la cultura de la pobreza anónima, y socavando la participación popular (Turner, 1976).

Las ideas de Turner también podrían enmarcarse dentro de las concepciones de la teoría de la planificación inclusiva "advocacy planning"22 propuesta por el urbanizador estadounidense Paul Davidoff, quien a mediados de los años 60 se percató de que las sociedades del futuro serían urbanas, por lo que era necesario agenciar políticas que promovieran una respuesta adecuada al caótico desarrollo urbano, políticas que permitieran igualar a los ciudadanos en oportunidades y en derechos (Davidoff, 1965).

En su teoría, los aportes de los planificadores urbanos, van más allá de los asuntos meramente técnicos e incluyen la comprensión de los aspectos funcionales de la ciudad y recomendaciones de acciones futuras para mejorar los temas urbanos, a fin de que las comunidades no quedaran inermes y expuestas a lo que pudieran hacer por ellas las instituciones públicas (Davidoff, 1965). Davidoff se convirtió en un defensor y proponente de soluciones sustantivas específicas, que consideró más convenientes para la ciudad y para los intereses de los ciudadanos generalmente excluidos en la toma de decisiones gubernamentales:

In performing it's role of prescribing courses of action leading to future desired states, the planning professional must engage itself thoroughly and openly in the contention surrounding political determination. Moreover, planners should be able to engage in the political process as advocates of the interests both of government and of such other groups, organizations, or individuals who are concerned with proposing policies for the future development of the community (Davidoff, 1965, págs. 423-424).

Davidoff afirmó que la participación de los ciudadanos debía ir más más allá de simplemente ser escuchados, pues poseen el derecho de estar informados de las razones subyacentes en los propósitos de

22 Cfr Davidoff, Paul (1965). "Advocacy and Pluralism in Planning". Journal of the American Institute of Planners. 
la planificación urbana y por tanto, se les debía respetar la posibilidad de encarar el debate técnico de las mismas, como una manera de democratizar la planificación urbana de forma efectiva, con ciudadanos desempeñando un papel activo en la ejecución de las políticas públicas y participando activamente en la planeación y el diseño a partir de los intereses y necesidades de sus propias comunidades (Davidoff, 1965). De esta manera la planificación no debía establecerse únicamente desde las agencias gubernamentales, sino que se debía proyectar como una forma de planificación plural tomando en cuenta las ideas e intereses de los grupos urbanos desfavorecidos, sin desconocer la responsabilidad y obligatoriedad de la planificación pública (Davidoff, 1965).

En este sentido, la concepción de la auto-construcción abogaba por una descentralización del sistema de producción de vivienda, mediante sistemas flexibles, gestionados a nivel local, capaces de lidiar con la diversidad cultural de las comunidades, la posibilidad de adecuaciones, acceso a servicios básicos, seguridad, confort, régimen de tenencia y transformaciones en el tiempo de acuerdo a las condiciones económicas y circunstancias de orden local de los propietarios. De allí que, en otro de sus textos, Freedom to build, Turner afirma:

\footnotetext{
When dwellers control the major decisions and are free to make their own contribution to the design, construction or management of their housing, both the process and the environment produced stimulate individual and social wellbeing. When people have no control over, nor responsibility for key decisions in the housing process, on the other hand, dwelling environments may instead become a barrier to personal fulfillment and a burden on the economy (Turner, 1976).
}

Aunque Turner consideraba indispensable el aprovechamiento de la mano de obra local con sus tecnologías, capacidad de asociación, imaginación, recursos y reutilización de materiales; también creía en la importancia del papel del Estado como facilitador de la autogestión, a través de la regulación de recursos como el suelo, la financiación de vivienda o su gestión en lo atinente a la infraestructura de servicios.

Según Jorge Robledo, la autoconstrucción fue una política institucionalizada por los gobiernos en primera instancia, como una forma de esquivar las responsabilidades estatales para con los deficitarios de vivienda (Robledo, 1985), es importante mencionar que también fue la única forma en que una buena parte de la población en Colombia tuvo acceso a un techo, al punto que, hasta la misma Central Nacional Provivienda CENAPROV utilizó la metodología de la autoconstrucción 
en los lugares donde promovió sus planes de urbanización.

Según Gloria Elvira Naranjo, la organización CENAPROV conocida comúnmente como PROVIVIENDA, creó alrededor de 500 centros de inquilinos en 156 municipio en todo el país, desarrollando un intenso trabajo de organización y formación política, dotando de vivienda propia por autoconstrucción a cerca de cien mil familias (Naranjo, 2017):

\footnotetext{
Desafiando persecuciones y grandes dificultades consolidaron proyectos exitosos de autoconstrucción, a través del trabajo colectivo y solidario. Mediante procesos de concertación y negociación con el estado lograron legalizar la posesión de sus viviendas, obtener servicios públicos domiciliarios, pavimentación de vías y acceso a la salud y a la educación pública (Naranjo, 2011).
}

Pereira fue una de las ciudades donde la auto-construcción también se constituyó en mecanismo efectivo de acceso a la vivienda principalmente para los recién llegados a la ciudad que aspiraban a solucionar su carencia habitacional. Ejemplo fehaciente de este proceso, fue la construcción del Barrio Cuba en el año 1961 por parte del ICT mediante la modalidad de autoconstrucción, allí fueron otorgadas 1300 soluciones de vivienda distribuidas en tres etapas. Si bien dicho barrio fue construido con asesoría técnica y económica del ICT, también fue indispensable el esfuerzo colectivo de la comunidad para culminar con éxito las viviendas generalmente elaboradas con materiales de desecho y guadua (Grupo de acción comunitaria y social (ACCOMS), 1990).

Algunos años después, bajo las políticas de gobierno del presidente Alfonso López Michelsen, centradas en la desconcentración industrial, la descentralización administrativa y el impulso a ciudades intermedias (Departamento Nacional de Planeación , 1975), Francisco Londoño - en el momento del Bloque cívico ${ }^{23}$, se constituyó en promotor de la autoconstrucción en la ciudad. En aquel momento el señor Londoño ocupaba el cargo de secretario de planeación Municipal de Pereira (1974-1976) asesoró desde la administración pública los primeros asentamientos urbanos e invasiones en la ciudad, aplicando -como afirma en las entrevistas- los principios de John Turner sobre la auto-construcción. Logrando así el desarrollo progresivo de algunas urbanizaciones que para la época eran ilegales, como la del Plumón, la Avenida del Río y el Barrio la Isla de Cuba en 1974.

23 Generación de jóvenes liberales con ideas de renovación en la administración pública, entre los que se encontraban Marta Leonor Vélez, Gustavo Orozco, Cesar Gaviria, Alfonso Gutiérrez Millán. Cfr. https://www.youtube.com/watch?v=ziv5bAEFna8\&t=15s 
Según el testimonio de Francisco José Botero, uno de los fundadores del barrio la Isla de Cuba e integrante de CENAPROV, es hacia el año de 1971 cuando la Central Nacional Provivienda empieza a tener protagonismo en el suroccidente de la ciudad de Pereira. Momento en que un buen número de personas sin techo, lideradas por Francisco Morales, Horacio Bermúdez y el mismo Joaquín Botero obtuvieron el reconocimiento por parte de CENAPROV como el centro de inquilinos número $01^{24}$ dando inicio a la gestión para la compra por parte de la entidad de un terreno a la orilla de la quebrada El Oso donde se llevaría a cabo la construcción de un plan de vivienda a partir de 1973 que se conocería como el Barrio La Isla de Cuba. Primer barrio promovido por la Central Nacional Provivienda en la ciudad, levantado desde sus cimientos mediante la modalidad de autoconstrucción y en el que jugó un papel fundamental el trabajo colectivo de la comunidad, los convites, los bazares, los líderes comunales y las orientaciones de los representantes más reconocidos de la organización de viviendistas. (Botero Barrera, 2009).

Según relata Francisco Londoño, el hecho de que dichos asentamientos no fuesen invasiones sino planes de vivienda con lotes propios gestionados por la comunidad, contribuyó en gran medida a que la resistencia de la administración municipal de la época frente a la Central Nacional Provivienda fuera mínima y en el peor de los casos, solo mediática (Londoño Marulanda, 2018). De hecho, no son conocidos, $\mathrm{o}$ al menos no constituyen un aspecto relevante $\mathrm{o}$ un denominador común, dentro de la información disponible de la época, alusiones o testimonios de desalojos forzados a éste tipo de urbanizaciones que, aunque no contaban con todos los permisos de construcción, sí fungieron como las dueñas legítimas de los terrenos que preparaban para la autoconstrucción con base en el asesoramiento tanto de funcionarios de la administración municipal como de arquitectos, ingenieros y urbanistas de las organizaciones viviendistas (Central Nacional Provivienda, 1983).

Los planes de vivienda en Pereira en su mayor parte para la segunda mitad del siglo XX fueron autoconstruidos con participación comunitaria. Cada familia levantaba su vivienda de acuerdo a sus propios intereses y posibilidades económicas. La participación estatal

24 Figura de la estructura organizativa creada por CENAPROV. Como se precisará más adelante, los inquilinos eran en su gran mayoría personas de estratos bajos o de la clase media baja, dedicados a los oficios varios, las artesanías, la construcción y el comercio informal (Ayala, 2016). 
consistió principalmente en facilitar los créditos y en la formulación de sugerencias sobre los estilos y los materiales a utilizar en la construcción de las casas. Ejemplo de lo anterior, fue el barrio 2500 lotes; promovido por el ICT y ejecutado a través del Fondo de Vivienda Popular mediante la modalidad de autoconstrucción en 1.982 .

En la consecución de dicho barrio, se otorgó status legal a 20 comunidades organizadas con sus respectivas personerías jurídicas, entre ellas la de CENAPROV cuyo presidente era José Bautista Osorio. Según la revista Ciudadela perla del Otún, Plan 2500 lotes con servicios, publicada por la dirección del ICT en Pereira en 1987, la ciudadela fue un programa diseñado para dotar de techo a los sectores más pobres de la ciudad de Pereira y de paso para poner freno a la oleada de invasiones generalmente ubicadas en laderas de riesgo para los pobladores. Este programa se llevó a cabo a partir de 1982, en alianza y con el apoyo técnico e interinstitucional de distintas entidades estatales, y con el trabajo comunitario, lo que permitió que las organizaciones participaran en la construcción activa de sus viviendas y de paso que se establecieran vínculos entre vecinos que favorecieron la cohesión del tejido social (Instituto de Credito Territorial, 1986).

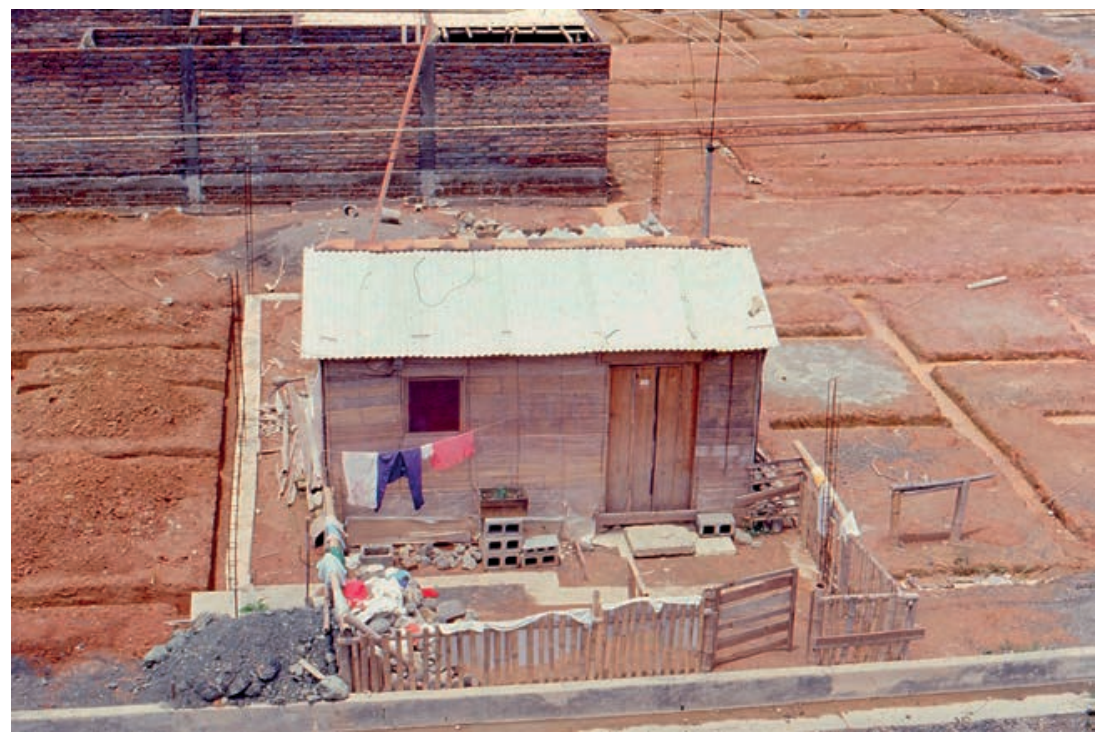

Fotografía 5: Vivienda de Autoconstrucción 1987. Barrio 2.500 lotes. Fuente: Archivo personal de Francisco Londoño Marulanda. 
Siendo la participación de la comunidad un factor esencial dentro del esquema de la auto-construcción, conviene ahora, considerar el papel que tuvo CENAPROV dentro de la organización popular en la lucha por el derecho a una vivienda digna, sus estrategias de autogestión de espacios dentro de la urbe, la metodología organizativa de las comunidades dentro de los barrios y su accionar político en las contiendas electorales de orden local y nacional. Todos estos elementos resultan indispensables para comprender el alcance e influencia que tuvo la organización de viviendistas CENAPROV dentro del desarrollo urbano del país y de la ciudad de Pereira en particular y serán objeto de análisis en el siguiente capítulo. 


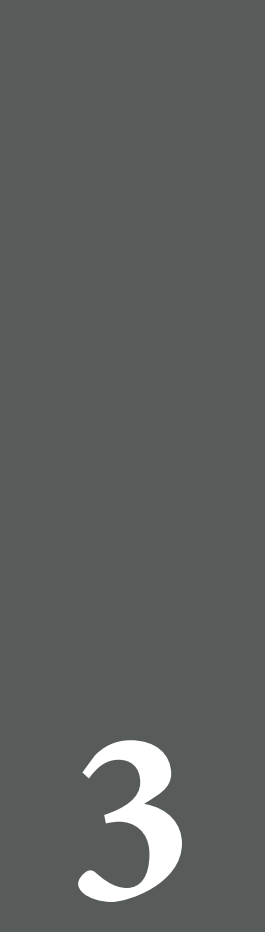

\section{CAPÍTULO TRES:}

La Central Nacional Provivienda Y LA LUCHA POR EL DERECHO A LA VIVIENDA URBANA 

Como se pudo describir en los anteriores capítulos, la problemática de la vivienda en Colombia afectaba directamente un gran número de pobladores a mediados del siglo XX. Pobladores que en su mayoría llegaban como consecuencia del desplazamiento y el conflicto en las zonas rurales, y otro tanto, en la búsqueda de nuevas oportunidades en los centros urbanos del país. Estos emigrantes engrosaron las estadísticas del déficit habitacional, convocando la búsqueda de diferentes maneras de solución a esta problemática. Soluciones que se darían dentro de los parámetros legales e ilegales, como lo demuestran los grupos invasores, piratas, urbanizadores públicos y privados, que en la ciudad de Pereira tendrían un importante dinamismo entre la década de 1970 y 1980.

Con el precedente anterior, el presente capítulo pretende reconstruir la influencia de CENAPROV en la ciudad de Pereira, teniendo en cuenta la relevancia nacional que tuvo dicha organización. Para ello, las fuentes que se emplean incluyen documentos oficiales, de prensa, fuentes hemerográficas, archivos personales y fuentes testimoniales. Aunque es difícil encontrar archivos documentales para el caso de Pereira, algunos integrantes de la junta directiva de la organización de viviendistas aún se encuentran con vida y lograron proporcionar información valiosa para reconstruir algunos hechos que se pueden contrastar con las fuentes documentales que se encontraron sobre CENAPROV en el archivo de esta entidad en la ciudad de Bogotá.

Respecto a la información sobre Pereira fueron hallados dos folios denominados AZ con información sobre CENAPROV de la ciudad. Dicha información fue clasificada de la siguiente manera para facilitar su citación en el trabajo: Dos carpetas denominadas AZ I Pereira y AZ II Pereira. Al interior de cada AZ se clasificó la documentación en las siguientes categorías: Correspondencia, Notariales, Denuncia, Prensa. 
De este modo para la citación se procederá a establecer en primer orden el Archivo de la entidad, es decir, CENAPROV, como segunda instancia la $\mathrm{AZ}$ correspondiente y por último el tipo de documentación de acuerdo a las categorías establecidas.

Cabe resaltar el valioso trabajo de la doctora Gloria Elvira Naranjo, docente de la Universidad Nacional de Colombia quien organizó el archivo de la entidad en la sede que se encuentra en el barrio Policarpa Salavarrieta de Bogotá y quien facilitó el acceso a documentos específicos relacionados con el desarrollo de la entidad en la ciudad de Pereira. Así mismo, este capítulo se estructurará en tres grandes momentos que según las fuentes primarias y secundarias permiten describir características puntuales en algunas temporalidades, haciendo más claro el accionar de CENAPROV en el país y en la ciudad de Pereira.

El primer momento va de la década de 1960 a 1970. En este periodo se da origen a la organización, a partir de los antecedentes de las disputas agrarias por la propiedad rural y su posterior traslado a la lucha de muchos desplazados del campo por la propiedad urbana en la ciudad. Allí se enmarcan las primeras formas de intervención de CENAPROV, siendo el barrio Policarpa Salavarrieta en la ciudad de Bogotá un importante bastión de la organización dadas las implicaciones sociales y políticas alrededor de su conformación.

Un segundo momento se delimita entre la década de 1970 y 1980 donde se logra consolidar la organización a lo largo del país con presencia en más de 38 municipios y con más de 200 barrios (Naranjo, 2011). En este periodo se promueven nuevas formas de acción por el derecho a la tierra urbana, especialmente las compras comuneras, realizadas con planificación previa y bajo los parámetros exigidos por la ley, sin desconocer las grandes dificultades que se tuvo con la entidad reguladora Superintendencia Bancaria. Cabe destacar que en este segundo momento es donde CENAPROV hace presencia en la ciudad de Pereira combinando algunas formas de intervención, como las compras comuneras, las tomas de terrenos o invasiones e incluso los convenios de algunos planes de vivienda con el ICT.

El tercer momento se delimita del año de 1980 en adelante, siendo allí donde inicia el declive que repercute en la disminución de la fuerza social y política de la Central Nacional Provivienda. Esto gracias a la confluencia de diferentes factores, como problemas a nivel interno organizacional, el incremento de urbanizadores privados, la violencia sistemática en contra de la Unión Patriótica, la injerencia de las juntas 
de acción comunales en los barrios, entre otros.

\section{La Central Nacional Provivienda en la década de 1960}

La Central Nacional Provivienda, también conocida como CENAPROV o Provivienda, es definida según Gloria Elvira Naranjo como "la primera organización social de destechados, aún vigente e integrada por desplazados forzados que buscaron refugio y obtuvieron vivienda propia mediante acciones colectivas" (Naranjo, 2014). Esta organización se define como una entidad sin ánimo de lucro, que adquirió su personería jurídica ante el Ministerio de Justicia bajo la resolución número 001458 del 5 de mayo de 1961 (Archivo CENAPROV Pereira AZ II -Notariales- Ver Anexo 2).

Para comprender suficientemente el accionar de la Central Nacional Provivienda en el país, es importante reseñar las luchas populares por la colonización rural, de donde se hereda gran parte de las disputas por la vivienda urbana, según se encuentra consignado en la revista de la X asamblea de CENAPROV (Central Nacional Provivienda, 1983). En otras palabras, para comprender la iniciativa entorno a la lucha por la vivienda que CENAPROV emprendió bajo la dirección del Partido Comunista Colombiano, se debe dar una mirada al problema agrario, a partir de la década de 1920, donde campesinos, aparceros y agregados empezaron luchas por la tierra en contra de latifundistas y hacendados por el derecho a la propiedad. Situación retratada por Jorge Orlando Melo, cuando refiere que

"el problema agrario resurgió en la década de 1920. En zonas de latifundios, (...) organizaciones de asalariados o aparceros buscaban mejorar sus condiciones laborales (...) los problemas surgían del choque entre terratenientes y colonos, debido a la falta de claridad en los títulos de propiedad" (Melo, 2018).

Estos enfrentamientos brindan un antecedente que permite ubicar la tierra como centro de procesos de confrontación entre quienes la poseían incluyendo el Estado y quienes no tenían acceso a ella.

Estas luchas, según el urbanista Jacques Aprile, aunque carentes de fuerza, dieron origen a diferentes movimientos agrarios con una conciencia política reivindicativa por el derecho a la tierra y a unas garantías sociales mínimas frente a los hacendados y latifundistas (Aprile-Gniset, 1992). Este conflicto dio paso también al fortalecimiento del campesinado que se vio reflejado en el establecimiento de pequeñas fincas o parcelas en la vertiente y laderas de la cordillera central, 
principalmente en el viejo caldas que a la postre se convertiría en el más importante centro agrícola cafetero del país (Aprile-Gniset, 1992).

De igual manera, surgieron movimientos como las autodefensas campesinas o el movimiento armado agrario que permitieron adquirir una experiencia de lucha social y política frente al problema de la tierra (Central Nacional Provivienda, 1983). Aspectos como los lotes baldíos y la discusión sobre las leyes que daban garantías a los colonos del usufructo de estas tierras, permitieron un mayor empoderamiento de campesinos y aparceros que conllevó a un enfrentamiento directo contra los hacendados o terratenientes que buscaban despojarlos de sus tierras ya mejoradas y cultivadas (Central Nacional Provivienda, 1983).

Este precedente es relevante, debido a que muchos de los líderes que hicieron parte de las disputas agrarias, incorporaron la experiencia adquirida en este tipo de luchas hacia la ciudad. Fortaleciendo con ello la base para las organizaciones de viviendistas en su lucha por el suelo urbano como sucedería con CENAPROV, que iniciaba su accionar bajo la dirección del Partido Comunista Colombiano por la década de 1960, como quedó consignado en la breve reseña que hace Gilma Mosquera Torres para la revista de la X asamblea nacional de CENAPROV en 1983 (Central Nacional Provivienda, 1983).

Las grandes dificultades de los centros urbanos y el crecimiento de problemáticas como la informalidad laboral, los inquilinatos, los barrios de invasión y el encarecimiento de la tierra urbana, fomentaron el surgimiento de grandes cinturones de miseria en las ciudades e incrementaron la demanda de servicios de todos los niveles. Situación que, aunada a una importante, aunque insuficiente oferta estatal de vivienda por parte de ICT o el Fondo de Vivienda Popular, generó un déficit habitacional de orden cuantitativo y cualitativo como se procuró demostrar en el capítulo anterior.

Cabe aclarar, que los nuevos moradores en condición de deficitarios en su gran mayoría se encontraban ejerciendo trabajos informales e inestables. Ocupándose como albañiles, carpinteros, zapateros, trabajadores independientes, trabajadores de la metalurgia, vendedores ambulantes, celadores (Torres Carrillo, 1993). Lo que constituyó una de las características socioeconómicas común a las personas que habitaron los "centros de inquilinos" de los planes de vivienda de CENAPROV en el país y en Pereira, donde según se describe en la prensa de la época, la mayoría de familias que habitaban los barrios de CENAPROV eran familias de obreros y artesanos (El Diario 3 diciembre 1976), de origen 
humilde, estrato bajo, trabajadores y pueblo en general sin mayores recursos económicos (Ayala, 2016).

La población migrante y desplazada incrementó la densidad poblacional en los principales centros urbanos y ciudades intermedias del país. Al mismo tiempo fomentó nuevas formas de acción por el espacio urbano, especialmente entre la década de 1950 y 1980. Años en los que se consolidaron movimientos viviendistas bajo diferentes modalidades, como la ocupación ilegal de terrenos especialmente en las laderas de las ciudades y a orillas de los afluentes hidrográficos, las compras colectivas o comunales de terrenos dirigidos por urbanizadores piratas u organizaciones constituidas legalmente, como sería el caso de CENAPROV, organización que también promovió movilizaciones por la legalización, desenglobe de los terrenos y adquisición de los servicios públicos (Central Nacional Provivienda, 1983).

De esta manera se concreta un proceso que para Jacques Aprile se denomina la colonización urbana, en sus palabras: "se pasa de la colonización de los baldíos por la de los ejidos. Las tierras baldías de la nación a las ejidales de los cabildos" (Aprile-Gniset, 1992); lo que significa pasar de la ocupación de grandes terrenos de la nación a la de otros más pequeños con jurisdicción de los municipios.

Se puede señalar que la primera forma de lucha por la vivienda que experimentó la organización se dio bajo la modalidad de tomas de terrenos de manera ilegal, lo que se denominó ocupaciones de hecho, solidarias o recuperaciones de terrenos y que constituyeron, para la Central Nacional Provivienda, sus primeras experiencias organizativas en la ciudad de Cali.

Según Carlos Arango Zuluaga, para 1940 la ciudad de Cali sufría los embates del éxodo masivo de la población rural a causa de las disputas bipartidistas, allí se inscriben las primeras acciones de algunos líderes sociales de izquierda como Julio Rincón y Alfonso Barberena quienes se destacaron por hacer frente al problema de vivienda. Estos líderes, buscaron organizar el flujo de nuevos moradores llegados a la urbe, puesto que sin ningún tipo de orientación profesional, ocupaban cualquier clase de terreno, levantando pequeños ranchos, cambuches de plásticos o cartones, sin servicios públicos ni vías de acceso, debido a que lo urgente se convirtió en el objetivo inmediato: solucionar su problema habitacional (Arango Zuluaga, 1986). Por esta razón, Julio Rincón y Alfonso Barberena organizaron la comunidad para mejorar sus condiciones de habitabilidad liderando grandes luchas por el derecho 
de los desposeídos a la tierra y al trabajo desde el concejo municipal y la asamblea departamental del Valle (Naranjo, 2011).

Cali se caracterizó por liderar los primeros procesos organizativos de destechados por una vivienda digna, a través de comités viviendistas que unían diferentes tipos de luchas: Las ocupaciones de hecho especialmente en terrenos ejidales, luchas jurídicas y acción cabildante desde el concejo. Según Carlos Arango, las familias que ocupaban terrenos, al mismo tiempo llenaban los formularios para la adjudicación del respectivo lote, cuyo único requisito en la época era demostrar que no tenían vivienda (Arango Zuluaga, 1986).

Las ocupaciones de hecho en terrenos ejidales implicaron además de la toma del terreno su adecuación para ser habitado. Así lo demuestran los testimonios registrados por los integrantes de CENAPROV en el desarrollo de los diferentes proyectos de vivienda que lideraron en la ciudad de Pereira y así lo registraron Carlos Arango Zuluaga y María Elvira Naranjo en el resto del país. Elemento de suma relevancia como característica primordial de la colonización popular y que es descrito suficientemente por Jacques Aprile cuando afirma:

Colonización urbana popular y solidaria, concertada y organizada, es el desmonte de un pastizal para transformarlo en barrio. Colonización colectiva son los convites dominicales para realizar unos indispensables banqueos en laderas muy inclinadas. Luego, es preciso abrir las calles considerando la topografía, y en pendientes muy adversas trazar unas escaleras perpendiculares a las curvas, las cuales se consolidan reforzando la parte vertical de los peldaños con llantas gastadas. Habrá que buscar una fuente de agua potable, de pronto será necesario cavar pozos de varios metros de profundidad, organizar la distribución, nombrar un fontanero, instalar lavaderos y baños colectivos, y casetas para sanitarios comunitarios encima de alguna cañada. Posteriormente corren por las calles las mangueras de la primera red de distribución doméstica, se abren los surcos para la evacuación de las aguas residuales; desde la red primaria circula la energía hasta unos postes en guadua, a los cuales cada familia conecta sus alambres. Grupos de niños están nivelando y limpiando la maleza de la plazoleta del barrio; poco después en su centro funciona la primera escuela bajo una ramada, caseta comunal de las reuniones y las fiestas. Desde el Caribe hasta Ipiales, desde los años 1940 hasta 1980, miles de barrios nuevos surgen en cien ciudades (Aprile-Gniset, 1992).

Teniendo en cuenta que el proceso que adelantó la Central Nacional Provivienda encaja con la estrategia de colonización popular urbana mencionada con anterioridad, es necesario también aclarar que a mediados del siglo XX, muchos colonizadores urbanos fueron cooptados por Julio Rincón y Alfonso Barberena en la ciudad de Cali para lograr 
construir una organización de viviendistas denominada PROVIVIENDA que involucró diferentes grupos de personas espontáneas que lideraron las disputas por la legalización de nuevos barrios de ocupación ilegal. De esta forma, se empezó a consolidar una organización que brindó la orientación necesaria para que quienes carecían de vivienda tuvieran un respaldo de hecho y jurídico frente a su situación. Es así como se originó la organización objeto de estudio en esta investigación.

Es importante anotar que en el momento que se originó PROVIVIENDA, no existía legislación que regulara los urbanizadores. Hecho que podría presumirse, fue un factor que detonó el surgimiento de diferentes grupos de viviendistas invasores que ocuparon terrenos a lo largo de diferentes ciudades del país. Sólo hasta 1968 se creó la ley 66 por la cual se otorgan facultades reguladoras a la Superintendencia Bancaria para vigilar e inspeccionar los temas relacionados con la vivienda y los grupos urbanizadores.

Además del vacío jurídico en el ámbito de la urbanización, el país se encontraba permeado por acontecimientos sociales y políticos que impactaron el ámbito electoral, es el momento del Frente Nacional, se conformó en esta época la Unión Nacional de Oposición, reconocido movimiento de izquierda que aglutinó diversas organizaciones como el MOIR ${ }^{25}$, MAC $^{26}$ y el Partido Comunista Colombiano del cual era integrante Julio Rincón. La resistencia de sectores políticos divergentes al Frente Nacional como la CSTC ${ }^{27}$ orientada por el PCC $^{28}$ y el impacto de la revolución cubana, abonaron el terreno para el fortalecimiento ideológico de la naciente organización de viviendistas y su forma de operar en el país.

Aunque no son claras las razones por la cuales PROVIVIENDA no prosperó en la ciudad de Cali, se pueden considerar dos situaciones relevantes, como fueron el asesinato de Julio Rincón en 1951 y el hecho de que la organización, según Carlos Arango, cayó en manos de oportunistas. La experiencia rápidamente se traslada a la ciudad de Bogotá, de la mano de Alfonso Barberena en reunión efectuada el 16 de febrero de 1959, en la que se crea el centro de inquilinos seccional Bogotá y dos años después adquiere su personería jurídica ante el ministerio de justicia el 5 de mayo de 1961 bajo el nombre de Central Nacional Provivienda (Arango Zuluaga, 1986).

25 Movimiento Obrero Independiente y Revolucionario.

26 Movimiento Amplio Colombiano.

27 Central Sindical de los Trabajadores de Colombia.

28 Partido Comunista Colombiano. 
En la capital del país se estructura paulatinamente la organización que rápidamente haría presencia en otras ciudades y municipios, conservando el mismo objetivo de orientar a los destechados en la adquisición de vivienda y unificar acciones por los derechos a la propiedad del suelo urbano por parte de los más necesitados (Naranjo, 2011). A la cabeza de la organización estaba en este momento Mario Upegüi, importante líder de izquierda quien formó parte de la Central Nacional Provivienda desde sus comienzos y abanderó políticamente la lucha por los destechados como concejal por el PCC en la capital, y quien además tendría gran injerencia en el desarrollo de Provivienda en la ciudad de Pereira (Oviedo, 2012).

El primer barrio conformado por CENAPROV en Bogotá fue el barrio Las Colonias. No obstante, la conquista barrial más significativa por sus implicaciones sociales y políticas, al constituir una lucha emblemática para la organización, fue la del barrio Policarpa Salavarrieta ubicado en el centro de la ciudad de Bogotá, cuya construcción se adelantaría bajo la modalidad de toma de terrenos, lo que produjo enfrentamientos directos con la policía que dejaron como resultado 4 muertos y más de 100 heridos entre los que se encontraban algunos niños, hecho que se registró como el "viernes sangriento", dado que ocurrió el viernes santo de marzo de 1.961 (Naranjo, 2011).

Esta toma, que daría origen al barrio Policarpa Salavarrieta, fue registrada por diferentes fuentes entre ellas el periódico $L a$ Voz que publicó en su portada: “iMASACRE OFICIAL EN BOGOTÁ! 4 muertos, 100 heridos y 80 presos en el Policarpa. Lunes sepelio de las víctimas" (Naranjo, 2011).

Este barrio ha sido objeto de estudio de diferentes investigaciones entre las que se destaca el texto Barrio Policarpa Salavarrieta, 50 años, de la investigadora María Elvira Naranjo o el texto de Alfonso Torres Carrillo, Estudios sobre pobladores urbanos en Colombia: Balance y perspectivas (Torres Carrillo, 1993). En dichos estudios se registran los pormenores de la ocupación que se dio a escasas cuadras del capitolio y la plaza de Bolívar de la capital del país, allí se describen las características organizativas bajo las cuales adelantaron la conformación de los barrios multitudes de personas sin techo pertenecientes a la Central Nacional Provivienda. Se puede observar aquí un accionar estratégico preparado anticipadamente por los viviendistas, debido a que en reuniones se planeaba desde la toma de un terreno hasta la manera como se debía enfrentar a la fuerza pública y la forma como se haría la presión 
mediática y política por la legalización de los predios (Naranjo, 2011).

En la ocupación del terreno del barrio Policarpa Salavarrieta concurrieron diferentes factores que se pueden inferir en el análisis del libro de Gloria Elvira Naranjo. Factores relevantes dentro del accionar estratégico de la organización a nivel nacional que podrían enumerarse de la siguiente manera:

1. Ubicación de terrenos ociosos o ejidales.

2. Estudios urbanísticos por profesionales vinculados a la organización.

3. Orientación a los destechados que ya habían sido desalojados en otros lugares.

4. Planeación cooperativa alrededor de los pormenores de la ocupación, (estrategias, tiempos, materiales de construcción, vigilancia, toma de agua y de energía, estrategias de enfrentamiento ante el inminente desalojo por parte de las autoridades).

5. Resistencia y orientación política por el partido comunista (Naranjo, 2011).

Ajustándose a esta ruta se produjo la consolidación del barrio Policarpa Salavarrieta. Fue clave la resistencia de la comunidad, su organización en tareas conjuntas, la presión mediática y el esfuerzo de sus líderes no sin enfrentar como es lógico problemas de índole judicial debido a las órdenes de captura que recayeron sobre muchos de ellos. La toma del barrio Policarpa Salavarrieta fue exitosa, sus moradores lograron conseguir su legalización cuando se escrituraron los predios bajo la figura de posesión sobre el terreno (Naranjo, 2011).

Rápidamente este tipo de luchas se fue replicando en diferentes ciudades a lo largo y ancho del país bajo la dirección de la organización y la participación de los diferentes centros de inquilinos, como se documenta en la revista del X Congreso de CENAPROV en 1983 (ver Gráfico 4) donde se aprecia el incremento de los Centros de Inquilinos por todo el país.

La multiplicación de Centros de inquilinos al interior de las ciudades colombianas, se gestó desde la ciudad de Bogotá, como una manera de organizar las comunidades y al mismo tiempo posibilitar desde la capital las asesorías y orientaciones correspondientes a los líderes locales y regionales de modo que las personas en condición de déficit de vivienda pudieran vincularse a la organización. A partir de allí, en muchas ciudades del país como Pereira se empezarían a adelantar acciones colectivas por la solución de vivienda, utilizando las diferentes acciones conocidas como lo fueron: las ocupaciones de terrenos ociosos y las compras comuneras, todo ello de la mano de la asesoría jurídica y la acción cabildante de CENAPROV desde la ciudad de Bogotá. 


\section{Gráfico 4: Multiplicación de los centros de inquilinos de la Central} Nacional Provivienda a nivel nacional.

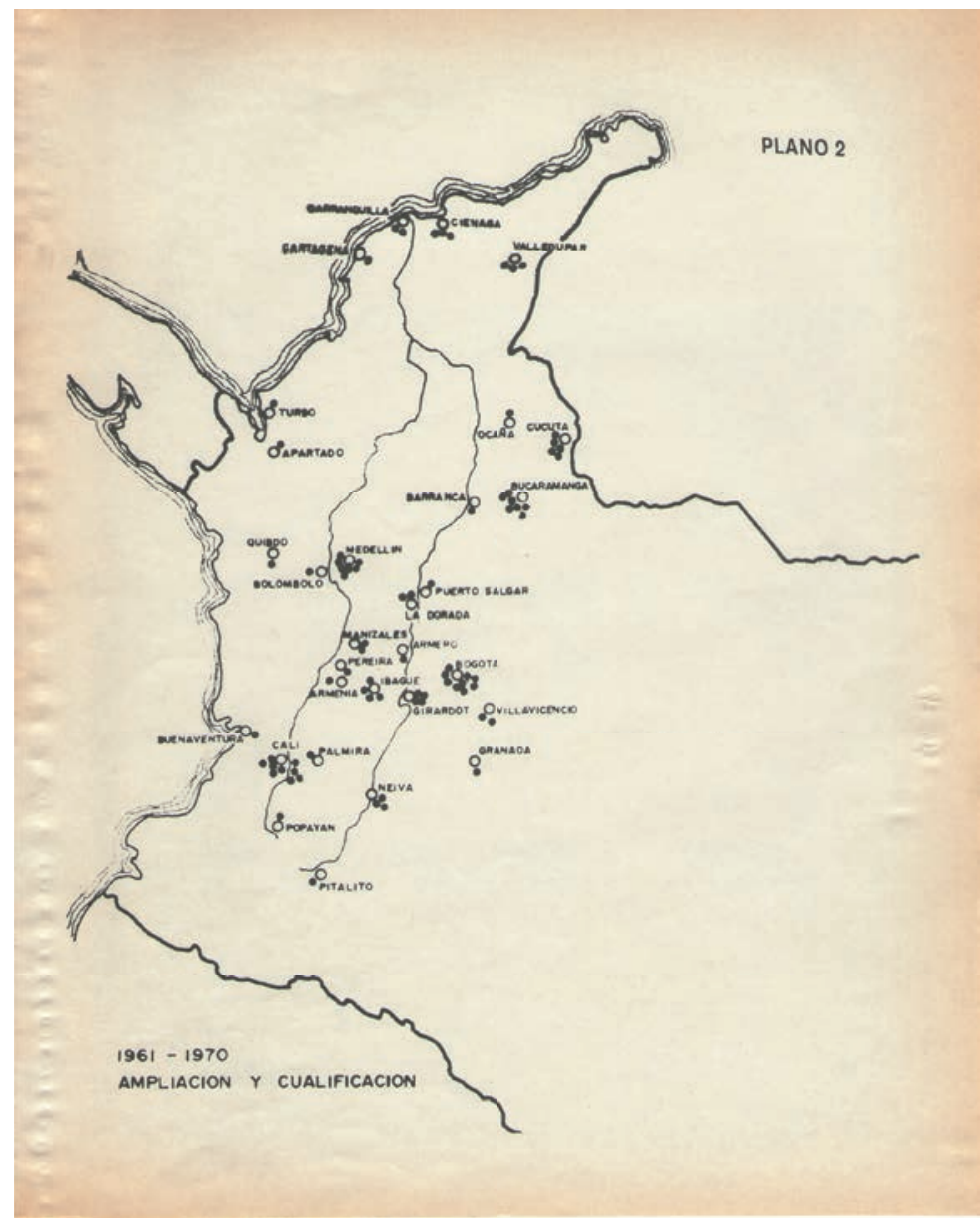

Fuente: Imagen tomada de la Revista del X Congreso Nacional CENAPROV 1983 (Central Nacional Provivienda, 1983).

\section{La influencia de la Central Nacional Provivienda en Pereira}

La multiplicación de los centros de inquilinos de CENAPROV a lo largo del territorio nacional a partir de la década de los 60, conlleva de manera significativa la demanda de vivienda por parte los nuevos moradores en ciudades como Pereira, ubicada en el centro de la región occidental de Colombia. Esta ciudad, como ya se explicó en el capítulo 
dos, padeció un crecimiento demográfico acelerado a mediados del siglo XX, derivado de procesos migratorios producto de la violencia en el viejo Caldas y de constituirse en un lugar receptor de habitantes debido a su atrayente crecimiento económico, como consecuencia de su privilegiada posición geográfica, además de constituir un lugar generador de alternativas económicas para los recién llegados (Torres Tovar, 2009, pág. 241).

La situación migratoria de Pereira a mediados de sigloXX y su desborde demográfico sirvió de acicate para que organizaciones de viviendistas, urbanizadores piratas e invasores iniciarán procesos organizativos con diversas comunidades en distintas zonas de la ciudad, para resolver de manera informal el déficit habitacional que la administración municipal de la época era incapaz de suplir. Hecho que la prensa oficial de la ciudad retrató en algunos momentos, cuando referían la problemática de las invasiones piratas en Pereira y Dosquebradas, denunciando que grupos de personas debidamente organizadas llevaban a cabo tomas de terrenos de propiedad del municipio y de particulares (El Diario, 1975).

Así, desde la periferia, la ciudad empezó a adquirir una nueva forma; los promotores de vivienda ubicados a las orillas de los ríos y quebradas o en terrenos ejidales, empezaron a conformar barrios autoconstruidos de manera informal que a la par de los barrios construidos por programas como el ICT y el Fondo de Vivienda popular, empezaron a trazar las líneas de lo que constituyó unos años después la complejidad urbana de la ciudad. De acuerdo con Beatriz Rojas:

Buscando solucionar su problema de vivienda, la gente construyó sus casas en terrenos que no contaban con vocación urbanística, pues fueron las tierras de menores costos, marginales por sus restricciones para la ocupación, las que fueron destinadas de forma irresponsable por estos actores de la urbanización, incluso con el beneplácito de la administración local (Rojas B. E., 2003, pág. 44).

Siguiendo la tesis de Carlos Alberto Torres, para comprender suficientemente la realidad social urbana de la ciudad colombiana, es importante sobrepasar la dicotomía entre construcción formal de vivienda y construcción informal, comprendiendo que ambas categorías están intrínsecamente unidas ya sea porque los mercados alrededor de ambas se relacionan o porque la vivienda y el suelo a través del tiempo cambian de categoría. En otras palabras, algo que inició como un asentamiento ilegal se puede legalizar con el paso de los años o viceversa (Torres Tovar, 2009, pág. 42). 
Siguiendo esta línea de pensamiento, es inevitable considerar que tanto la formalidad como la informalidad, están implicadas en el crecimiento urbano de la ciudad de Pereira. Y todavía más, en algunas ocasiones interrelacionadas, como se puede notar en la prensa de mediados de los años 70, donde de un lado del establecimiento se dio respaldo a algunos grupos de invasores para que no fueran desalojados de los terrenos propiedad del municipio y de otro lado se los desaprobaba, como consta en noticia publicada en el periódico El Diario el 26 de noviembre de 1.975, donde se aprueba por parte del Concejo Municipal lo siguiente:

"Dígase al señor alcalde que cuando terrenos del municipio sean INVADIDOS se abstenga de ordenar el DESALOJO”

\section{DESACUERDO}

Con relación a la anterior moción del cabildo el alcalde doctor César Gaviria Trujillo se mostró en total desacuerdo y declaró oficial y públicamente que hará defender la propiedad privada u oficial, pues ello lo contempla la constitución y las leyes de la república (El Diario, 26 Noviembre 1975).

Del mismo modo, son constantes los llamados de atención por parte de la oficina de planeación municipal a las organizaciones viviendistas piratas a detener la ejecución de sus proyectos de vivienda, por no tener el permiso de la Superintendencia Bancaria según ley 66 de 1968, además de no contar con la aprobación por parte de la misma oficina de planeación para la ejecución de sus proyectos (El Diario, 13 Mayo 1976). $\mathrm{Al}$ punto que se adoptaron medidas judiciales contra los urbanizadores que no cumplieran los mínimos requisitos legales y se denunció que algunos políticos promovían la ejecución de muchos de estos planes de vivienda de manera irresponsable, pues se construyeron barrios en zonas de alto riesgo, sin agua, energía y sin vías de acceso (El Diario, 24 Mayo 1976).

La relación entre formalidad e informalidad era tan latente para la época que, hasta el modelo de vivienda autoconstruida explicado en el capítulo anterior, fue puesto en práctica tanto por destacados grupos de urbanizadores piratas a nivel local y por los programas del ICT y FVP a partir de 1961 cuando inicia la construcción del barrio Cuba. Esta zona presentó el mayor proceso de asentamiento de población en la década de 1960 (Rojas B. E., 2003, pág. 44).

Según la tesis de Beatriz Elena Rojas, el asentamiento denominado San Joaquín ubicado en el suroccidente de la ciudad cerca al Barrio Cuba fue creado en 1950. Pero su proceso de consolidación y expansión 
se dio en la década de 1970 cuando se desarrolló un rápido proceso de urbanización, en el que casi la totalidad de barrios de dicha comuna fueron producto de urbanizaciones piratas y procesos de invasión como el del Barrio la Isla de Cuba (Rojas B. E., 2003, pág. 42). En esta década, el 32\% de la población del municipio 96.071 habitantes, presentaban un alto índice de necesidades básica insatisfechas como la carencia de vivienda, a la cual no pudo acceder la población de menores recursos debido a la implementación de requisitos para los beneficiados y el manejo político que se le otorgó a entidades como el Fondo de Vivienda Popular (Rojas B. E., 2003, pág. 44).

De este modo, la relación entre las carencias de los habitantes y la política no se hizo esperar. Y la promesa de vivienda a cambio del apoyo electoral empezó a manifestarse a tal grado que hasta en la toponimia de los Barrios quedaría latente la huella de sus promotores, como lo es el del barrio Sinaí, nombre de un reconocido líder viviendista de la época o el barrio El Plumón, que era el apodo de Oscar Vélez Marulanda, padrino político de la invasión (Contreras, 2018). En palabras de Beatriz Rojas:

(...) la población de menores recursos, por lo general marginada de los diferentes procesos de mejoramiento, se constituía como un sector de alta vulnerabilidad debido a su bajo acceso a servicios como salud y educación. Condiciones que fueron aprovechadas por cierto grupo de particulares para satisfacer sus intereses económicos y marcadamente políticos, ofreciendo planes de vivienda con grandes facilidades de pago en diversos sectores de la ciudad bajo procesos de autoconstrucción y con el voto como garantía de pago. Bajo estas características, se desarrollan en la ciudad amplias zonas en la ribera del río Otún, San Nicolás y lo que hoy son las comunas El Oso, San Joaquín y Villa Santana (Rojas B. E., 2003, pág. 44).

Otra de las claridades que conviene considerar en este punto, es la concepción de barrio utilizada en la presente investigación, debido a que el resultado del accionar de la Central Nacional Provivienda en el departamento de Risaralda fue la conformación de aproximadamente 15 barrios. Carlos Alberto Torres, en su texto La ciudad informal, define al barrio como una unidad de análisis urbano, en el cual se pueden identificar la ciudad y sus habitantes, dicha unidad de análisis representa una porción del espacio urbano construido, reconocido y apropiado por la comunidad, quienes, desde su construcción procuran su mejoramiento y consolidación (Torres Tovar, 2009). Así de la mano de la concepción de territorio aportada por Gilberto Jiménez, en la cual, el territorio es aquel espacio apropiado y valorado a partir de la representación y el trabajo, el barrio constituye esa unidad orgánica 
identitaria o primer lugar de apropiación simbólica (Giménez, 1999) producto de la articulación de múltiples elementos físicos, naturales, económicos, políticos, sociales, culturales e ideológicos.

Se puede señalar, que los barrios construidos por CENAPROV se acogen a las características anteriormente mencionadas, en tanto las acciones que orientaba la organización llevaban a desempeñar un rol activo por parte de cada uno de sus asociados para la solución de las diferentes problemáticas. Asumiendo la vivienda como eje principal, del que se derivaron implicaciones políticas y organizativas inherentes a esta labor y que los llevó a transitar una delgada línea entre lo legal y lo ilegal. Así se podrá evidenciar en el desarrollo de los diferentes barrios, denominados de "nuevo tipo" que CENAPROV construyó en la ciudad y a lo largo del país.

En este punto, vale la pena resaltar el rol de CENAPROV como movimiento social de viviendistas, entendido, parafraseando a Touraine como la conducta colectiva organizada de un actor luchando contra su adversario por la dirección social en una colectividad concreta (Touraine, 2006). Visto desde esta dicotomía actor/adversario este movimiento viviendista estaría enfrentado en el plano social y político la incapacidad estatal por brindar oportunidades para la solución de vivienda a un amplio sector en condición de deficitaria. Del mismo modo, en relación a los movimiento sociales Mauricio Archila precisa: "Por movimientos sociales entendemos aquellas acciones sociales colectivas más o menos permanentes, orientadas a enfrentar injusticias, desigualdades o exclusiones y que tienden a ser propositivas en contextos históricos específicos" (Centro de estudios sociales de la Universidad Nacional de Colombia, 2001).

Ahora bien, como movimiento social de viviendistas CENAROV se distancia de los demás grupos de viviendistas, puesto que su objetivo era además de solucionar el problema de vivienda, desarrollar un proyecto político reivindicativo en cada uno de sus habitantes, que comulgaba con los principios ideológicos de izquierda frente a la lucha de clases, factor que lo llevo a consolidarse a lo largo y ancho del territorio nacional. Adicionalmente, las dinámicas orientadas por esta organización estarían debidamente reglamentadas y direccionadas desde unos estatutos y una estructura organizativa claramente definida a nivel nacional, departamental y municipal.

En este orden de ideas, la intención de la Central Nacional Provivienda, además de solucionar el problema habitacional de los 
destechados, era desempeñar un rol político bajo los principios que orientaba en ese entonces el Partido Comunista Colombiano. Es por ello que diferentes directivos de la organización para la década de 1970 y 1980 como Manuel Ayala, Fernando Botero, Miguel Castañeda, entre otros, coinciden que el objetivo principal no era únicamente ayudar a construir sus viviendas, sino empoderar a los inquilinos de los diferentes centros en la lucha por sus derechos, entre ellos el derecho a la tierra urbana en manos de la burguesía. Para alcanzar dicho objetivo, combinaban estrategias de orden legal e ilegal, como se puede rastrear en la forma que consolidaron los diferentes barrios en Pereira, La Virginia, Dosquebradas y Santa Rosa de Cabal, al igual que en el resto del país.

La Central Nacional Provivienda contaba con unos estatutos definidos, que sus directivos se encargaban de replicar al interior de los centros de inquilinos, como lo relata Manuel Ayala: "luego que las personas se afiliaron, había que explicarles cómo eran los estatutos, sus derechos, sus deberes, en que estaban metidos, eso lo hacíamos en reuniones periódicas en los diferentes centros de inquilinos" (Ayala, 2016). De igual manera los directivos y los nuevos afiliados eran debidamente carnetizados, así se pudo constatar en el archivo personal de Hernán Botero.
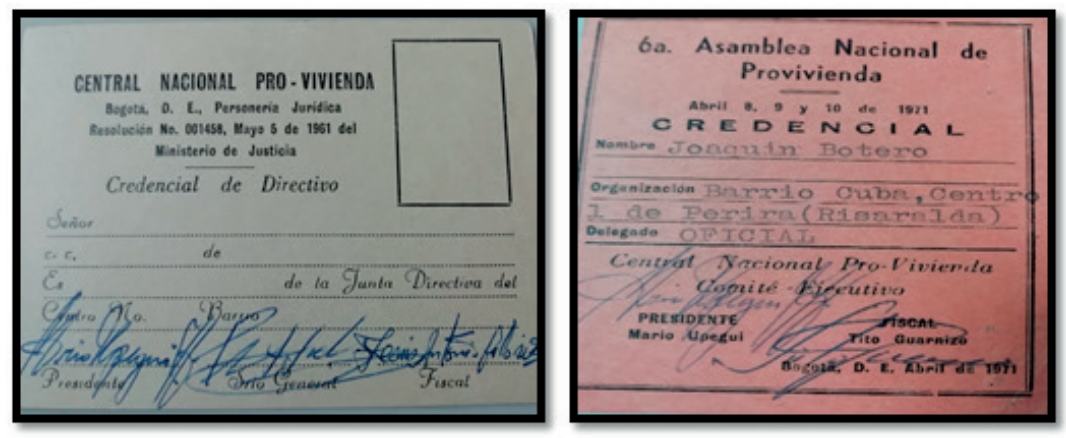

Fotografía 6: Carnés de Provivienda de Joaquín Botero, uno de los fundadores de CENAPROV en Pereira.

Fuente: Archivo personal de Hernán Botero.

Los estatutos y objetivos eran socializados a través de diferentes comunicados y revistas que realizaba la organización. De igual manera se discutían y se debatían en las diferentes asambleas nacionales, a las cuales asistían directivos de todas las ciudades o municipios en los que tenía presencia CENAPROV. Algunos de los elementos más importantes 
que contenían los estatutos de la organización en sus seis capítulos y que debían conocer los inquilinos eran los siguientes:

Art $1^{\circ}:$ El nombre de esta corporación es CENTRAL NACIONAL PROVIVIENDA, creada sin fines de lucro, siguiendo las normas de los artículos 44 de la Constitución Nacional de Colombia y 635 a 652 del Código Civil Nacional (Morales \& Puentes, 1996).

En el capítulo segundo, artículo cuarto se contemplan los objetivos de la organización a nivel nacional, que brindan un panorama de su intención con relación al accionar político por la solución de la vivienda, por tal razón se transcriben literalmente dada su importancia para esta investigación:

Art $4^{\circ}$ : Las finalidades que persigue la CENAPROV, son en general las siguientes:

a. Desarrollar una política permanente y eficaz tendiente a conseguir lotes de terreno en donde cada uno de sus socios pueda construir para su familia una casa de habitación propia.

b. Ejecutar los actos conducentes a la construcción de las viviendas, en los lotes que hayan sido adquiridos por la Central Nacional Provivienda o por sus socios a cualquier título.

c. Desarrollar por todos los medios lícitos posibles la solidaridad entre sus miembros, buscando asociar a las capas menos favorecidas de la colectividad.

d. Hacer investigaciones sociales a fin de tener conocimiento de los problemas de la colectividad y así poder plantear soluciones acertadas que correspondan a las capacidades de las diferentes capas de la sociedad.

e. Luchar para que los concejos municipales creen las cajas de vivienda popular y le den cumplimiento a la ley 61 de 1936, que destina un porcentaje del presupuesto municipal para vivienda popular. También exigir que se le dé cumplimiento a la ley 41 de 1948 y otras leyes, ordenanza y acuerdos similares, como una forma de impulsar los planes de vivienda popular, exigiendo la representación de miembros de la Central Nacional Provivienda en las directivas de las cajas de vivienda popular o institutos similares.

f. Desarrollar una lucha ante los concejos, asambleas y parlamento nacional por la obtención de terrenos y partidas para nuestra organización y por el aumento de las partidas y los personajes destinados a la construcción de viviendas populares.

g. Adquirir con particulares terrenos urbanizables para adjudicarlos entre los afiliados a la CNP.

h. Verificar las parcelaciones o urbanizaciones de estos terrenos, utilizando preferencialmente a sus miembros o por medio de contratos con particulares y denunciar los lotes ociosos, el acaparamiento y la especulación con los terrenos, con miras a obtener rebajas e impulsar la construcción de nuevos planes populares de vivienda.

i. Luchar por el mejoramiento de los barrios populares, porque sean dotados de servicios públicos tales como: agua, luz, teléfono, alcantarillado, casa cultural, 
escuelas, puestos de salud, salas cunas, canchas deportivas, etc.

j. Buscar los medios para que las familias de nuestros afiliados obtengan casa propia y cómoda, evitando la promiscuidad del tugurio y del inquilinato.

k. Formar comisiones con los miembros de esta corporación, de acuerdo con su arte, oficio o capacidades, a fin de conseguir una cooperación dinámica y eficaz en la construcción de habitaciones, en obras de urbanismo y construcción de servicios públicos. Así se buscará aunar a los albañiles, mecánicos, electricistas, profesores, artistas, deportistas, etc.

1. Propender por la educación de todos sus miembros, organizando cursos de alfabetización, dictando conferencias sobre temas sociales, económicos, de historia nacional y extranjera; capacitación en arte, el folklore y en general actos que tiendan a capacitar o enaltecer al pueblo colombiano.

NOTA: Para el cumplimiento de este punto se debe impulsar la construcción de una CASA CULTURAL en todos los barrios de Provivienda (Morales \& Puentes, 1996).

De acuerdo con lo anterior, la Central Nacional Provivienda facilitó un proceso de formación política de líderes del Partido Comunista (cuadros), quienes tenían capacitación constante en las direcciones políticas del partido no solo en asambleas nacionales sino internacionales, lo cual, dio pie a que se fortaleciera su lucha cabildante a nivel nacional y se consolidara el proyecto comunitario alrededor de los destechados de manera exitosa entre las décadas de 1970 y 1980.

Resulta evidente que la consolidación barrial de los proyectos de vivienda sin cuota inicial de la mentada entidad no surgió de forma espontánea o respondiendo únicamente a las carencias de algunos pobladores, sino que respondían a una estrategia cuyo direccionamiento político era dictaminado por los dirigentes barriales adscritos a la entidad. Teniendo presentes los lineamientos organizativos de la Central Nacional Provivienda conviene pasar a analizar en mayor detalle los procesos de conformación barrial que llevó a cabo en la ciudad.

\section{La Isla de Cuba}

Según entrevistas realizadas a algunos de los promotores de la Central Nacional Provivienda en Pereira como Jairo Mejía Vélez y Hernán Botero, dicha entidad inició su proceso organizativo en la ciudad a partir de la década del 60 con la llegada de dirigentes de la ANAPO como Gabriel Darío Londoño y el presidente de CENAPROV a nivel nacional Mario Upegüi, quienes de la mano de un importante líder comunitario llamado Joaquín Botero militante del partido Comunista e inspirados en la experiencia del Barrio Policarpa Salavarrieta en Bogotá, empezaron a desarrollar la estrategia de consolidación del primer centro 
de inquilinos en la ciudad de Pereira, bajo la dirección de la Central Nacional Provivienda, cuya primera sede estaba ubicada en la carrera 23 entre calle 72 y 73 sur occidente de la ciudad (Botero H. , 2018).

El desborde demográfico a mediados de siglo XX en la ciudad facilitó el surgimiento de invasiones y todo tipo de urbanizaciones piratas en los terrenos periféricos, principalmente en la zona sur occidental cercana al aeropuerto Matecaña. El albor del crecimiento de la ciudad en su periferia, específicamente en el suroccidente, puede ser evidenciado por la aerofotografía, la cual permite apreciar el desborde urbano de la ciudad en el año de 1.969 después de construido el Barrio Cuba. En dicho sector, en las que hoy día son las comunas San Joaquín, El Oso y Perla del Otún se concentró el accionar de la Central Nacional Provivienda con el 70\% de sus barrios autoconstruidos (Ver Fotografía 7).

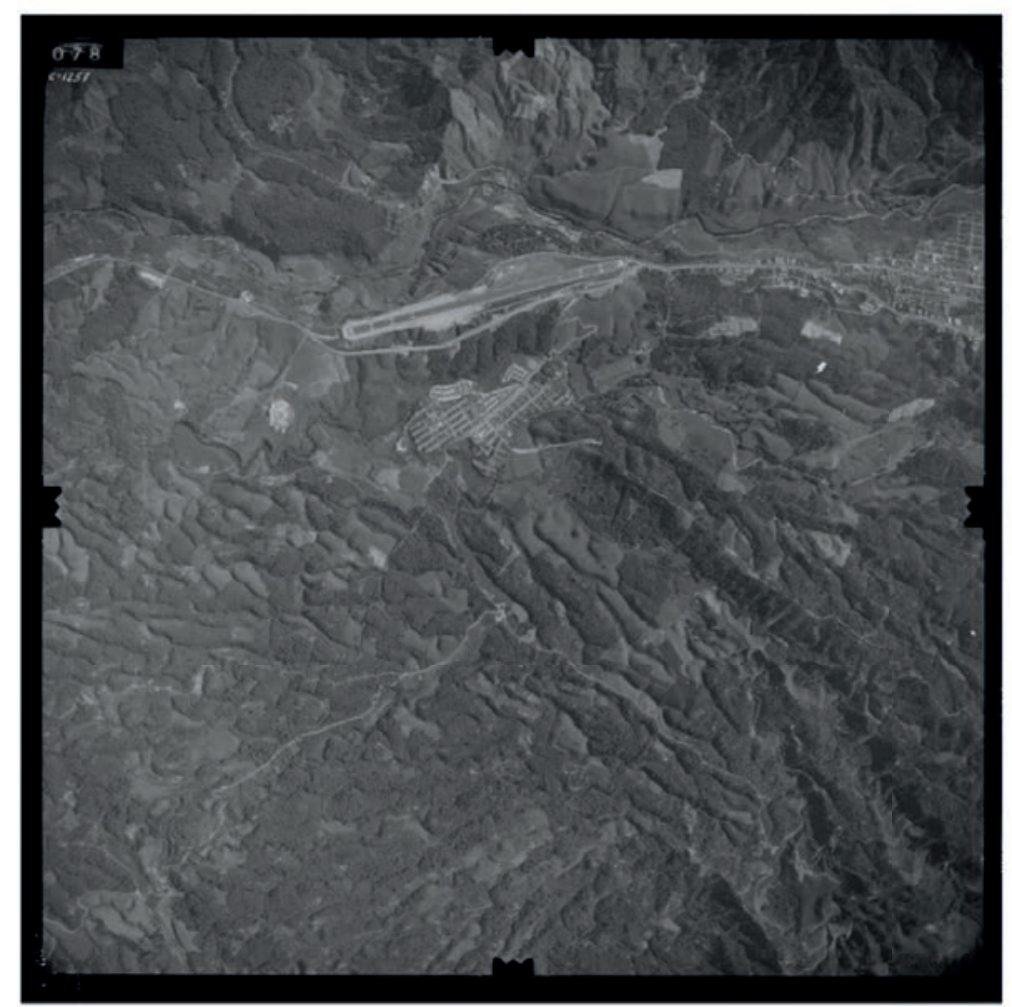

Fotografía 7: Aerofotografía del sector suroccidental de Pereira en 1969, donde se aprecia el inicio de conformación urbana.

Fuente: IGAC, Aerofotografía C-1257 foto 78, 1969. 
De esta manera, las actividades de CENAPROV en Pereira durante la década del 60 fueron de carácter eminentemente organizativo. Proceso que fue apoyado a mediados de los años 70 con la llegada de miembros del Partido Comunista Colombiano PCC y la Confederación Sindical de Trabajadores de Colombia CSTC, entre los que se destacaron Manuel Castillo (Diputado) y Carlos Alberto Benavides (Diputado), quienes según testimonios, llegaron a desarrollar la estrategia de organización política que sirvió de apoyo a la consolidación del accionar de la Central Nacional Provivienda en la ciudad (Botero H. , 2018).

Según relata Jairo Mejía Vélez actual dirigente de CENAPROV en Pereira, por aquella época, los dirigentes de CENAPROV al conocer las carencias en muchas familias de la ciudad en lo relativo al tema de la vivienda, gestionaron las condiciones para la creación del primer centro de inquilinos, en el cual se convocó a muchas familias que estuviesen pagando arriendo y tuviesen alguna capacidad de ahorro para afiliarse a la organización. Realizada la afiliación, las personas iniciaban un plan de ahorro mensual en la misma entidad hasta completar las sumas de dinero que permitiría la negociación de predios para la realización de los primeros planes de vivienda en el sur occidente (Mejía J. , 2016).

Como consta en la publicidad repartida por miembros de la organización en la época para promocionar los planes de vivienda y en documentos de archivo de la misma organización, las condiciones para la admisión de personas dentro de CENAPROV fueron:

- Ser cabeza de familia.

- No ser propietario de casa ni lote, es decir, no tener propiedad raíz.

- Dos fotografías tamaño cédula.

- Dos nombres de personas que conozcan al afiliado, con su dirección o teléfono.

- Asistir a las asambleas generales.

- Realizar un curso sobre Provivienda.

- Participar en las diferentes tareas en procura de la vivienda.

- Pagar la suma de $\$ 450.00$ por afiliación.

- Pagar la suma de $\$ 50.00$ mensuales para el sostenimiento de la organización. Nota: Con el valor de la afiliación se entrega el respectivo carné y los libros del curso. (Archivo CENAPROV, AZ I Pereira -Correspondencia-, Ver Anexo 3).

Las condiciones de admisión de los inquilinos a la organización de viviendistas, permiten apreciar tres componentes que conviene resaltar. El primero, su accionar va dirigido a captar personas de bajos recursos, sin propiedad y con deseo de adquirir vivienda a largo plazo; el segundo, formar políticamente y direccionar estratégicamente a sus integrantes 
fortaleciendo los lazos de la organización; y el tercero, impulsar el principio de auto - sostenibilidad de la organización a partir del recaudo de dineros a sus afiliados. Las condiciones descritas distan mucho de las establecidas por programas estatales como el ICT para adquirir vivienda en la ciudad. Según relata Jairo Arango, uno de los gerentes el ICT en la ciudad en los 80, las siguientes eran las condiciones para acceder al beneficio de la vivienda:

- Ser mujer u hombre cabeza de familia. La demostración de composición familiar a cargo de la verificación por parte de trabajadora social. Personas solteras no hacían parte del proceso.

- El deficitario debía poseer ingresos que no superaran los dos salarios mínimos. Pese a que no era requisito un trabajo formal, los trabajadores informales debían certificar ingresos por dos salarios mínimos a través de una carta autenticada.

- Pertenecer a los estratos cero, uno y dos.

- No tener o haber tenido propiedad raíz.

- No se permitía la venta de la vivienda hasta que no se cancelara la totalidad del crédito. Entre 15 y 20 años.

- La escritura se entregaba en patrimonio familiar.

- Estos requisitos eran evaluados por la sección de adjudicaciones y trabajo social (Arango Gaviria J. , 2018).

Es claro que en ambas entidades procuraban satisfacer la necesidad de vivienda en las clases más necesitadas. Sin embargo, el factor económico fue determinante a la hora de tener acceso a los beneficios por parte del ICT, pues la capacidad de endeudamiento establecida dejaba por fuera a muchas personas en condición de deficitarios, especialmente aquellas que subsistían de trabajos informales y que no estaban en capacidad de demostrar ingresos por 2 salarios mínimos y mucho menos la posibilidad de pagar una cuota inicial. Además de esto, como ya se anotó, las entidades estatales no fueron capaces de dar respuesta adecuada al déficit de vivienda del numeroso grupo de deficitarios de escasos recursos. De hecho, para la época, no eran muchas las soluciones de vivienda que se pretendían ejecutar por el ICT en comparación con otras ciudades del país.

Según la prensa local de la ciudad, para el año de 1975 con un poco más de 226.877 habitantes y 33.367 viviendas según censo de 1973 (Dane, 2018), Pereira ocupaba el modesto séptimo puesto en la proyección de construcción de vivienda por el ICT con un total de 366 soluciones, en comparación con Armenia 675, Barrancabermeja con 622, Cartagena con 1.785, Bogotá con 3.106 y en el primer lugar Cali con una proyección de 3.163 (El Diario, 22 Febrero 1975). De lo cual, 
nuevamente se puede colegir que muchas de las familias que quedaron por fuera de las proyecciones del ICT en Pereira en 1974 serían la base social que haría parte de las urbanizaciones de viviendistas en la ciudad, como la Central Nacional Provivienda entre 1970 y 1980.

Como ya se afirmó en el capítulo anterior, se considera que es aproximadamente hacia el año de 1973 cuando inicia el accionar de la Central Nacional Provivienda en el sur occidente de la ciudad de Pereira después del reconocimiento de su primer centro de inquilinos. A partir de ahí se inicia la lucha por la construcción de su primer Barrio llamado la Isla de Cuba por medio de la compra comunera, en la cual, los comités de inquilinos reunieron dinero para la negociación de terrenos privados aledaños al cementerio de la zona y a la quebrada el Oso cuya propietaria era la señora Laura Cano, como queda registrado en el documento de compraventa N-07841837, el 19 de noviembre de 1973, donde "comparece ante la notaría segunda de Pereira Laura Rosa Cano vda de Gomez y Joaquín Botero para hacer compra y venta de un lote de terreno ubicado en el paraje denominado San Joaquín, cerca al sector de cementerio del barrio Cuba jurisdicción del municipio de Pereira con una extensión de tres hectáreas aproximadamente, por la suma de 100 mil pesos (Archivo CENAPROV AZ II Pereira -Notariales-, Ver Anexo 4).

Después de negociado el predio se procedía a la distribución y utilización de lotes entre los inquilinos (Mejía J. , 2016). En otras palabras, después de la compra de los terrenos, se transforman los usos y funciones del suelo desconociendo la normativa y las obligaciones que toda entidad urbanizadora en Colombia debía cumplir para desarrollar un plan de vivienda, pese a que en el documento de compraventa se establece que se destinaría a construcción de vivienda popular. Por lo anterior, CENAPROV fue catalogada dentro de la tipología urbanística de la vivienda informal como un urbanizador pirata.

Es importante resaltar la diferencia entre los urbanizadores piratas y los viviendistas, dado que, en muchos testimonios oficiales, este concepto se confunde fácilmente. El principal elemento que los diferencia, es el ánimo de lucro de los urbanizadores piratas que, por aquella época (1970-1980), igualmente hicieron importante presencia en la ciudad, además sus planes de vivienda en muchos casos adolecían de estudios urbanísticos profesionales que determinaran la viabilidad de la urbanización.

Por su parte, CENAPROV como organización de viviendistas 
debidamente legalizada, sostenía una labor estrictamente social y política a favor de los destechados de la ciudad, esto quiere decir, que dentro de sus objetivos no se contemplaba el lucrarse u obtener algún beneficio económico con el desarrollo de los planes de vivienda, de ahí la facilidad con que sus afiliados podían acceder a los planes de vivienda y llevar a cabo las compras comuneras. Su accionar se desplegaba en torno de las acciones colectivas para la consecución de los terrenos y los servicios que requerían los barrios. De igual manera, fue destacado su rol político alrededor de la lucha urbana por el empoderamiento de los derechos sociales, argumento que los diferencia notablemente de los demás grupos de urbanizadores piratas.

En ese orden de ideas, dentro de la organización, sus miembros no aceptan ni han estado de acuerdo con la denominación que les señalaba como viviendistas pirata, pues son una entidad con personalidad jurídica y una declarada función social que consistía en desarrollar una política permanente y eficaz destinada a conseguir lotes de terrenos para que cada uno de sus miembros pudiese adquirir su casa de habitación propia (Torres Carrillo, 1993). Esta idea que no es ajena al argumento planteado por Carlos Alberto Torres en su texto La ciudad informal, al afirmar que la informalidad no necesariamente es sinónimo de ilegalidad, pues puede ser entendida como un fenómeno social, económico, ideológico, político y cultural, por medio del cual la comunidad busca solucionar sus carencias, a través de acciones que los colocan por fuera de los marcos normativos y legales convencionales (Torres Tovar, 2009). Así lo puede corroborar el testimonio de Miguel Castañeda, concejal de Pereira por la Unión Nacional de Oposición en 1974 y promotor de Provivienda en la ciudad:

Nosotros teníamos en Provivienda varias opciones, o la toma sin compra ni nada. Averiguábamos previamente en los lotes o los sitios como estaba la situación. Para así de esa manera lograr con los afiliados a la Central Nacional Provivienda, hacer una lista, hacíamos reuniones semanales, y teníamos una pequeña cuota para los gastos de papeleo y las visitas que había que hacer a la alcaldía o al concejo. Entonces si había una finca que era urbanizable, hacíamos los estudios pues teníamos compañeros que eran topógrafos o eran ingenieros y arquitectos, y nos ayudaban en la planeación. Y de esa manera empezábamos nosotros el trabajo de concientizar a la gente que había la opción de negociar un lote o una finca, o tomárnosla, porque nosotros en esa época la consigna era dotar de vivienda a los destechados así fuera como fuera. Y si era con negociación con la autoridades municipales o departamentales se hacía, o sino también se tomaba la tierra. Y eso lo hicimos como política de la Central Nacional Provivienda, y fue así como construimos infinidad de barrios en el país (Castañeda, 2017). 
De hecho, según versión del señor Francisco Londoño, secretario de planeación municipal de Pereira entre 1974 y 1978, a muchas invasiones como la del Plumón y planes de vivienda pirata como la de la Isla de Cuba, se les facilitó su tránsito de la informalidad a la formalidad a partir de la aplicación de los principios de John Turner sobre la autoconstrucción y la concepción de desarrollo progresivo de dichas formas de urbanización, en la cual se confiaba a los pobladores la construcción de sus viviendas y se les asesoraba en el cumplimiento de unas directrices urbanísticas mínimas en lo relativo a líneas de las fachadas, zonas comunes y vías de acceso a los barrios (Londoño Marulanda, 2018).

Es hacia el año de 1973 cuando el plan de vivienda pirata del Barrio La Isla de Cuba se empieza a gestar a partir de la compra de los terrenos, su ocupación y posteriormente la participación decidida de la comunidad a través de convites y bazares en los cuales se daba inicio a la adecuación de terrenos y construcción de viviendas. Actividades gestadas de la mano de líderes como Joaquín Botero y la asesoría del comité técnico de ingenieros y arquitectos de la misma organización de viviendistas CENAPROV que permitió sacar adelante dicho plan de vivienda fundado oficialmente en el año de $1974^{29}$ y que benefició a 220 familias.

Su nombre: la Isla de Cuba, según algunos testimonios se debió a la proximidad con el Barrio Cuba y al estar circundado en parte por la quebrada el Oso (Botero H. , 2018). Todo aquello no sin antes librar una batalla jurídica por la legalización del predio dado que la señora Laura Rosa Cano con la cual se negoció inicialmente, resultó no ser la propietaria legal de los terrenos, por lo que se tuvo que iniciar diferentes procesos de reclamaciones y demandas penales por estafa, debido a que el verdadero dueño, el señor Ramón Cano, se presentó 3 años después a reclamar los terrenos y buscar desalojar los habitantes del Barrio la Isla de Cuba. Siendo necesario comprobar mediante un estudio de títulos adelantado el 10 de marzo de 1980 por CENAPROV, la veracidad del propietario e iniciar un nuevo proceso de negociación, logrando que el reclamante aceptara los términos del nuevo contrato para legalizar los títulos del terreno (Archivo CENAPROV AZ II Pereira -Notariales-, Ver Anexo 5).

Sumado a este impase, según la versión de algunos de sus fundadores y la tesis de Carlos Arango en su texto La Lucha por la vivienda en Colombia, las tensiones entre la oficina de planeación municipal y

29 Según la tesis de Beatriz Rojas fue fundado en el 1.976 (Rojas B. E., 2003) 
los ocupantes del nuevo barrio por la legalización del mismo fueron constantes desde 1973, debido a que los funcionarios de Planeación Municipal argumentaban que los moradores del asentamiento además de no tener títulos de propiedad ni escrituras, habitaban sobre terrenos cenagosos e inundables, lo que impedía que obras públicas brindara los servicios básicos, consiguieron que en varias ocasiones la policía decomisara los materiales de construcción (Arango Zuluaga, 1986). De hecho, pese a que en entrevista el secretario de planeación municipal de la época, Señor Francisco Londoño manifestó un apoyo decidido para la legalización de dicho plan de vivienda, otra parecía ser su posición durante la época pues según archivo de prensa del jueves 12 de diciembre de 1974 en el periódico El Diario, él mismo se pronunciaba en contra de la urbanización pirata del Barrio La Isla:

El departamento administrativo de Planeación comunica a la ciudadanía y en especial a las personas que han adquirido lote en un globo de terreno no ubicado en el Barrio de Cuba, sector de la quebrada del Oso.

1. Que la Urbanización propuesta no tiene la aprobación de la Superintendencia Bancaria, entidad que regula las actividades de urbanización, construcción y Crédito para la adquisición de viviendas de acuerdo a la ley 66 de 1968.

2. Que la Superintendencia Bancaria ha ordenado a la Central Nacional Provivienda abstenerse de realizar negociaciones sobre el mencionado lote.

3. Que la urbanización de no cumplir con los requisitos exigidos por el Departamento Administrativo de Planeación carece de aprobación de este departamento.

4. Que el lote en mención es altamente inundable y ofrece serio peligro para los futuros habitantes.

El departamento Administrativo de Planeación ofrece la colaboración necesaria a las personas afectadas, las cuales deben hacer conocer a este despacho la forma en que se han ofrecido los lotes.

Francisco Londoño M

Director

Pereira, Dic 6 de 1974 (El Diario, 12 Diciembre 1974).

Según la versión de Carlos Arango todas estas dificultades para la legalización del plan de vivienda llevaron a que CENAPROV y los inquilinos elevaran una denuncia en 1974 ante la Procuraduría General de la Nación, lo que arrojó como resultado el despido de algunos funcionarios y comisarios de policía, pero que además se levantara el bloqueo que se tenía sobre el naciente barrio (Arango Zuluaga, 1986). 
La difícil situación que afrontó la comunidad por aquella época, quedó plasmada en una carta enviada al periódico el Diario el 22 de noviembre de 1975 titulada Problemas en el barrio La Isla de Cuba:

Por medio de su prestigioso Diario desearíamos que el pueblo de Pereira y Risaralda se enterara de la grave situación que afrontamos más de 2000 personas que habitamos el barrio La Isla de Cuba de la Central Nacional Provivienda de esta ciudad. Este barrio fue construido por medio del esfuerzo colectivo de todos y cada uno de sus habitantes que a través de la organización lograron la consecución de sus viviendas sin que hubiera existido ayuda alguna por parte de las autoridades municipales.

Durante más de un año hemos venido solicitando la instalación de los servicios públicos como agua, energía y alcantarillado sin lograr hasta la fecha resultados positivos.

En estos momentos la solución de tan grave problema ésta en manos del señor gerente de la oficina de Planeación Municipal, doctor Francisco Londoño, a quién le hacemos un llamado para que con su sentido social nos resuelva favorablemente esta situación que ya toma caracteres alarmantes dado el alto índice de población y donde los más afectados son los niños y los ancianos que allí residen. Por nuestra parte manifestamos nuestro deseo de realizar en conjunto con las EE.PP. los trabajos que requieran estas obras de infraestructura.

Solicitamos de toda la ciudadanía su respaldo a nuestras justas peticiones.

Atentamente

Central Nal. Pro Vivienda

Centro $\mathrm{N}^{\circ} 2$

Bernardo Vásquez

Presidente

Benjamín Martínez

Tesorero (El Diario, 22 de noviembre de 1975).

Con la consolidación de la principal fuerza política de izquierda en la ciudad desde 1974, entre los concejales Gildardo Castaño, Luis Enrique Arango, Miguel Castañeda, y los diputados Manuel Castillo, Santiago Londoño y Carlos Alberto Benavides, se logró el equipamiento total de servicios públicos, alcantarillado y transporte público tanto para el Barrio La Isla de Cuba como para muchos otros fundados años después por CENAPROV en la ciudad (Castañeda, 2017). De hecho, mientras grandes concentraciones de simpatizantes del liberalismo se reunían en los barrios Cuba y San Fernando, en torno a las propuestas del barón electoral liberal de la región y senador Camilo Mejía Duque (El Diario, 
19 Junio 1976), en el barrio la Isla de Cuba por su parte, se gestaban relaciones entre los moradores del barrio y los políticos de izquierda que defendían sus intereses en el Concejo y la Asamblea Departamental, a tal punto que para el año de 1986 se realizaban manifestaciones de apoyo dentro del barrio a los candidatos de la Unión Patriótica: Arturo Sanín a la Asamblea Departamental, Gildardo Castaño y Edgar Cardona al Concejo de la ciudad, quienes aprovechaban la oportunidad para inaugurar obras como el alumbrado público, gestionadas por ellos mismos (El Diario, 31 Enero 1986).

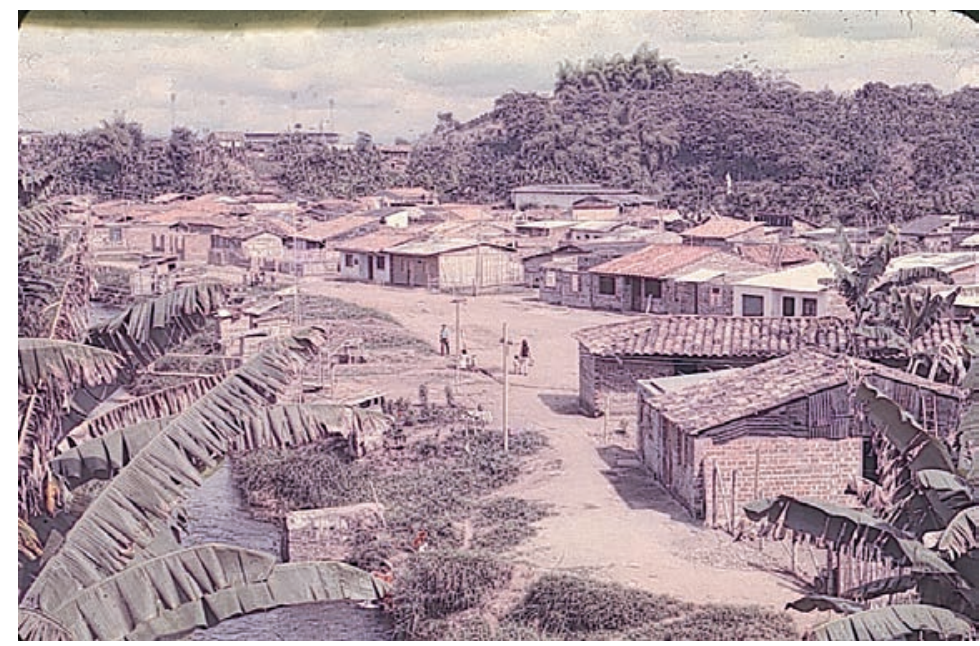

Fotografía 8: Panorámica del Barrio La Isla de Cuba años 70.

Fuente: Archivo personal de Francisco Londoño Marulanda.

La manera como se daría el proceso de urbanización del barrio la Isla de Cuba Centro de inquilinos número 2, bajo la modalidad de compra comunera y no la de una toma violenta, contiene elementos característicos compartidos con la concepción de la colonización popular descrita por el urbanista Jacques Aprile, cuando narra el esfuerzo de los nuevos colonizadores urbanos para consolidar sus terrenos y abrirse espacio dentro de su nuevo hábitat urbano (Aprile-Gniset, 1992). Así se pudo constatar en el testimonio de uno de los fundadores del barrio la Isla:

Esto aquí era una laguna, donde cada 8 días veníamos a desyerbar, fue muy duro porque era esa maleza espesa (...) luego empezamos a medir los lotes con lazos con la asesoría de Joaquín Botero, Mario Upegüi y Castillo, luego en las asambleas 
empezamos a entregar los lotes a un costo de $\$ 3500$, la luz y el agua la tomamos de barrios vecinos, hicimos letrinas y lavaderos a la orilla del río que eran utilizados por todos lo viviendistas (...) ocurrieron inundaciones porque se salía la quebrada, pero poco a poco de la mano del doctor Gildardo Castaño se fue legalizando el barrio. (Botero F. , 2018).

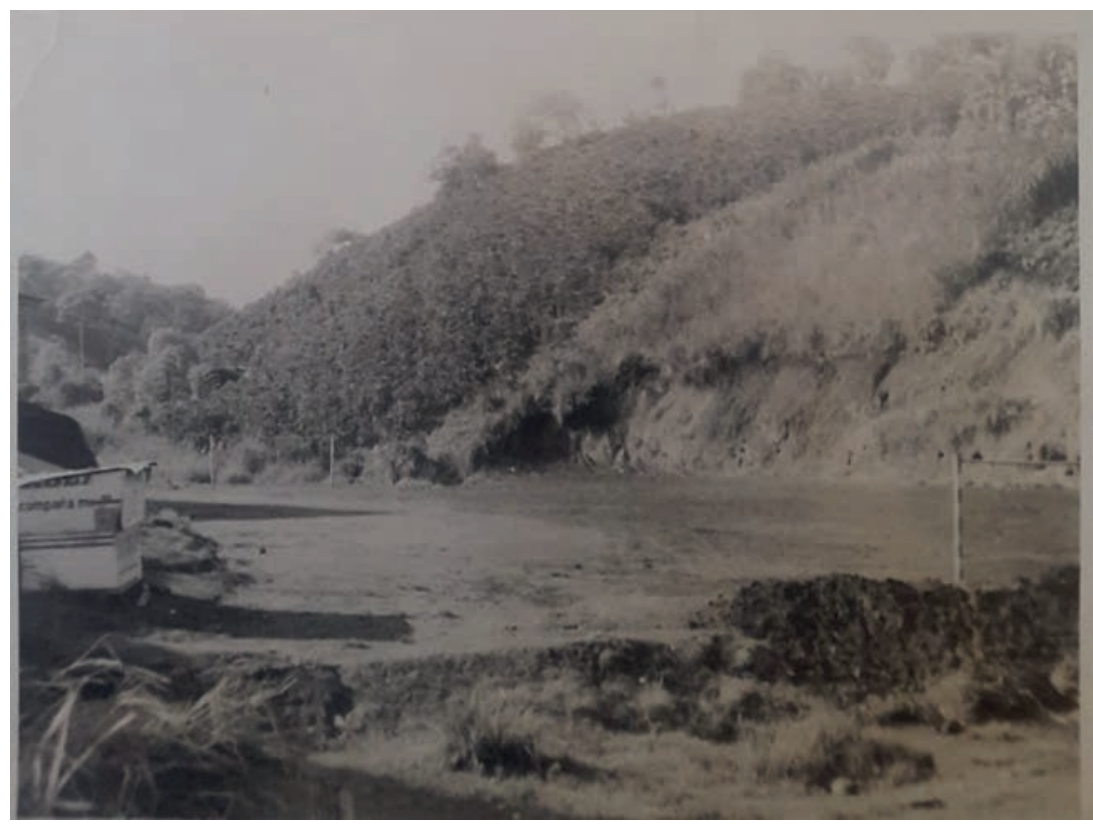

Fotografía 9: Terrenos cerca a la quebrada El Oso donde se construiría el barrio La Isla. Fuente: Archivo personal de Fernando Botero.

\section{Leningrado I, II y III}

La misma modalidad de compra comunera se gestó en el año de 1977, específicamente el 15 de febrero, día en que según contrato de compraventa $\mathrm{N}^{\circ} 246$ suscrito en la notaría primera, el señor Jesús María Zuluaga Restrepo vende a la Central Nacional Provivienda un lote denominado "El Oso" de diez hectáreas en el paraje San Joaquín, por un valor de 300.000 pesos (Archivo CENAPROV AZ I Pereira -NotarialesVer Anexo 6). Dichos terrenos, como consta en la documentación de archivo de la entidad, ya habían sido aprobados por el comité técnico de la organización, al igual que su plan urbanístico donde se tenía previsto la entrega de 578 soluciones de vivienda entre sus afiliados (Archivo CENAPROV AZ I Pereira -Correspondencia-, Ver Anexo 6). Esta experiencia fue tomada del Barrio Pablo Neruda, en el municipio de Sibaté, Cundinamarca (Arango Zuluaga, 1986). La ocupación de los 
terrenos del Barrio Leningrado por parte de los inquilinos inició en 1978 bajo la modalidad de autoconstrucción. Allí la solidaridad vecinal por medio de bazares y convites fue clave para la conformación del barrio que posteriormente concluiría con 3 etapas (Mejía J. , 2016). Su nombre, Barrio Leningrado, según testimonio de algunos fundadores militantes activos del partido comunista, fue recomendado por María Aydee Jaramillo -integrante de la Junta Directiva del comité de inquilinos $\mathrm{N}^{\circ} 4$ del barrio Galán 3ra etapa- inspirada en el libro de Jean Paul Ollivier ¿Cuándo amanecerá Tovarich?, donde se cuenta en detalle la historia de la Gran Revolución Rusa, conocida como la Revolución de Octubre de 1917 y donde está plasmada la importancia de la ciudad de Leningrado (Ayala, 2016).

La toponimia de los barrios, implica el que no pueda desconocerse la plataforma ideológica que conformaba y lideraba las actividades de la organización CENAPROV, sus miembros más activos y dirigentes, consideraban la solución al problema de vivienda de los más pobres como una cuestión no separada de los lineamientos ideológicos de la lucha de clases. Esto es latente, en muchas de las discusiones al interior de la organización que por fortuna quedaron plasmadas en la correspondencia. En uno de estos documentos se les indica a dirigentes regionales como deben proceder en la consolidación de un plan urbanístico en el municipio de La Virginia en mayo de 1980. En dicho documento queda en evidencia que el accionar de la Central Nacional Provivienda estaba basado en principios eminentemente ideológicos:

El objetivo de Provivienda no es como ustedes lo afirman, “... lograr el mayor número posible de soluciones de vivienda", consideramos que la lucha por el techo es un medio más no un fin (...) estamos de acuerdo con ustedes y es parte de la plataforma de lucha de la Central Nal. Provivienda (ver págs. 35-36-37, material IX Asamblea) el de arrancar a la oligarquía, al gobierno, y a los latifundistas los terrenos ociosos, no solo para solucionar el problema recreacional, sino para realizar planes masivos de vivienda con luz, agua y alcantarillado (...) podemos hacer un barrio de "Nuevo Tipo" con las suficientes áreas libres, con buenas zonas deportivas, con nuevos sistemas de vías... mostrarle a la oligarquía cómo podemos realizar verdaderos proyectos urbanísticos con nuestro esfuerzo, sin las limosnas y el oportunismo de los politiqueros de turno (Archivo CENAPROV, AZ Pereira II -Correspondencia-).

La complejidad barrial en los asentamientos organizados por CENAPROV en la ciudad, implicaba como era lógico el desafío de la convivencia entre los nuevos moradores de los barrios, la mayor parte de ellos migrantes y desplazados campesinos de la violencia. Frente a 
la tensión social propia de cualquier organización comunitaria, las normas estatutarias de CENAPROV estaban concebidas bajo el modelo disciplinario de los comunistas que, como bien afirma Gloria Elvira Naranjo, no todos estaban en disposición de cumplir.

Entre las normas más conflictivas se hallaban la prohibición de vender el lote o la casa durante un período apreciable y la obligación de someter a la junta directiva cualquier tipo de transacción. Los directivos y las células del Partido que funcionaban en los barrios de CENAPROV ejercían diversas formas de presión política sobre sus habitantes (Naranjo, 2011).
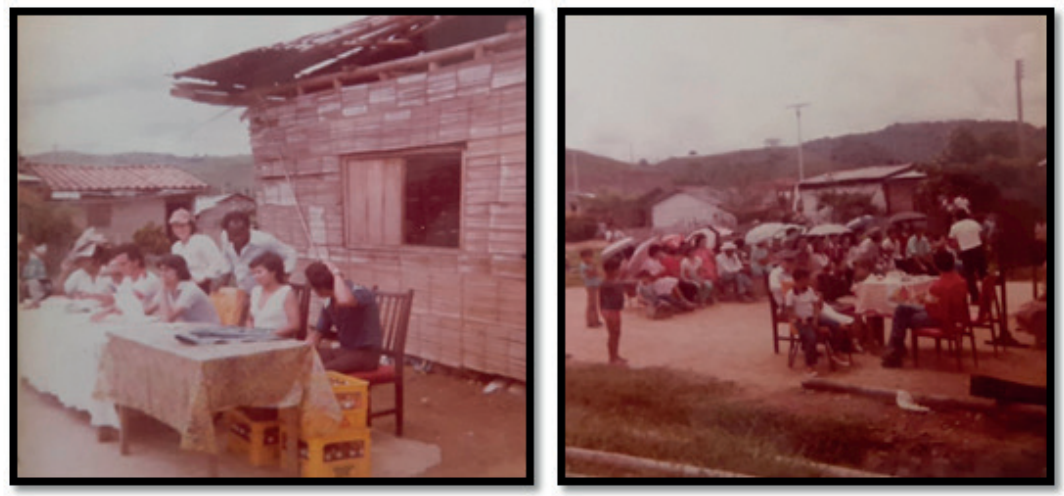

Fotografía 10: Primeras viviendas del barrio Leningrado. Fuente: Archivo personal de Fernando Botero.

La Central Nacional Provivienda orientó desde sus inicios el trabajo de su comité ejecutivo nacional, hacia la conformación de juntas directivas seccionales regionales, de las cuales se desprendían centros de inquilinos en cada uno de los barrios con su respectiva junta directiva, compuesta por un presidente, un vicepresidente, un secretario, un fiscal, un tesorero y el mismo número de vocales o suplentes que servirían de apoyo en caso que llegase a faltar algún titular de la junta directiva. Además de esto en cada barrio se organizaban diferentes comités, cada uno con una función específica de manera que se pudiese garantizar la convivencia y el orden al interior de la comunidad (Mejía J. , 2016).

Como lo narra Manuel Ayala, existía un comité de vigilancia encargado de la protección de los habitantes, que organizados en grupos de 3 o 4 vecinos se intercambiaban turnos principalmente en las noches para garantizar la seguridad. Un comité femenino, encargado 
de la celebración de actos sociales tradicionales como el día de la mujer, el día de la madre, el día del padre, la navidad etc. Dicho comité era autosuficiente, pues gestionaba recursos para sufragar los gastos que demandaban estas celebraciones, mediante la realización de festivales bailables, rifas o empanadas (Ayala, 2016).

\section{Gráfico 5: Estructura organizativa de CENAPROV.}

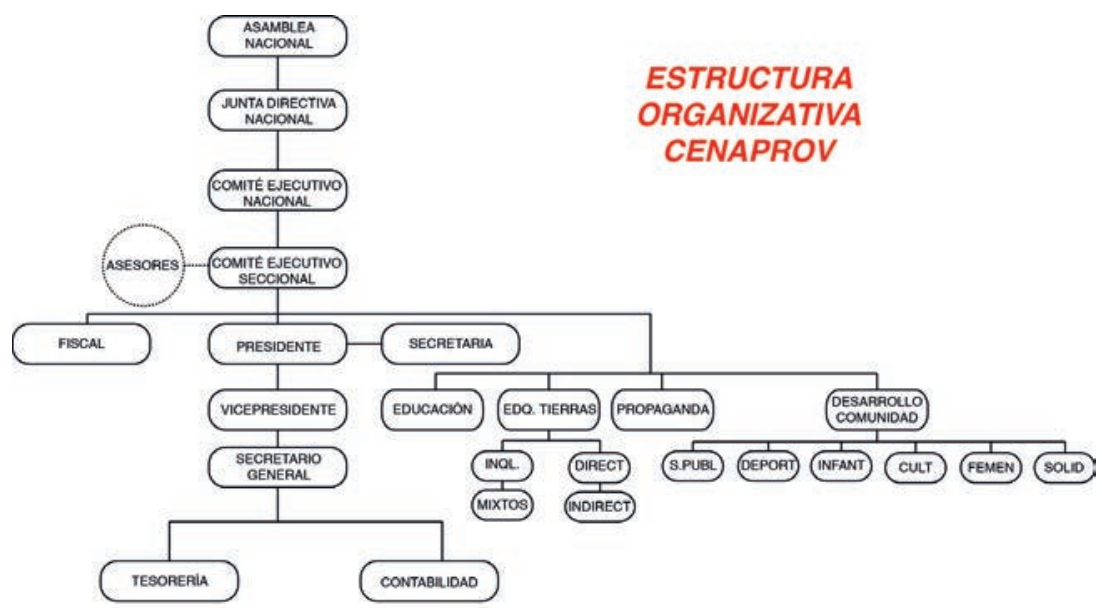

Fuente: Tomado y modificado del Archivo CENAPROV AZ II Pereira -Correspondencia-.

El comité deportivo, tenía como objetivo principal fomentar la actividad física y la recreación por medio de actividades como el microfútbol, atletismo, ajedrez, entre otros. No menos importante era el comité cultural, encargado del estímulo de las manifestaciones artísticas al interior de los barrios y el rescate de valores culturales tradicionales. Finalmente estaba el comité de pioneros, cuyo objetivo era estimular la creatividad en los niños a partir de concursos de dibujo y todo tipo de actividades lúdicas (Ayala, 2016).

Esta estructura organizativa permitió la consolidación del proyecto político de CENAPROV al interior de los barrios que serían la base electoral de muchos de sus dirigentes y al mismo tiempo el avance de la vivienda autoconstruida por medio de la participación solidaria, a través de la planificación de actividades culturales, convites y bazares para recolección de fondos y para poner en marcha proyectos que iban desde la adecuación de un terreno para solucionar el problema de las aguas negras de los barrios, hasta el levantamiento de la casa en esterilla de un vecino en corto tiempo. 
Era un trabajo organizado, carnetizamos a la gente y teníamos estatutos, teníamos plataforma de lucha, teníamos declaración de principios, teníamos responsabilidades y el que no cumplía con esos requisitos y esas responsabilidades no podía estar en la organización. Y los mejores y los más disciplinados, y los que llegaban a las tareas y toda esa cosa, eran los primeros que estaban en la lista para la adjudicación de la vivienda. Eso no era ahí que porque es mi compadre o comadre sino por mérito (Castañeda, 2017)

Era tal la organización comunal y la presión política que ejercían sus dirigentes en la administración municipal, que para el año de 1981, según documentos certificados del departamento administrativo de planeación municipal y empresas públicas de Pereira, el barrio Leningrado -también conocido como centro de inquilinos número 8- contaba ya con los planos de urbanización legalmente aprobados, instalaciones completas de energía eléctrica y el 60\% del alcantarillado, adoleciendo únicamente de la redes de acueducto, lo que implicaba que el suministro de agua se realizará por medio de piletas comunales situadas en la parte alta del sector (Archivo CENAPROV AZ II Pereira -Correspondencia-, Ver Anexo 7).

Para el año de 1986 debidamente autorizada por la Superintendencia Bancaria, la Central Nacional Provivienda inicia la entrega de las escrituras a los adjudicatarios del Barrio Leningrado en sus tres etapas, mostrando con ello que no eran ninguna organización de viviendistas pirata como lo querían hacer ver algunos miembros de la Junta de Acción Comunal del Barrio paralela a la Junta Directiva de CENAPROV (La Tarde, 26 Enero 1986). Según documentación de archivo para el año de 1988, el centro de inquilinos $\mathrm{n}^{\circ} 8$ barrio Leningrado III etapa, tenía como presidente al señor Antonio Alfaro; vicepresidente Eduardo Guarín; secretaria Ana Tulia Colorado; tesorero Rodrigo Arias y fiscal Rosa Páez (Archivo CENAPROV AZ I Pereira -Correspondencia-).

Para 1980 la expansión de la ciudad en los sectores de San Joaquín y El Oso se hizo más evidente con la consolidación del barrio La Isla de Cuba y las tres etapas del Barrio Leningrado. La siguiente aerofotografía permite constatar un incremento significativo de la densidad de la población del sector. 


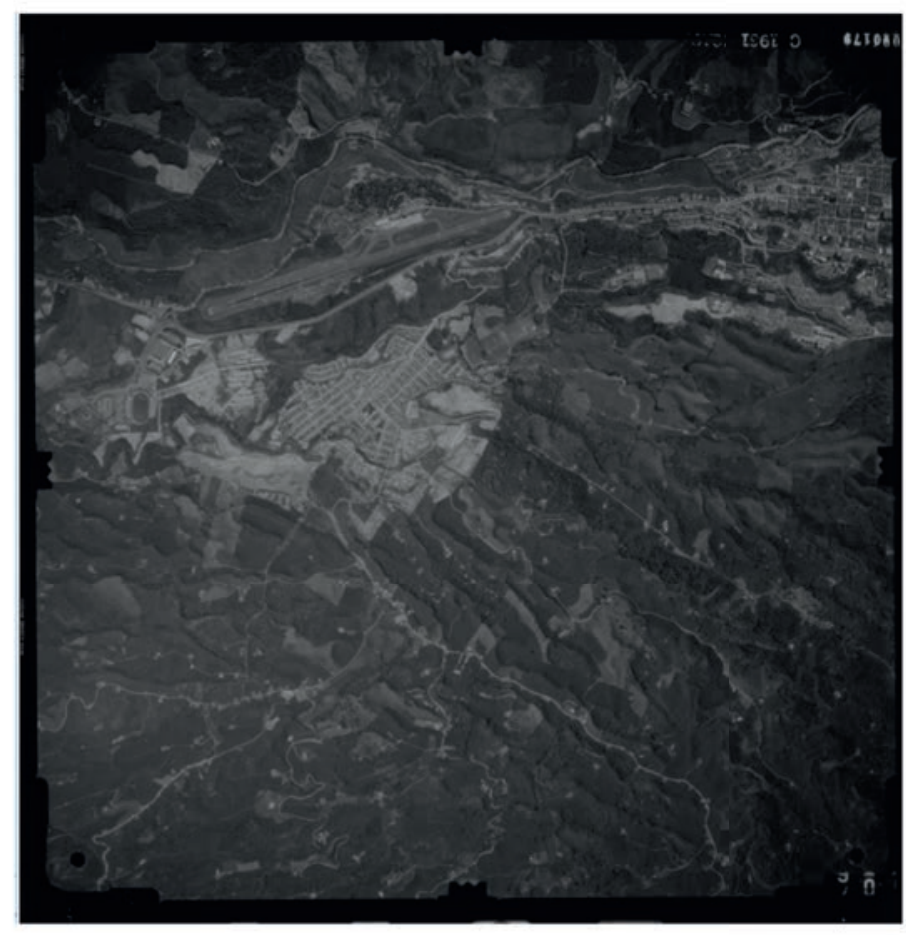

Fotografía 11: Aerofotografía del sector suroccidental de Pereira, donde se aprecia el inicio de conformación urbana.

Fuente: IGAC, Aerofotografía C-1961, foto 179, 1980.

\section{Salvador Allende}

En 1974, año en que el reconocido profesor universitario, dirigente regional del MOIR y concejal por la UNO, Luis Enrique Arango se pronunciara en prensa con motivo del aniversario del asesinato de Salvador Allende en Chile y declaraba su firmeza en la lucha de los pueblos del tercer mundo contra el imperialismo (El Diario, 12 Septiembre 1974), cerca al centro de la ciudad, en lo que hoy día está catalogado como la comuna Río Otún, se inicia una toma de terrenos en predios que pertenecían a la sociedad San Vicente de Paúl. Allí, unas 80 familias luego de escuchar que las hermanas pensaban vender la propiedad a una promotora, bajo la orientación de dirigentes de la Central Nacional Provivienda como Miguel Castañeda y Humberto Salazar e inspirados en la experiencia del Barrio La Isla de Cuba, ocupan un terreno aledaño al cementerio San Camilo de la ciudad de Pereira, 
como lo describe en entrevista Miguel Castañeda:

Logramos hacer una invasión cerca al cementerio central de Pereira y ahí creamos el barrio Salvador Allende, una invasión pequeña donde a más de uno nos dieron bolillo ventiao y gases, pero logramos consolidar el barrio (...) allí hubo tropel, pero se vio la solidaridad del movimiento obrero, el sindicato de profesores de los sectores más consecuentes, con la causa se logró la consolidación del barrio (Castañeda, 2017).

Esta toma se sostuvo durante algunos días, sin embargo, pese a que las familias fueron desalojadas, su acción de hecho, junto con la presión política que ejercieron sindicatos y políticos de izquierda, logró que el municipio negociara estos terrenos con la sociedad San Vicente de Paúl y se otorgarán las soluciones de vivienda requeridas por las familias. Vale la pena recordar que en aquella época Miguel Castañeda se encontraba como segundo renglón de Luis Enrique Arango en el concejo municipal, lo que facilitó la presión cabildante, como también se haría en la asamblea departamental. Aun así, varios de los dirigentes de la organización, entre ellos Miguel Castañeda, que hicieron parte de esta toma fueron encarcelados y liberados días después (Arango Zuluaga, 1986).

El nombre de este barrio: Salvador Allende, como lo recuerda uno de sus residentes, se colocó en honor a la lucha y resistencia de sus primeros moradores. Las escrituras de los predios fueron entregadas en el año de 1977 (El Diario, 2018). El caso de este barrio al igual que el del barrio José Martí (1978) y Pedro Pablo Bello (1978) en el municipio de La Virginia, fueron los únicos donde se llevaron a cabo tomas de hecho, invasiones u ocupaciones ilegales.

\section{José Martí, José Antonio Galán y Carlos Alberto Benavides}

En 1978, cuatro años después de la ocupación en los terrenos de la sociedad San Vicente de Paúl, se dio una nueva ocupación en terrenos de esta misma entidad, contiguo al Barrio Salvador Allende, entre la carrera 3a con calle 30, comuna Río Otún, de igual manera bajo la dirección de CENAPROV en cabeza del entonces concejal Gildardo Castaño y Humberto Giraldo Salazar. Alrededor de 120 familias, un primero de mayo de 1978, ocuparon ilegalmente el terreno, buscando conseguir una negociación con la alcaldía del municipio de la misma manera que se había conseguido con el barrio Salvador Allende, sin embargo rápidamente fueron desalojadas por la fuerza pública de 
manera violenta, dejando como consecuencia algunos heridos y otros llevados detenidos hacia la tercera brigada del ejército en Armenia donde estuvieron alrededor de 10 días, entre ellos los dirigentes de la organización antes mencionados (Arango Zuluaga, 1986).

Las familias desalojadas, cerca de 100 personas, entre ancianos mujeres y niños liderados por Gildardo Castaño, dirigente del partido comunista, se tomaron las instalaciones de la gobernación buscando negociar con el gobernador Carlos Arturo Ángel Arango la búsqueda de alternativas inmediatas para solucionar el problema habitacional en la invasión. Así lo registró el periódico El Diario en primera página el lunes 22 de mayo de 1978:

Última Hora - DESDE LAS 10 DE MAÑANA RETENIDO EN SU OFICINA EL GOBERNADOR DEL DEPTO - CERCA DE CIEN PERSONAS DE LA INVASIÓN "JOSÉ MARTÎ"

Minutos después de las diez de la mañana de hoy comenzaron a llegar al $7 \mathrm{mo}$ piso del Palacio Municipal, donde funcionan las dependencias de la gobernación del departamento, grupos de personas, hombres y mujeres ancianas y ancianos, niños y niñas dirigidos todos por el camarada Gildardo Castaño principal dirigente del partido comunista en nuestro medio (...) unos 180, más o menos, integrantes de grupo de invasión con el nombre José Martí.

Al no conseguir que el gobernador Ángel Arango les concediera una audiencia procedieron a tomarse parte del piso de la gobernación (...) manifestando que no permitirían la salida del gobernador y sus principales funcionarios, ni la entrada de ninguna autoridad (...) Gildardo Castaño quien desde un principio se mostró totalmente opuesto a la entrada de las autoridades y anunciando que estaban dispuestos a llegar hasta las últimas consecuencias de no lograr una atención adecuada por parte del gobierno departamental y especialmente del jefe del Ejecutivo Doctor Carlos Arturo Ángel Arango en las demandas que le han presentado (El Diario, 22 Mayo 1978).

Protestas y plantones fueron constantes durante ocho meses alrededor del predio para no perder la posesión del mismo. En muchas ocasiones fueron desalojados, luego de continuas reuniones de la comunidad en el reconocido Parque de la Libertad, en pleno centro de la ciudad, acordaron que aquellos terrenos por los que luchaban o más exactamente su futuro lugar de residencia se llamaría José Martí (Arango Zuluaga, 1986).

Luego de muchos meses de protestas, pleitos y la gestión de los dirigentes de CENAPROV a nivel regional con la administración municipal, el Concejo Municipal aprueba un acuerdo que autorizaba 
al alcalde y al gerente del fondo de vivienda popular adquirir el lote, previo a crédito bancario por la suma de 550.000 pesos. Dicho plan de vivienda, según consta en la correspondencia de la entidad, contaba con la aprobación por parte de la oficina de Planeación Municipal, más no de la Superintendencia Bancaria, entidad encargada de vigilar y regular la reglamentación y direccionamiento de los planes de vivienda a nivel nacional. Además de esto, en el mismo documento se manifiesta que en dicho acuerdo aprobado por el Concejo Municipal para la adjudicación del terreno, se aceptó que los adjudicatarios pagarán sus respectivas cuotas $^{30}$ al Fondo de Vivienda Popular. Los dirigentes estudiaban la posibilidad de que el Fondo de Vivienda Popular le escriturara los terrenos a la Central Nacional Provivienda, de modo que ésta última pudiese asumir la responsabilidad de la deuda de los adjudicatarios. Situación que resultaba compleja en la medida en que, por parte de la administración municipal, con la ayuda de algunos políticos, se buscaba que un grupo de adjudicatarios conformara una junta de acción comunal para sacar de en medio a CENAPROV (Archivo CENAPROV AZ II Pereira -Denuncia-, Ver Anexo 8).

Los planes de creación de una junta de acción comunal no se llevarían a cabo, pues para 1979, como consta en información de archivo, el Barrio José Martí, también conocido como Centro de Inquilinos número 9 ya contaba con una junta directiva debidamente organizada y avalada por la Central Nacional Provivienda. El presidente era Abundio Yate, vicepresidente Luis Alfredo Villegas, secretaria Ana Lesbia Herrera, tesorero José Duván Fajardo y fiscal Alfonso Calvo. (Archivo CENAPROV AZ I Pereira -Correspondencia-, Ver Anexo 9). De igual manera, la junta directiva regional, o Seccional Risaralda también estaba debidamente conformada, según correspondencia enviada desde Pereira hacia Bogotá el 31 de marzo de 1980. Fungía como presidente de la Seccional Risaralda el señor Manuel Castillo, como vicepresidente Eduardo García, como secretario Carlos Alberto Benavides, como fiscal Jaime Franco y como tesorero Hugo Vélez (Archivo CENAPROV AZ I Pereira -Correspondencia-, Ver Anexo 10).

Algunos de estos dirigentes no sólo pertenecían a CENAPROV, sino que también eran militantes activos del Partido Comunista, la Unión Patriótica y centrales obreras como la Confederación de Trabajadores de Colombia. De hecho, uno de los proyectos de vivienda construidos por el ICT a mediados de los años 80 , en el cual se buscó dotar de

30 Cuotas que según Carlos Arango eran de 300 pesos mensuales (Arango Zuluaga, 1986). 
vivienda a algunos de los sectores más pobres de la ciudad de Pereira fue la Ciudadela Perla Del Otún comúnmente conocida como el Plan 2.500 lotes. En ella, se les dio vida jurídica a 20 comunidades, una de ellas de la Central Nacional Provivienda llamada la comunidad Carlos Alberto Benavides, en honor al reconocido dirigente comunal de Provivienda, presidente de su seccional Risaralda en 1983, militante del partido comunista y miembro de la CSTC ya fallecido. Para la época, a mediados de los años 80, fungía como presidente de dicha comunidad, Centro de Inquilinos $n^{\circ} 10$, el señor José Bautista Osorio (Instituto de Credito Territorial, 1986). Para el año de 1988 continuaba como presidente José Bautista Osorio; como vicepresidente Héctor Fabio Osorio; como secretaria Luz María Ríos y como fiscal Laila Luisa Velásquez (Archivo CENAPROV AZ I Pereira -Correspondencia-, Ver Anexo 11).

La Central Nacional Provivienda tenía un poder organizativo tan sólido en la ciudad que donde no adelantaba un plan de vivienda, aportaba en la culminación de otro. Y es que, por la misma época, cerca al Barrio José Martí, CENAPROV tuvo injerencia en la conformación de la tercera etapa del Barrio José Antonio Galán, Centro de Inquilinos número 4, proyecto que adelantó sus dos primeras etapas por parte del ICT. Según documentos de archivo, en el año de 1980 la junta directiva de dicho barrio estaba compuesta por Balbino Rodríguez quien fungía como presidente, Edelberto López su vicepresidente, Arturo Velásquez como fiscal, Leonel García como tesorero y Rodrigo Ríos como el secretario (Archivo CENAPROV AZ II Pereira-Correspondencia-, Ver Anexo 12).

Según testimonio de Manuel Ayala, uno de los integrantes de la organización y pionero del centro de inquilinos número 4 José Antonio Galán etapa III, el surgimiento de dicho barrio se dio de la siguiente manera:

Este barrio nace de la organización del sindicato de zapateros que venían buscando solución al problema de vivienda acudiendo al ICT, donde nos ofrecieron un programa llamado "las ciudadelas artesanales" donde ofrecían vivienda y un taller, sin embargo, como la mayoría de proyectos politiqueros, esto quedó en nada; aun así nosotros seguimos luchando creando COARCUR (cooperativa artesanal del cuero de Risaralda), invadimos varias veces el INSCREDIAL presionando vivienda y nos resultó después de muchas peleas en el barrio Galán que ya estaba fundado y tenía dos etapas. La tercer etapa nos la dieron a tres grupos organizados que funcionábamos entre ellos COARCUR (...) allí fue por adjudicación, lotes, pero ya eran lotes para pagarlos a cuotas que nosotros habíamos impuesto, por ejemplo, mi casa me costó 57 mil pesos con cuotas de 500 pesos mensuales era al alcance de 
nosotros (Ayala, 2016).

Pese a que los lotes fueron adjudicados por el ICT, la asesoría, la presión y reclamo ante dicha entidad siempre fueron orientados por la Central Nacional Provivienda que dirigió la creación del grupo de inquilinos en dicha etapa y la manera como se darían las negociaciones para acordar los costos y cuotas de los predios.

Gráfico 6: Plano de la ciudad de 1984, con ubicación Aproximada de lote en negociación para la construcción del Barrio Jaime Pardo Leal.

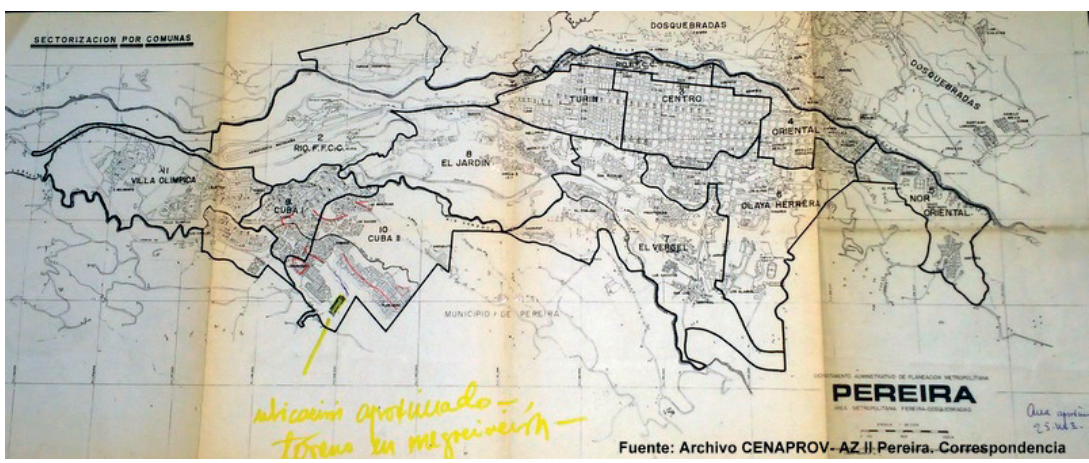

Fuente: Tomado y modificado del Archivo CENAPROV AZ II Pereira -Correspondencia-.

\section{Nueva Colombia y Jaime Pardo Leal}

Los dos últimos barrios que CENAPROV construyó bajo la misma modalidad de autoconstrucción en el sur occidente de la ciudad serían el plan de vivienda llamado Nueva Colombia en 1986, ubicado en el sector conocido como La Cuchilla de los Castro, en la comuna El Oso, con 56 viviendas (El Diario, 5 Agosto 2018) y un poco más el sur, en el mismo sector, el Barrio Jaime Pardo Leal, en 1987. Este último barrio se proyectó, según la correspondencia de la organización, aprovechando las buenas relaciones que tenía para la época el presidente de CENAPROV a nivel regional Eduardo García Buriticá con la administración municipal de la época, en cabeza del alcalde Jairo Arango, primer alcalde popular de la ciudad ${ }^{31}$.

Según el mismo documento, se tenía previsto adquirir un lote de 25.000 metros cuadrados aproximadamente cerca al plan Nueva

31 En este punto es importante resaltar que varios secretarios de despacho de la administración de Jairo Arango en 1987, pertenecían a la Unión Patriótica. Lo que se presume facilitó aún más este tipo de negociaciones. 
Colombia, con opción de vertimiento de alcantarillado y buenas opciones de aprovechamiento de servicio de energía y agua (Archivo CENAPROV AZ Pereira II -Correspondencia-, Ver Anexo 13).

Dichos terrenos fueron adquiridos como consta en el contrato de compraventa del 28 de diciembre de 1987 de la notaría cuarta de Pereira, en el cual el señor Guillermo Castro Becerra vende a la Central Nacional Provivienda y su representante legal Luis Eduardo García Buriticá, un predio rural denominado "EL GUAYABO" de 30 varas de frente por dos y media cuadras de centro, mejorado con plantaciones de café y plátano, con dos fuentes de agua por un valor de 3.700 .000 pesos (Archivo CENAPROV AZ I Pereira -Notariales-, Ver Anexo 14).

El año de 1987, año en que es asesinado el dirigente y candidato presidencial de la Unión Patriótica, Jaime Pardo Leal, marcaría el inicio del declive de la organización a nivel local con la culminación del proyecto de vivienda Jaime Pardo Leal, nombre colocado en honor al dirigente de izquierda asesinado. A partir de allí, a causa de diversas razones, entre ellas la persecución a muchos de sus dirigentes, la Central Nacional Provivienda no volvería a adjudicar ningún plan de vivienda en la ciudad Pereira.

\section{Gráfico 7: Mapa de Pereira y ubicación de los barrios construidos por CENAPROV.}

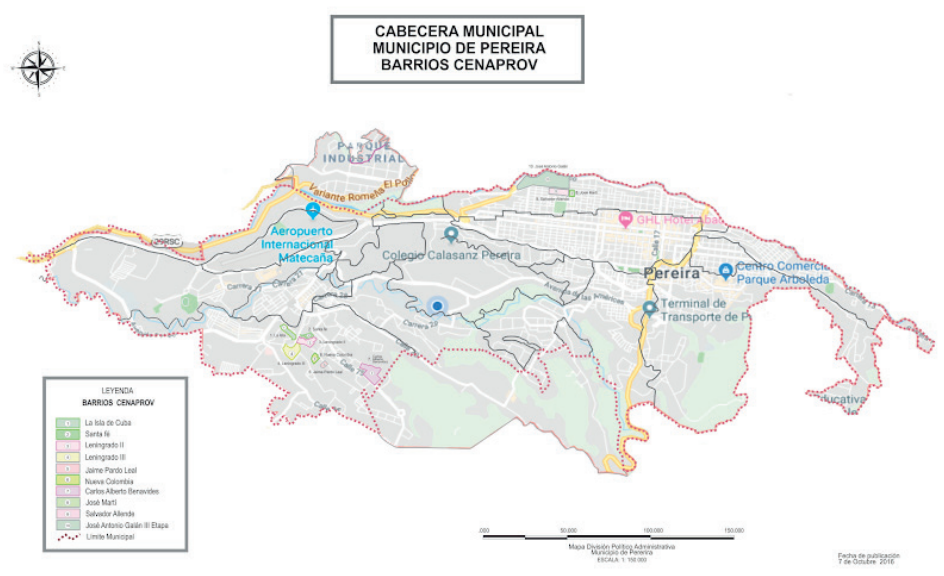

Fuente: Tomado y modificado de DANE 2004, con base en plan de ordenamiento territorial de Pereira, 2001. 


\section{Tres experiencias significativas en los municipios cercanos}

El vecino municipio de la Virginia Risaralda vivió otra de las tomas icónicas bajo la modalidad de ocupación ilegal, orientada por la Central Nacional Provivienda para los deficitarios del municipio, que según datos de Carlos Arango Zuluaga rondaban por las 3.000 soluciones para 1976 (Arango Zuluaga, 1986). Además del déficit cuantitativo y cualitativo que sufría el municipio de la Virginia, las inundaciones que provocan los ríos Cauca y Risaralda agravaban la situación de los deficitarios.

Atendiendo las condiciones especiales que caracterizaban al municipio, la Central Nacional Provivienda creó un centro de inquilinos en mayo de 1975 y empezó a diseñar la estrategia para tomar los terrenos ejidales ubicados a las afueras del municipio. La toma de los terrenos se llevó a cabo el 12 de agosto de 1978, día en que alrededor de 50 familias de manera organizada, construyeron sus cambuches en horas de la noche (Arango Zuluaga, 1986).

Días después, en horas de la madrugada, la policía irrumpió en la invasión para adelantar el desalojo de la comunidad destruyendo sus ranchos. Situación que por su puesto dio lugar a enfrentamientos con los inquilinos. Estos últimos se resistieron a abandonar el predio hasta no tener una respuesta favorable a su problema habitacional, pues reclamaban, entre otras cosas, el haber acudido en varias ocasiones a la oficina del Instituto de Crédito Territorial demandando con urgencia solución a su problema habitacional y no obtuvieron atención oportuna (Arango Zuluaga, 1986). Las autoridades realizaron un cerco alrededor de la invasión que no permitía la entrada ni salida del lugar, acontecimiento narrado por uno de los miembros del comité ejecutivo y tesorero CENAPROV regional en aquellos años:

El barrio Pedro Pablo Bello fue una toma de hecho o lo que nosotros llamamos una recuperación de tierras donde se hizo un estudio de terreno donde se estudiaban detalles como: propietario, capacidad y viabilidad; se orientó el centro de inquilinos para la toma del lote y se hizo la toma con todo lo necesario para hacer un cambuche provisional, material ligero de construcción, plásticos y básicamente tres estacas (...) duró 62 días la toma con toda la represión de la policía, al final de cuentas tuvieron que negociar y ahí está el barrio que se dio por toma o recuperación de tierra (...) una anécdota muy bonita es que la policía cercaban la toma y bloqueaba la zona con el ánimo de dejar sin suministros a los invasores, además tumbaban las ollas en las que preparaban el sancocho y apagaban los fogones, pero ellos se las ingeniaron para hacer unos huecos en medio de la toma, profundos, donde se hacía el fogón para que no los vieran y los compañeros de la CNP que apoyaban en horas de la madrugada o en el cambio de guardia les tiraban los alimentos por encima para 
que dentro realizaran los sancochos. Es muy bonita esta anécdota porque la policía solo los veía comiendo, pero no sabían cómo ni por donde entraban la comida (Ayala, 2016).

La resistencia de la comunidad en aquellos terrenos por un tiempo prolongado de uno a dos meses, arrojó como resultado el que las autoridades municipales otorgarán en el lugar el plan de vivienda a las familias deficitarias, consiguiendo con éxito consolidar el barrio ${ }^{32}$. Posteriormente y de manera mancomunada con los habitantes del barrio Los Libertadores, se exigió por medio de manifestaciones y un paro cívico, la solución de los servicios de acueducto y alcantarillado para sus barrios. Logrando el compromiso del gobierno departamental de un presupuesto de 30 millones para atender dichas necesidades (Archivo CENAPROV AZ II Pereira -Correspondencia-, Ver Anexo 15).

En contraste con la información obtenida del texto Lucha por la vivienda en Colombia (Arango Zuluaga, 1986). Respecto al barrio Pedro Pablo Bello, conviene tener en cuenta algunas precisiones referidas por el señor Fernando Arias Cardona, quien fuera el presidente del primer centro de inquilinos en la Virginia en el año de 1975, y quien además orientó, - según su propio testimonio - las directrices de la toma del terreno para construir el barrio (Arias, Entrevista, 2020).

En primer lugar, es menester aclarar que el Partido Comunista Colombiano, en cabeza de las juventudes comunistas ya venía adelantando labores políticas en la orientación y conformaciones de los sindicatos de trabajadores del Ingenio Risaralda SINTRAIDISA y SINTRAICAÑAZUCOL, los areneros, los trabajadores de la madera de las empresas $\mathrm{ABC}$ y Muebles Clavijo entre otras organizaciones sociales de la zona (Arias, Entrevista, 2020).

Lo anterior abonó un trabajo comunitario y popular que sirvió como base social para las personas que se vincularon al primer centro de inquilinos del municipio de la Virginia. Centro de inquilinos que se crearía entre 1975 y 1976 con 25 familias deficitarias, un enclave social suficiente para permitir la llegada del primer concejal de oposición del municipio, quien sería el señor Fernando Arias Cardona, por la Unión Patriótica en el año de 1978 (Arias, Entrevista, 2020).

La toma se da porque en condición de concejal el señor Fernando Arias presentó un proyecto en 1978 para que el municipio le brindara una franja de terreno inoficioso a los deficitarios de vivienda que para

32 La mayor parte de la información sobre el barrio Pedro Pablo Bello, es tomada del texto, La lucha por la vivienda en Colombia" de Carlos Arango Zuluaga, debido a que no se encontraron fuentes documentales de archivo. 
la época constituían un promedio de 120 familias. El proyecto fue negado porque un concejal de mucho peso político para la época dio el argumento que si permitían esto se propagarían las ideas comunistas. Debido a esta negativa la Central Nacional Provivienda orientó la toma de estos terrenos (Arias, Entrevista, 2020).

Por otra parte, contrario a lo expresado en entrevista por el señor Manuel Ayala, Fernando Arias plantea que la toma de dichos terrenos no tardo más de 20 días y que fueron desalojados por la cantidad de fuerza pública que los rodeó. Otro aspecto y quizás el más relevante de todos, es que el barrio Pedro Pablo Bello, no fue construido en el mismo lugar que se dio la toma, puesto que luego de ser desalojados del lugar y ante la negativa de la administración municipal de negociar el terreno, por orientación de la Central Nacional Provivienda se buscó una propiedad que se pudiera negociar para solucionar el problema de vivienda (Arias, Entrevista, 2020).

La propiedad negociable fue conseguida por el señor Francisco Sierra en la entrada al municipio después del puente que conecta a Pereira con La Virginia, mientras que la toma previa se dio en una franja de tierra ubicada entre la salida hacia Balboa y la salida hacia Medellín. Vale la pena aclarar que estas tierras se adquirieron con el ahorro de los inquilinos y el apoyo de CENAPROV en el año de 1979, un año después de la toma de terrenos iniciales. De ahí en adelante, se desarrolló el mismo proceso que en los barrios dirigidos por la Central Nacional Provivienda en Pereira, en los cuales, los directivos de la entidad realizaron convites, basares y las gestiones necesarias para la dotación de servicios públicos y vías de acceso, etc (Arias, Entrevista, 2020).

El barrio Santiago Londoño ubicado en el vecino municipio de Dosquebradas, fue otro de los barrios construido bajo la orientación de la Central Nacional Provivienda. A diferencia del Pedro Pablo Bello, se adelantó bajo la modalidad de compra comunera (Morales \& Puentes, 1996). Tras un largo proceso y luego de tres años de reuniones y actividades entre los integrantes del único centro de inquilinos del mencionado municipio se logró adquirir los predios de una finca ubicada en el sector de Frailes conocida como Casa Roja, propiedad del señor Rafael Duque en el piedemonte del municipio industrial ${ }^{33}$.

Es así como el 7 de marzo de 1981 se hizo entrega de los lotes a

33 Como se pudo constatar con la señora Constanza Duque, hija del propietario del predio, en entrevista realizada el 3 de diciembre del 2018 (Duque, 2018). 
los 180 socios que conformaban el centro de inquilinos como grupo de pioneros en dicho proceso en 1982 y que levantaron la bandera de CENAPROV al lado del nombre del barrio como símbolo de su triunfo.

Se le coloca como nombre Santiago Londoño en homenaje al médico e importante líder comunista, quien fundó la Casa de la Amistad de los Pueblos para promover la cultura y difundir la idea del socialismo en la ciudad (Martínez, Serna, \& Correa, 2013), quien además apoyó la acción de cabildeo por los viviendistas de la ciudad e impulsó importantes acciones de mejoramiento del sistema de salud, como dotar el primer equipo de radiología para el hospital San Jorge (Morales \& Puentes, 1996).

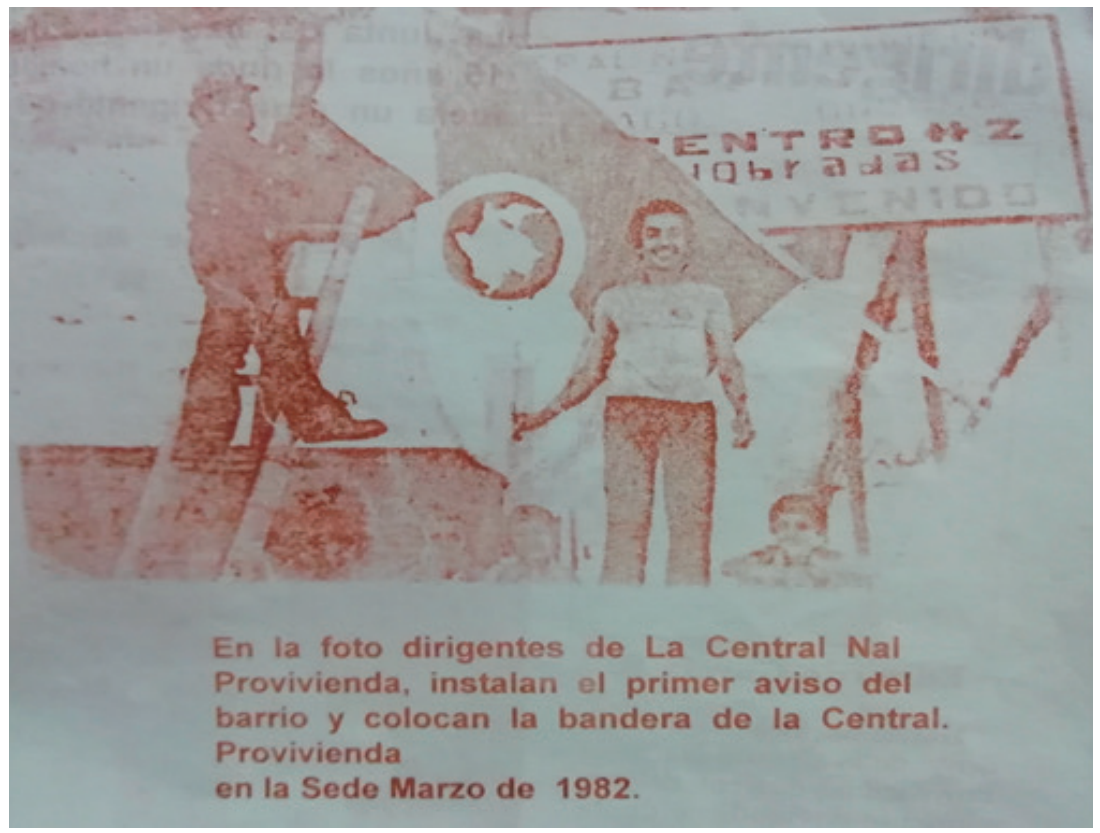

Fotografía 12: Imagen de dirigentes de la Central Nacional Provivienda instalando el primer aviso del Barrio Santiago Londoño en Dosquebradas.

Fuente: Morales \& Puentes, 1996.

El barrio Santiago Londoño reunió las características de lo que los directivos de CENAPROV denominaban barrio de Nuevo Tipo, que consistió en una destacada cohesión social entre los inquilinos, que permitió la realización de convites generando la fuerza social necesaria y los recursos para dotar al barrio de todos los servicios necesarios. Pues al no contar con servicios públicos ni acueductos, sus habitantes 
adelantaron la construcción de lavaderos y pozos comunitarios. La primera junta directiva del barrio fue integrada por: Eusebio Ospina, Fernando Montoya, Humberto Morales, Jorge Eliecer Cardona, Gloria Inés Ramírez, Pedro Ardila y Jairo Rojas (Morales \& Puentes, 1996).

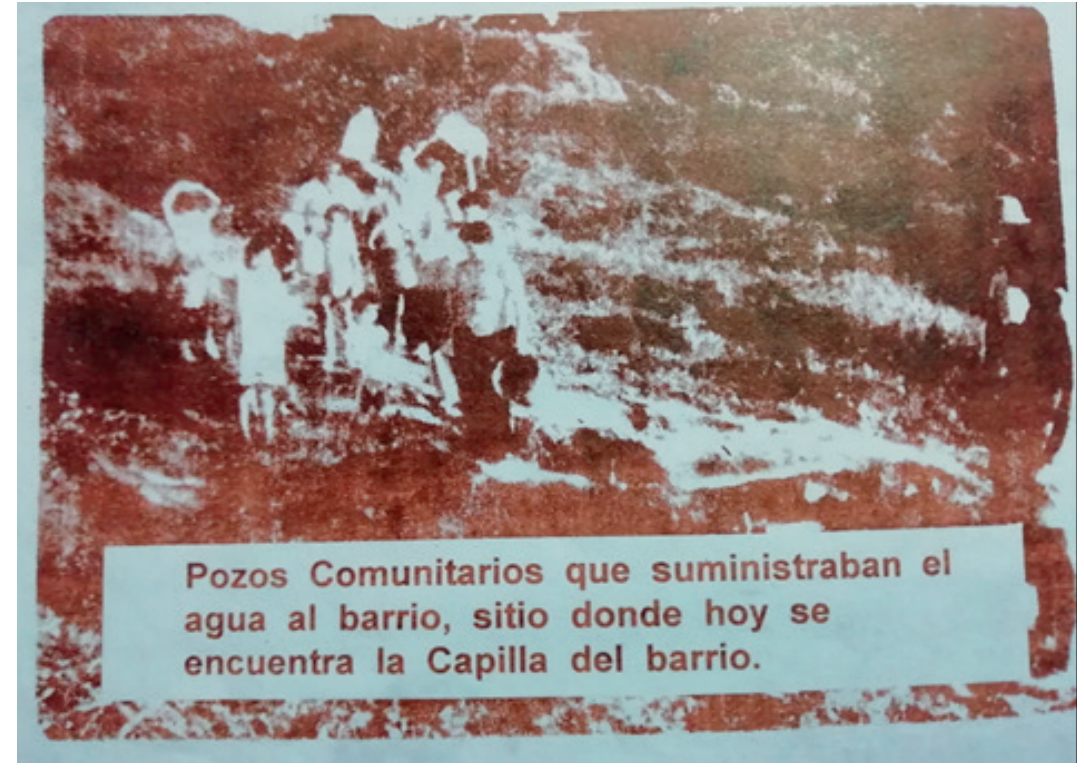

Fotografía 13: Imagen de los pozos comunitarios del barrio Santiago Londoño en Dosquebradas.

Fuente: Morales \& Puentes, 1996.

$\mathrm{Al}$ igual que en otros barrios conformados por la misma entidad, se adelantaron actividades colectivas para construir las canchas, la escuela y su sede cultural conocida como La Casa Roja. Sumado a esto, debido a que la Central Nacional Provivienda llevaba un recorrido de más de una década en la ciudad, se encargó de hacer las gestiones necesarias ante la administración municipal de Dosquebradas, para la dotación de servicios públicos y la pavimentación de sus calles.

El municipio de Santa Rosa de Cabal la Central Nacional Provivienda también participó en la consolidación de tres planes de vivienda a finales de la década de los 70: Los Andes, La Trinidad y Villa Alegría. Los tres planes de vivienda tuvieron un denominador común: Las personas se asociaron, después autorizaron a una o varias personas para comprar y hacer firmar la escritura pública de los terrenos y finalmente iniciar espontáneamente la construcción del plan de vivienda (Archivo CENAPROV AZ I Pereira -Denuncia-, Ver Anexo 8). 
De acuerdo a la información de archivo, se pudo establecer que en Los Andes en un inicio dos grupos de familias carentes de vivienda se asociaron entre sí y con sus propios ahorros y trabajo colectivo compraron y distribuyeron dos lotes de terreno para construir en ellos las viviendas. Todo ello a partir de su propia iniciativa, sin asesoría y personería jurídica de ningún tipo. Aproximadamente iniciando la década de 1980 encontraron en CENAPROV la asesoría y el apoyo para conseguir reconocimiento jurídico, no sin antes aceptar los estatutos, las normas orgánicas de la entidad y el modelo de junta directiva establecido en cada uno de sus centros de inquilinos (Archivo CENAPROV AZ II Pereira -Denuncia-, Ver Anexo 8).

Amparados en la personería jurídica de CENAPROV, dichos planes de vivienda tenían el respaldo para la tramitación de todo tipo de documentación legal como planos urbanísticos, de servicios públicos y hasta la posibilidad de recibir donaciones oficiales. La oposición a la Central Nacional Provivienda por parte de la Superintendencia Bancaria en su sede de Manizales, para que los dirigentes barriales abandonaran CENAPROV y así poder apoyar el plan de vivienda oficial (Archivo CENAPROV AZ II Pereira -Denuncia-, Ver Anexo 8), no fue impedimento para que dichos planes de vivienda se consolidaran.

Al punto que para el año de 1980 según documentación de archivo la junta directiva del barrio Los Andes Centro de Inquilinos $\mathrm{N}^{\circ} 2$ estaba compuesta por: presidente el señor Luis Aníbal Osorio; vicepresidente Gildardo Ramírez; secretario Stella Castaño; Fiscal Edison Molina y como tesorero al señor Amado Valencia (Archivo CENAPROV Pereira AZ I -Correspondencia-, Ver Anexo 16). Posteriormente para la consolidación de dicho barrio y en una acción jurídica sin precedentes en la región, se realizó la escrituración colectiva en la notaría única del municipio. En la cual, el señor Luis Aníbal Osorio Rincón transfiere el derecho de dominio sobre los terrenos, con un área de 6.796,66 M2, a 41 integrantes de la comunidad Barrio Los Andes (Archivo CENAPROV Pereira AZ I -Notariales-, Ver Anexo 17).

En el barrio La Trinidad el terreno, a finales de la década de los 70, fue adquirido mediante escritura pública y autorización verbal previo al pago de una cuota inicial por parte de Alberto Chica quien sería el presidente de su centro de inquilinos $\mathrm{n}^{\circ} 1$. El valor del terreno fue de 160.000 pesos y su adecuación fue facilitada por la ayuda de la personería municipal (Archivo CENAPROV Pereira AZ I -Denuncia-, Ver Anexo 8). 
Quedará por establecerse cuál fue el papel que jugó la Central Nacional Provivienda en relación al barrio Villa Alegría, debido a que las fuentes documentales y testimoniales no dan claridad suficiente sobre el hecho. Lo único que las fuentes permitieron establecer con claridad fue que el terreno fue adquirido mediante escritura pública firmada por once personas, sus planos fueron diseñados por Gabriel Valencia, arquitecto de la Universidad Nacional, con ayuda de personas cercanas a la organización, circunstancia que pudo determinar la asesoría constante a dichos asentamientos por parte de los miembros de la Central Nacional Provivienda en Risaralda en la década de 1980 (Archivo CENAPROV Pereira AZ I -Denuncia-, Ver Anexo 8).

En síntesis, los barrios que hicieron parte del proceso CENAPROV en los municipios de Pereira, Dosquebradas, La Virginia y Santa Rosa de Cabal, permiten apreciar una dinámica alternativa en torno a la solución de las carencias habitacionales de la comunidad más vulnerable y de escasos recursos económicos en la región. Dichas dinámicas fueron orientadas por una organización que al tiempo que proyectaba planes de vivienda de muy bajo costo y sin cuota inicial a sus afiliados, les permitía también vincularse a un proyecto político de orientación izquierdista como parte de una estrategia de organización popular que soportó la participación política de sus dirigentes en las contiendas electorales.

Esta participación electoral se vio rodeada por un contexto social propicio desde 1970 a 1987. Años en que también se vivía un ambiente de constante presión política tanto en el país como a nivel local. Basta revisar los archivos de prensa de la época para encontrar múltiples sindicatos de todas las esferas laborales como: salud, transporte, educación, trabajadores informales y públicos, que promovieron huelgas y paros en reclamo a los diferentes empleadores y gobiernos por la solución a sus necesidades.

Algunas de estas situaciones que la Central Nacional Provivienda apoyó de forma directa fueron, por ejemplo, denunciar en 1978 ante la opinión pública la represión de la que fueron objeto más de 50 trabajadores de la empresa Industria Gales Ltda, a quienes se les retuvo el salario por más de un mes sin justificación alguna (El Diario, 30 Marzo 1978). En una carta dirigida el gobernador del departamento José Ramón Ortega Rincón en 1980, los dirigentes Manuel Castillo y Carlos Alberto Benavides, denuncian los graves problemas que aquejan a los inquilinos y trabajadores de la ciudad de Pereira afectados por la carencia de vivienda, hacinados en casas de inquilinato y en las laderas 
y riberas del río Otún:

Consideramos, señor gobernador, que parte de estos problemas se presentan por la falta de planes de vivienda oficiales que garanticen a los trabajadores la consecución de sus viviendas sin cuota inicial y con cuotas de amortización bajas, acorde al salario promedio en esta región. Así mismo y como consecuencia del numeroso déficit habitacional, se han constituido una serie de organizaciones o agencias de arrendamientos y compraventa de inmuebles que han coadyuvado seriamente para que los alquileres suban de precio según sus criterios egoístas. Nos hemos dado cuenta que éstas famosas agencias de arrendamientos funcionan con personería jurídica por la gobernación y se amparan en esta para dirigir sus negocios sin ningún control y dirigidos contra los intereses de los trabajadores que carecen de vivienda propia para su familia. (Archivo CENAPROV AZ I Pereira -Correspondencia-, Ver Anexo 18).

También fue patente su decidida oposición a la descongelación del valor de los arrendamientos por medio del decreto número 3450 de diciembre de 1981, plasmado en carta dirigida al presidente de la República Julio César Turbay Ayala, donde además de solicitar la derogación del decreto, se manifiesta el malestar por las alzas en los precios de los artículos de primera necesidad y la precariedad del salario mínimo (Archivo CENAPROV AZ I Pereira -Denuncias-, Ver Anexo 19).

En ese orden de ideas, la lucha por la vivienda siempre estuvo articulada dentro del contexto político a las necesidades de los habitantes de sus barrios y de las clases sociales más vulnerables en la ciudad. De modo que, desde sus inicios, los Centros de Inquilinos empezaron a servir además de fortín electoral a sus representantes ${ }^{34}$. Desde el momento en que algunos dirigentes y aliados de CENAPROV lograron alcanzar puestos de elección popular, su gestión empezó a ser decisiva en la legalización de los planes de vivienda y la dotación de todos los servicios públicos esenciales para los barrios.

De este modo, la actividad continua dela Central Nacional Provivienda en la ciudad de Pereira con las comunidades en las que tuvo influencia, empezó a marcar un cambio en la dinámica política de oposición en la ciudad. De 1974 en adelante empiezan tener protagonismo nombres como Manuel Castillo, Santiago Londoño, Miguel Castañeda, Gildardo

34 Esto se evidencia en documento de archivo en el que, para el año de 1974, los dirigentes de CENAPROV invitan a través de panfletos a votar por los candidatos que han apoyado el proceso viviendistas, además es claro la posición política frente a la acción cabildante de la misión coadministradora y el llamado a sus afiliados para apoyar los candidatos Joaquín Botero y Horacio Bermúdez (Documento Archivo Personal - Hernán Botero). 
Castaño, Carlos Alberto Benavides, Eduardo García, los cuales fueron elegidos en el Concejo y la Asamblea Departamental, como importantes líderes de los partidos de oposición de gran valor para los proyectos viviendistas de CENAPROV en la ciudad de Pereira.

\section{Declive de CENAPROV en Pereira}

La organización de viviendistas, Central Nacional Provivienda, tuvo su mayor fuerza entre las décadas de 1970 y 1980 en la ciudad de Pereira. En este tiempo logró consolidar 10 planes de vivienda, algunos en convenio con el ICT como la tercera etapa del barrio José Antonio Galán, el barrio Nueva Colombia y comunidad Carlos Alberto Benavides ubicado en el proyecto 2.500 lotes. Esta colaboración permite establecer que, aun siendo una organización direccionada por el partido comunista, no tuvo problema en unir sus esfuerzos con la oficialidad en la búsqueda de solución de vivienda para los destechados.

Aunque la Central Nacional Provivienda no ha desaparecido por completo de la esfera nacional, en la ciudad de Pereira empezó a tener una paulatina decadencia que se puede rastrear a partir de 1987, año en que como ya se afirmó, se desarrolló su último proyecto de vivienda en la ciudad llamado Barrio Jaime Pardo Leal. Varios fueron los motivos que permiten evaluar los pormenores del declive, entre ellos: La violencia política en el marco de genocidio de la Unión Patriótica, la injerencia de las juntas de acción comunal en los barrios constituidos por la organización, las políticas de control y vigilancia de los planes de vivienda en manos de Superintendencia Bancaria, los problemas internos entre sus directivas zonales y el aumento de urbanizadores privados como se corrobora en el siguiente apartado.

\section{Violencia política}

En primer lugar, una de las razones principales del declive de la organización fue el que muchos de los dirigentes de CENAPROV se encontraron involucrados en el contexto del ejercicio de la violencia sistemática de la ultraderecha en contra de la Unión Patriótica UP. Esta violencia sistemática tiene su origen en el surgimiento de dicho partido político y desde el acuerdo de paz de La Uribe en 1984 hasta el año 2002 cuando el CNE suspendió la personería jurídica de la UP (Centro Nacional de Memoria Histórica, 2018).

La violencia política contra los militantes de izquierda no fue ajena a la ciudad de Pereira. Así lo comenta uno de los líderes barriales en la 
ciudad, quien manifestó que a mediados de los años 80 fueron múltiples los allanamientos y amenazas a los dirigentes de la organización, por ejemplo en el barrio La Isla de Cuba, las autoridades policiales allanaron en repetidas ocasiones el salón social buscando armamento, destrozando los sacos de bienestarina, documentos y materiales (Botero F. , 2018). De igual manera, lo registraba El Diario, en noticia que publicaba el 25 de octubre de 1985, donde múltiples sectores de izquierda de la ciudad elevaban su voz de protesta por los allanamientos en viviendas de los integrantes de la UP, entre ellos la de Gildardo Castaño, con el mismo objetivo de buscar armamento o material subversivo (El Diario, 25 Octubre 1985).

Existe documentación de archivo que permite evidenciar toda un serie de denuncias por medio de comunicados en los cuales directivos de la Central Nacional Provivienda manifestaban su rechazo a hechos violentos como lo fueron: en 1980 el atentado del que fue víctima el fiscal del Centro de Inquilinos $n^{\circ} 9$ barrio José Martí, el señor Bernardo González Vargas; en 1985 con una carta dirigida al Presidente Belisario Betancur, se denuncia el acto terrorista contra la sede central de CENAPROV y en 1987 otra carta enviada el presidente Virgilio Barco denunciando el asesinato del presidente de la seccional de Provivienda en Meta, Gabriel Alfredo Briceño (Archivo CENAPROV AZ II Pereira -Denuncia-, Ver Anexo 20).

Todas estas situaciones fueron minando el tejido social dentro de la organización que vivió uno de los momentos más difíciles con el asesinato del entonces candidato presidencial por la Unión Patriótica Jaime Pardo Leal el domingo 11 de octubre de 1987 (La Tarde, 12 Octubre 1987). Situación que provocó el repudio nacional, pero sobre todo facilitó la creación de un ambiente de zozobra entre los militantes de la Unión Patriótica y el Partido Comunista. Muchos dirigentes entrevistados coinciden que el hecho de ver a su mayor líder asesinado y las constantes noticias a nivel nacional sobre los asesinatos de los dirigentes de izquierda, llevaron a que la lucha que habían adelantado con los destechados de la ciudad se paralizara. De ahí en adelante, no se construyeron más barrios en Pereira y municipios aledaños, ni se crearon nuevos centros de inquilinos.

Para el año de 1988, según documentos de archivo, los señores Luis Eduardo García presidente de CENAPROV en Risaralda y el señor José Bautista Osorio vicepresidente regional de la misma entidad, envían una carta al gobernador encargado de Risaralda el señor Diego Patiño 
Amariles, denunciando las amenazas de las que eran objeto, por parte de la organización autodenominada MAC (Muerte A Comunistas), y solicitando medidas de protección urgente para sus vidas (Archivo CENAPROV AZ II Pereira -Denuncia-, Ver Anexo 21):

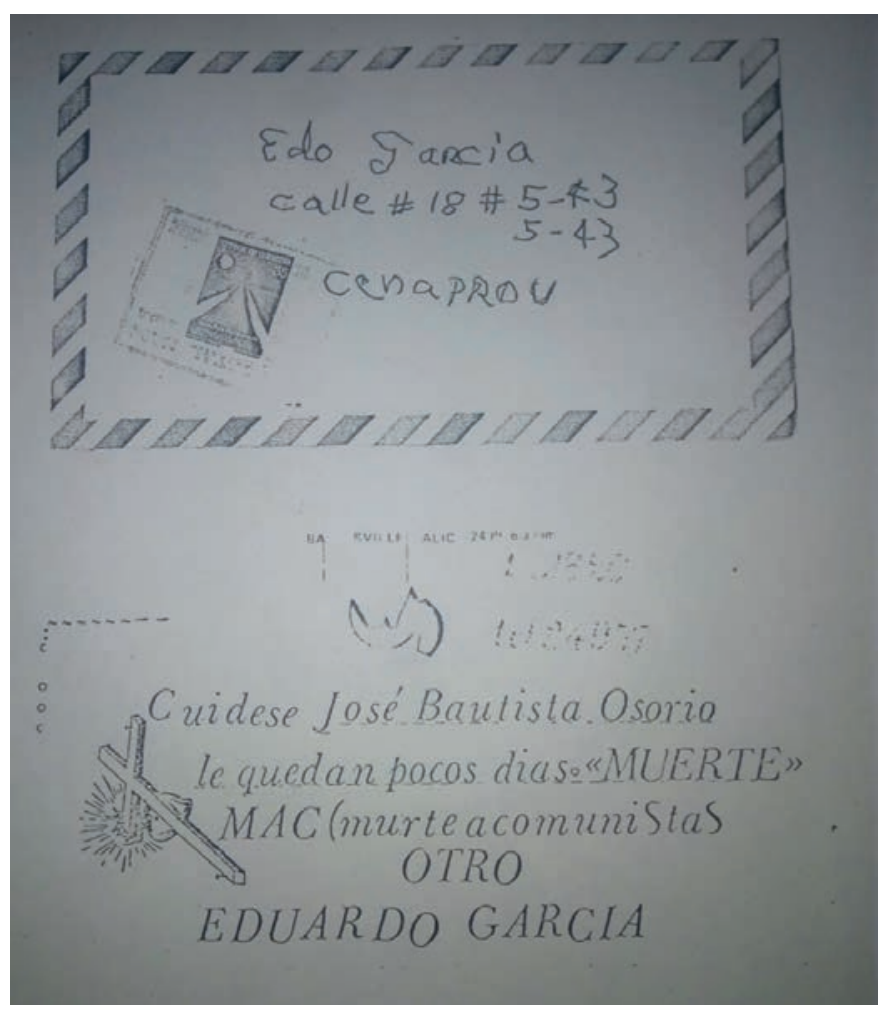

Fotografía 14: Amenaza contra los dirigentes de la Central Nacional Provivienda en Pereira Eduardo García y José Bautista.

Fuente: Archivo CENAPROV AZ II Pereira -Denuncia-.

Algunos años después, según se pudo constatar en la prensa de la ciudad, el señor Eduardo García Barítica, dirigente de la UP y presidente de la Central Nacional Provivienda seccional Risaralda, fallece el 11 de marzo de 1996 como consecuencia, según versiones oficiales de un "intento de asalto", en el que le propinaron tres impactos de bala. Según lo registró el periódico el Diario el 14 de marzo de ese mismo año en una noticia titulada: "Dirigente Político de la UP fue herido en atraco". No obstante, la versión suministrada por militantes de la UP para el mismo diario controvertía de manera contundente la versión 
oficial sobre todo si se tiene en cuenta la denuncia establecida ante el gobernador de Risaralda en el año de 1988.

La versión de los hechos suministrada a este medio por militantes de la UP, indica que se trató de un atentado contra la vida de Luis Eduardo García posiblemente por sus vínculos con la Unión Patriótica. "Desde hace aproximadamente dos años Felipe García Ochoa, el mismo Eduardo García y yo venimos siendo víctimas de amenazas contra nuestras vidas" dijo José Bautista Osorio.

Mediante llamadas telefónicas y cartas amenazantes les manifiestan que se cuiden, pues en cualquier momento pueden ser víctimas de pistoleros.

Los comunicados intimidantes son firmados por MAC (Muerte A Comunistas) Según lo indicó José Bautista Osorio, máximo dirigente del Movimiento Amplio Gildardo Castaño Orozco, fundado en memoria del sacrificado exconcejal y dirigente comunista de Pereira.

Felipe García Ochoa quien ha sido presidente del Sindicato de Educadores de Risaralda (SER) expresó el temor que sienten los militantes de la UP por una posible reactivación de atentados contra miembros de la Unión Patriótica.

Por su parte del coronel Mariano Jaimes informó no tener conocimiento de denuncias formuladas por amenazas contra miembros de agrupación política alguna. Manifestó que todo se trató de un hecho de delincuencia común (El Diario, 14 Marzo 1996).

La versión proporcionada por los militantes de la UP parece coincidir con la del informe elaborado por el centro de memoria histórica denominado Todo pasó frente a nuestros ojos (2018), donde se manifiesta que la UP fue golpeada duramente por la ola de violencia sistemática en la escala departamental ya que entre 1986 y 1997, 14 diputados en ejercicio fueron asesinados, entre ellos: Eduardo García en Risaralda (Centro Nacional de Memoria Histórica, 2018).

En Pereira otra delas muertes más impactantes paralas organizaciones de izquierda, y que se presume también influyó significativamente en el declive de CENAPROV, fue el asesinato de Gildardo Castaño el 6 de enero de 1989 (La Tarde, 7 Enero 1989), quien además de desempeñarse como concejal y diputado de izquierda, como se ha visto, también era un importante promotor y colaborador de la Central Nacional Provivienda en la ciudad. Fue tal el impacto del asesinato del concejal Gildardo Castaño que en primera plana del 7 de enero de 1989 el periódico La Tarde publicó: "Risaralda pierde a un líder". Era coordinador de la Unión Patriótica en Risaralda. Hacía 20 días se le había retirado la 
escolta. Cinco impactos de bala, todos en el tórax, cegaron su vida. La ciudadanía entera repudia el fatal atentado (La Tarde, 7 Enero 1989).

El asesinato de Gildardo Castaño, según la versión de la UP en un comunicado de prensa, se sumaba a la lista de 10 asesinatos de miembros de esa colectividad en los meses de diciembre y enero de 1988 y 1989 respectivamente en el país (El Diario, 7 Enero 1989). Lo que constituía la muestra de lo que muchos integrantes de la U.P. denominaban guerra sucia contra los militantes de la izquierda, y que se había trasladado a Risaralda. De hecho, algunos días después del homicidio del concejal Castaño, el MAC ratificaba sus amenazas contra los dirigentes de izquierda en la ciudad en un comunicado enviado a la prensa local:

Una tenebrosa organización al parecer de tendencia de extrema derecha en nota enviada a los medios de prensa ratificó sus amenazas contra varios dirigentes sindicales, concejales y políticos de la UP de Risaralda.

En la misiva los presuntos integrantes del movimiento Muerte a Comunistas (MAC) indican que están realizando la "Operación Caldas" y advierten a una lista de 13 personas que se cuiden ya que no les perdonaran la vida.

De la misma manera aseguran conocer muy bien los lugares de reunión de los amenazados y sus sitios de trabajo. La lista de las personas señaladas por la agrupación para presumiblemente darles muerte es: María Teresa Henao, secretaria del SER, Luis Eduardo García de Cenaprov y dirigente de la UP, José Bautista Osorio sindicalista de las Empresas Públicas de Pereira, Felipe García Presidente del SER, Jair Rodríguez de la UP, Fernando Arias de la UP, Rosalba Marín, Arturo Sanín tesorero de Pereira, el educador Jorge Eliécer Cardona y los concejales Emiro Rueda y Julio Arenas.

Las amenazas contra estas personas fueron entregadas ayer mismo a las autoridades competentes por el presidente de la Coordinadora de la UP (El Diario, 12 Enero 1989).

Según testimonios de dirigentes entrevistados el ambiente para los militantes de la UP y el PCC era tan tenso, que muchos jóvenes militantes e integrantes de la organización Central Nacional Provivienda prefirieron abandonar el país por temor a la oleada de violencia contra los simpatizantes de izquierda (Botero F. , 2018).

La estructura política y organizativa de CENAPROV a finales de los 80 y principios de los 90 , fue diezmada por la violencia política llevando a la organización casi a su desaparición. En 2016 la Central Nacional Provivienda fue reconocida como víctima del conflicto debido a que, de acuerdo con la resolución No.2016-13802 de 28 de julio de 2016 
expedida por la Unidad Para la Atención y Reparación Integral a las Víctimas, a partir de 1984 se inició una ola de persecución que conllevó amenazas, asesinatos y atentados contra los miembros y dirigentes de la entidad Central Nacional Provivienda por parte de grupos armados ilegales, particularmente paramilitares, lo que tuvo como consecuencia el debilitamiento de la organización a nivel nacional. Según la misma resolución:

Es necesario recordar que, en el año de 1984, se firmó un acuerdo fallido entre el Gobierno de Belisario Betancur y las FARC, mediante el cual se pensaba la incorporación de los miembros de tal guerrilla a la vida civil, política y legal. Tal proceso se desarrolló paralelo a la creación del Movimiento Político Unión Patriótica (UP), el cual tuvo una movilización social y política que se desarrolló bajo relaciones de solidaridad con diversas organizaciones sociales y políticas como la Asociación Central Nacional Provivienda. En este marco, luego de los poderosos resultados electorales en favor de la UP, en 1986 empezó el exterminio de la UP y la persecución a las organizaciones asociadas, una de las cuales era la Asociación Central Nacional Provivienda. (...) se debe resaltar que la Asociación Central Nacional Provivienda, tenía entre sus objetivos crear bancos de tierra, denunciar la existencia de lotes ociosos y el acaparamiento de tierras, así como promover la democratización de la tierra, la capacitación de sus afiliados para la tenencia de tierras y organizar a las comunidades para el desarrollo de proyectos para la consecución de vivienda. Al plantearse tal proyecto quedaron inmersos en medio de uno de los principales motivadores del conflicto armado interno, la disputa por la tierra (Resolución, 2016).

Siguiendo esta línea argumentativa, la pérdida de personas valiosas por sus habilidades de gestión y organización dentro de las comunidades, sumada a las vulneraciones al derecho a la seguridad, a la libre circulación, a un ambiente sano, a la libre asociación y autonomía organizativa, socavaron los cimientos de la Central Nacional Provivienda en los barrios donde tuvo influencia. Al punto que, según Gloria Elvira Naranjo, todos estos hechos de violencia ${ }^{35}$ contra sus miembros que se extienden hasta el año 2005, terminaron acabando con el tejido social construido por la organización. En consecuencia, sus directivas terminaron adoptando un nuevo perfil alejado de sus objetivos originales, buscando con ello no ser afectados por la violencia (Resolución , 2016).

\section{Juntas Directivas y Juntas de Acción Comunal}

Otra de las razones que alimentaron el declive de la organización

35 Amenazas, desplazamientos forzados, despojos forzados (Resolución , 2016). 
fue la confrontación de las juntas de acción comunal con las juntas directivas de CENAPROV al interior de los mismos barrios. Como se intentó demostrar anteriormente, la organización de viviendistas Central Nacional Provivienda operó con sus propias formas organizativas orientadas al interior de sus centros de inquilinos bajo estatutos y lineamientos independientes, debidamente socializados con todos sus afiliados. Elemento que los diferenció de los demás grupos viviendistas y urbanizadores piratas del momento. Este tipo de organización política al interior de los barrios se conformó bajo el nombre de: Juntas Directivas, las cuales darían lugar a la consolidación de lo que CENAPROV denominaba barrios del nuevo tipo.

Paralelo a esta forma organizativa orientada por CENAPROV, el Estado colombiano promovía la asociación barrial a través de las Juntas de Acción Comunal (JAC) que surgen desde 1958, bajo la ley 19 de 1958, pero se consolidan en la década de 1960 en el gobierno de Carlos Lleras Restrepo (Torres Tovar, 2009). Las JAC se convirtieron en la apuesta organizativa más difundida en el país para intervenir los sectores populares a nivel urbano en el contexto del Frente Nacional dentro del esquema del bipartidismo tradicional y clientelista. Dicha estrategia con el propósito de impulsar la idea de "la paz y la integración" se basaba en la autoayuda, la solidaridad y el restablecimiento de la paz (Moreno, 2014).

En otras palabras, las juntas de acción comunal eran una apuesta por cimentar las bases de la descentralización de la administración pública, hacia los sectores populares, como reza en el artículo 22 de la ley 19 de 1958:

Los concejos municipales, las asambleas departamentales y el gobierno nacional podrán encomendar a las juntas de acción comunal integradas por vecinos de cada distrito que se organicen de acuerdo con las normas que expidan los respectivos concejos, y a otras entidades locales, funciones de control y vigilancia de determinados servicios públicos, o dar a esas juntas cierta intervención en el manejo de los mismos (Función Pública, 2018).

Según lo describe Juan Carlos Moreno, la propaganda que se hizo a las Juntas de Acción Comunal como la solución a las problemáticas de los barrios fue bastante difundida (Moreno, 2014). Y por supuesto, la vivienda era uno de sus principales argumentos. El impulso a las JAC por parte del gobierno fue tan importante que la prensa de la ciudad de Pereira refería las adiciones presupuestales por parte de la 
administración municipal y departamental a las JAC de los diferentes barrios, así lo anunciaba un titular del 21 de marzo de 1974 "Auxilios para diferentes juntas de acción comunal en los municipios señaló el gobierno nacional" (El Diario, 21 Marzo 1974).

Sin embargo, como era de esperarse, rápidamente las juntas de acción comunal fueron cooptadas por los políticos tradicionales. No se puede olvidar que las JAC se gestan dentro del marco del Frente Nacional, contexto en el que el Partido Comunista Colombiano fue excluido de las contiendas electorales, y excluido de las redes clientelistas de las JAC que, riñeron al interior de los barrios con los dirigentes de oposición que mantuvieron la estructura organizativa de Junta Directiva orientada por la Central Nacional Provivienda. Historiadores como Marco Palacios y Frank Safford explican la forma en que las JAC fueron un factor determinante para apalancar las aspiraciones de los políticos tradicionales:

En las regiones más rurales y periféricas fueron creciendo considerablemente las Juntas de Acción Comunal. Esta fue una de las creaciones más importantes del FN de su primer presidente Alberto Lleras (1958-1962), para organizar y cooptar inicialmente los pobres de las ciudades. El principio de las JAC es que en cada comunidad (una manzana de barrio, por ejemplo) hay un líder natural que puede organizarla y darle un sentido de cooperación. Ese Estado ofrece unos fondos modestos para que la comunidad emprenda sobre la base del trabajo voluntario la construcción de escuelas, centros de salud, calles, obras de alcantarillado. Estas juntas han sido uno de los canales favoritos de los políticos clientelistas, otorgándoles auxilios parlamentarios (Safford \& Palacios, 2012).

Esta apreciación de Palacios y Safford coincide plenamente con los testimonios de las entrevistas adelantadas a los dirigentes de CENAPROV como Fernando Botero, Hernán Botero y Manuel Ayala, quienes vieron en este fenómeno una de las problemáticas que más afectaron la estabilidad política de la organización. Argumentaban que las juntas de acción comunal fueron cooptadas por líderes de la politiquería tradicional, al punto que en algunos casos hasta se cambió el nombre de los barrios, como sucedió con el Leningrado primera etapa. Allí, la junta de acción comunal decidió cambiar el nombre a barrio Santa Fe. De todos modos, algunos dirigentes de CENAPROV como Fernando Botero optaron por integrarse a las juntas de acción comunal, según él, con el objetivo de no dejar perder la esencia del trabajo de CENAPROV con la comunidad en los barrios (Botero F. , 2018).

Las juntas de acción comunal a la postre y como era de esperarse, 
se convirtieron en un fortín político decisivo para las candidaturas municipales del que se deriva aún hoy día un amplio caudal electoral al interior de los barrios. Así lo evidenció la prensa política de la época cuando declaraba en sus titulares: "Juntas comunales célula principal de la elección popular de alcaldes" (La Tarde, 1987). Aunque la Central Nacional Provivienda tuviera el mismo objetivo político en los proyectos de vivienda que logró consolidar, la injerencia de las JAC fue uno de los factores que se sumaron al declive de su estructura interna, puesto que su relación conflictiva con las Juntas Directivas hizo difícil la consolidación del proyecto político y organizativo de CENAPROV a nivel barrial constituido bajo el modelo comunista. Poco a poco y gracias a las dádivas ofrecidas por los políticos tradicionales, las personas fueron renunciando a los estatutos orientados por CENAPROV y terminaron por apoyar las orientaciones de la Juntas de Acción Comunal de los barrios.

\section{Superintendencia Bancaria}

Otro aspecto que contribuyó al declive de CENAPROV, fue la relación que se tuvo con el organismo de control Superintendencia Bancaria, entidad encargada de controlar y vigilar los grupos urbanizadores bajo la ley 66 de 1968, y mediante la cual "el Gobierno nacional, a través del superintendente Bancario ejercía la inspección y vigilancia de las actividades relacionadas con la enajenación de inmuebles destinados a vivienda y decidía el otorgamiento de créditos para la adquisición de lotes o viviendas o para la construcción de las mismas" (Alcaldía Mayor de Bogotá DC, 2018).

En los documentos de archivo de CENAPROV sobre Pereira, especialmentesobrela construcción delbarrio Leningrado, son constantes las reclamaciones que la Superintendencia Bancaria hace a la Central Nacional Provivienda por no cumplir con los requisitos necesarios para dar paso a la construcción del barrio o el recaudo de dineros con dicho fin (Archivo CENAPROV AZ II Pereira -Correspondencia-, Ver Anexo 22). Esta dinámica generó un creciente proceso de reclamaciones y exposición de motivos entre la oficina de la Superintendencia Bancaria con sede en Manizales y los dirigentes de Pereira quienes remitían todas las novedades a la central en Bogotá. Lo que significó que se presentaran algunos inconvenientes para cumplir con la documentación solicitada, razón por la cual la Superintendencia Bancaria impuso el 12 de junio de 1980 una multa por 50 mil pesos a CENAPROV por incumplir con 
los requisitos que exponía la ley 66 de 1968 ante CENAPROV (Archivo CENAPROV AZ II Pereira -Correspondencia-, Ver Anexo 22):

Resolución n 3008 de 1980 por la cual se impone una sanción a la Corporación denominada Central Nacional Provivienda. (...) LENINGRADO se adecua a lo preceptuado en el artículo 2 numeral 5 del decreto 2610 de 1979 que dispone: La celebración de promesas de venta, el recibo de anticipos de dinero o cualquier otro sistema que implique recepción de los mismos, con la finalidad de transferir el dominio de inmuebles destinados a vivienda (...) Que el artículo 28 de la ley 66 de 1968 modificado por el artículo 11 del decreto 2610 de 1979, faculta al Superintendente bancario para imponer multas sucesivas de $\$ 10.000$.oo a $\$ 50.000$. oo M/CTE, a las o entidades que incumplen las órdenes impartidas por esta Entidad en uso de las facultades de inspección y vigilancia, e infrinja las disposiciones de alguna ley o reglamento relativas a la vivienda (Archivo CENAPROV AZ II Pereira -Correspondencia-, Ver Anexo 22).

Las reclamaciones, prórrogas y litigios se extendieron alrededor de 4 años, en los que comparecieron los dirigentes de CENAPROV en cabeza de Carlos Alberto Benavides y Manuel Castillo como presidentes de la seccional Pereira, ante los requerimientos de la Superintendencia Bancaria, hasta conseguir luego de este complejo proceso, por ejemplo, la legalización del barrio Leningrado.

La compleja tramitología ante dicha entidad provocó dificultades a nivel interno en la organización. En el archivo de CENAPROV se encuentran más de 20 oficios entre la seccional Pereira y la central en Bogotá, llamando la atención en los más de 13 requisitos que exigía la Superintendencia Bancaria para la legalización del barrio, requisitos de difícil recolección por parte de las juntas directivas de CENAPROV, en razón del poco tiempo que otorgaban a la organización para satisfacerlos, dificultando con ello la legalización de los planes de vivienda (Archivo CENAPROV AZ II Pereira -Correspondencia-, Ver Anexo 22). Así se puedo constatar en uno de los documentos que data del 14 de noviembre de 1980:

Apreciados Compañeros: Con la presente deseo referirle a uds la solicitud que en ocasión anterior hice en el sentido de que se sirva informar si la escritura y promesa de compraventa del barrio LENINGRADO fue corregida en cuanto al número de matrícula inmobiliaria (...) Tal información es indispensable para efectuar la petición de aprobación de dicho plan ante la Superintendencia Bancaria (...) Les recuerdo igualmente que en ocasiones anteriores por el no lleno de requisitos, que eran de difícil obtención, la organización ha tenido que pagar elevadas multas (Archivo CENAPROV AZ I Pereira-Correspondencia-, Ver Anexo 22). 
Todas estas dificultades en lo relativo a la legalización de los planes de vivienda, coinciden con el testimonio de Jairo Mejía a propósito del declive de la Central Nacional Provivienda en Pereira:

CENAPROV sigue. El problema de CENAPROV ahorita es que la normatividad de vivienda en Colombia es muy exigente (...) en materia de costos. Entonces CENAPROV no puede entregar como entregaban ahora 40 años. Ya tiene que entregar con servicios públicos, transporte, gas, teléfono, Todo. Entonces eso son unos costos muy elevados que la gente no está en condiciones de asumir (Mejía J., 2016).

En algunos oficios los dirigentes de la seccional Pereira manifestaban su inconformismo por la forma en que la Superintendencia Bancaria asumió su rol como ente vigilante, debido a que eran citados a reuniones en la oficina regional de la entidad en Manizales donde se les manifestaba que se retiraran de CENAPROV debido a que era una entidad ilegal y comunista. Y además se les recomendaba la afiliación a otras entidades urbanizadoras para que se les pudiera prestar la colaboración necesaria (Archivo CENAPROV AZ II Pereira -Denuncia-, Ver Anexo 23). De este modo, las múltiples y constantes dificultades que encontraron los dirigentes de la Central Nacional Provivienda para legalizar los barrios ante la Superintendencia Bancaria y la oficina de Planeación Municipal, constituyeron otra de las razones que debilitaron su accionar.

\section{Los urbanizadores privados}

Otro de los factores que incidió en el declive de CENAPROV fue el fortalecimiento de los grandes consorcios urbanizadores privados, que en su mayoría tenían convenios con la banca privada y se encontraban organizados en una asociación gremial llamada CAMACOL, entidad creada desde 1957 con el objetivo de proteger los intereses de los empresarios e industriales colombianos de la construcción (CAMACOL, 2019).

Este gremio ejerció una importante presión sobre el Estado en sus compromisos con la vivienda para los sectores populares. Según Jairo Arango, ex director del ICT por la década de 1980 y ex alcalde de la ciudad, CAMACOL fue determinante para la liquidación del ICT, en tanto el ICT se había convertido en una significativa competencia en el tema de vivienda (Arango Gaviria J. , 2018).

El ICT fue liquidado en 1991, sentando con ello un precedente que se presume influyó también en el debilitamiento de CENAPROV, 
según Jairo Arango, al estar la tierra urbana y la oferta de vivienda en manos de los consorcios privados, se incrementó el valor de la misma. El elevado costo de la tierra dejó por fuera la capacidad de acceder a ella por parte de grupos viviendistas, haciendo inviables las compras comuneras que adelantaba CENAPROV con ayuda de las comunidades en las zonas donde tenía influencia. La compra de terrenos se convirtió en un proceso difícil y oneroso. Por otra parte, después de la liquidación del ICT en 1991 y el INURBE 10 años más tarde, el Estado deposita los auxilios estatales en manos de los urbanizadores privados a través de las viviendas de interés social y los fondos de ahorro (Arango Gaviria J. , 2018).

Pereira y Dosquebradas como ciudades intermedias y depositarias de un importante flujo migratorio a partir de 1950 -como se demostró suficientemente en el capítulo I-, concentraron la atención de grandes consorcios urbanizadores que multiplicaron la oferta de vivienda y encontraron en los gobiernos a partir de Misael Pastrana un importante apoyo político, debido al impulso del Plan de Desarrollo de Colombia 1070-1970, formulado por Lauchlin Currie, quien reconoció en la construcción de vivienda un importante motor de desarrollo económico que logró canalizar los esfuerzos estatales y la inversión privada. (Lean Construction Enterprise LCE, 2019).

En resumen, si a la concentración de la oferta de vivienda en mano de consorcios privados, se le suma la escasez de tierras para construir planes de vivienda a bajo costo, se podrá deducir la incapacidad para competir por los terrenos y la construcción de planes de vivienda por parte de los grupos de viviendistas como CENAPROV, disminuyendo aún más el impulso de continuar con la lucha por dotar de vivienda a los destechados de la ciudad.

\section{Problemas internos}

Finalmente, todos estos elementos, sumados a las tensiones habituales existentes al interior de la organización entre sus dirigentes en Pereira, entorpecieron y frenaron el accionar de la entidad en la ciudad. Existe documentación que permite establecer que, a partir del año 1982, se presentaron dificultades entre el reconocido dirigente viviendista Manuel Castillo y la junta directiva de la Central Nacional Provivienda en Risaralda, presidida por el señor Eduardo García. Ésta última, en resolución $\mathrm{N}^{\circ} 10-47$ del 3 de julio de 1982 decide expulsar de las filas de la organización por motivos de incompatibilidad y 
malos manejos administrativos al señor Manuel Castillo. Según dicha resolución, el señor Castillo siendo diputado del departamento en los periodos 1978-1982, no hizo partícipe a los barrios filiales que apoyaron su candidatura de los auxilios ordenanzales a los que tenían derecho los sectores populares, indicando con ello una clara traición a la Central Nacional Provivienda y sus afiliados (Archivo CENAPROV AZ II Pereira -Correspondencia-, Ver Anexo 24).

En este mismo sentido, son varios los documentos de descargo del señor Manuel Castillo, quien a través de comunicados a la seccional Risaralda y a la dirección nacional de CENAPROV, denunció la manera como los dirigentes de la seccional regional enlodaron su buen nombre y el de su familia, al sugerir que era un ladrón. En dichos documentos trata de aclarar que su intención no era denunciar a la organización Central Nacional Provivienda ni dañar su buen nombre ${ }^{36}$, sino que sus denuncias las efectuaba desde el punto de vista personal para que los dirigentes regionales respondieran por las calumnias dirigidas en su contra (Archivo CENAPROV AZ II Pereira-Correspondencia-, Ver Anexo 25).

Otro caso similar se presentó en el año de 1985, cuando según resolución expedida nuevamente por la seccional de CENAPROV en Risaralda -cuyo presidente era el señor Eduardo García y su secretario general el señor José Correa-, se retira como directivo de la dirección seccional al señor Francisco Botero Barrera y se le sanciona con la prohibición de asumir cargos de dirección o responsabilidades dentro de la organización por un periodo de dos años. Esto debido a que el señor Botero recibió dineros de afiliaciones por fuera del marco legal de la organización y por hacer uso de un dinero que le fue entregado para que lo trasladara desde un centro de inquilinos a la oficina seccional (Archivo CENAPROV AZ II Pereira -Correspondencia-, Ver Anexo 26).

Según el mismo documento, este tipo de comportamientos al interior de la organización viviendista, eran negativos en tanto que acarreaban perjuicios directos a los miembros aportantes como al prestigio de la Central Nacional Provivienda en la ciudad (Archivo CENAPROV AZ II Pereira -Correspondencia-, Ver Anexo 26). Por esta razón, se considera que las disputas internas por malos manejos administrativos entre los

36 Resulta llamativo que para el mismo año 1982, en un artículo de prensa del 21 de julio del periódico La Tarde, el diputado Manuel Castillo manifiesta su inconformidad respecto al papel del Partido Comunista, al criticarlo por el simple hecho de tener novia, lo cual constituía una labor de espionaje a sus militantes, lo que constituía una práctica contraria a su ideario revolucionario (La Tarde, 1982). 
directivos de la entidad, aunque no constituyen el motivo principal del declive de la organización en la ciudad, probablemente sí repercutieron en la disminución de la confianza en los integrantes de la organización.

Después de la conformación de los barrios Nueva Colombia y Jaime Pardo Leal a finales de los años 80, CENAPROV no volvió a liderar más proyectos de construcción de vivienda en la ciudad de Pereira. No obstante, su representación del ideario comunista en la lucha por el derecho a la vivienda continúa vigente como necesidad sentida por todos aquellos que no logran acceder a la compra de una vivienda y como testimonio del ideario político de sus protagonistas, en los documentos de archivo y los nombres de sus barrios, negándose a desaparecer. De allí la importancia de recuperar la memoria de estas organizaciones y de sus líderes, como parte de un proceso histórico de construcción de ciudad que hasta el momento ha sido poco estudiado y aún permanece latente en los márgenes de la ciudad. 


\section{Conclusiones}

T o expuesto a lo largo de la presente investigación, desde el punto Lde vista de la historia urbana, permite considerar nuevamente el proceso de conformación urbana en la segundad mitad del siglo XX en la ciudad de Pereira desde su periferia. La tarea de revisión de las fuentes trae a consideración nueva información sobre el pasado de la ciudad, que permite comprender de una manera distinta la conformación de hábitat urbano desde la perspectiva de los colonizadores y pobladores de sus márgenes.

Este breve análisis del decurso histórico de CENAPROV, permite reconocer la dinámica migratoria de mediados del siglo XX en la región, de la que se desprendió la emergencia de un accionar en pro de la consecución de la vivienda en la ciudad. Situación que impulsó la capacidad de organización y autogestión de las comunidades de la mano de los dirigentes de CENAPROV para dar solución a las carencias habitacionales.

Se intentó establecer que el desborde demográfico de la segunda mitad del siglo XX en la región repercutió en el aumento de población migrante en la ciudad de Pereira, para refugiarse de la violencia o como forma de buscar mejores condiciones de vida derivadas del empleo. El 
mentado desborde demográfico, evidenciado en los censos de 1951, 1964, 1973 y 1985, supuso un incremento de la demanda cuantitativa y cualitativa de la vivienda que desbordó la capacidad de respuesta estatal. Dicho desborde facilitó la entrada en escena de grupos de invasores de terrenos, urbanizadores piratas y grupos de viviendistas que intentaron resolver las carencias habitacionales de muchos pobladores por medio de la organización y la autogestión como en el caso de la Central Nacional Provivienda.

CENAPROV o Provivienda, se sirvió de su experiencia en las luchas por la vivienda para los destechados a partir de la toma de terrenos y las compras comuneras principalmente en la ciudad de Bogotá en la década de los 60, y desplegó la misma estrategia en muchos municipios del país como Pereira, Dosquebradas y la Virginia, donde al igual que otras ciudades vecinas como Manizales, Armenia e Ibagué, también se padecía un significativo déficit habitacional.

Los hallazgos de esta investigación permiten establecer que desde 1959, la Central Nacional Provivienda como entidad vinculada al Partido Comunista se logró consolidarse como la organización de viviendistas líder a lo largo y ancho del país, haciendo presencia en más de 156 municipios, brindando solución de vivienda a las familias de escasos recursos que carecían de capacidades para obtener créditos o beneficios estatales en programas como el ICT.

La influencia de la Central Nacional Provivienda en la ciudad de Pereira se hace evidente a partir de 1973 con el protagonismo de sus líderes comunitarios para adelantar el primero de diez planes de vivienda en la ciudad, denominado la Isla de Cuba. A partir de allí, y de la mano del liderazgo de muchos de sus dirigentes de izquierda a nivel regional, como Joaquín Botero, Carlos Alberto Benavides, Manuel Castillo, Miguel Castañeda, Gildardo Castaño, Eduardo García y Jairo Mejía, se logró organizar a la comunidad en torno a principios como la solidaridad, el apoyo mutuo, y la formación política derivada de las orientaciones del partido comunista para establecer una estructura organizativa sólida y eficaz que permitió no solo la convivencia sino también la consolidación de una fuerte base o fortín electoral dentro de los barrios, que posibilitó a muchos de sus dirigentes la participación en cargos de elección popular.

Desde la oposición, CENAPROV encontró en los destechados una oportunidad para fortalecerse política y electoralmente, y éstos últimos, a su vez, en CENAPROV encontraron una forma de solucionar su 
problema de vivienda.

Con algunos de sus representantes elegidos en la Asamblea Departamental y el Concejo de Pereira, como Miguel Castañeda, Gildardo Castaño, Carlos Alberto Benavides, Manuel Castillo y Eduardo García, se fortaleció el trabajo de legalización de los planes de vivienda apoyados por la Central Nacional Provivienda y se realizaron las gestiones correspondientes para dotarlos de servicios públicos esenciales, como alcantarillado, agua, energía y vías de acceso.

Se pudo constatar que los postulados de Jacques Aprile alrededor de la lucha por la vivienda urbana, coinciden con el accionar de CENAPROV en la ciudad de Pereira. Debido a la forma como la organización de viviendistas adelantó la intervención de lugares periféricos, inhabitados y agrestes en espacios históricamente construidos. Así lo evidencia la zona donde se construyó el barrio La Isla de Cuba, donde se dieron acciones colectivas para transformar el espacio y hacerlo habitable. De este modo se agenció una nueva dinámica en la relación urbana de la ciudad con sus habitantes. Igualmente se intentó demostrar la existencia de relaciones sociopolíticas entre los integrantes de CENAPROV encaminadas a dotar de contenido y significado las intervenciones que realizaron en la periferia urbana para dar solución al problema habitacional de los destechados, especialmente en el suroccidente de la ciudad.

Las fuentes documentales también permiten deducir que la estrategia más utilizada por la Central Nacional Provivienda para la consecución de vivienda en la ciudad de Pereira, fue la compra comunera de terrenos urbanizables amparados en la personería jurídica que poseían. Sólo en dos ocasiones fueron invadidos terrenos privados sin comprar, para solucionar de manera rápida la carencia habitacional en lo que hoy son el barrio Salvador Allende y en el barrio José Martí ubicados ambos en la comuna Río Otún, no muy lejos del centro de la ciudad.

Ocho planes de vivienda se desarrollaron a partir de la negociación de terrenos, principalmente en el sector sur occidental de la ciudad, específicamente en las comunas San Joaquín, el Oso y Perla del Otún, zona que vivió una importante expansión urbana a partir de los años 70 y en la que CENAPROV consolidó el 70\% de sus planes de vivienda. Los testimonios de muchos de sus protagonistas permiten deducir que a partir de la autogestión y la solidaridad comunal por medio de bazares y eventos se adelantó la organización de terrenos, la construcción de casas, acueductos improvisados por medio de pozos y paulatinamente 
por medio de la gestión política de sus dirigentes.

Se transitó del ámbito de la informalidad hacia la formalidad gracias a la gestión político administrativa de CENPROV. En algunas ocasiones se trabajó de manera mancomunada con el municipio.

A pesar de las tensiones existentes con la oficina de Planeación Municipal y la Superintendencia Bancaria con la organización viviendista en lo relativo a permisos de construcción y al hecho de que CENAPROV fuese considerado un grupo urbanizador pirata, su accionar en la ciudad fue decisivo en la solución de vivienda para las personas de más bajos recursos que habían quedado por fuera de las soluciones promovidas por el Estado a través de instituciones como el ICT y el Fondo de Vivienda Popular. De este modo, también quizá es posible concluir que la Central Nacional Provivienda contribuyó de manera significativa en el crecimiento urbano de la ciudad de Pereira con la consolidación de sus 10 planes de vivienda mediante la modalidad de autoconstrucción.

Del mismo modo la evidencia documental y testimonial, permite establecer que la influencia de la Central Nacional Provivienda no se circunscribió a Pereira. Por el contrario, también promovió el desarrollo de planes de vivienda y juntas directivas a nivel barrial en los municipios vecinos como Dosquebradas con la conformación del barrio Santiago Londoño, en La Virginia con la conformación del barrio Pedro Pablo Bello y en Santa Rosa de Cabal asesorando algunos planes de vivienda ya conformados como Los Andes, La Trinidad y Villa Alegría.

De otro lado, también parece posible reconocer por medio de las fuentes periodísticas y testimoniales, la enorme relevancia que tuvo el componente ideológico y político de la organización y sus dirigentes en la lucha por el derecho a la vivienda y por supuesto, en la lucha por el poder político en la región. De modo que, en la toponimia de sus barrios -La Isla de Cuba, Leningrado, José Martí, Salvador Allende, Jaime Pardo Leal, Carlos Alberto Benavides- ha quedado reflejado el protagonismo de la izquierda en la lucha popular por la vivienda y el eco de la fuerza que tuvo la Central Nacional Provivienda en la ciudad en la segunda mitad del siglo XX.

Se rastreó el declive de la organización iniciado a finales de los años 80 como resultado de la suma de diversos elementos que la información testimonial y de archivo consultada permitieron establecer. Como factor preponderante se resalta la violencia política y la persecución de la que fueron objeto muchos de sus dirigentes en el contexto del genocidio 
del partido de izquierda Unión Patriótica, violencia que cegó la vida de líderes a nivel local y a nivel nacional, fracturando el tejido social de la organización.

Se corroboró que CENAPROV en la actualidad hace parte de un proceso de reparación colectiva en el marco de la ley de víctimas y restitución de tierras, según la resolución No. 2016-13802 de 28 de julio de 2016 expedida por la Unidad Para la Atención Reparación Integral a las Víctimas.

Se identificaron como factores secundarios del declive de CENAPROV, las nacientes y promocionadas Juntas de Acción Comunal en los años 70, cooptadas por los líderes políticos tradicionales. Estas Juntas de Acción Comunal fueron desplazando a las Juntas Directivas de la Central Nacional Provivienda en los barrios, al punto que algunos dirigentes de Provivienda terminaron adhiriéndose a las JAC para no perder contacto con la comunidad.

El auge de los urbanizadores privados alentó el encarecimiento de la tierra urbana, la complicada tramitología, y los requisitos de legalización de los planes de vivienda frente a la Superintendencia Bancaria fueron también otro de los aspectos secundarios que desgastaron y dificultaron el surgimiento de nuevas iniciativas de CENAPROV para adelantar la consolidación de nuevos proyectos de vivienda.

Finalmente, problemas internos en la dirección regional de la organización y la llegada de nuevos propietarios a finales de los 80 a los barrios, quienes desconocían los esfuerzos y luchas de los fundadores en la conformación de los barrios, puede suponerse, fueron debilitando la cohesión social fundamental para consolidar una fuerza social que permitiera poner en marcha nuevas compras comuneras por parte de CENAPROV.

Quedan por establecer con más detalle otros motivos del declive que no fueron tenidos en cuenta en el presente análisis. Es necesario también clarificar aún más el protagonismo que tuvo CENAPROV en los municipios aledaños, sobre todo en Santa Rosa de Cabal debido a que los tiempos del trabajo académico y de campo y las fuentes consultadas no permitieron satisfacer este apartado de la investigación.

Resultaría muy interesante complementar el presente trabajo con una investigación de mayor calado sobre el impacto de otros movimientos sociales en Pereira en la segunda mitad del siglo XX. De modo que se pueda rastrear las formas de participación de otros grupos de viviendistas distintos a CENAPROV en la conformación de planes 
de vivienda al interior de la ciudad, por ejemplo, en el contexto del plan ARDECO de 1964 y el plan de zonificación del IGAC en 1967, para que se pueda establecer desde el punto de vista urbanístico los alcances reales del crecimiento informal en la ciudad. 
Anexos 



\section{Anexo $\mathbf{N}^{\circ} 1$}

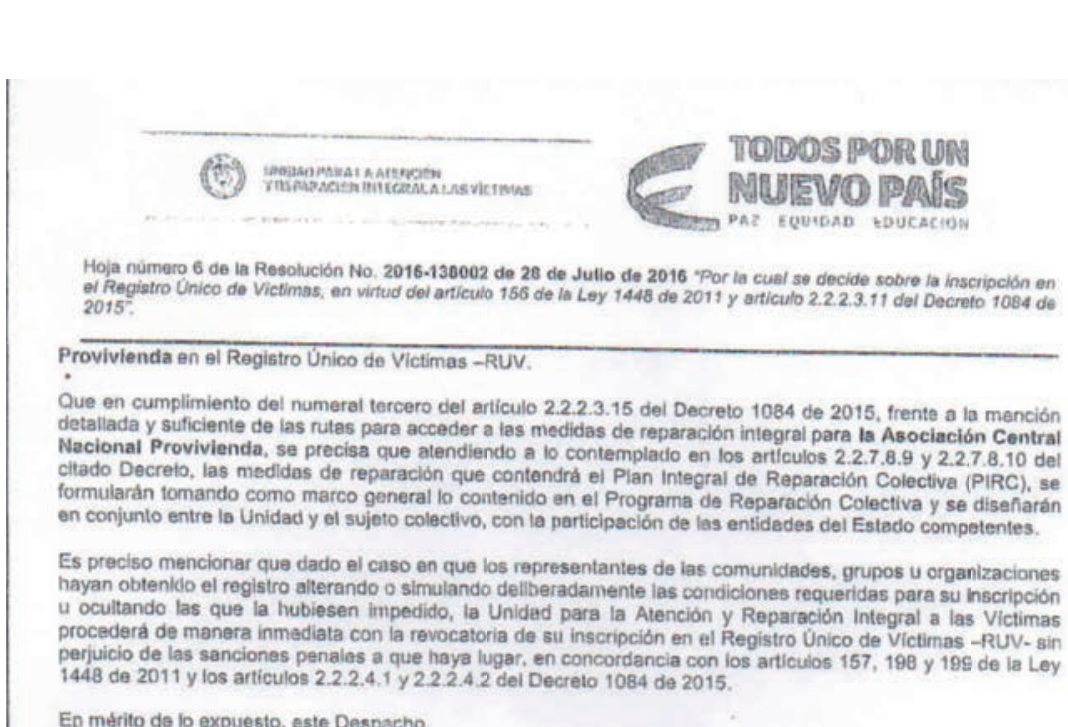

Ep mérito da lo expuesto, este Despacho.

\section{RESUEL.VE:}

ARTICULO PRIMERO: INCLUIR en al Registro Único de Victimas a la Asociación Central Nacional Provivienda, con fundamento en las razones señaladas en la parte motiva de la presente resolución.

ARTICULO SEGUNDO: NOTIFICAR el contenido de este acto administrativo, de conformidad con lo previsto en los articulos 68 y 69 del Codigo de Procedimiento Administrativo y de 10 Contencioso Administrativo, Ley 1437 de 2011, al señor EL.8O MILLER ORJUEL.A AGUILAR, en representación dis la Asociación Central Macional Provivienda.

ARTICULO TERCERO: COMUNICAR el contenido de este acto administrativo a la Parsoneria de Bogoth. Contra la decisión que concede el registro, proceden los recursos de reposición ante el funcionario que tomó la decisión y de apeleción ante el Director de la Unidad para la Atención y Reparación Integral a las Victimas de que trata la presente ey, dentro de los cinco (5) dias siguientes contados a partir de su comunicación. Lo anterior, de conformided con el articulo 157 de la Ley 1448 de 2011.

\section{NOTIFIQUESE Y CÚMPLASE}

Dada an Bogotd, D.C., a los 28 dies del mes do Jullo del afio 2016

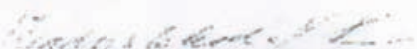

GLADYS CELEIDE PRADA PARDO

DIRECTORA TÉCNICA DE REGISTRO Y GESTIÓN DE LA IMFORMACIÓN

DE LA UNIDAD PARA LA ATENCIÓN Y REPARACION INTEGRAL A LAS VICTIMAS 
CENAPROV Y EL CRECIMIENTO URBANO DE PEREIRA 1973-1987

Una mirada a la construcción barrial de Pereira desde sus márgenes

\section{AneXo $\mathrm{N}^{\circ} 2$}

\section{AF 02699459}

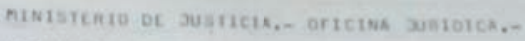
HCSDLUCTON AUME HO OOLASB DC 1.961

$$
\text { ( } 5 \text { mavo } 1.062 \text { ) }
$$

Por ta cuel se reconace una personerfin jurfesen CL MINISTRO or Jus TIC1A,

on uso de la facultad que te conflere el Decreto 1716 de 1.960 , Y C O N 5 I D E A A A D O :

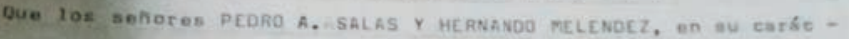
ter de Presidente y Secretario, reapectivamente, de la entidad denominada "CENTRAL NACIONAL PRO-VIVIENDA", con domieilio en la oiu dad de Bogotá, D.E., solicitan de este Miniaterio - por conducto de la Gobernación de Cundinamabca- se reconozca personería jurí dice a dicha Corporación;

Que los peticionarios acompañan a su solicitud copias autentica des de las Actas sobre constitución de la entidad, elección de dignaterios y aprobación de los estatutos que la van a regir, te Qlamentos que también allegan en copias iqualeente autenticadas; Quo la Gobernación de Cundinamarca, en providencia que obra a fo 1io 2 del informativo, emite concepto favorable al reconocimiento de personerfa solicifact;

Que hecho el estudfo des. dis

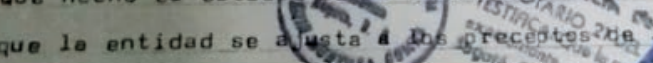

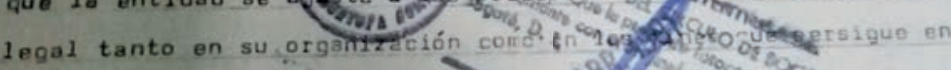

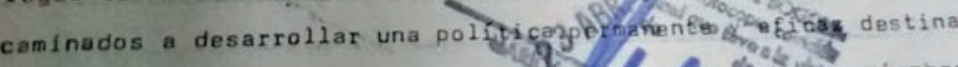
da a conseguir lotes de terreno parang cade und de bas miembros pueda construir su casa de habitacioripuefon yejecutar actos conducentes a la construcción de dichas casas, lo mismo que a de satrotlar la solidaridad entre sus miembros u propender por el me Joramiento de las clases menos favorecidas de la Sociedad;

Que se han 1 lenado las formalidades prescritas por el Artículo 44 de la Constitución Nacional, Título 36 del Libro. Primero del Có. Jigo Civil y Decretos 1326 de 1.922 y 1.510 de 1.944 ; lue por las razones expuestas es el caso de habilitar a la Corpi 


\section{Anexo $\mathbf{N}^{\circ} 3$}

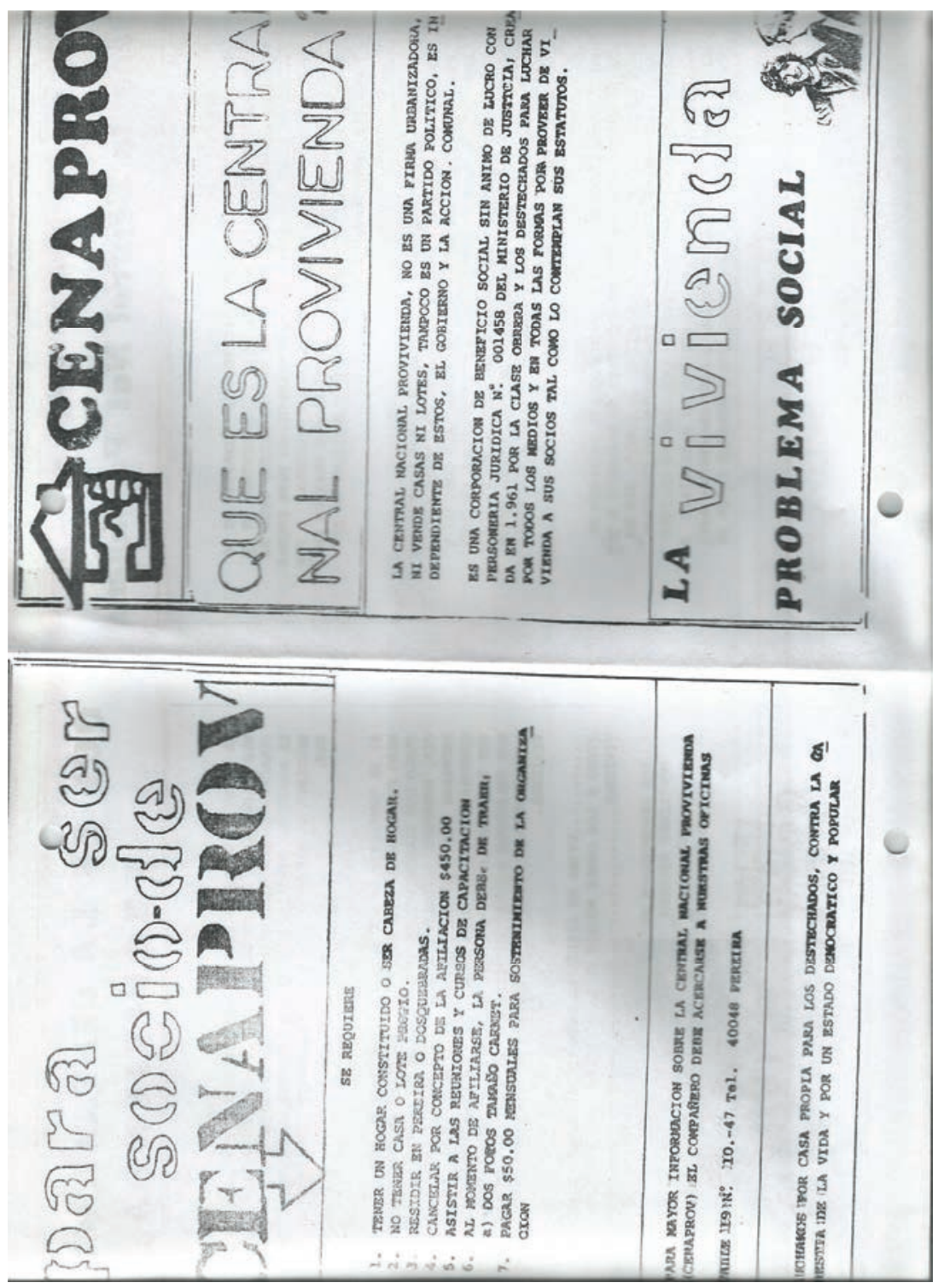


CENAPROV Y EL CRECIMIENTO URBANO DE PEREIRA 1973-1987

Una mirada a la construcción barrial de Pereira desde sus márgenes

\section{ANEXo $\mathrm{N}^{\circ} 4$}

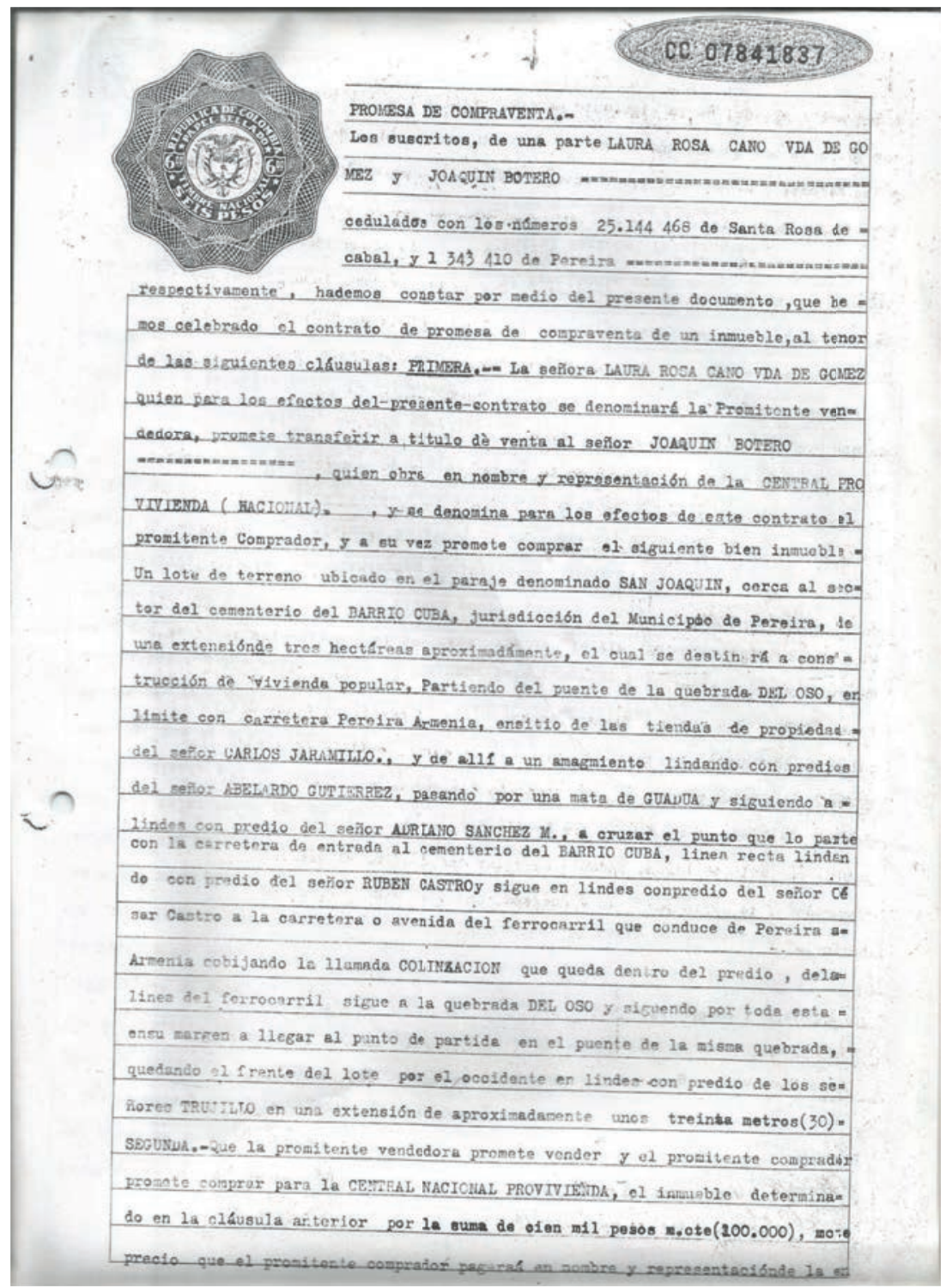




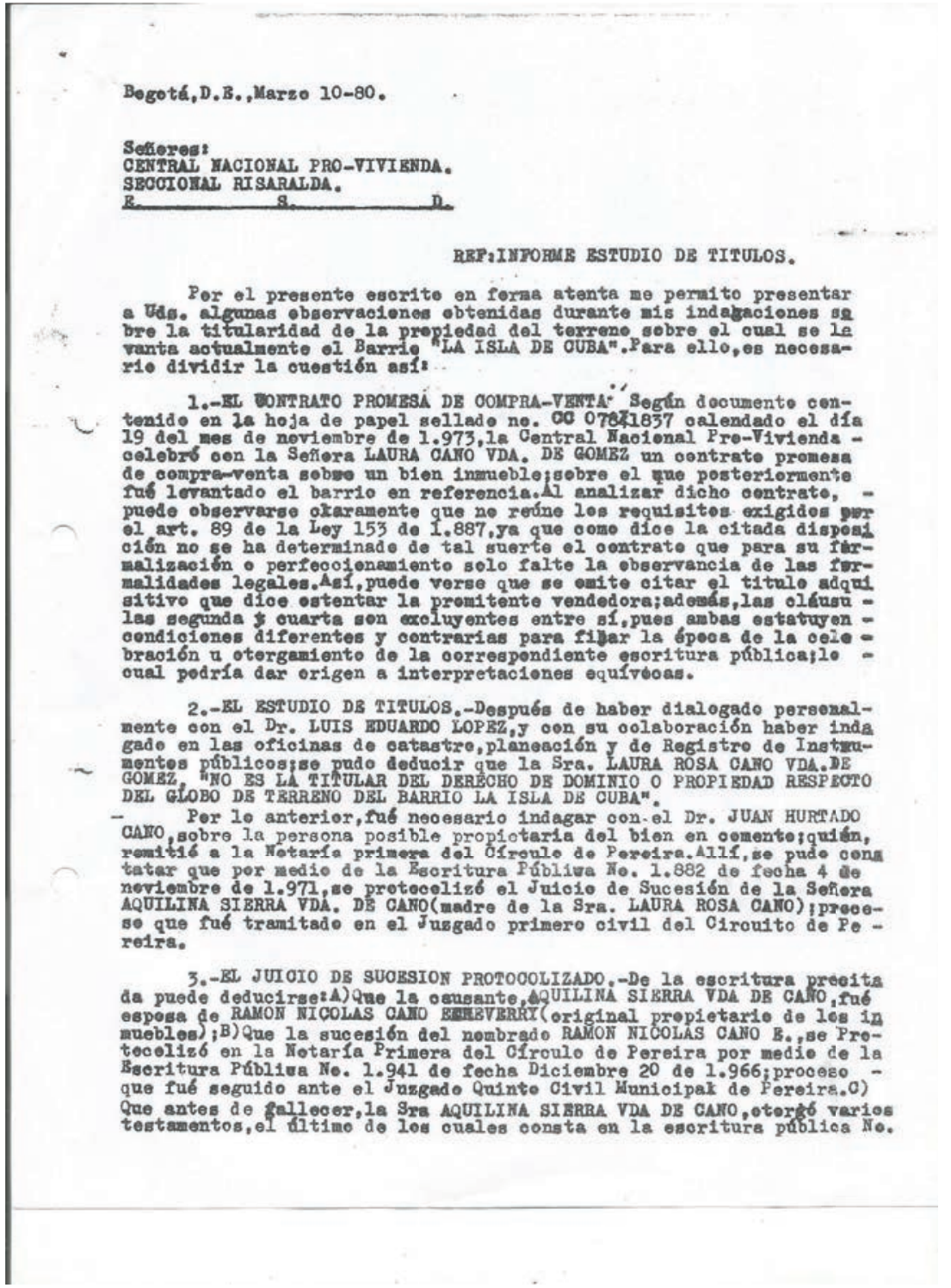


CENAPROV Y EL CRECIMIENTO URBANO DE PEREIRA 1973-1987

Una mirada a la construcción barrial de Pereira desde sus márgenes

\section{ANEXo $\mathrm{N}^{\circ} 6$}

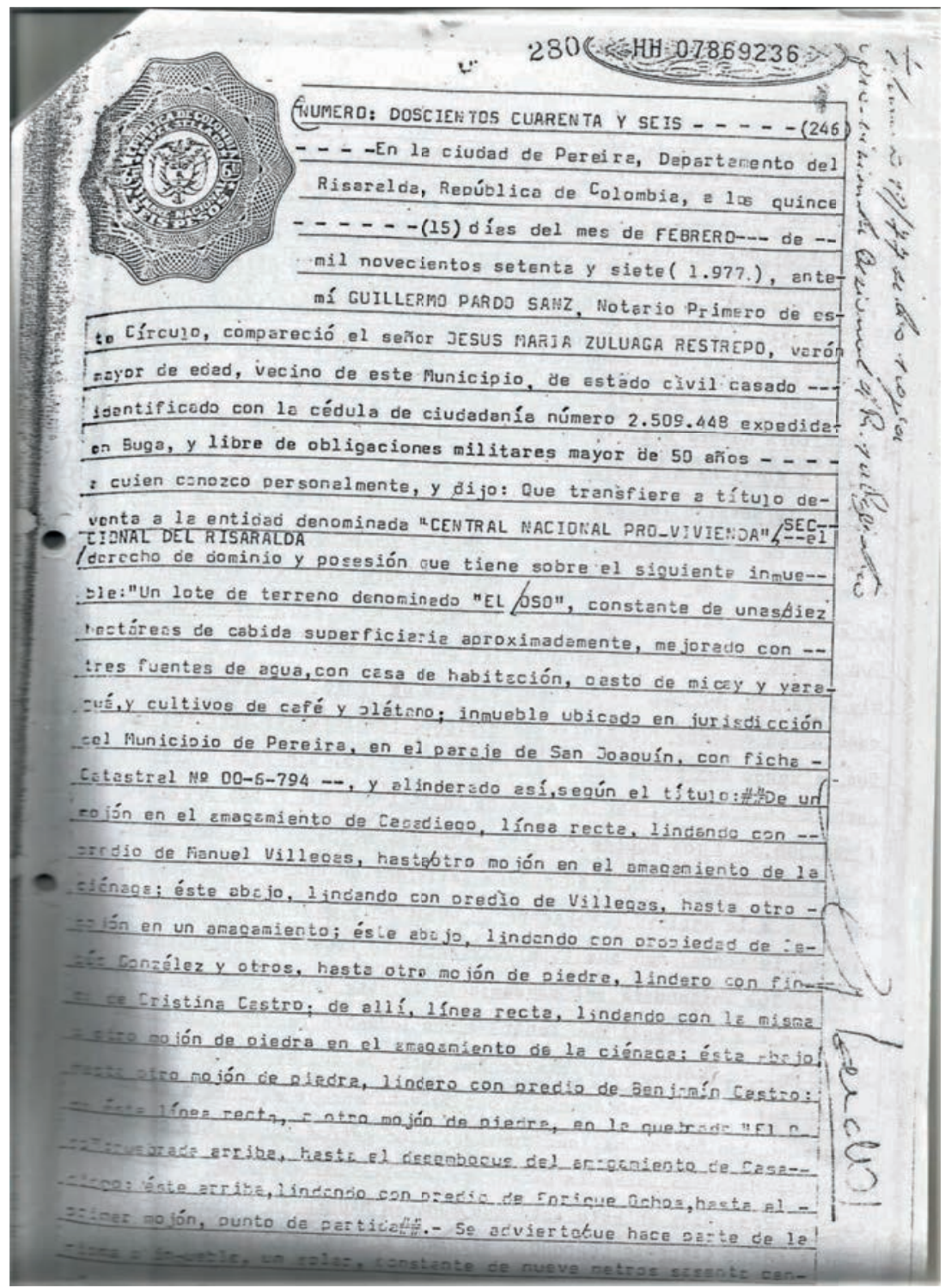




\section{AneXo $\mathbf{N}^{\circ} 7$}

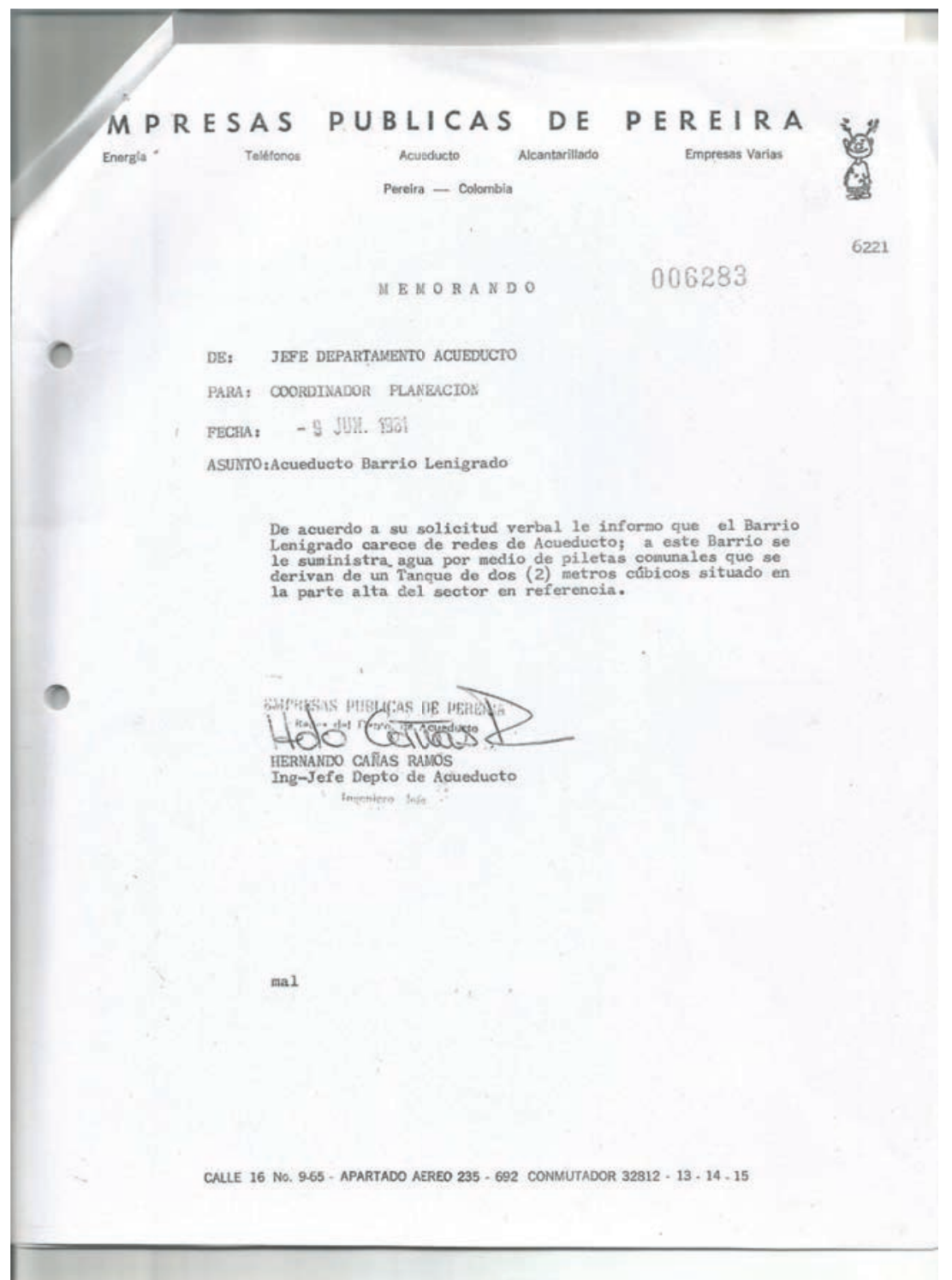




\section{AneXo $\mathbf{N}^{\circ} 8$}

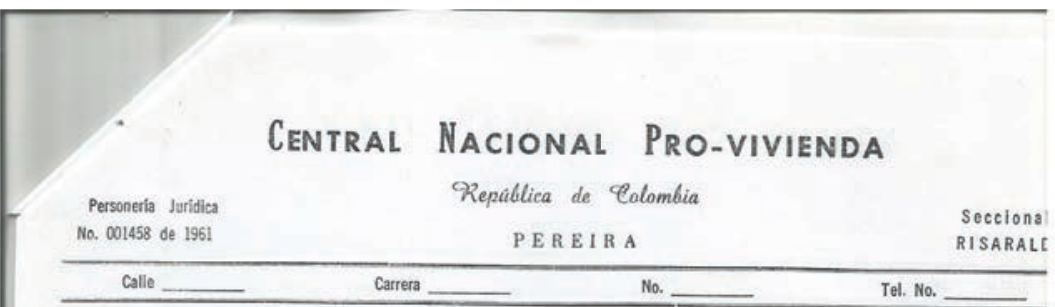

BI caso del "Jose Yarti: obedec16 a la lucha librade por los actuales adjudicatarios, Iog do que el Concejo lunieppal aprobara un Acuera autorlzando al Alcalde y Gerente del ${ }^{\prime}$ ond Vivienda Popular para adquirir, previo erfaito bencarlo, el lote de terreno por la sura di $\$ 550.000 .00$. Aotualmerite $10 s$ adjudicatarlos están posesionados đel lote y se desarrlis el de vivienda, el que 'cuonta' con la aprobactón de Planeación pero sin el visto bueno de is . bencaris. Dicha posesión fue directa, es decir, que no existe ningín documento $\mathrm{y}$ hasta la el Fondo no ha comenzado a cobrar las respectivas cuotas eatablecidas en el Acuerdo aunict (anexo lo amunciado), como quien dice existe deuda por parte de log adjudicatarios. BI Pls miento que exdate en esta Seccional es la de que se presenta la posibilidad de que el Pont escriture a la Central y eata ${ }^{2}$ ruma la responsabilided de la deuda. Creanos que os posible qui riendo de 100 adjudicatarios el poder para la esoritura $y$ establocer clánaulas que nos ranticen el pago posterior de la deuda.

PARTB POITICA.- In el caso del Jose Marti el "obierno Munioipal ha venido utilizando a uz grupo de adjudicatarios para la fundacion de una Junte Comunal, hecho que se venfa convtr do antes de elecciones a corporaciones públicas y ouja Pinalidad, segrín parece, era la de trar a negociar con dicha Junta C. $y$ sacamos de por medio, pero nuestro trabajo orgenizat y politico no ha pervitido a estos elementos tal objetivo. Sinembargo estos elementos aig. Is espeotativa de una nueva oportunidad, pare lo cual se alimentan de las dádivas que les cen 208 politiqueros. Bate barrio reviste de una gran importanoia por su ubicaci-on y el y que puede desarrollar cono influencia en berrios aledeños.

In los otros casos también prima el aspecto polftioo, como en Ios Andes, donde la adminiat cion de Senta Aos ha venudo obstaculizanio la realización del plan de vivienda $y$ coso en dencia planes la causa est estar afiliados o habar pedido la orientación $\mathrm{y}$ aseanorfe de la 6 tral liacional Provivienda.

Coso pueden apreciar este problena tiene sus conplejidades $y$ por 10 tanto regulere de su $\varepsilon$ mización y de la asesoria de un buen abogado que nos elabore 109 docuentos concernientes de més luces al respecto.

Pinglmente queremos infornarles que on la ciudad de Sente Rosa de Cabel (seguraida en ol De mento), se presente una bonita oportunidad con un terreno de 15 cuadras en (terreno plano) bilidad de servloios $y$ se encuentra sobre carretera. Ios terrenos adyacentes están siendo banizedos. Hay un montaje compuesto de una oqsa quinta, lo que alrve para un centro educat con luz (hay un traafomador), acueducto, telefono, alcantarillado; hay cinco estables en rial $y$ otros servicios menores. Se calcula que eate montaje tiene un valor no menor a los

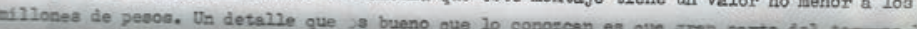




\section{Anexo $\mathrm{N}^{\circ} 9$}

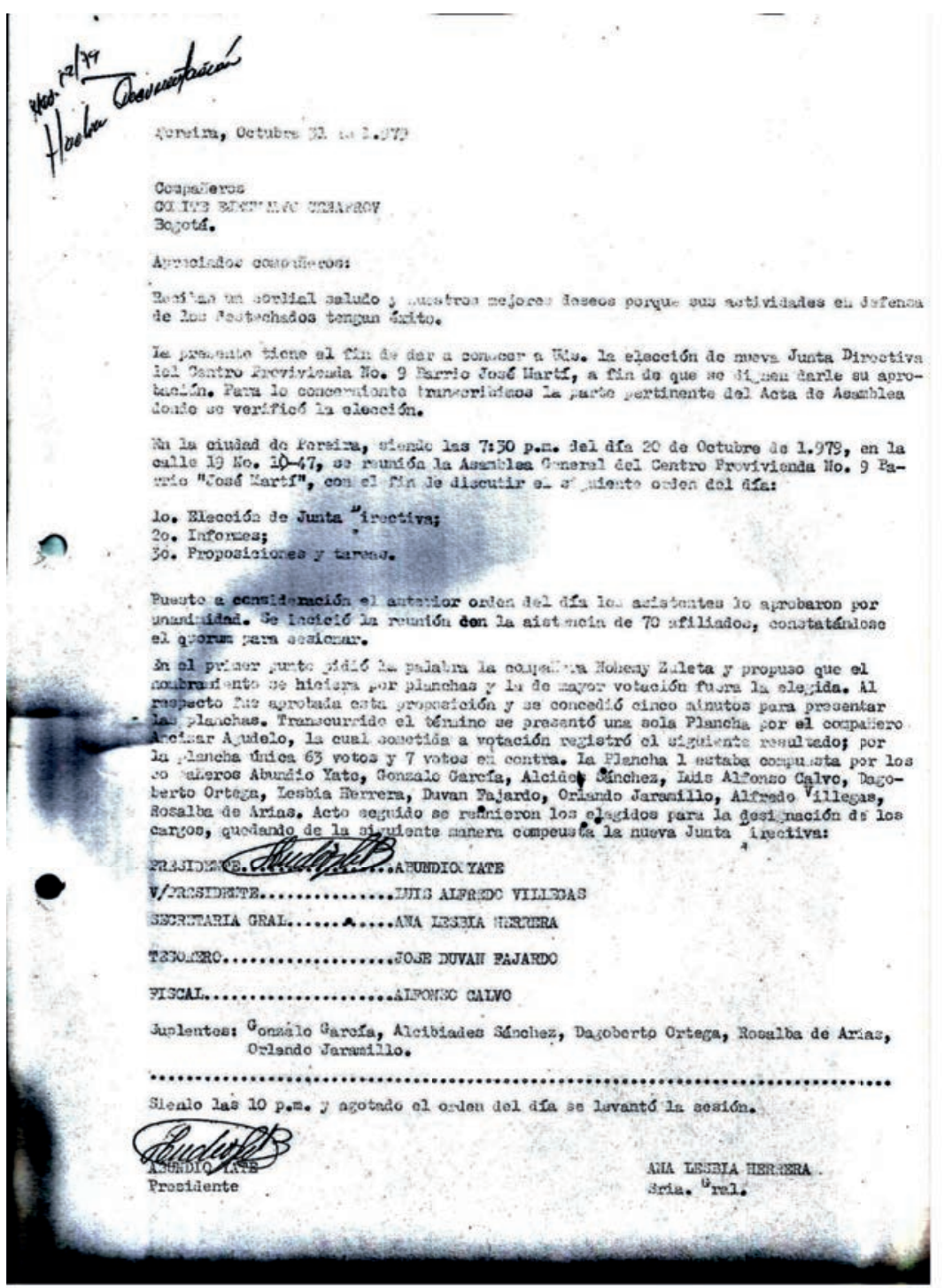




\section{AneXo $\mathrm{N}^{\circ} 10$}

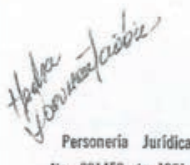

\section{Central Nacional Pro-vivienda}

No. 001458 de 1961

Republica de Colombia

Calle

Carrera

No.

Tel. No.

Pereira, Larzo 31 de 1.980

Conpaülero:

CQUITB BJBCUNTV CBUAPROT

Bogota.

Apreciados cetystiozos:

Ia prosente thene el ein de solioitarles la aprobación de la nueva Junta Directira Seco nal, pars lo cual transcribimos la parte pertinente del Aota de dicha Asanblea.

Bn Pereira, a los 29 dies del mea de Harzo de 1.980, en la calle 13 lio. 6-39, siendo Ia

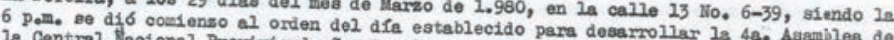
la Central Nacional Provivienda Seccional Biseralda, lo cual se eatable 4a. Asamblea de alsuiente:

10. Inetalación pública el día 29 de Marzo;

20. Mleceín de lleas Directiva de la Asamblea;

30. Informes de la Directiva Seccional y los Centros; discualón de informes;

40. Nonbram

50. Discusión de los informes de Conialones (Conclualones).

70. Clausura.

En el sexto punto del cla de candideto deración de la 1lo, Bdua do

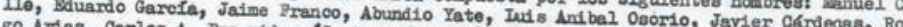
go Arlas, Carlos A. Benavides, (Javier C6́rdenas) J Hernán Iondoño, planoha gue gomettas, Ro cuaion fue aprobada por unanimidad. Seguidemente los elegidos, planoha que sometida a pars efectuar la elección de dignatarios, quedando de lagidos se reunieron en recinto sp PRTMCIPAISS

PRPSTDgres

VIRPRESTDARE PISCAL JANTE FRANCO TBSORBRO

MUNUBL A. CASTIITO BDUARDO GARCIA

HUGO VBISZ

CARIOS A. HEYVIDES

\section{VOCALBS}

HERTAN IOSDONOO

JAVIER CARDENAS

ABUNDIO YATB

IUIS AIIBAL OSORIO

RODRICO ARTAS

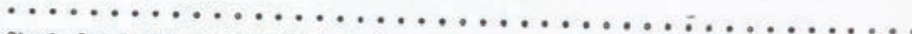

Siendo las 5 y $30 \mathrm{pem}$. del dia 30 de Marro y habib́ndose agotado el orden del dia el pregd te levanto la seaión.

ES PIBL COPIA DE SU ORIERAL.

CBNTRAL HACIONAL PEOVIVIJMA SECCIONAL RISARATDA 


\section{Anexo $\mathrm{N}^{\circ} 11$}

EL SUSCRITO PRESIDENTE NACIONAL DE LA CENTRAL NACIONAL PROVI VIENDA, EMTIDAD CON PERSOHERIA JURIDICA No. 001458, EMANADA DEL MINISTERIO DE JUSTICIA

\section{E R T I F I C A :}

Que revisando los archivos que sobre resoluciones se lleva en la Secreta ría de la Central Nacional Provivienda, se encuentra vigente la creación y reconocisfento del CEITRO Ho.10 OE PEREIRA, BARRIO "CARLOS AL BERTO BENAVIDEZ", cono mienbro de esta Corporación $y$ amparado en su Personería Jurfdica, que como đ1tina y vigente nómina de directivos de dicho Centro se encuentra la siguiente:

Presidente:
Vicepresidente:
Secretaria:
Tesorero:
Fiscal:
Vocales:

JOSE BAUTISTA OSORIO MOSCOSO HECTOR FABIO OSORIO ARBELAEZ LUZ MARIA RIOS ANEER SERNA BARRIOS LAILA LUISA VELASQUEZ. MARINO TORO LOPEZ, ROMELIA MARU LANDA, RAMON ALONSO OSORIO, ALVARO ARIAŚ $\mathrm{Y}$ JOSE VALERIANO NORALES $M$.

Para constancía y en cumplififiento a lo ordenado en el Artículo 40. de la citada resolucion, expido la presente certificación, en la ciudad de Bogotf, D.E., a los dtez (10) dfas del mes de agosto de nil novecientos ochenta y ocho (1988).

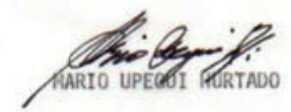

C.C. No. 2'913.576 de Bogotå

Presidente Nacional

CENTRAL MACIONAL PROVIVIENDA 
CENAPROV Y EL CRECIMIENTO URBANO DE PEREIRA 1973-1987

Una mirada a la construcción barrial de Pereira desde sus márgenes

\section{ANEXo $\mathrm{N}^{\circ} 12$}

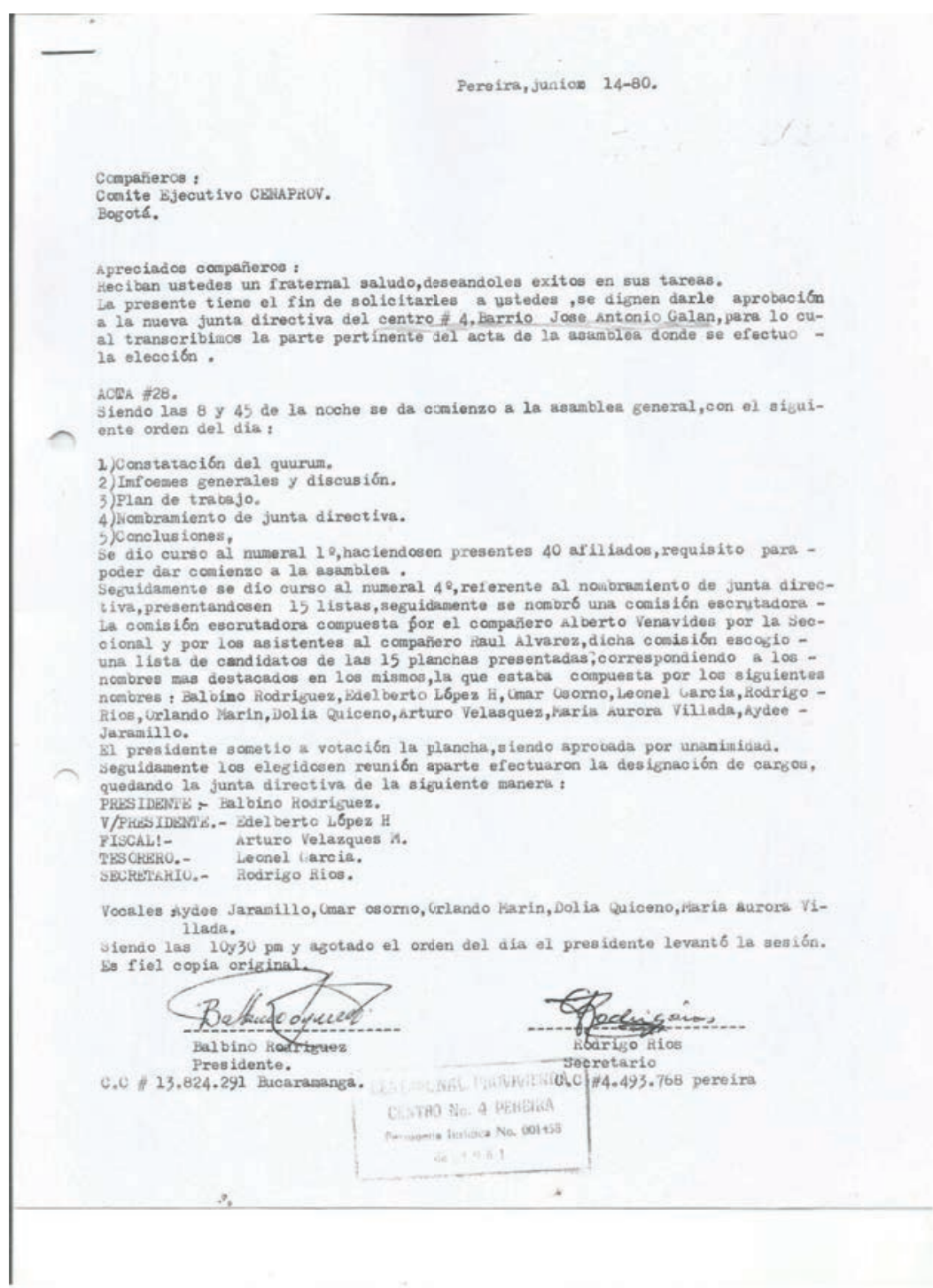




\section{ANEXo $\mathrm{N}^{\circ} 13$}

\section{IMFORME : $\quad$ SECCIONAL RISARALDA}

El plan de vívínda Colombía Nueva ya se copó totalmente.

Se tiene previsto adquirir un Lote de 25. M2 aproximadamente junto al Plan Colombia Nueva. Al terreno lo atraviezan los servicios de agua y luz. El alcantarillado tiene dos opciones para vertirlo.

Despues del terreno existe el Barrio Villa del Sur conn más de 100 soluciones y los servicios primarios.

Eduardo propone que si se autoriza la negociación iriamos en sociedad y el ejecutivo aportaría dinero en Diciembre.

Me parece que deberiamos autorizar la compra, aprovechando la experiencia y las buenas relaciones de Eduardo con la Administraciój Municipal de Pereira.

Hay que decir que a 200 Mts el fondo Municipai está adjudicando lotes con servicios a Un millon doscientos mil pesos, financiados a 10 años y al final el adjudicatario paga más de dos milliones.

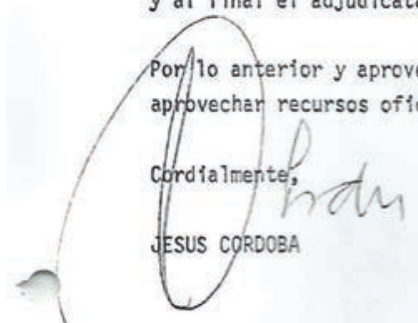

Adjunto: Fotocopia del pláno de la ciudad de Pereira con la ubicación aproximada del lote. 
CENAPROV Y EL CRECIMIENTO URBANO DE PEREIRA 1973-1987

\section{Anexo $N^{\circ} 14$}

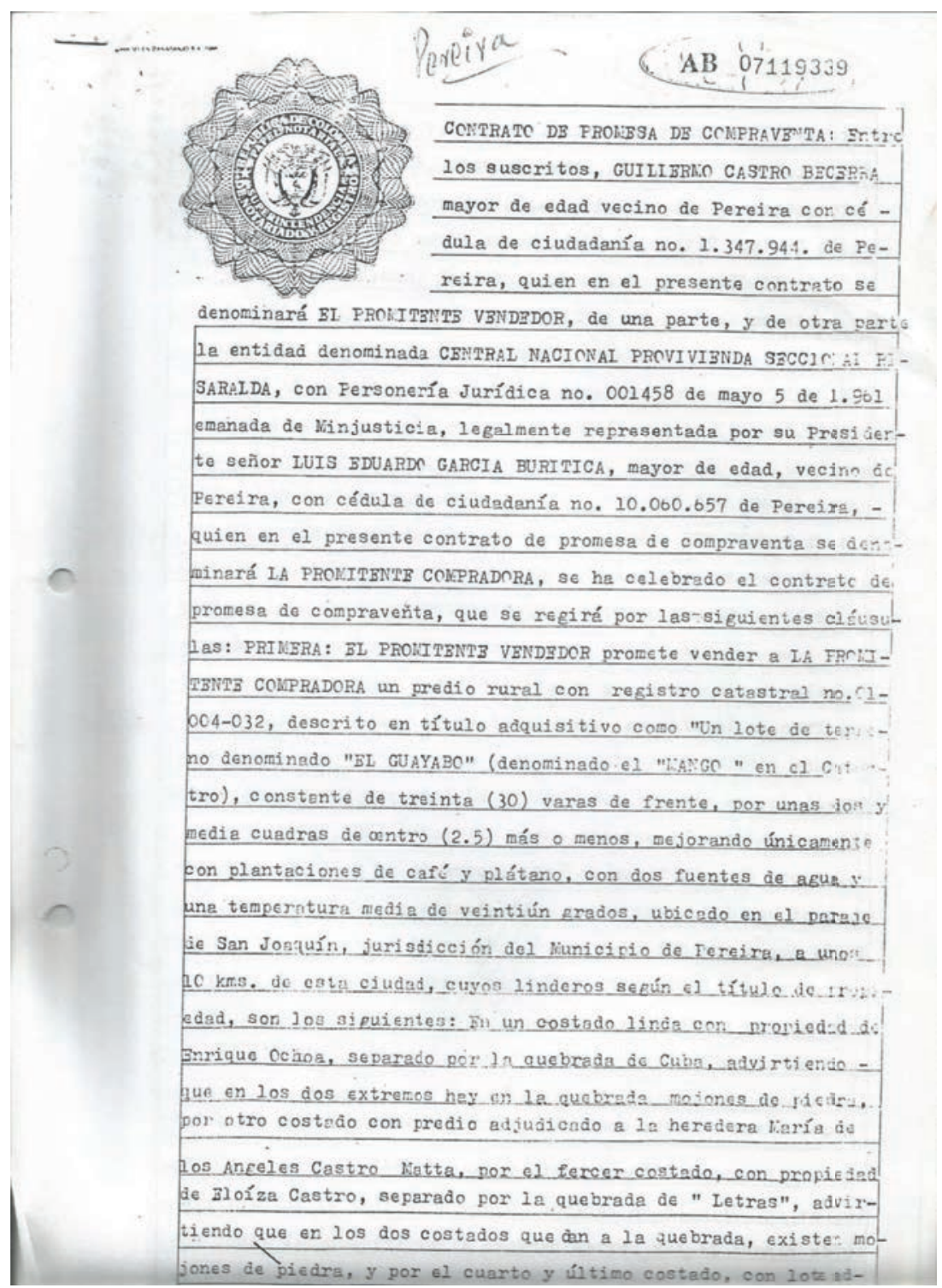




\section{AneXo $\mathrm{N}^{\circ} 15$}

\section{PARTE DIE VICTOMIA}

Bl Barrio " PADRO PABLO BZLLO " y la Central Nacional Provivienda, cono parte intęrante del Conité Cívico que llevó a feliz término el paro cívico del 13 de octubre, aportaron su colaboración y participación deciajida en esta jornada de lucha del Pueblo Porterio. Hay que destacar la participactón ue nuestro vecino jarrio Los Libertadores, con quienes noe uner problemas comunes $y$ con quienes debemos seguir luchando unicos para lograr ruestras justas reivin-

Bl Gobiemo Departanental ha anunciaco púj:.cesnente que Ha destinad 30 millones para servicios de acueciucto y aicunturillado en la VirPABLO B UABLO BLLIC" y "LOS IIEARTADOLIES", I0 que ciebenos considerar como Ia luche civico. Ahor corresponde continua: la lucha para que se cunpla éste ofrecimiento oficial en unidad en accion con nuestros vecinos y apoyancio al comité cívico en todas las tareas concernientes a conseguir sus juistos objetivos.

Pelicitamos a los hombres y mujeres del P.DTO PJBIO Bitlo por su decidida participación er esta jomida civiea.

Atentamente,

$$
\text { JUNTh DIRECIVA SSCCICNAJ CAIAPROV }
$$

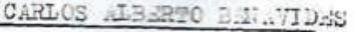

PRASIDEITA

CENTRA! NACIOMAR: PROVIVIENDS

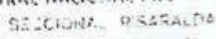

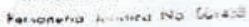

JOSZ AVTOSIO LOPLZ

FISCAI

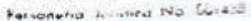

30R6- IIINCDE CARDONA

VRUARESIUATIIL

GAVUST AYALA

\section{IXSORBRO}

LUIS SDUARDO GARCIA

SICRATARIO GIII IRAI 


\section{ANEXo $N^{\circ} 16$}

IT SUSCRTTO SECTITARIO DE LA CMTRAL FACTOMAL, PRO-VIVIMTDA, JWLIDAD COR PSRSOULIA JU:IDICA \# 001458 FEA TADA DKE ITIMSTERTO DIS JUSTICIA.-

$$
\text { C B R T I PICA }
$$

Que revisando los axchivos que sobre resoluot onos ee 11eva on la Secretaría de la Centrel Ileotional Prom71 vienda; gen encuentra vigente le oresalon y reoonocimiento dol Gentro Pto Vivienda \# 2 del lantoipio de Santa Rosa do Cabal, barrio Ios Andos, miembro

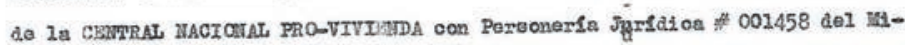
nisterio de Justiola, que cono ultime $y$ vigento inscripedón do directivoe de Dicho Centro we encuentre vigents in siguiente: Prealeentes tJIS ANIBAT, -

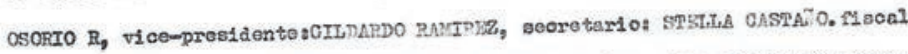

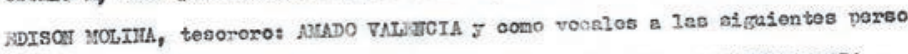

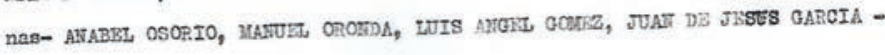
ALVARO GIL.-

Para conatenois $y$ on cumplimionto a 10 ortonodo en el Art. crarto de la citada resolucion, exphto la presento oertificacion, on la ciudad lo Bogoth a -

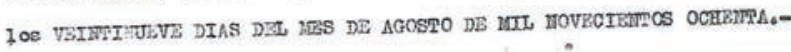

ITSABL WARTITEZ.

Secretarto Ital.

c. 0.17340 .589 do Pacho (c).

CIMTRAA TAL PIO-VIVIEATDA. 


\section{Anexo $\mathbf{N}^{\circ} 17$}

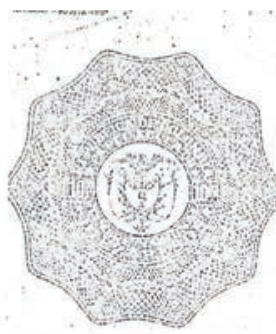

\section{AF 09057057}

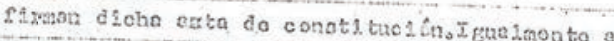

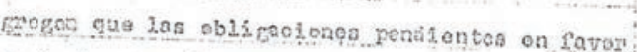

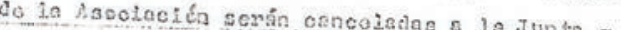
Dirgetiva quo la roprosonto logalmon to puon la

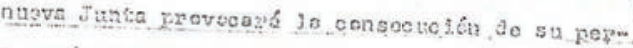

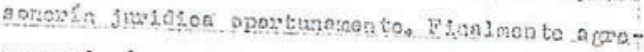

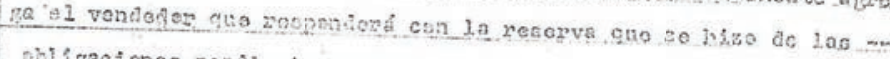

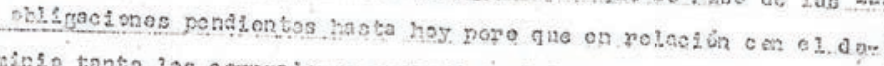

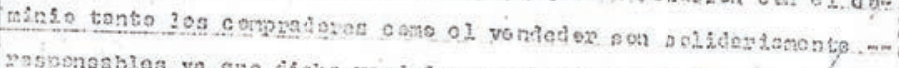

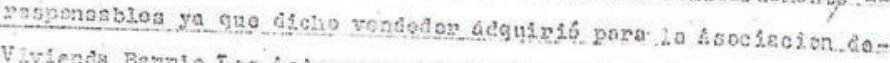

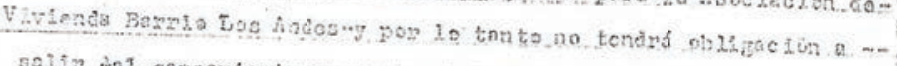

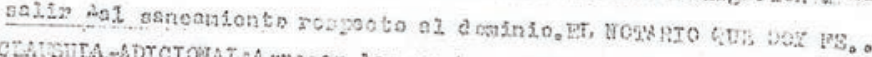

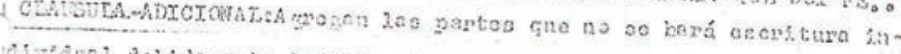

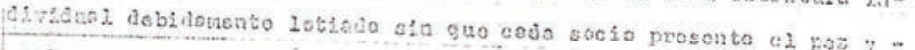

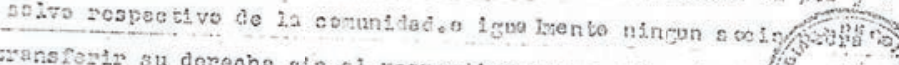

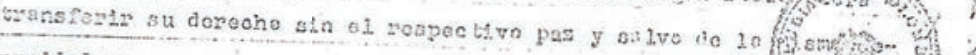

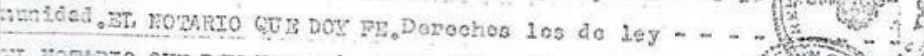

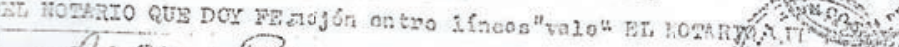
- Secionsoid

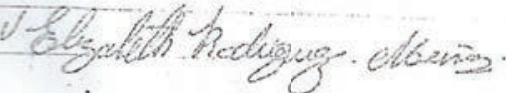

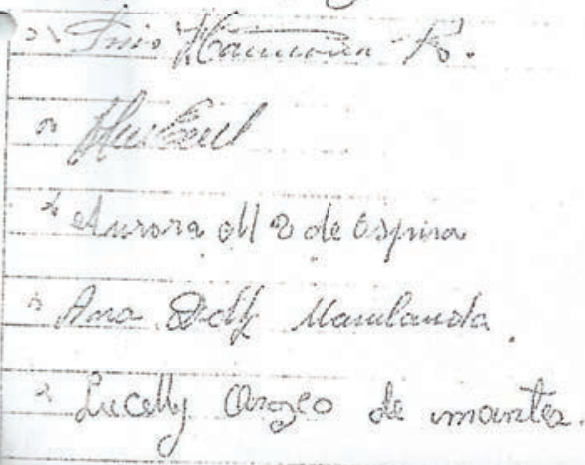

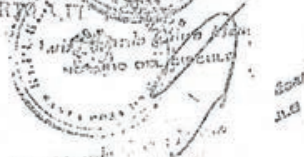


CENAPROV Y EL CRECIMIENTO URBANO DE PEREIRA 1973-1987

Una mirada a la construcción barrial de Pereira desde sus márgenes

\section{ANEXO $\mathrm{N}^{\circ} 18$}

\section{Central Nacional Pro-vivienda}

\begin{tabular}{l}
$\begin{array}{l}\text { aeria Juridica } \\
458 \text { de } 1961\end{array}$ \\
\hline Falle 19 \\
\hline
\end{tabular}

Pereira, Hayo 22 de 1.980

Señor

GOPLRMADOR DAPARTALLETO RI SARATAA

B. 5 .

Por medio de la presente nos peraltimos saludarle $y$ desearle muchos bxtos en sus labos
diarias al frente de tan importante cargo.

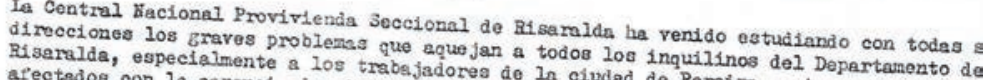
alectadog con la carencia de vivienda, vióndose la ciudad de Pereira, quienes son los ms insalubrea $\mathrm{y}$ de permenente

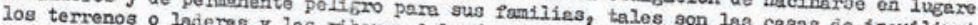
épocas de invlerno, des improvisadas.

Consideremos, serior Gobernator, que parte a estos problem ge presentan planes de vivienda oficlales que garanticen a 100 problemas se presentan por ls falta $c$ vienda sin cuota inicial y con suranticen a loo trabajadores la consocuoion de su vidio en esta regib́n. Asi mismo $y$ cono consecuntización bajas, acorde con el anlario prome han constiufao ung aerie de orr and consecuonola del numeroso deficlt habitacionel, se imuebles que han coadjuvado seriemente 0 agencias de arrendeniontos y cceapravente da oriterios egoistas. Nos hemos daio cuente gue que los alquileres suben de procio segín su Punclonnn con personería jurfdico cuente que estas fowoses acenclas de armondomiontos Fus nezocios ain ningún control y diri la Gobemación y se amparan en osta para desarroli carecen de vivienda propia pera gu faglifa, contra los intereses de los tratajadores qua

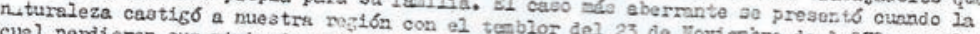
cuel perdieron sus viviendas mugher con el tenblor del 23 de Iovienbre de 2.979 , on meno fue utilizado de inediato por femilias de todos los niveles econbalcos. Bote fer6vulores de 103 inmubles que se enconrmben las famoas casa de arrendaniento para triplicar 10. propietarios para que hicieran otro tanto. bajo wu control $\mathrm{y}$ en eoa forma presionar a la doniento, en lo que va corrido del presente of talez cireunatenctas, lou cánonog de armon-

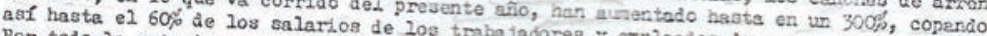
Por todo 20 anterior deducimos que ses trabajadorea $\mathrm{J}$ cmpleados de nenor puruneracion.

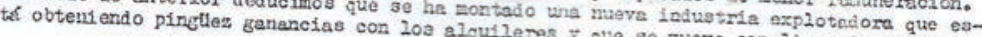

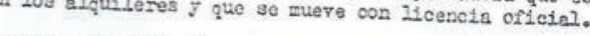
runctonaniento de dichas entidades ni al Bstado, ni a la sociedad, sntes por el de arrendenientos), pues no le producen rade tedores ain medida ni control. Atentamente,

CAWTRAL NACIOHAL PROVIVIGIDA SECCIOULL RI SARAIDA
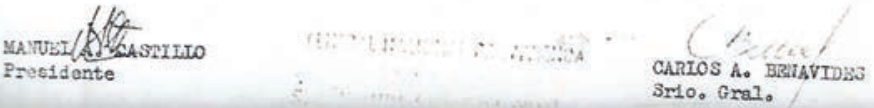


\section{ANEXo $\mathrm{N}^{\circ} 19$}

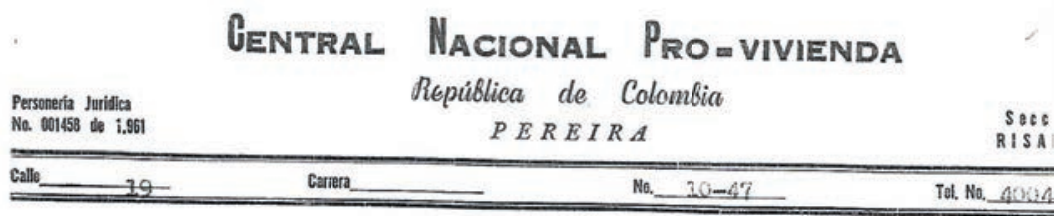

Pereira, inoro 10 de 1.981

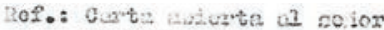
irovidato de la om

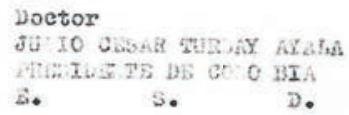

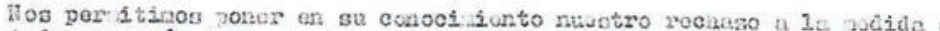
toda on ruson de 1 ia decone el coibn de los arrenditiontos or adio de: eroto lio. 3450 de Dicia ire de $1.980,10$ cul contideranos comstitur

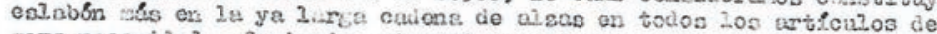

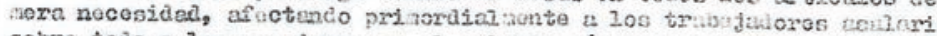

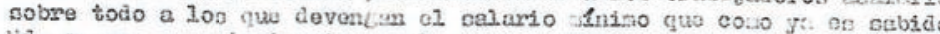

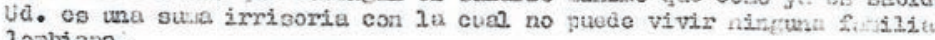
2orbiana.

Pars corroborus nuestro plantevilento poneros ol g:i conociniento dos

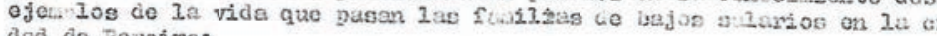
and de Feroire:

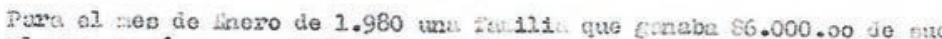
al nos, pags por survicio de onerela eléctrica l. suna de $\$ 240.00 ;$ p

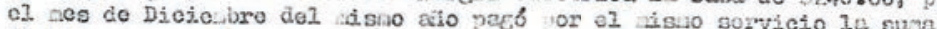
81.190.00 y tonf́a el ajs:a silario. Otra fuiliza on faero do 1.980 pe

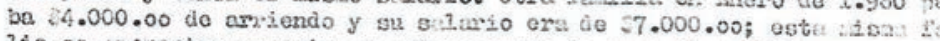

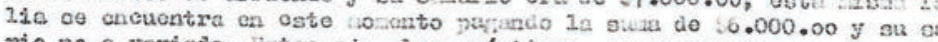
rio no a variado. Estos eje 3 os prícticos, so ior prostionto, Los din

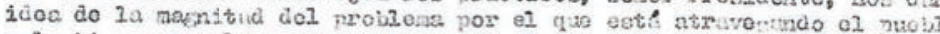
colosbiano, por 10 que on deber del Gobiamo ajercer el control $y$ la

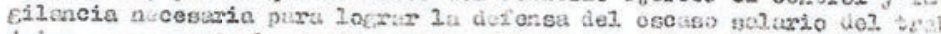
judor, no con bijplos asurcios sino decrotudio vertatieras it ditias co:

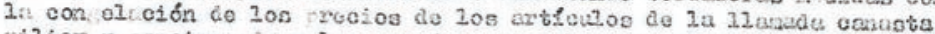

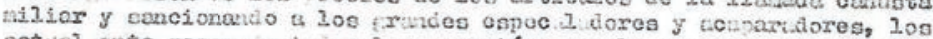

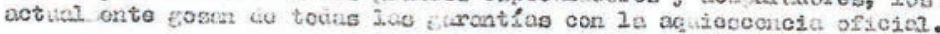

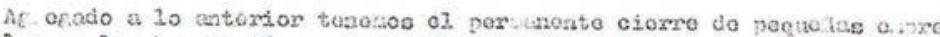

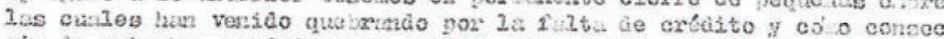

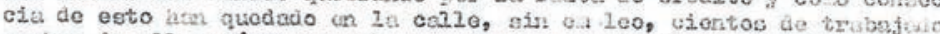

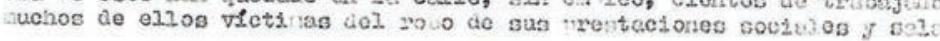

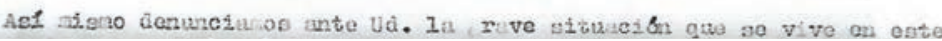




\section{ANEXo $\mathrm{N}^{\circ} 20$}

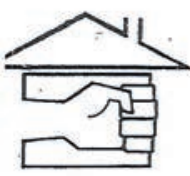

CENAPROV

\section{CENTRAL NACIONAL PROVIVIENDA} CENAPROV

SECCIONAL RISARALDA

PERSONERIA JURIDICA NO. DI.45E DE 1.95:

minuUsticia
SEOE CENTRAL

BOGOTA CALLE 3a, sue Cact 10.25

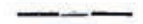

SECCIONALES

ANTIOOUIA ANTIONTIC BOYACA CALONS

CAOUETA

CAUCA

CESAR CUINUINAMARCA CUInINAMARCA ML ALENA META Namino SANTANDER SANTANDIR
OUINDIO RISARALO Ristralon TOLIMA VALLE

Doctor

VIRGIIO BARCO

FRESIDBITE DB IA RBPUEIICA

E.

$S$. D.

Respetable señor Presidente:

Bn el día de hoy mertes 10 de marzo del año en curso hemos tenido conocimiento del vil asesinato de que fue víctima nuestro compañero Directivo Nacional de Nuestra Organización, Presidente de la Seccional Keta y Concejal principal por la U.P. en Villavicencio compañero GABRIEL AIFRBDO BRICSNio por sicarios a sueldo que siguen cobrando vidas de destacados lideres populares, asesi nato éste que se suma a la interminable lista de militantes y Parlamentarios de Ia U.P. asesinados en un aĩo largo por ejercita particulares y organismos paramilitares auspiciados por fuerzas oscuras y reaccionarios que quieren desestabilizar la Nación. Señor Presidente, son miles las denuncies y pruebas que se han aportado de quienes integran $y$ auspizian estos ejercitos particulares y organismos paramiliteres, sin que autoridad ninguna los toquen, los persiga y los castiglue $y$ antes por el contrario continuan en la impunidad como clere eviciencia de impedir la apertura de una verdadera democracia en nuestro país que permite la mayor participación del pueblo en la discusión y soluvión de los problemas que nos agobian.

A nombre de nuestros asociados $y$ gentes de bien muy respetuosatente sefior Presidente exigimos su compromiso de brinàr garantías para la Acción cívica y popular y para que los crimenes contra nuestros dirientes se investiguen hastas las úlitas consecuencias $y$ se castigue a sus ejecutores. Respetuosamente,

CETIRAL FACIONAI PROVIVIBNDA SECCICNAL RISARAIDA 


\section{AneXo $\mathbf{N}^{\circ} 21$}

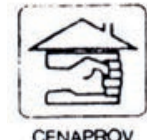

CENAPROV

SEDE CENTRAL BOCOTA Calle 3a. Sur No. 10.25

\section{SECCIONALES}

Antioguia Attsntico

Boyacs

Caldas

Caquets

Cavea

Cesar

cratoba

c. zamarca

Huils

is. Iena

Meta

Nariño

Norte de Santander

Quindio

Risaralda

Santander

Totime

valle

\section{CENTRAL NACIONAL PRUYIVIENDA \\ C E N A P R O V}

SECCIONAL RISARALDA Personeria Juridica No, 001.458 de 1.961

$$
\text { Minjusticia }
$$

Pervira, thouto 17 ae L.yot

Doctor

DEZNU RATYNO AWARLES

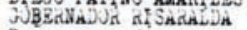

E.

\section{Estimado Doctor:}

kespetuosamente $y$ en ejercicto de los Derechos Constitucionales Consarrados en los articulos 16 y 45 de la Constitacion politica. Jos perintimos poner en su conociniento $y$ denunciar ante usted como autoridad lesitima, las amenazas de que hemos sido objeto Dirisentes de la Central Jacional frovivienda Seccional itsaralda

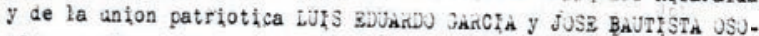
afo por elementos adscritos al sinjestro srupo paranilitar $y$ de sicarios de rectente aparicion en la resion itiac uluerte a Comunls tas".

Xos preocupa esta situacion toda vez que la suerra sucia desatada contra el movimfento sindical civico y popular en otras resiones del pahs donde han caido centenares de dirisentes populares, viejen siendo trasladadas sfstenaticamente a nuestra resion, pues hecho: recientes como la muerte del dirisente sindical de jngenjo kisaralda aUjUSTU WUNUZ, La muerte del diritente de la wiJS en Fueblo kico las amenezas contra un dirisente comunal en juatica $y$ ultimamente el asesinato del companero ZUS3BFo TukJ, diritsente de apenecafe y de la union Fatriotica en el correcimiento de Comoia ast lo dencies -

de antenáno arradecenos las sestiones que se sirva adelantar para la salvosuarda de nuestro derecinos ciudadanos, al fual que la vifilanchade nuestras sedes y la posiollijad de que se nos pueda otorvar salvoconducto para porte de arma para nuestra defensa. atentanente,

CENTRAL DACFUDAL FROVGVEENDA SECCFUNAL KFSARALDA

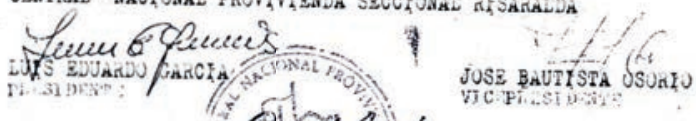


CENAPROV Y EL CRECIMIENTO URBANO DE PEREIRA 1973-1987

Una mirada a la construcción barrial de Pereira desde sus márgenes

\title{
$\operatorname{ANEXO} \mathrm{N}^{\circ} 22$
}

\section{GURERINTENDENCIA BANCARIA}

\author{
BOGOTA, D.E. - COLOMBIA
}

RESOUUCION NUACRO 3008 DE 1920 - Por la cual se impone une sanción a la Corporeselón denominada "CENTRAL. NACIONAL PROVIVIENDA " HOJA No.-2-

cion "LENINGRADO", se edecua e tb preceptuedo en el articulo 2 Numeral 5 del Decreto 2610 de 1979 que dispone : " Le celabrocib́n de promesas de vento, al recibo de antlcipos de dinero o cualquier otro sh temo que inpliquse recspetín de los mismos, con la finalídod de transforif el clonainio de innuebles destinedos a viviendo."

Que ef articulo 28 de la Ley 66 de 1960 modifícado por of artículo 11 del Decreto 2610 de $197 \%$, faculita al Superimbendonte toncerio pera imponor multes sucesives de $\$ 10.000 .00$ a $\$ 500.000 .00$ pesos M/CTE. a las persones o entidados que incumplen las bodenes impertldes por estra Entidod en uso do las foculnades de inspecelon y vigilancia, e infrija les disposiciones de alguna ley o Reglemento relotives a vivienda.

\section{RESUELVE:}

AtriCULO To.- Imponer a la Corporacion denominerda " CENTRAL NACIONAL. PROVIVIENDA Señor MARIO UPECUI H., una mulita en euentia de CINCUENTA MIL PESOS N/CTES 50.000.00)., imporie que deberb consigner o fovor dol Tesano Nocianel dentro de los elnco (5) días slgulentes a lo sjecuteria de esta Providancia sin perjuieio de que, de no subsencesse los bechos moteria de sancibn, seen inpuestas multes sucesives ol tenor del Decreto 2610 de 1979.

PARAGRAFO. - El paso de la mules que se impone en ésto Resolucibn debert ocreditarse medianhe presentación a este Despo= cho del original del recibo que expide le Seceión de Caja de la DI rección Generol de Tesorerla dentro de los clnoo (5) dies sigulentes a lo - jecutoria de eate Providencia, su incuapliniento derá lezor ef la aplicaeirn del artículo 12 del Decreto 2610 de 1979.

ARTICuLO 20.- El poos de la multa no oxime e te Corporoción deno mineda "CENTRAL NIACIONAL PEOVIVIENDA" del eumpliatiento de le Loy 66 de 1968 y dol Decrsto 2610 de 1979.

ARTICULO So.- Lo presente Rlesoluciba rige a portir de le focha de su notifleceilin.

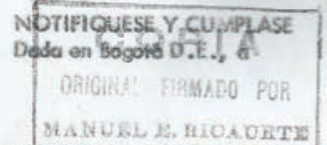

MANUEL ERNESTO GHCAUITE SUPERINTENDENTE BANCARIO TERCER DELEGADO

Exe. No.0171286-7

Dirocetonsavenide Corbous No.15 wi2 Pigo 20.L.C.

CMVA.iHCEB. oddo.
2 . उसम. 1980

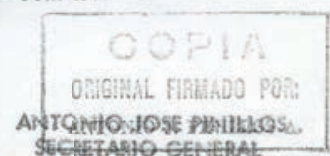




\section{Anexo $\mathrm{N}^{\circ} 23$}

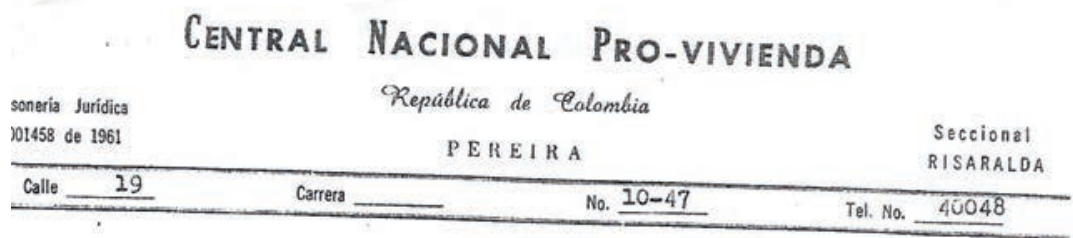

tener dos de los dirigentes de la counidud ye se enoon truban canstruyendo el Barrio los Andes do dicha 200 alidu. puralelo con bsta situación, solicitb a la Super-Bancaria con sede on Manizales pura que $20 s$ interviviera $\mathrm{y}$ oomo 6 s I0 noral fuerion oitados, ara que se presenturin a respon der por $10 a$ Barrios que eataban construyendo, sir. lioenci de la entidad. Se hicieron present6, ol. noñor ALESRTO $\mathrm{CA}$, presidunte del Cenbro No. I Barrio La Trinidad y el gé ñor LUIS ANIBAL OSORIO prealdente del Centro NO. 2 Bario 108 Andes. Ouendo los señores monofonudos se procontaron cump-iendo la oitución, ge llevar un la sorpresa de que ge iniois la conversacibn, pidiéndoles que se salieren de la Central Nacional Provivienda y que se afiliaran a otra encidad, porque la Centrul no era legal en ́rtes regiones, que 8010 Iunolonaba en Uundinamarca y qua si ge gellan de vorque la Oen les daban tode la colaboreoi on necesaria, vorque la Gentral disque ora de flliacion comunista y que raciba. raciba. Por todo 10 anterior, lo sollcitamos muy comedida cicrarios delce una rigurosa investigación sobre 10g funciorarios de la upenintendencia Banoaria, espocialmenta sobre del Drainto, el oual hizo planteamientos de verdade ro lacartiaso contra la Contral, pues a nosotros nos parooe que no be la supermBanaria on sede on lfanizalea quien nos o no ser nuestros afiliados.

iln otro partioulur y con el respeto que Ud. merece nos b́ ivato susoribimos como aus servidores y emigos.

Asontamente,

CWTTRAI NAGIOAAI PROVIVIBNUA SBCOIONAI DB RSDA.

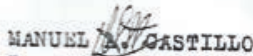

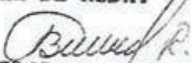

Presidente

CENTZAL MACIOUAL, PROVIVIENDA seoretar of o/rar.5 CCIO Personerio juridice No. Coy 450 $-5$ 


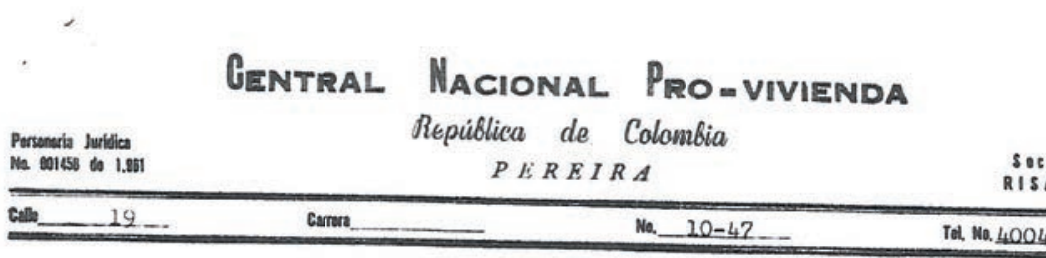

RFSOLUCION

La Junta Directiva de la Central Nacional Provivienda, Seccional de Ris da, reunida el dia 3 de Julio de 1.982 , y

\section{CON S I D E R A N D O}

10. mQue por motivos de incompatibilidad y malos manejos administrativos Befior MANUEL ANTONIO CASTILLO PERILLA, en el mes de marzo del pres año se le exiglo renuncia de su cargo, lo cual se hizo y fe acepto el resto de directivos de la Central ovitando asl graves traumatis

20. Que con el apoyo de los votos de los aflliados de todos los centro la Central Nacional Provivienda en Risaralda el mencionado señor f Departamento, candidatizado que desde 1.976 ha venido por el Frente Demscratico, movimiento rrios fili rrios filiales de sus auxilios ordenanzales, siendo estos invertidi obras de desarrollo de la comunidad;

3o. Que el señor MANUEI. ANTrNIO CASPT: t.O p IIIAA Bin ninima autoridad tica, violando principlo: y acuerdos con nuestra orpanizacion y a

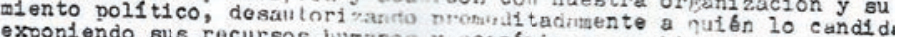
exponiendo sus recursos bumanos y oconomicos, no hizo particine en presente perfodo de lor auxilios otctuanzales a nizo participe en cen como son los barrior. I. . . codes, etc., suma quo awcilende Intereses de jos quo des, de jando burlados chos auxllios. lo que indicines que tienen el logltimo derecho Provivienda y todos sus arili dos

40. Que los estatutos de la Central Nrcional proviviendu preveen sencis para quienes cometen actos de deshonestidad para con la organizacic que la actitud asumida por Castillo viola flagrantemente nuestros:
ciptos organicos;

$$
R \text { \& S U E I. V E }
$$

a) FXPULSAR, como en efocto lo hace, de las filas de la Central Nacior Provivienda, Seccional de Kisaraida, a MANULI ANTONIO CAS'IILIO PFRI por considerarlo traidor a los intereses de la mi ama.

b) Hacer de pablico conocimiento la presente Resolucion y denunciar co vehemencia ante nuestros afiliados y la opinibn pablica la actitud a nuestros afillados auiene dejar sin auxili ron sor sacrificios y se esf y defendiera.

c) Enviar copia de la precente vesolución a la Mesa Directiva de la As blea Departamental del Risaralda; al señor Gobernador del de la As al Comito Ejecutivo Nacional de Cenaprov; a todos los Centros rrovi 


\section{ANEXo $\mathbf{N}^{\circ} 25$}

Pereira Octubre $11 / 82$

Señores

Conite Bjecutivo

Central Nacional Pro-vivienda

B. S. D.

Apreciados anigos: por medio de la presente me permito poner en su c conocimiento, los problemas que se han seguido susediendo por parte de los seriores que Hoy se encuentran en la dirección de la Central en éste Departamento. Los directivos en mención,se han dado a la tarea de poner en circulación berval y práctica,una serie de calumnias contra mí, que enloda toda mi familia en forna por demas des carada e injustificada, diciendo en reuniones y en forma individual, que yo soy un perfecto ladrón y que hasta los utencilios que tengo en mós Hogar, los consegur con to aue me robé cuando estube trabajanio cono presidente de la entidad.

IDS. y yó sabenos quienes iniciaron dicha campaña y otras, que las comuniqué en forma oportuna ante esa dirección y que la práctica me está denostranio aue no se hizo nada para exijirles responsabilidad a dichos seîores, teniendo en cuen ta la importancia de la entidad donde se encuentran trabajando.

Ia irresponsabilidad de éstos señores, llegó hasta la erpresa doncic estoy trabajando:por medio de sus voceros igmorantes, le plantear on al selior Gerente que turiera mucho cuidado cormigo, que yo soy un petfeeto ladrón,que en la Cen tral hice lo que the dió la gana $i$ WS. deven saber por medio de su secretario general (pues élpđrticipó en todas las reunionescuando entregué la dirección) que todo quedó muy claro $y$ eso deve estar en las respectivas Actas,- y que la Central me

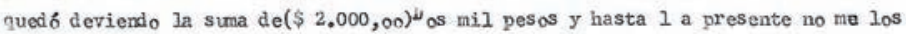
han pagado.

Ante semejantes condiciones, yo desidi formular demuncias penales, con contra tan temerarios nersonajes para que ante los jueses de la República me sean comnrovadas tan temerarias afirmaciones o de lo contrario sean jusgados de acuerdo con la ley vigente en nuestro Paíz.

Ia presente comunicación la Hago en rason de que cuanio los haga craparecer ante las autoridades, no vayan a decir que me bltié contra la Central - que soy un renegado politico; yo quiero que ésto quede mu claro. los denuncio del punto de vista personal para que respondan poe sus calumias contra mí y contra mi familia, pues ésta carpaña venenosa me causa grave daño, En consecuencia, yá consedi pocler a mi abngado respectivo, para que actúe de coniormidad y así mismo se constituya en parte Civil defendiendo nis intereses y mi reputación onesta, tal como lo boy a demostrar ampliamente.

Con sentinientos de consicieración y aprecio, me suscrivo de LDS. cono su servider y amigo.

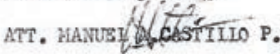




\title{
ANEXo $\mathrm{N}^{\circ} 26$
}

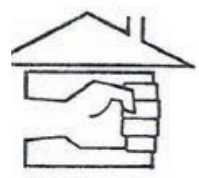

CENAPROV

\section{in 523 it mata is}

\section{CENTRAL NACIONAL PROVIVIENDA}

\author{
CENAPROV \\ SECCIONAL RISARALDA \\ PERSONERIA JURIDICA N. COIASB DE 1.961 \\ Minjusticia

\section{RESOIUCION}

E REIRA

CALLE IO NO. S.4S TELEFONO 40040

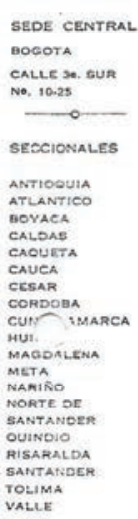

Ia Dirección Seccional de la Central Nacional Provivienda, en uso dè sus facultades que le confieren los artículos 13 y 14 de $10 s$ estatutos de la organización y teniendo en cuenta:

1- Que el Compañero Francisco Botero Barrera socio de la Organizacj $y$ en calidad de tal ocupa el cargo de directivo seccional $y$ al ieual fue funcionario de medio tiempo de la organización.

2- Que el compañero Francisco Botero Barrera traicionó la confianza que la organización depositó en él, haciendo uso de $\$ 17.000 .00$ pe.sc dinero que se le fue entrezado pera qe lo trajera de un centro a oficina seccional.

3- Ante esta falta el compafiero Francisco Botero Berrera renuncia a la funcionaria y se compromete con la oreanización a reponer con trabajo la falta y a ractificar nuevamente la confianza que antes tenia.

4- La Dirección Seccionel le da la oportunidad nuevamente al compaĩero Francisco Botero Barrera ante su petición para que este enmen de su falta y puede nuevanente vincularse a la oreanización.

5- Pero este intento de nada sirvió puesto que el conpafiero utilize: do un talonario de recibos recibio aleunos dineros $y$ afiliaciones por fuera de la oreanización en cuentía de $\$ 0.5 u C .00$.

o- Que el comportamiento de exte conpefiero ocasiona serios perjuicios no solo a los socios aportantes sino al prestigio de nuestri organización.

7- Que ante el comportami nto del compefiezo Francisco Botero Barrers la dirección seccional:

\section{RESU BLVB:}

1- Retirar como miembro directivo de la dirección seccional al compafiero Prancisco Botero Barrera.

2- Il compañero Francisco Botero Barrera no podrá ocupar nineún cerEo de dirección o asumir nineuna responsabilidad dentro de la orEarización por un período de dos (2) arios.

3. Comunicar al afectado y a todos los centros de la oscarización a nivel eeneral la determinación tomeda. 


\section{Bibliografía}

\section{FUENTES PRIMARIAS}

\section{ArCHIVo CENAPROV}

Archivo CENAPROV, Bogotá. Barrio Policarpa Salavarrieta (2017) AZ I Pereira. Correspondencia, Notariales, Denuncia, Prensa.

Archivo CENAPROV, Bogotá. Barrio Policarpa Salavarrieta (2017) AZ II Pereira. Correspondencia, Notariales, Denuncia, Prensa.

\section{Archivo Fotográfico}

Archivo fotográfico. Francisco Londoño Marulanda (2019).

Archivo fotográfico. Fernando Botero (2018).

\section{Archivo Municipal}

Archivo Municipal, Pereira. Fondo de Acuerdos del Concejo Municipal de Pereira. 1971.

Archivo Municipal, Pereira. Fondo de Acuerdos del Concejo Municipal 
de Pereira. 30 de noviembre de 1976.

\section{Archivos de Prensa}

Diario de Risaralda. (10 de Diciembre de 1966). Mil afiliados en el sindicato de educadores de Risaralda. Diario de Risaralda, pág. 3.

Diario de Risaralda. (30 noviembre 1966). Inician hoy la demolición de los rachos piratas. Diario de Risaralda.

El Diario (3 de Enero de 2016). Gildardo Castaño: Ciudadano de la democracia y la educación en Pereira. El Diario, pág. 1.

El Diario (12 Diciembre 1974). Contra una Urbanización Pirata se Pronuncia Planeación Municipal. El Diario, págs. 1-16.

El Diario (12 Enero 1.989). El MAC ratifica sus amenazas. El Diario, págs. 1-15.

El Diario (12 Septiembre 1974). Concejal por la UNO y el Aniversario de la Muerte del Presidente Allende. El Diario, págs. 1-8.

El Diario (13 Mayo 1976). Disposiciones sobre Urbanizaciones en la ciudad. Planeación Mpal. El Diario, págs. 1-15.

El Diario (14 Marzo 1996). Dirigente político de la UP fue herido en atraco. El Diario, págs. 1-16.

El Diario (19 Junio 1976). Gran Concentración Liberal en el Barrio Cuba el Lunes. El Diario, págs. 1-16.

El Diario (15 de Septiembre de 1975). Problemas de Invasiones en Pereira y Dosquebradas. El Diario.

El Diario (28 de Mayo de 1986). Votación en Risaralda. El Diario, pág. 1.

El Diario (6 de Enero de 2009). Homenaje a líder sindical. El Diario, págs. 5-9.

El Diario (10 de Diciembre de 2014). Santiago Londoño, el hombre y la leyenda. El Diario, págs. 20-25.

El Diario (27 de 11 de 2016). "Patria o muerte, venceremos" Fidel Castro un hito en la historia política. El Diario.

El Diario (22 de Enero de 2018). Salvador Allende, con problemas de seguridad. El Diario. 
El Diario (21 Marzo 1974). Auxilios par diferentes juntas de acción comunal en los municipios señaló el gobierno nacional. El Diario, págs. 1-16.

El Diario (22 Febrero 1975). Modesto Séptimo puesto en construcciones del ICT Registra Pereira. El Diario, págs. 1-16.

El Diario (22 Mayo 1978). Última hora - DESDE LAS 10 DE LA MAÑANA RETENIDO EN SU OFICINA EL GOBERNADOR DEL DEPTO-CERCA DE CIEN PERSONAS DE LA INVASIÓN "JOSÉ MARTÍ". El Diario, págs. 1-10.

El Diario (22 Noviembre 1975). Carta a EL DIARIO - Problemas en el Barrio "Isla de Cuba". El Diario, págs. 1-16.

El Diario (24 Mayo 1976). Medidas contra Urbanizaciones que no Cumplen Requisitos se Conoceran en la Próximas Horas. El Diario, págs. 1-15.

El Diario (25 Octubre 1985). Seguirán los allanamientos. El Diario, págs. 1-15.

El Diario (26 Noviembre 1975). Los Invasores no deben ser desalojados: Orden del Cabildo Municipal. El Diario, págs. 1-15.

El Diario (30 Marzo 1978). CENTRAL NACIONAL PRO-VIVIENDA COMUNICADO DE PRENSA Y RADIO. El Diario, págs. 1-15.

El Diario (31 Enero 1986). Manifestación de respaldo a la UP mañana en la Isla. El Diario, págs. 1-16.

El Diario (5 Agosto 2018). Nueva Colombia combate la basura. El Diario.

El Diario (7 Enero 1989). Asesinado concejal Gildardo Castaño O. El Diario, págs. 1-15.

El Tiempo (22 de Enero de 1991). El Tiempo. Obtenido de: https://www. eltiempo.com/archivo/documento/MAM-13629

El Tiempo (7 de noviembre de 1997). El Tiempo. Obtenido de: http:// www.eltiempo.com: http://www.eltiempo.com/archivo/documento/ MAM-684807

La Tarde (1 Junio 1979). Reglamentados programas para vivienda popular. La Tarde, pág. 4. 
La Tarde (12 Octubre 1.987). Asesinado Jaime Pardo Leal. La Tarde, págs. 1-15.

La Tarde (13 Septiembre 1977). Barrio Granada modelo tugurial. La Tarde, págs. 1-11.

La Tarde (21 de Julio de 1982). Por tener novia. La Tarde, pág. 1.

La Tarde (19 de Septiembre de 1987). Juntas comunales célula principal de la elección popular de alcaldes. La Tarde, pág. 1.

La Tarde (22 julio 1977). "La Internacional" desplazó al himno nacional en los colegios. La Tarde, pág. 6.

La Tarde (26 Enero 1986). Entrega de escrituras en el B. Leningrado. La Tarde, págs. 1-15.

La Tarde (6 Septiembre 1977). Once invasiones en Pereira se registraron este fin de semana. La Tarde, págs. 1-4.

La Tarde (7 Enero 1989). Risaralda pierde a un lider. La Tarde, págs. 1-16.

Salazar, L. (26 de 04 de 2015). Así fue la visita de María Cano a Pereira. El Diario.

\section{ENTREVISTAS}

Arias, F. (9 de Marzo de 2020). Entrevista (J. Restrepo, Entrevistador).

Arango, J. (10 de Diciembre de 2018). Entrevista (J. Restrepo, Entrevistador).

Arango, J. (16 de Abril de 2018). La vivivienda en Pereira (J. Restrepo, Entrevistador).

Ayala, M. (23 de Noviembre de 2016). Entrevista (J. Restrepo, Entrevistador).

Botero, F. (24 de Marzo de 2018). Entrevista (O. Arias, \& J. Restrepo, Entrevistadores).

Botero, H. (13 de Octubre de 2018). Entrevista (O. Arias, \& J. Restrepo, Entrevistadores).

Castañeda, M. (9 de Abril de 2017). Entrevista (J. Restrepo, \& O. Arias, Entrevistadores). 
Duque, C. (3 de Diciembre de 2018). Entrevista (J. Restrepo, Entrevistador).

Londoño, F. (28 de Marzo de 2018). Entrevista (J. Restrepo, \& O. Arias, Entrevistadores).

Mejía, J. (9 de Noviembre de 2016). Entrevista (O. Arias, Entrevistador).

\section{OTros}

DANE (25 de Febrero de 2018). Dane información estrategica biblioteca virtual. Obtenido de Dane información estreategica biblioteca virtual categoria Censo: http://biblioteca.dane.gov.co/biblioteca/ categories/45/

DANE (25 de Marzo de 2019). https://www.dane.gov.co. Obtenido de https://www.dane.gov.co: https://www.dane.gov.co/files/banco_ datos/Migracion/migracion_pereira.pdf

Resolución No. 2016-138002 de 28 de julio de 2016. Unidad para la Atención y Reparación Integral de las Víctimas.

\section{REFERENCIAS BIBLIOGRÁFICAS}

Acevedo Vélez, J. J. (2009). La planeación nacional y los planes de gobierno: una mirada al desarrollo social, político y económico de Colombia. Revista Ciencias Estratégicas, 291-308.

Alcaldía Mayor de Bogotá DC. (14 de Noviembre de 2018). www. alcaldiabogota.gov.co. Obtenido de www.alcaldiabogota.gov. co: https://www.alcaldiabogota.gov.co/sisjur/normas/Norma1. jsp?i=310

Aprile-Gniset, J. (1992). La ciudad colombiana Siglo XIX y Siglo XX. Bogotá: Talleres Gráficos Banco Popular.

Arango, C. (1986). La lucha por la vivienda en Colombia. Bogotá: Ecoe.

Arango, O. (1989). Pereira Años 80. Pereira: Funderalda.

Archila, M. (2005). Imágenes de los subalternos en Colombia 1886-1958. Logos, 71-88.

Archila, M. (2001). Vida, pasión y... de los movimientos sociales en Colombia, en Movimientos sociales, Estado y democracia en Colombia, 
(págs. 16-47). Bogotá: Centro de Estudios Sociales de la Universidad Nacional de Colombia, LitoCamargo Ltda.

Botero Barrera, F. (31 de Marzo de 2009). Mi pequeño barrio. Obtenido de MIi pequeño barrio: http://lacomunasanjuaquin.blogspot. com/2009/03/una-breve-historia-del-barrio-la-isla.html

Calle, A. (1964). Conflictos familiares y problemas humanos. Madrid: Sagrado Corazón ISBN.

CAMACOL. (15 de Enero de 2019). Cámara colombiana de la construcción. Obtenido de Cámara colombiana de la construcción: https://camacol.co/camacol/quienes-somos

Castro Caycedo, G. (1986). Colombia Amarga. Bogotá: Círculo de lectores.

Central Nacional Provivienda. (1983). El movimiento de los destechados en Colombia. Bogotá: Publicaciones de la Central Nacional Provivienda.

Centro Nacional de Memoria Histórica. (2018). Todo pasó frente a nuestros ojos. El genocidio de la Unión Patriótica. Bogotá: CNMH.

Contreras, C. (28 de Agosto de 2018). TrazaSueños Compañía Creativa. Obtenido de TrazaSueños Compañía Creativa: https://trazasuenos. org/en-el-barrio-el-plumon-de-pereira-tiene-que-hacer-rancholigero-porque-lo-pueden-invadir-la-ocupacion-de-la-zona-de-lacarrilera-en-los-setentas/

Correa, J. J. (2014). Civismo y eduación en Pereira y Manizales (19251950): Un análisis comparativo entre sus sociabilidades, visiones de ciudad y cultura cívica. Pereira: Universidad Tecnológica de Pereira.

Davidoff, P. (1965). Advocacy and Pluralism in Planning. Journal of the American Institute of Planners, 422-432.

Davis, M. (2007). Ciudades muertas ecología catástrofe y revuelta. Madrid: Traficantes de sueños .

De Certeau, M. (2006). La escritura de la historia. México: Iberoamericana.

De Zubiría, S. (2015). Dimensiones políticas y culturales en el conflicto colombiano. En Víctimas, Contribución al entendimiento del conflicto armado en Colombia (págs. 1-54). Bogotá: Comisión Histórica del 
Conflicto y sus Víctimas, Ediciones Desde Abajo.

Departamento Nacional de Planeación (1975). Para cerrar la brecha. Plan de desarrollo social, económico y regional 1975 - 1978. Bogotá: Departamento Nacional de Planeación, Banco de la República.

Escobar, C. (1966). Historia furtiva: mujer y conflictos laborales. Pereira: Universidad Tecnológica de Pereira.

Fernandez Maldonado, A. M. (2015). Las barriadas de Lima como estímulo a la reflexión urbana sobre la vivienda. Revisitando a Turner y de Soto. Revista de Estudios sobre Vivienda (WASI), 2-20.

Foucault, M. (2002). La arqueología del saber. Buenos Aires: Siglo XXI.

Función Pública. (27 de Diciembre de 2018). Espacio virtual de asesoria de la Función Pública. Obtenido de Espacio virtual de asesoria de la Función Pública: http://www.funcionpublica.gov.co/eva/ gestornormativo/norma.php?i=8271

Gil, A., Bedoya, A., \& Tascón, J. (2013). Un acercamiento a las primeras expresiones de las organizaciones de mujeres en Pereira durante los años 70 y 80: Una mirada desde el liderazgo articulador de Stella Brand (Cali, 1946-Pereira, 1993). Gestión y Región N¹5, 91-104.

Gil, A., Tascón, J. A., \& Bedoya, A. (2013). Izquerda en Pereira entre 1970-1990: Un acercamiento desde el perfil intelectual de Stella Brand. Simposio "Otras miradas a la historia".

Giménez, G. (1999). Territorio Cultura e identidades. La región sociocultural. Estudios sobre las culturas contemporáneas, vol. V Nº 9, 2557.

Ginzburg, C. (13 de agosto de 2010). El hilo y las huellas. Lo verdadero, lo falso y lo ficticio. Buenos Aires: Fondo de Cultura Económica

Giraldo Botero, C. (2013). La ciudad prodigio. En Al recio empuje de los titanes (págs. 82-87). Pereira: La Tarde, Academia Pereirana de Historia e Instituto de Cultura de Pereira.

Grupo de acción comunitaria y social (ACCOMS) (1990). Monografía del barrio Cuba Pereira. Pereira: XYZ.

Guzmán, G., Fals Borda, O., \& Umaña, E. (2005). La Violencia en Colombia. Bogotá: Taurus.

Hartog, F. (2007). El oficio de la historia. Regímenes de historicidad. 
México: Universidad Iberoamericana.

Harvey, D. (2013). Ciudades rebeldes. Del derecho a la ciudad a la revolución urbana. Madrid: Akal.

Hobsbawm, E. (2015). Historia del siglo XX. Bogotá: Planeta.

Instituto de Credito Territorial. (1986). Ciudadela Perla del Otún, Plan 2.500 lotes con servicios. Pereira: Azu Press Editores.

Jaramillo, H. A. (1983). Pereira: Proceso histórico de un grupo étnico colombiano. Pereira: Gráficas Olímpica.

Jenkins, K. (2001). Repensar la historia. Madrid: Siglo XXI.

Junguito, R. (19 de Julio de 2018). La República. Obtenido de: https:// www.larepublica.co/analisis/roberto-junguito-500053

Lean Construction Enterprise LCE. (20 de Enero de 2019). http:// www.leanconstructionenterprise.com. Obtenido de: http://www. leanconstructionenterprise.com/documentacion/historia-del-sector

Lefebvre, H. (1975). El derecho a la ciudad. Barcelona: Península.

Martínez, H., Serna, C., \& Correa, J. (2013). Intelectualidad cosmopolita en provincia: El caso de los Santiago Londoño Londoño en Pereira, Colombia. Historia y Espacio, 55-79.

Mejía Pavony, G., \& Zambrano Pantoja, F. (2000). La ciudad y las ciencias sociales. Bogotá: CEJA.

Mejía, C. (2 de MAYO de 2017). Repositorio Univeridad tecnológica de Pereira . Obtenido de: http://repositorio.utp.edu.co/dspace/ handle/11059/7982

Mejía, G. (2001). Reseña de: Los años del cambio. Historia urbana de Bogotá 1820-1910. Territorios, 155-158.

Melo, J. O. (2018). Historia mínima de Colombia. Bogotá: Turner.

Montoya, J. (2013). El desarrollo del comercio en Pereira. Colección Maestros $\mathrm{N}^{\circ} 17,21-49$.

Morales, H., \& Puentes, G. (1996). Barrio Santiago Londoño 15 Años. Central Nacional Provivienda, 1-20.

Moreno, J. C. (2014). De Centros Cívicos a Juntas de Acción Comunal. El cambio de modelo de gestión y participación barrial en Medellín 
en la segunda mitad del siglo XX. Estudios Políticos, núm. 45, 185203.

Naranjo, M. E. (2011). Barrio Policarpa Salavarrieta 50 años. Bogotá: Impresol ediciones.

Naranjo, M. E. (2011). Experiencias colombianas de autoconstrucción de vivienda popular: El caso de la Central Nacional Provivienda. Buenos Aires: IX Jornadas de Sociología. Facultad de Ciencias Sociales.

Naranjo, M. E. (2014). Provivienda: protagonista de la colonización popular en Colombia. Historia y memoria, 89-118.

Naranjo, M. E. (2017). Aportes de los viviendistas colombianos a la paz en el posacuerdo: Un ejercicio de investigación acción participativa con fundadores barriales. Revista Colombiana de Sociología, 157-174.

Ortiz, C. M. (1994). Historiografía de la violencia, en Tovar Zambrano, B., La historia al final del milenio: ensayos de historiografía colombiana y latinoamericana, págs. 371-424. Bogotá: Universidad Nacional de Colombia, Facultad de Ciencias Humanas Departamento de Historia, Editorial Universidad Nacional.

Oviedo, Á. (2012). Memoria y luchas urbanas. Por el derecho a una vivienda digna. Bogotá: Izquierda viva.

Pabón, M. (1985). Estimación de la migración en Risaralda en el periodo intercensal 1964-1973. Cuadernos de Ciencias Sociales, 38-58.

Palacios, M. (2012). Violencia pública en Colombia 1958 - 2010. México D.F: Fondo de Cultura Económica.

Programa de divulgación científica . (21 de Junio de 2007). Universidad del Rosario. Obtenido de: http://www.urosario.edu.co/UniversidadCiencia-Desarrollo/ur/Fasciculos-Anteriores/Tomo-II-2007/ Fasciculo-11/ur/La-evolucion-de-la-politica-de-vivienda-enColom/

Rivera, J. A. (2013). Proceso de urbanización y agentes urbanos en Pereira, Colombia. Barcelona: Universitat de Barcelona.

Robledo, J. (1985). El drama de la vivienda en Colombia y la política del "sí se puede". Bogotá: El Áncora Editores.

Rojas, B. E. (2003). La urbanización y la dinámica poblacional en la 
generación de condiciones de riesgo en Pereira. Una evaluación ambiental histórica (1950-2000). Pereira: Universidad Tecnológica de Pereira.

Rojas, D. M. (2010). La Alianza Para el Progreso en Colombia. Análisis político, 91-124.

Romero, J. L. (1999). Latinoamérica: Las ciudades y las ideas. Medellín: Universidad de Antioquia.

Rueda, R. (2000). El desplazamiento forzado y la pacificación del país. Enfoques y metodologías sobre el hábitat: Memorias de una experiencia pedagógica, 105-114.

Safford, F., \& Palacios, M. (2012). Historia de Colombia. País fragmentado, sociedad dividida. Bogotá: Uniandes.

Sanchéz, G., \& Meertens, D. (1983). Bandoleros Gamonales y Campesinos El caso de la violencia en Colombia. Bogotá: El Ancora Editores .

Sanchéz, L. M. (2008). Éxodos rurales y urbanización en Colombia. Bitácora Urbano Territorial Vol 2, 57-72.

Sociedad de Mejoras Pereira. (1989). Reseña Histórica de los 39 años de Instituto de Crédito Territorial Regional Risaralda. Sociedad de Mejoras Pereira, 13-20.

Torres, A. (1993). Estudios sobre pobladores urbanos en Colombia: balance y perspectivas. Maguaré, 131-146.

Torres, A. (1993). La ciudad en la sombra. Bogotá: CINEP.

Torres, A. (2014). Hacer historia desde abajo y desde el sur. Bogotá: Ediciones Desde Abajo.

Torres, C. (2009). Ciudad informal colombiana, barrios construidos por la gente. Bogotá: Universidad Nacional de Colombia.

Touraine, A. (2006). Los movimientos sociales. Revista Colombiana de Sociología, 255-278.

Turner, J. (1976). Housing by People Towards autonomy in building. New York: Pantheon Books.

Upegui, Alberto; Casas Jairo. (1960). Monografía de Pereira. Bogotá: Hemisferio.

Valderrama, L. F., Gil, A., \& Correa, J. J. (2013). La historia barrial en 
Pereira. En Al recio empuje de los titanes (págs. 172-177). Pereira: La Tarde, Academia Pereirana de Historia e Instituto de Cultura de Pereira.

Vattimo, G., \& Zabala, S. (2012). El comunismo hermenéutico de Heidegger a Marx. Barcelona: Herder.

Zambrano, F. (1994). La ciudad colombiana. Una mirada de larga duración. En Lucio, A., Pobladores urbanos: ciudades y espacios (págs. 35-72). Bogotá: Instituto Colombiano de Antropología, Tercer Mundo Editores. 

Este libro terminó de imprimirse en el mes de octubre de 2020 en los talleres de Gráficas Olímpica, bajo el cuidado de los autores.

Pereira, Risaralda, Colombia. 
La Editorial de la Universidad Tecnológica de Pereira tiene como política la divulgación del saber científico, técnico y humanístico para fomentar la cultura escrita a través de libros y revistas científicas especializadas.

Las colecciones de este proyecto son: Trabajos de investigación, Ensayos, Textos Académicos y Tesis Laureadas.

Este libro pertenece a la Colección Tesis Laureadas y a la Colección Maestría en Historia. 
En este libro se analiza el papel desempeñado por la organización social de viviendistas Central Nacional Provivienda (CENAPROV) en el crecimiento urbano de la ciudad de Pereira entre 1973 y 1987. Se indaga la forma en que dicha organización, adscrita al Partido Comunista Colombiano (PCC), de la mano de impertantes líderes comunitarios como Joaquîn Botero, Manuel Castillo, Carlos Alberto Benavides, Gabriel Darío Londoño, Gildardo Castaño, Eduardo García, entre otros, agenció la conformación de por lo menos diez barrios bajo la modalidad de autoconstrucción en nuestra ciudad. Para ello, se analizan aspectos relevantes como el déficit habitacional derivado de las migraciones y el rápido crecimiento demográfico de Pereira en la segunda mitad del siglo XX. Al mismo tiempo, a partir del análisis de fuentes tanto documentales como testimoniales, se procura evidenciar las tensiones y acuerdos llevados a cabo entre la organización de viviendistás y la administración municipal para hacer realidad la construeción de los planes de vivienda. El texto examina, además, algunas de las razones que condujeron al declive de CENAPROV en la ciudad. El análisis desplegado en el trabajo investigativo está inscrito en el campo de los estudios sobre Historia Urbana y constituye un aporte, desde sus márgenes, a la comprensión de la complejidad del entramado de la ciudad y, al mismo tiempo, pone de relieve el protagonismo de la izquierda en la lucha por el derecho a la vivienda para los más necesitados.

elSBN: 978-958-722-527-3

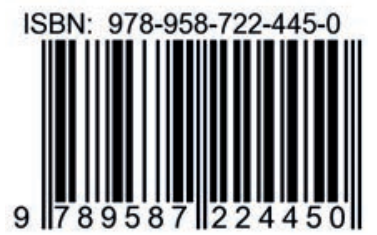

